Portland State University

PDXScholar

$1-1-2011$

\title{
Investigating Technological Organization at the Buck Lake Site (45PI438) in Mount Rainier National Park Using a Lithic Debitage Analysis
}

Michael Charles Schurke

Portland State University

Follow this and additional works at: https://pdxscholar.library.pdx.edu/open_access_etds Let us know how access to this document benefits you.

\section{Recommended Citation}

Schurke, Michael Charles, "Investigating Technological Organization at the Buck Lake Site (45PI438) in Mount Rainier National Park Using a Lithic Debitage Analysis" (2011). Dissertations and Theses. Paper 721.

https://doi.org/10.15760/etd.721

This Thesis is brought to you for free and open access. It has been accepted for inclusion in Dissertations and Theses by an authorized administrator of PDXScholar. Please contact us if we can make this document more accessible: pdxscholar@pdx.edu. 
Investigating Technological Organization at the Buck Lake Site (45PI438) in Mount

Rainier National Park Using a Lithic Debitage Analysis

by

Michael Charles Schurke

A thesis submitted in partial fulfillment of the requirements for the degree of

Master of Arts

in

Anthropology

Thesis Committee:

Kenneth M. Ames, Chair

Greg C. Burtchard

Douglas C. Wilson

Cameron M. Smith

Portland State University

2011 


\begin{abstract}
Few lithic analyses have been conducted or published on collections from Mount Rainier National Park (MORA). This study's lithic debitage analysis, and investigation of hunter-gatherer technological organization through time, contributes to the knowledge base and understanding of how hunter-gatherers used subalpine environments in MORA. The debitage sample is from archaeological excavations between 2005 and 2007 at a Buck Lake Site (45PI438) activity area in the subalpine environmental zone. Two cultural components were examined: the pre-Mount St. Helens Yn tephra component (before 3500 RCYBP) is thought to represent a foragerlike mobility strategy and the post-Mount St. Helens Yn tephra component (after 3500 RCYBP) is thought to represent a collector-like strategy. Expectations theoretically grounded in hunter-gatherer mobility, tool design, raw material procurement, site function, and tool function were developed and tested. Results suggest that huntergatherers at Buck Lake relied on and maintained small, lightweight, transported bifaces made of nonlocal raw material regardless of expected changes in mobility strategy through time. For both foragers and collectors at Buck Lake, similar lithic raw material availability, terrain, and seasonality constraints and a common resource acquisition goal and overlapping site function resulted in similar hunter-gatherer technological organization strategies. Slight differences between the cultural components include: the use of more local igneous raw material in the forager-like component, the use of a more expedient technology in the collector-like cultural
\end{abstract}


component, and smaller size debitage in the forager-like component. The use of expedient bipolar technology in both cultural components is possible, but only partially supported. Evidence of bipolar technology would suggest that huntergatherers were conserving nonlocal CCS by using the bipolar technique on exhausted transported tools or cached cores to produce expedient flakes used for small-game hunting and processing. Further research for the Buck Lake site should include: the sourcing of raw material; conducting experimental lithic reduction on toolstone found at Buck Lake to produce comparative debitage specimens; and increasing the lithic analysis sample size to include debitage recovered from 2008-2009 excavations and other artifact types. 


\section{ACKNOWLEDGEMENTS}

Without the help and support of a number of people this thesis would not have been possible. I would first like to thank Greg Burtchard, Mount Rainier National Park Archaeologist, for the opportunity to study the Buck Lake (45PI438) site lithic collection for this thesis. Your patience, comments, and guidance are also much appreciated. I hope that we both benefit from this study.

I would like to thank Dr. Ken Ames for his suggestion that I contact Greg about a possible thesis project. Without that suggestion, this study and learning opportunity most likely would not have happened. I also appreciate Ken's guidance and constructive criticism.

I would like to thank committee members Dr. Doug Wilson and Dr. Cameron Smith for their thorough review of this thesis and comments.

I greatly appreciate Andrew Bradbury and Dr. Philip Carr's time and help in determining what methods would work for this thesis. Andrew also graciously provided raw experimental lithic technology data for my analysis.

Thanks go out to Dr. Bradford Andrews, Dr. David Huelsbeck, Hannah Tofte, Dr. Patrick McCutcheon, Kevin Vaughn, and Todd Volkenand for sharing their research on the Helipad, Tipsoo Lakes, Sunrise Ridge Borrow Pit, and Berkeley Park Rockshelter sites.

Thanks to my friend Terry Schumann for his assistance in processing and analyzing the debitage collection for this study. Your hours of help and company are much appreciated. 
I would like to thank my loved ones for their patience and support. My mom, Linda Schurke, and dad, Charles Schurke, have been nothing but supportive and patient through this long journey. Thanks go out to my father-in-law, Upendra Pai, and mother-in-law, Sheila Pai, for their continued support and patience. Much love and thanks go to my wife, Sona Pai, for her much appreciated data entry and editing skills. Sona has also been extremely patient and supportive.

Finally, I would like to thank Sona and my son Kiran Pai Schurke for being incredible sources of inspiration. This is all for the both of you. 
TABLE OF CONTENTS

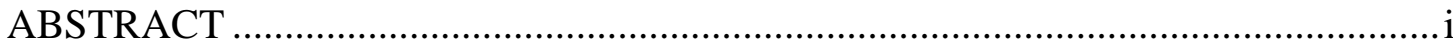

ACKNOWLEDGEMENTS ................................................................................

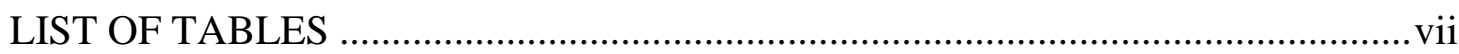

LIST OF FIGURES ......................................................................................

CHAPTER ONE

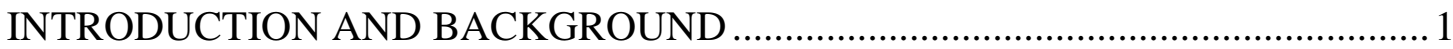

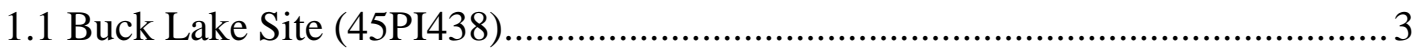

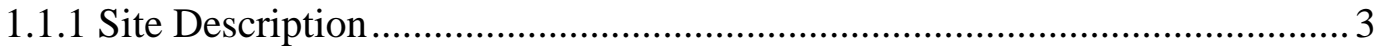

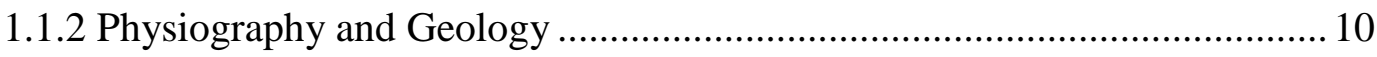

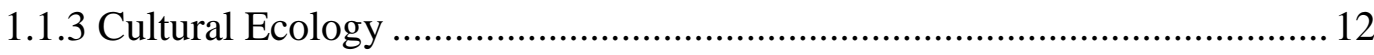

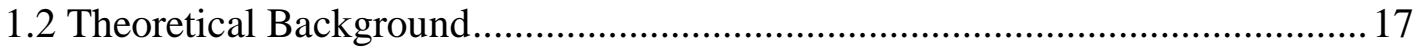

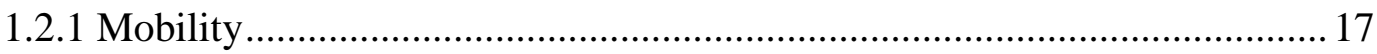

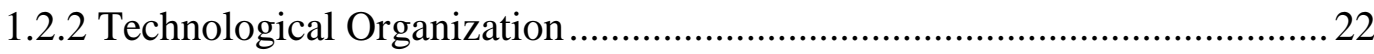

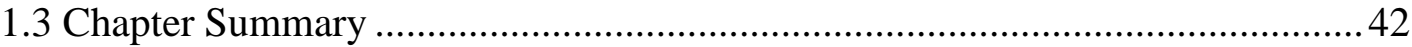

CHAPTER TWO

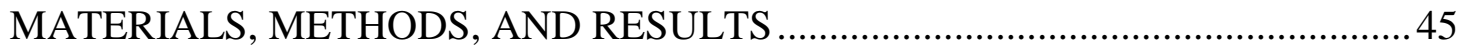

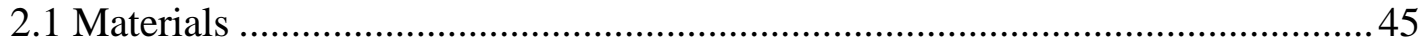

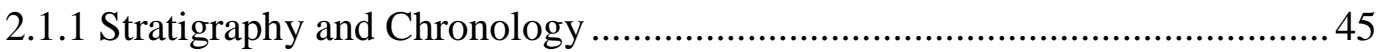

2.1.2 Sampling and Cultural Components .......................................................... 46

2.2 Debitage Analysis Methods and Results ......................................................52

2.2.1 A Note on the Use of Technological Typologies.........................................53

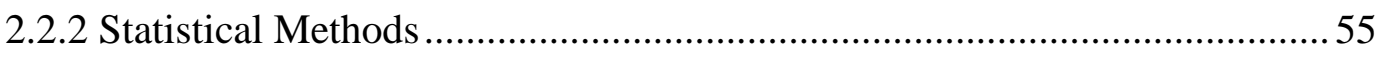

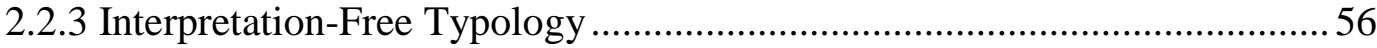

2.2.4 Method to Determine the Frequency of Local and Nonlocal Toolstone...... 59

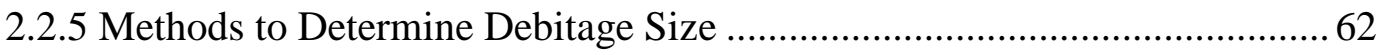

2.2.6 Methods to Determine the Presence of Bifacial Reduction and Production

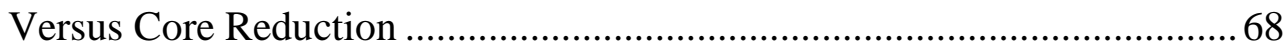




\section{TABLE OF CONTENTS (continued)}

2.2.7 Method to Determine the Frequency of Lithic Production and Reduction

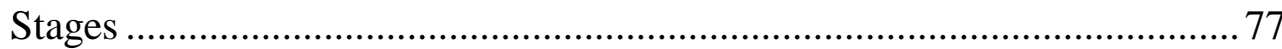

2.2.8 Method to Determine the Frequency of Usable Expedient Flakes ............... 85

2.2.9 Method to Determine the Frequency of Blade Core Technology ................. 86

2.2.10 Method to Determine the Frequency of Bipolar Core Technology ............ 89

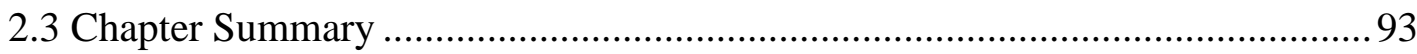

CHAPTER THREE

SUMMARY, CONCLUSIONS, AND RECOMMENDATIONS …………………....99

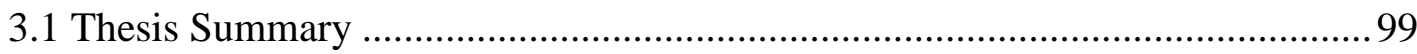

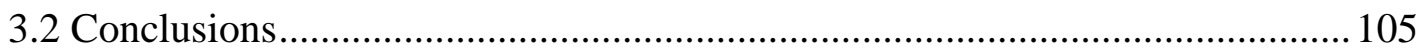

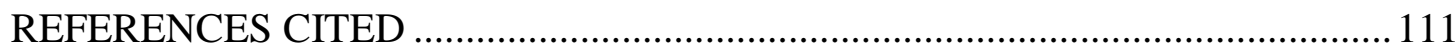

APPENDIX A

LITHIC DEBITAGE ANALYSIS DATA ENTRY CODES.......................................122

APPENDIX B

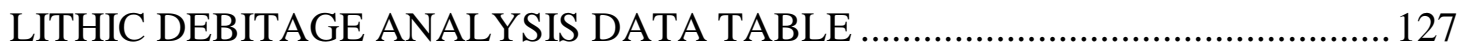




\section{LIST OF TABLES}

Table 1. Summary of Upper White River Drainage Basin Prehistoric Sites.

Table 2. Stratum Depths, Artifact Density, Radiocarbon Dates, and Tephra Layers for TUs 1-3.

Table 3. Interpretation-Free Debitage Type Percentages and Frequencies (Italicized) for Pre- and Post-MSH Yn Cultural Components.

Table 4. Debitage General Raw Material Type Percentages and Frequencies (Italicized) for Pre- and Post-MSH Yn Cultural Components.

Table 5. Debitage Weight Descriptive Statistics for Pre- and Post-MSH Yn Cultural

Components.

Table 6. Debitage Diameter Size Class Percentages for Pre- and Post-MSH Yn Cultural Components

Table 7. Broken and Complete Flake Maximum Length Descriptive Statistics for Pre- and Post-MSH Yn Cultural Components.

Table 8. Greater Than $10 \mathrm{~mm}$ in Length Broken and Complete Flake Weight, Maximum Length, and Striking Platform Width for Pre- and Post-MSH Yn Cultural Components with K-S and T-test Results (Italicized). 73

Table 9. Broken and Complete Flake Dorsal Scar Count to Weight (g) Ratio Descriptive Statistics for Pre- and Post-MSH Yn Cultural Components... 75

Table 10. Broken, Complete, and Fragment Flake Dorsal Cortex Coverage Percentages and Frequencies (Italicized) for Pre- and Post-MSH Yn Cultural Components.

Table 11. Mean Weight, Maximum Length, and Maximum Thickness for Pre- and Post-MSH Yn Cultural ComponentsProximal Flakes with K-S and T-test Results (Italicized). 


\section{LIST OF TABLES (continued)}

Table 12. Platform Type Percentage for Pre- and Post-MSH Yn Cultural Component

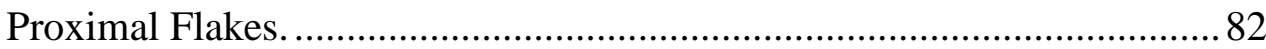

Table 13. Broken, Complete, and Fragment Flake Greater Than or Equal to $25 \mathrm{~mm}$ Diameter Size Class Percentages for Pre- and Post-MSH Yn Cultural Components. 86

Table 14. Percentages and Frequencies (Italicized) of Flakes in the Group with a Length-to-Thickness Ratio Greater Than or Equal to Five and that Weigh Less than Five Grams for Pre- and Post-MSH Yn Cultural Components.. 88

Table 15. Debris and Flake Percentages and Frequencies (Italicized) for Pre- and Post-MSH Yn Cultural Components........................................................ 91

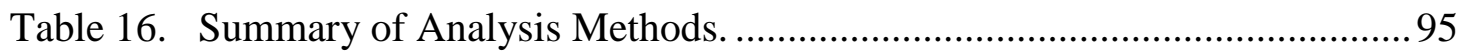

Table 17. Summary of Technological Organization Expectations and Analysis

Results 


\section{LIST OF FIGURES}

Figure 1. Location of Buck Lake (45PI438) in Washington...................................... 4

Figure 2. Location of Buck Lake (45PI438) in MORA (dashed line).........................5

Figure 3. Location of Buck Lake (45PI438) on a topographic map..........................6

Figure 4. Location of Locus 4 on an aerial photograph. ........................................ 9

Figure 5. The Upper White River Drainage Basin (shaded) and archaeological sites

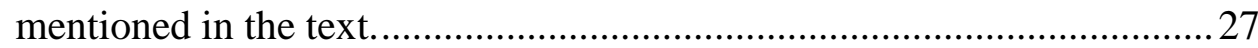

Figure 6. Typical test unit soil profile, strata, tephra, and radiocarbon samples from Greg Burtchard, personal communication 2008 and Greg Burtchard, 45PI438 field sediment description, Locus 4, test unit 1100N/972E, 8/25/2005, on file at Mount Rainer National Park, Natural and Cultural Resource Division Offices, Longmire, Washington. 


\section{CHAPTER ONE}

\section{INTRODUCTION AND BACKGROUND}

In recent years, archaeological research on the use of subalpine environments by prehistoric hunter-gatherers in the Pacific Northwest has been increasing.

Researchers previously ignored subalpine areas because of the widely held assumption that they were not used prehistorically (Burtchard 2007:1); recent research, including work conducted in Washington's Mount Rainier National Park, otherwise known by the National Park Service shorthand MORA, suggests otherwise. As of 2008, approximately 100 archaeological sites and isolated finds have been discovered within MORA (Burtchard 2007:4). Although an appreciation for high elevation archaeology in the Cascades has become more widespread over the last 20 years, "information remains limited by the presence of relatively few published site excavation accounts" (Lubinski and Burtchard 2005:35).

Over the past 10 years, archaeologists have conducted extensive research at MORA and other southern Washington Cascades areas (i.e., Andrews et al. 2008; Burtchard 2003; Burtchard 2007; Dampf 2002; Lubinski and Burtchard 2005; Mierendorf et al. 2006; Mierendorf et al. 1998; Nickels 2002; Tofte 2009; Tweiten 2007; Vaughn et al. 2007; Vaughn and McCutcheon 2008). In 2003, Greg Burtchard published a model of hunter-gatherer settlement and subsistence within MORA based on ecological, environmental, and preliminary archaeological data (Burtchard 2003). Recent MORA archaeological excavations have recovered thousands of artifacts, but 
only two published studies (Dampf 2002; Andrews et al. 2008) and one unpublished study (Tofte 2009) have used analyzed lithic data sets to extensively examine expected hunter-gatherer behaviors in and around MORA.

Among other areas of interest, MORA Archaeologist Greg Burtchard has suggested that ongoing archaeological research in MORA should investigate changes in technological organization through time with larger samples and chronological control (Burtchard 2003:92); the research detailed in this thesis was conducted in response to this suggestion. The Buck Lake (45PI438) site in MORA provides an excellent opportunity to investigate prehistoric hunter-gatherer technological organization through time in a subalpine environment; thousands of lithic artifacts have been recovered through controlled excavations and radiocarbon dates and tephra layers provide chronological control. It is possible that the technological organization of hunter-gatherers in MORA would have changed as mobility strategies changed between the mid to late Holocene; although, as this thesis suggests, lithic raw material availability, terrain, and seasonality constraints and a common resource acquisition goal and overlapping site function resulted in similar hunter-gatherer technological organization strategies at this locality through time regardless of mobility strategies. The purpose of this study is to investigate possible changes in hunter-gatherer technological organization through time using the results of a lithic debitage analysis to make technological inferences at the subalpine Buck Lake (45PI438) site.

MORA and the southern Washington Cascades are nestled between the Southern Northwest Coast and the Southern Plateau (Ames 2003:21, Figure 1; Ames 
et al. 1998:104, Figure 1). Until recently, little attention has been given to Mount Rainier and the Cascade Range; instead, researchers have concentrated on prehistoric hunter-gatherer adaptations to the east and west of the Cascade Range in the Plateau and the Northwest Coast regions (Burtchard 2007:1). Archaeological research, including the results and conclusions of this study, expands our recent knowledge and understanding of how hunter-gatherers used high-elevation montane environments in MORA and the Pacific Northwest.

\subsection{Buck Lake Site (45PI438)}

\subsubsection{Site Description}

Buck Lake (45PI438) is located in the northeast corner of MORA, in Pierce County in the western half of Washington, approximately $80 \mathrm{~km}$ southeast of Seattle (Figures 1 and 2). The site is located in the southern Cascades atop a mountain bench landform slightly below the tree line northeast of Mount Rainier at 1,646 m above sea level (ASL) (Burtchard 2003:104; Burtchard 2007:19) (Figure 3). The site is surrounded by a subalpine fir (Abies lasiocarpa) forest with open meadow vegetation occurring on slopes south of Buck Lake (Tweiten 2007:1). There are five activity loci within the site area north and east of the at least $7143 \pm 49$ RCYBP glacial Buck Lake within the subalpine environmental zone (Burtchard 2003:121; Greg Burtchard, personal communication 2008; Tweiten 2007:4) (Figure 4). This study is concerned 


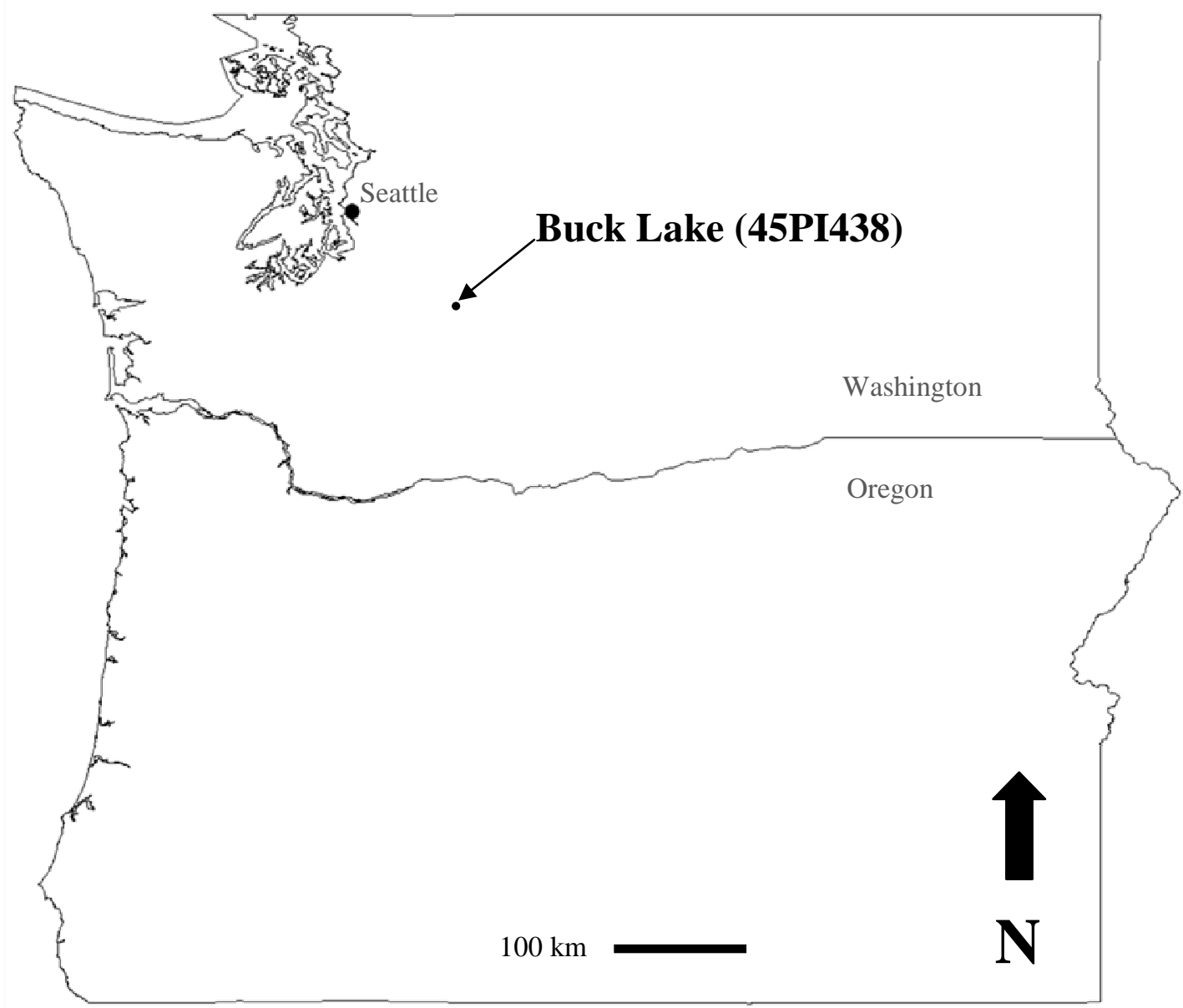

Figure 1. Location of Buck Lake (45PI438) in Washington. 


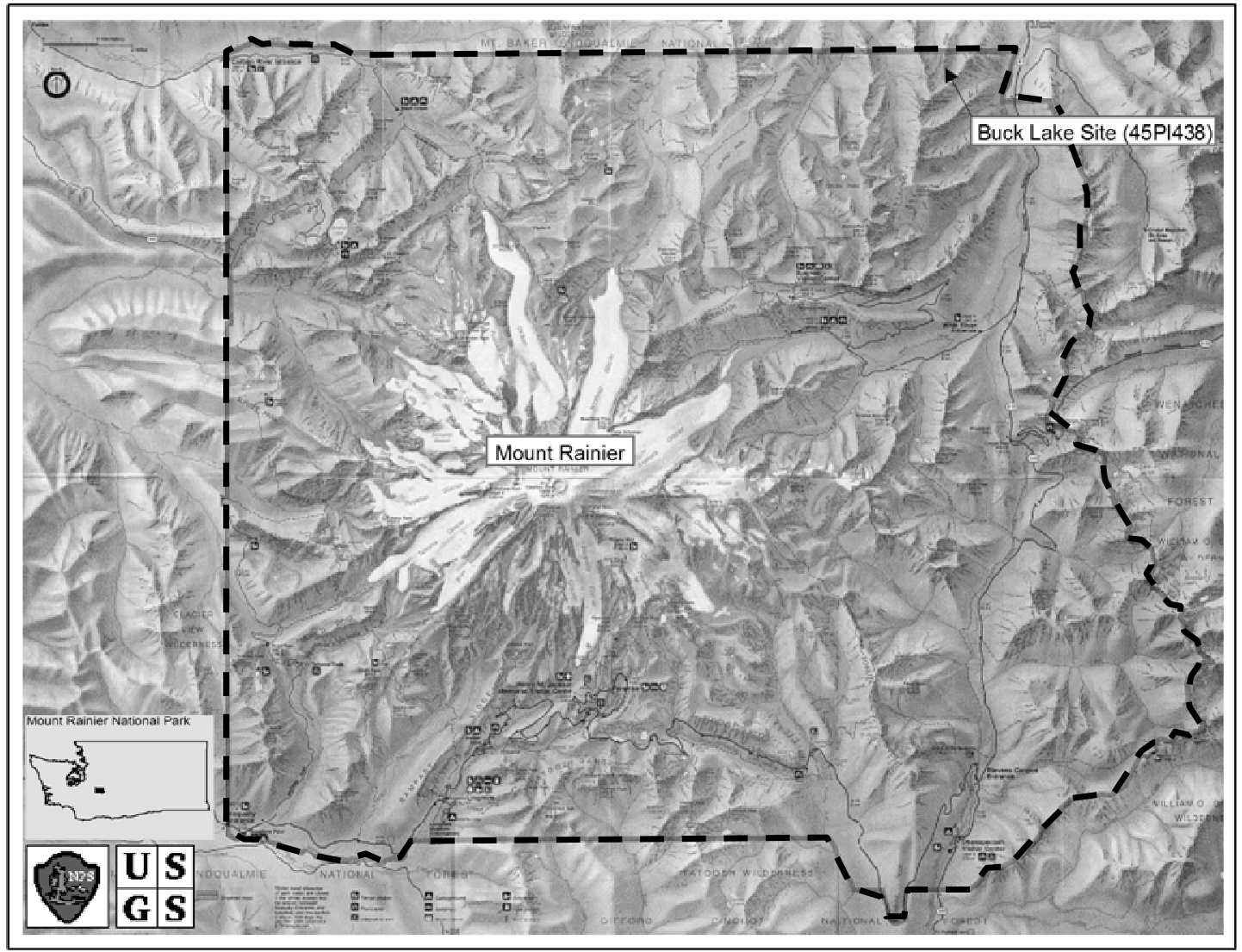

Figure 2. Location of Buck Lake (45PI438) in MORA (dashed line). 


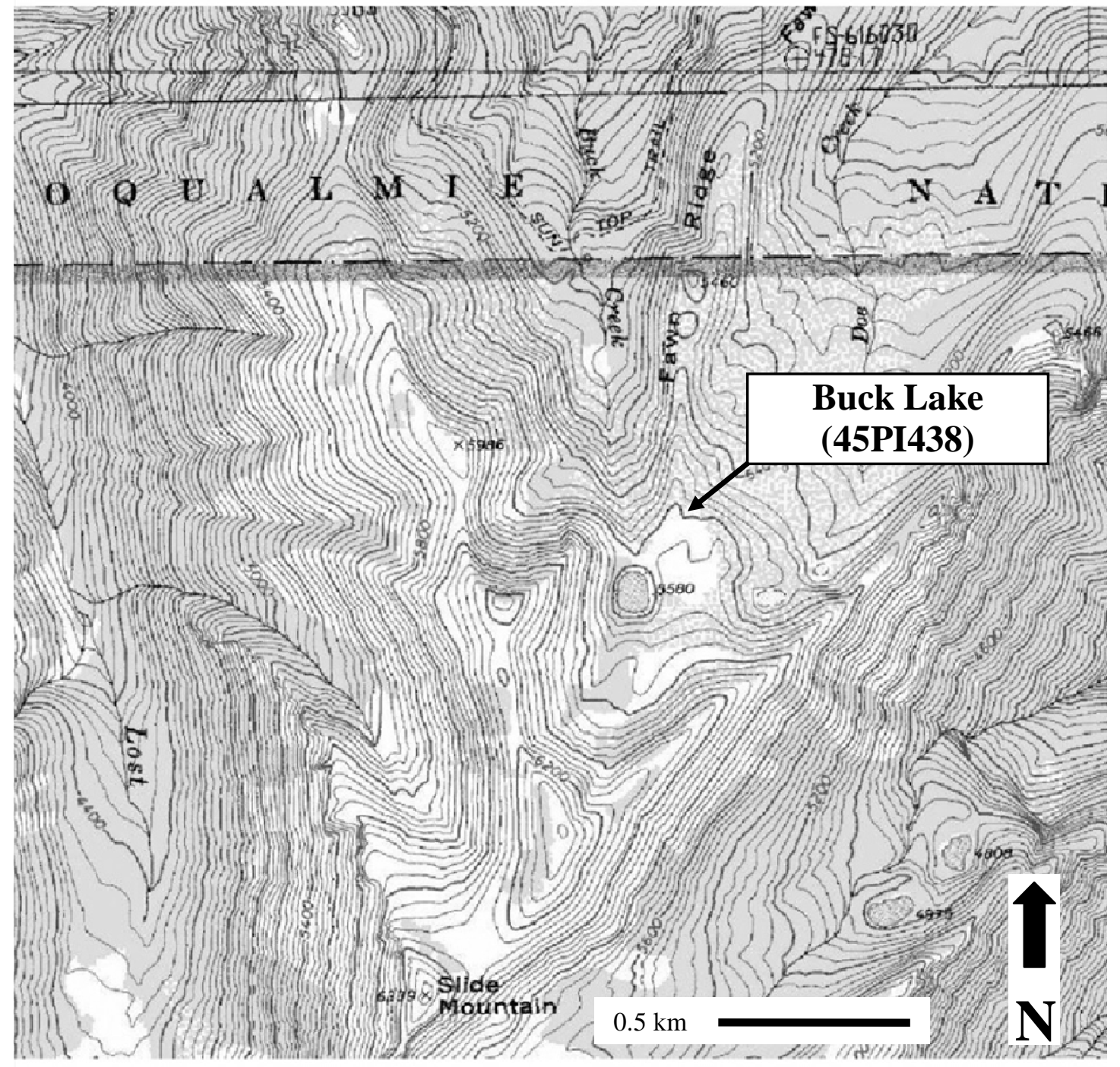

Figure 3. Location of Buck Lake (45PI438) on a topographic map. 
with Locus 4, just northeast of Buck Lake.

John Dalle-Molle, a MORA naturalist, originally reported the site in 1971, and Burtchard and crew confirmed its location during a 1995 reconnaissance project (Burtchard 2003:196). In 2004, an archaeological survey around the lake located five localities with artifacts that define the site area. This study is concerned with the test unit excavations at Locus 4 northeast of Buck Lake. Following extensive testing using a constant volume sampling technique (see Burtchard and Miss 1998:74-79 for a description of this method), Locus 4 was regarded as having the greatest potential to provide data relevant to early through late Holocene occupations (Burtchard 2006, Greg Burtchard, personal communication 2010). Accordingly, a crew excavated a $1 \mathrm{x}$ $1 \mathrm{~m}$ test unit (TU 1) in 2005. This test unit intended to investigate the vertical extent of the cultural material at Locus 4 and determine whether it was stratigraphically intact and warranted future archaeological investigation; the crew encountered two separate artifact-bearing strata (Burtchard 2006).

In the summer of 2006, two additional $1 \times 1 \mathrm{~m}$ test units (TU 2 and 3 ) were dug adjacent to the 2005 test unit. Burtchard expected these test units to recover more archaeological data from the two artifact-bearing strata. One test unit (TU 2) was completely excavated, and a second test unit (TU 3) was only partially excavated because of time and weather constraints (Burtchard 2006:1-2; Greg Burtchard, personal communication 2006). 
Excavation continued in the summer of 2007 with the completion of the summer 2006 test unit (TU 3) and an additional test unit (Greg Burtchard, personal communication 2007). Subsequent investigations were conducted in the summers of 2008 and 2009. This study is only concerned with artifacts from TUs 1-3, excavated in 2005, 2006, and 2007.

Buck Lake (45PI438) has been preliminarily interpreted as a repeated use residential base (Burtchard 2003:101, 113; Tweiten 2007:1). A residential base, as Binford (1980:9) explains, "is...the hub of subsistence activities...where most processing, manufacturing, and maintenance activities take place." At a residential base, artifact density will increase as cultural material accumulates from repeated site use or increased lengths of stay (Binford 1980:9; Burtchard 2003:94; Chatters 1987:345; Rafferty 1985:135; Shott 1986:23). The cultural material should also be diverse because of the array of activities that occurred at the site over a long period of time (Burtchard 2003:94; Chatters 1987:342, 345; Rafferty 1985:135; Shott 1986:23).

Burtchard's $(2003: 101,113)$ site type interpretation was based on the limited 1995 reconnaissance survey data that mainly included debitage. He reasons that a repeated use residential base will have a high debitage count and high raw material variety (Burtchard 2003:94). Buck Lake (45PI438) had a high debitage count and high raw material variety especially compared to other MORA sites (Burtchard 2003:94, Table 4.6, 95, Figure 4.3).

Burtchard (2003:112-113) believes Buck Lake (45PI438) would have been repeatedly used to exploit faunal and floral resources by mixed-age and gender groups. 


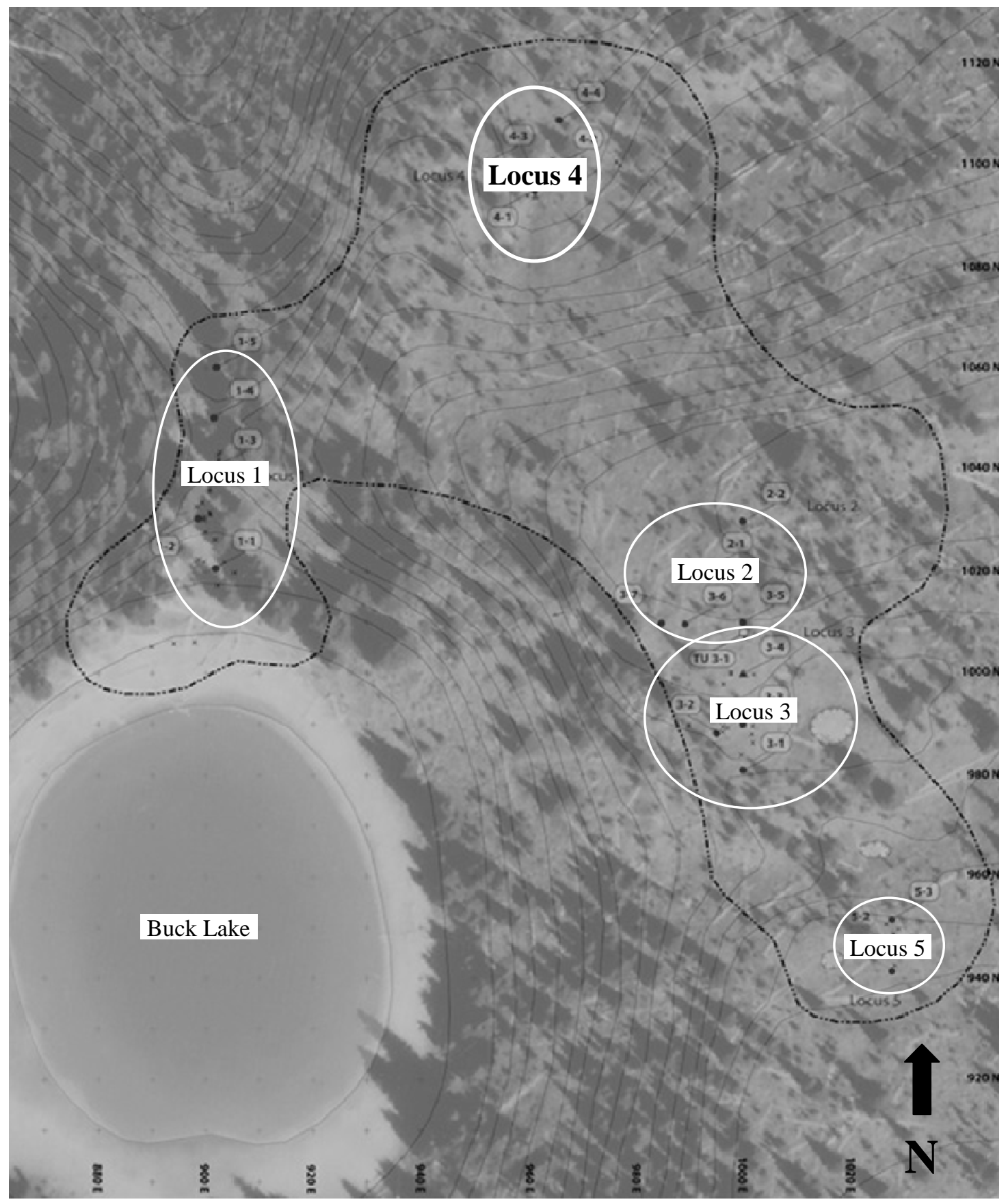

Figure 4. Location of Locus 4 on an aerial photograph. 
Occupation would have occurred during the late summer or early fall, when key upland faunal and floral resources such as elk and huckleberries were available.

\subsubsection{Physiography and Geology}

An overview of geological processes in MORA is warranted here to develop the geological context for Buck Lake (45PI438) regarding the availability of lithic raw material for making stone tools (toolstone) and glaciations that affected the timing of human occupation.

Buck Lake (45PI438) is located in the southern Washington Cascades physiographic province, approximately $19 \mathrm{~km}$ northeast of the 4,392 m ASL Mount Rainier summit (Pringle 2008:6-7). Mount Rainier, as with most mountains in the Cascade Range, is a young volcano resting on Cenozoic Age (less than 65 million years old) volcanic and sedimentary rocks that have been eroded and glaciated since their deposition (Pringle 2008:6).

Mount Rainier and its mountainous vicinity create "a formidable topographic barrier," with an average elevation of 1,500 m ASL and a $111 \mathrm{~km}$ width (Pringle 2008:6). Ethnographically, hunter-gatherers accessed Mount Rainier from the north, via stream valleys and ridges. They passed through MORA along east-west routes (Smith 2006:2). MORA is accessible from the east side of the Cascade Range through the Chinook Pass on the Park's eastern boundary or through the Naches Pass in the northeast. Access from the southeast was through the Carlton or Cowlitz Pass (Smith 
2006:3-4). As described by early geologist Bailey Willis, Mount Rainier is an island of diverse ecological habitats, timberline parklands, microclimates, and geological processes (Pringle 2008:6).

Volcanic eruptions between the Oligocene and Miocene created geologic formations in the vicinity of Buck Lake (45PI438). Early Cascade Range volcanoes began rapidly producing lava and volcanic debris around $10 \mathrm{~km}$ thick, creating the Oligocene Ohanapecosh Formation 37 million to 27 million years ago (Pringle 2008:21). This is the primary geologic formation surrounding Buck Lake (45PI438) (Schasse 1987:geologic map). The silt content of the lava increased during this time, changing basalt and basaltic andesite into andesite and dacite (Pringle 2008:21). Other geologic formations in the vicinity include the late Oligocene to early Miocene Stevens Ridge Formation, created 27 million to 22 million years ago, and the lower Miocene undifferentiated intrusive related to the Tatoosh pluton and the middle Miocene White River pluton created 22 million to 5 million years ago (Pringle 2008:23; Schasse 1987). Clearly, igneous lithic material dominates the Buck Lake (45PI438) area landscape.

Glacial sheets in MORA would have limited access to floral and faunal resources for prehistoric hunter-gatherers. The McNeeley advance was the last major glaciation in MORA and occurred between 11,370 and 9,950 calibrated years before present during the Late Pleistocene (Pringle 2008:30). The advances' latest moraines are radiocarbon dated between 10,900 and 9,950 calibrated years before present. This latest advance occurred after the Younger Dryas, when the climate became warmer 
(Pringle 2008:29-30). Some of these glaciers occurred in the vicinity of Buck Lake (45PI438). The use of Buck Lake (45PI438) is not expected to have occurred before the end of this glacial advance, i.e. after 8,990 year B.P. to 9,550 years B.P.

\subsubsection{Cultural Ecology}

Buck Lake (45PI438) is located within the subalpine parkland environmental zone (Burtchard 2003:121). The subalpine parklands were heavily used by prehistoric hunter-gatherers because of their "high resource potential" (Burtchard 2003:25). The subalpine parkland contains patches of conifers mixed with grassy meadows between the alpine tundra and the closed forest (Burtchard 2003:25; Franklin and Dyrness 1988:248). Early- to mid-seral stage habitats in the subalpine environmental zone are home to a number of useful floral and faunal resources that were attractive to prehistoric hunter-gatherers (Burtchard 2007:4). Because of the heavy snowpack and short growing season, forest maturity is low, creating ideal conditions for grasses, sedges, flowers, shrubs and plants that are preferred by ungulates, small mammals, and birds (Burtchard 2003:25; Franklin and Dyrness 1988:248-250, 264, 282-283; Taylor and Shaw 1927:11-13). Parks of open meadows occur within the subalpine parkland; the Bear (1,768 m ASL), Green (1,707 m ASL), and Burnt (1,737 m ASL) Parks are 4-5 km southwest of Buck Lake (45PI438) (Smith 2006:6-7). The lush herbaceous meadow plants provide optimal habitat for elk, deer, and marmots, all of which were most likely hunted by prehistoric hunter-gatherers (Burtchard 2003:27). 
These optimal subalpine habitats would have been "stable for a long period of time," and prehistoric use of MORA should occur mainly in the subalpine zone and be evident throughout the MORA archaeological record (Burtchard 2003:28).

In prehistoric, proto-historic, and historic times, it is likely that the Buck Lake (45PI438) area was an important hunting and collecting area for both Coastal and Plateau peoples (Smith 2006:149). During times of less than optimal animal forage during the Hypsithermal Interval in the Columbia Plateau east of the Cascades, between 7,800 and 4,500 B.P., prehistoric hunter-gatherers might have utilized the optimal open-forest habitats of MORA lower elevation and subalpine areas (Burtchard 2003:41). Buck Lake (45PI438) would have been accessible from east of the Cascades by way of the Naches or Chinook Passes along the Cascade Divide (Smith 2006:xxiii, 3-4).

Burtchard (2003:41) suggests prehistoric use of MORA could have coincided with climatic episodes that created conditions for optimal ungulate habitat. During the Hypsithermal Interval (7,800 to 4,500 years B.P.), habitat would have improved in the Mount Rainier vicinity and the Puget Trough, but became more restricted in MORA itself due to snow-melt and associate forest encroachment into former subalpine parklands. As forests closed in the Puget Trough west of MORA from 4,500 to 2,800 B.P., and reopened in MORA, prehistoric hunter-gatherers might have moved east from lowland habitats to Mount Rainier subalpine areas such as Buck Lake (45PI438) to exploit animals where foraging habitat was better (Burtchard 2003:42). People could have moved to Buck Lake (45PI438) from the Puget Sound by way of the White 
River valley within the Upper White River Basin as access to the northern MORA is gained by way of river valleys (Smith 2006:2-3; USGS 2009). During the Modern Interlude 2 (4,500 to 2,800 years B.P.) and Modern Interlude 3 (2,100 to 900 B.P.), as defined by Burtchard (2003:39-43), the forests closed in the Puget Trough and lower elevations of the Cascades forcing prehistoric use of the more open subalpine and alpine areas of Mount Rainier where ungulate habitat was optimal (Burtchard 2003:42).

Fire may have been used to improve ungulate habitat (Burtchard 2003:41). In 2004, Burtchard and crew extracted a lake sediment core to investigate chronological changes in climate, vegetation, and fire frequency (Tweiten 2007:1). Pollen and charcoal analyses of a Buck Lake sediment core reveal a 7,000-year climatic, vegetation, and fire frequency sequence (Tweiten 2007:4-6). Based on the pollen and charcoal analyses, Tweiten (2007:9) concludes there were major shifts in vegetation and fire frequency at Buck Lake (45PI438). Prior to ca. 4000 RCYBP, the vegetation was open forest pines. After ca. 4,000 RCYBP, vegetation then changed to closed Abies forest with the exception immediately after the Mount St. Helens Yn (MSH Yn) tephra deposition ca. 3350 to 3400 RCYBP when the forest became open. This shift coincides with an increase in cultural material at Buck Lake (45PI438), although fire frequency did not increase. At $2700 \mathrm{RCYBP}$, increase in fire frequency does not appear to coincide with changes in vegetation or climate. This increase is attributed to prehistoric fire management by Buck Lake (45PI438) occupants to produce optimal ungulate habitat. 
A number of animals exploited during proto-historic and historic times during the late summer occur within the subalpine zone at MORA. These animals were expected to be available to prehistoric hunter-gatherers as well. Animals hunted within the subalpine zone during proto-historic and historic times include black-tailed deer (Odocoileu columbianus columbianus), elk (Cervus canadensis roosevelti), mountain goat (Oreamnos montanus montanus), bear (Ursus americanus americanus), hoary marmot (Marmota caligata cascadensis), and sooty grouse (Dendragapus obscurus fuliginosus) (Smith 2006:170-171, Figure 7.2). Mountain sheep (Ovis Canadensis) also might have been exploited, although in limited numbers (Smith 2006:139,170). Marmots or pikas (Ochotona princeps brunnescens) frequent rockslides and meadows and were most likely hunted in the vicinity of berry areas in the late summer or early fall (Burtchard and Lindeman [editors] 2006:140; Smith 2006:140-141). The limited prehistoric archeaofaunal record at MORA indicates that birds (most likely grouse or ptarmigan), mountain beaver, marmot, and most likely mountain goat were exploited in the subalpine zone (Burtchard and Lindeman [editors] 2006:143; Lubinski and Burtchard 2005:35).

Ungulates were an important resource in MORA. As Burtchard (2003:iv-v) points out, "Primary attractors to Mount Rainier are believed to have been large ungulates_principally elk and deer..." Columbia black-tail deer "was the primary game sought by all tribal groups" (Smith 2006:124). The Muckleshoot Tribe hunted them in the upper West Fork White River area just west of Buck Lake (Smith 2006:124). Plateau tribes were also known to have hunted them (Smith 2006:125). 
Black-tailed deer were found throughout MORA in meadows and forests up to 1,829 m ASL (Smith 2006:125). In the summer, they usually migrated from the lower elevation forests where they winter to the subalpine meadows (Smith 2006:126). Around August, they ascended to meadows at 1,219 to 1,829 m ASL to seek out more desirable vegetation (Smith 2006:126).

The Olympic elk were most likely the native species found throughout MORA forests and parks and were hunted by coastal and plateau tribes (Smith 2006:127-128). Like the black-tail deer, elk migrate to the subalpine meadows in the early summer from the lower elevation forests where they winter (Smith 2006:128). Elk might possibly have been hunted between August and September when huckleberries were available (Smith 2006:128). Elk meat was cut in pieces and then dried for transport back to winter villages (Smith 2006:144-145). Sometimes the meat was wrapped in deer or elk skin or transported in cedar bark sacks (Smith 2006:145).

Mountain goats were also important to proto-historic and historic tribes; although they are known to be difficult to hunt because of the treacherous areas they frequent (Smith 2006:130-131). They are typically found above the treeline but have been known to descend to the subalpine meadows when the weather is poor (Smith 2006:131). It has been suggested that their present ranges are most likely the same as those in the past (Smith 2006:132). The closest present-day range to Buck Lake (45PI438) is at Yakima Park, approximately $8 \mathrm{~km}$ southwest (Smith 2006:xxii, xxiii, 6-7, Figure 1.1, 135). The Muckleshoot Tribe has been known to hunt mountain goats in this area (Smith 2006:139). 


\subsection{Theoretical Background}

The following section presents the fundamental hunter-gatherer technological organization research used to develop expectations tested by this study for Buck Lake (45PI438). This research is only pertinent to this study and does not attempt to present all of the research conducted on this topic. The concept of hunter-gatherer mobility is presented first because archaeologists generally recognize that technological organization is determined by mobility. Archaeologists also recognize that other factors contribute to the technological organization strategies of hunter-gatherers though. For both foragers and collectors at Buck Lake (45PI438), similar lithic raw material availability, terrain, and seasonality constraints and a common resource acquisition goal and overlapping site function resulted in similar hunter-gatherer technological organization strategies through time regardless of mobility strategies.

\subsubsection{Mobility}

Archaeologists believe that technological organization is typically determined by mobility, so the concept of hunter-gatherer mobility will be presented here. Binford (1980:5) identifies two types of present-day hunter-gatherer mobility patterns and used ethnographic fieldwork data to develop his hunter-gatherer mobility model. He recognizes a continuum in hunter-gatherer mobility patterns based on how they moved their residential bases with reference to resource distributions and how 
resources were harvested. He labeled the two ends of the continuum foragers and collectors. The forager-collector continuum is considered "a useful heuristic device" (Odell 2004:190-191). As Odell (2001:63) states, "Binford's model remains a useful framework for structuring archaeological data." The forager-collector dichotomy lays the path for developing models and archaeological expectations to explore differences in hunter-gatherer strategies of resource exploitation through time and across space (Ames 2000).

Forager and Collector Mobility. Foragers are mobile, moving their residence from resource patch to resource patch. They obtain their food daily by leaving their residential base, gathering the necessary resources, and then returning. If a resource patch is fairly large and "homogenous" (Binford 1980:5), typical of nonseasonal environments, the residence will move more frequently with a short distance between moves (Binford 1980:5, 14-15). If resources are spread out and few in number, the hunter-gatherer group will be relatively small and will be distributed over a wide area to exploit a number of resources (Binford 1980:7). In his research, Binford (1980:7) acknowledged that there was some variability in forager strategies within the above framework as a result of environmental differences, but generally these characteristics serve as the typical forager model.

Two site types are associated with foragers, each resulting in archaeologically visible artifacts and tendencies. The "residential base" is the location of "processing, manufacturing, and maintenance activities" (Binford 1980:9). Artifacts at residential base sites should reflect these activities. "Location" sites are where resources are 
harvested (Binford 1980:9). Artifacts, including lithic tools, at locations sites should be particular to the method of resource extraction, obtained close to the extraction activity, and then discarded at the activity location (Binford 1980:9).

Collectors practice logistical mobility strategies (Binford 1980:10). Like foragers, they also generate residential bases (Binford 1980:10). Instead of moving the residence from resource patch to resource patch like foragers, collectors send out specialized task groups to extract resources and return them to the residential base. The residential base remains in place from part of a year to several years depending on the group (Binford 1980:10). The specialized task groups extract resources from a "field camp" (Binford 1980:10) or "station" (Binford 1980:12) away from the residential base and then return to the field camp or station to process the resource for the trip back (Binford 1980:10,12). Task groups are highly operationalized and plan their resource extraction carefully where important resources are widely distributed and seasonally available. For collectors, sending out task groups is an efficient way to gather resources and bring them back to the residential base (Binford 1980:14-15).

Although both foragers and collectors generate residential bases such as Buck Lake (45PI438), researchers have refined this site type and recognize assemblage differences between foragers and collectors. Shott (1986:21-22) along with Kelly (2007:120-130) considers the number of moves and the distances traveled to be factors that differentiate the degree of mobility between hunter-gatherer groups. Generally, assemblage diversity decreases as mobility increases; therefore, it could be expected 
that the tool assemblage of collector residential base occupations should be more diverse than foragers (Shott 1986:45-46).

Chatters $(1987: 338,340)$ considered the differences between residential bases for foragers, termed residence camps, and collectors, termed base camps, in the Columbia Plateau. Considering the high mobility of foragers, tool assemblages are more generalized and multifunctional to reduce the transportation costs of hauling a number of tools (Chatters 1987:342). The tool assemblage of collectors, on the other hand, is more specialized resulting from the specialized logistical tasks conducted away from the residential base (Chatters 1987:342). Generally, the tool assemblages at residential bases for collectors should be more diverse than those for foragers (Chatters 1987:342).

Mobility at MORA. Generally, a forager mobility strategy is employed when population density, and thus resource competition, is low (Binford 1980:7; 2001:356357, 438; Burtchard 2007:9). In the Pacific Northwest, it is generally accepted that the population density increased from the early to late Holocene. Buck Lake is situated in the area of the Southern Plateau region (Ames et al. 1998:104, Figure 1) and in the area of the Southern Coast and Straight Coastline subregions of the Northwest Coast (Ames 2003:21, Figure 1). In the Southern Plateau, a gradual increase in population occurred after 4,000 RCYBP with a peak between 3,000 and 2,600 RCYBP (Ames 2000; Chatters 2004:71-73). On the Northwest Coast, it is suggested that the population increased between 1,800 BC to AD 200-500 (Ames 2003:26, 30). 
Therefore, a forager mobility strategy might be expected when population densities were lower, before the dramatic mid-Holocene population increase.

The forager-collector continuum has been useful for recognizing temporal changes in hunter-gatherer resource procurement strategies in the archaeological record of Pacific Northwest montane environments. Aside from MORA, models exist for North Cascades National Park (Mierendorf 1986), Olympic National Park (Schalk 1988), and Mt. Hood National Forest (Burtchard 1990). All of the models recognize a change in the settlement and subsistence patterns of hunter-gatherers as a result of population increase between 3,000 and 5,500 years B.P. (Burtchard 2007:Figure 4).

Burtchard (2007:13-36) uses an ecological approach to predict changes in hunter-gatherer settlement and subsistence patterns over time in MORA. Changes occur when the environment in which hunter-gatherers live does not provide the necessary resources for the population. Settlement and subsistence patterns will remain stable as long as the balance between the population size and the available resources is sustained (Burtchard 2007:13). According to Burtchard (2007:22), a more forager-like mobility strategy shifted to a more collector-like strategy between 4,500 and 3,500 RCYBP.

During the forager to collector shift at MORA, the environment became cooler and wetter, affecting forests and ungulate habitats in the lowlands (Burtchard 2007:2122). Ungulate populations are believed to have decreased as hunter-gatherer populations increased (Burtchard 2007:22). As Burtchard (2007:22) points out, "elevated population density and declining ungulate habitat reached a point at which 
competition for available resources was too high to reliably sustain rest-rotation foraging practices." Sedentary residences would have been located in areas where storable foods were harvested, such as around major anadromous fish-bearing rivers and streams (Burtchard 2007:24). "Supplemental" resources may have been acquired from the subalpine zone by "limited-task groups tethered to the residential hub or ... supplied by trade" (Burtchard 2007:24).

\subsubsection{Technological Organization}

After Binford's (1980) forager-collector mobility model was introduced, researchers began investigating technological expectations caused by humans practicing residential or logistical mobility. One approach to studying the stone tools of hunter-gatherers is to investigate how hunter-gatherers might have organized their stone tool technology to coordinate with their mobility strategy. Andrefsky (2008:4) defines technological organization as:

...a strategy that deals with the way lithic technology (the acquisition, production, maintenance, reconfiguration, and discard of stone tools) is embedded within the daily lives and adaptive choices and decisions of tool makers and users. [Andrefsky 2008:4] 
Technological organization is influenced by economic strategies, which in turn are influenced by environmental conditions. Prehistoric hunter-gatherers adapt to environmental conditions that are variable in space and time through the use of economic strategies like the residential mobility of foragers and the logistical mobility of collectors mentioned above (Nelson 1991:58-59): "Strategies are viewed as problem-solving processes that are responsive to conditions created by the interplay between humans and their environment." The environmental context and resulting mobility planning strategies then influence prehistoric hunter-gatherers technological organization planning strategies through the design of tools and toolkits (Nelson 1991:58).

Technological organization research generally recognizes two planning strategies that influence the design of tools and toolkits: curation and expediency (Nelson 1991:62). These strategies are "plans for facilitating human uses of the environment that can be carried out in a variety of ways and are responsive to a variety of conditions" (Nelson 1991:62). Curation involves the forethought of having prepared toolstone on-hand to counteract future conditions when materials and/or tool reduction and production time is not available when needed or when its availability is unknown. An expedient strategy is used when future conditions conducive to the availability of needed materials and/or tool production and reduction time are known (Nelson 1991-62-64).

Curation and expediency strategies can be combined and should not be considered independent of one another. Curation can sometimes lead to an expedient 
strategy when curated tools are cached for future expedient use over a long occupation or regular reuse of a resource acquisition area. Expedient tools can be made and then carried to another area for curated use (Nelson 1991:64-65).

Technological Organization and Mobility. Archaeologists continue to recognize some general technological organization expectations for foragers and collectors (Andrefsky 2008:8). Foragers are expected to use tools that are curated, and collectors are expected to use expedient tools. More recently though, researchers recognize that there are several other factors that influence the technological organization of hunter-gatherers, including raw material and tool function (Andrefsky 2008:8).

Archaeologists recognize that forager and collector archaeological signatures might be similar to each other or might be different from what is commonly expected. This should be considered when investigating changes in technological organization at Buck Lake. Technological organization can vary from site to site within a settlementsubsistence system (Kuhn 1995:26). If a site was occupied for a short period of time, an assemblage will most likely resemble a mobile toolkit despite the mobility strategy of the occupants. Nelson (1991:85) points out that forager and collector strategies are not so clear-cut and can be variable or mixed. Foragers might use a logistical strategy when extracting a particular resource or in a particular environmental setting. Logistical task groups might rely on portable toolkits if high mobility is necessary.

The archaeological evidence of hunter-gatherers using MORA subalpine areas might appear the same through time for a number of reasons, regardless of the 
foraging or collecting strategies employed (Burtchard 2007:27). Burtchard (2007:27) suggests the possibility that site types "may not appear substantially different if forager to collector land-use practices evolved" as he proposes in his MORA model. Burtchard (2007:27) continues, stating, "factors affecting site selection and use may have been much the same throughout the Holocene." Similar to this suggestion, I propose that toolstone availability, seasonality, and terrain constraints and a common resource acquisition goal and overlapping site function resulted in similar huntergatherer technological organization strategies through time for both foragers and collectors at Buck Lake (45PI438).

\section{Technological Organization and Toolstone Procurement. Andrefsky}

(1994a:21; 1994b:377, 379, 381) and MacDonald (2008:222-223) suggest that the availability, quality, size, and shape of toolstone, not hunter-gatherer mobility, ultimately influence how hunter-gatherers strategically organize their technology. A "detailed" survey has not been conducted for toolstone sources within MORA; although possible sources were documented during the 1995 MORA reconnaissance survey (Burtchard 2003:92-93). In general, Burtchard (2003:iv) suggests that good quality toolstone is not readily available within MORA. Definitions of local and non-local raw-material for this study are warranted here.

"Local" raw material is a relative term that should be realistically defined by the researcher (Odell 2004:24). Local raw material for this study will be defined based on terrain, foraging radius, and watershed boundaries. Buck Lake (45PI438) nestles in a high-elevation environment surrounded by steep terrain. It is fair to 
suggest that people would not traverse long distances in upper elevations for immediate sources of toolstone (Wilson 2007:319-321). Maximum foraging limits for hunter-gatherers traveling by foot in MORA can be expected to be at least $4 \mathrm{~km}$ and could extend up to $9.4 \mathrm{~km}$ based on ethnographic (Kelly 2007:133-141) and mountain (Morgan 2008:255, Figure 11) research. In proto-historic and historic times, tribal territories were usually defined by the watershed they commonly used (Smith 2006:76-77), although long distance trading was possible with the introduction of the horse (Smith 2006:162). The boundaries of the Upper White River Basin (USGS 2009), where Buck Lake (45PI438) is located, will be considered the local raw material zone for this study considering the steep terrain, expected foraging radius, and possible territorial boundaries (Figure 5). The Upper White River Basin extends approximately $32 \mathrm{~km}$ to the north, $24 \mathrm{~km}$ to the south, and $16 \mathrm{~km}$ to the east and west from Buck Lake (45PI438).

Toolstone within the defined local zone includes: tuff, breccias, andesite, basalt, dacite, rhyolite, sandstone, pumice, diorite, gabbro, granite, and granodiorite (Kooyman 2001:31-34; Odell 2004:18; Pringle 2008:186-187; Schasse 1987). None of this material would be considered high or even moderate quality toolstone for flaking (Whittaker 1997:66, 69-72).

A number of usable non-local toolstone sources of CCS and obsidian have been mapped outside of the Upper White River Basin approximately 24 to $97 \mathrm{~km}$ from Buck Lake (Burtchard 2003:Figure 3.4; Dampf 2002:93; McClure 1989:59; Northwest Research Obsidian Studies Laboratory 2009a; Northwest Research Obsidian Studies 


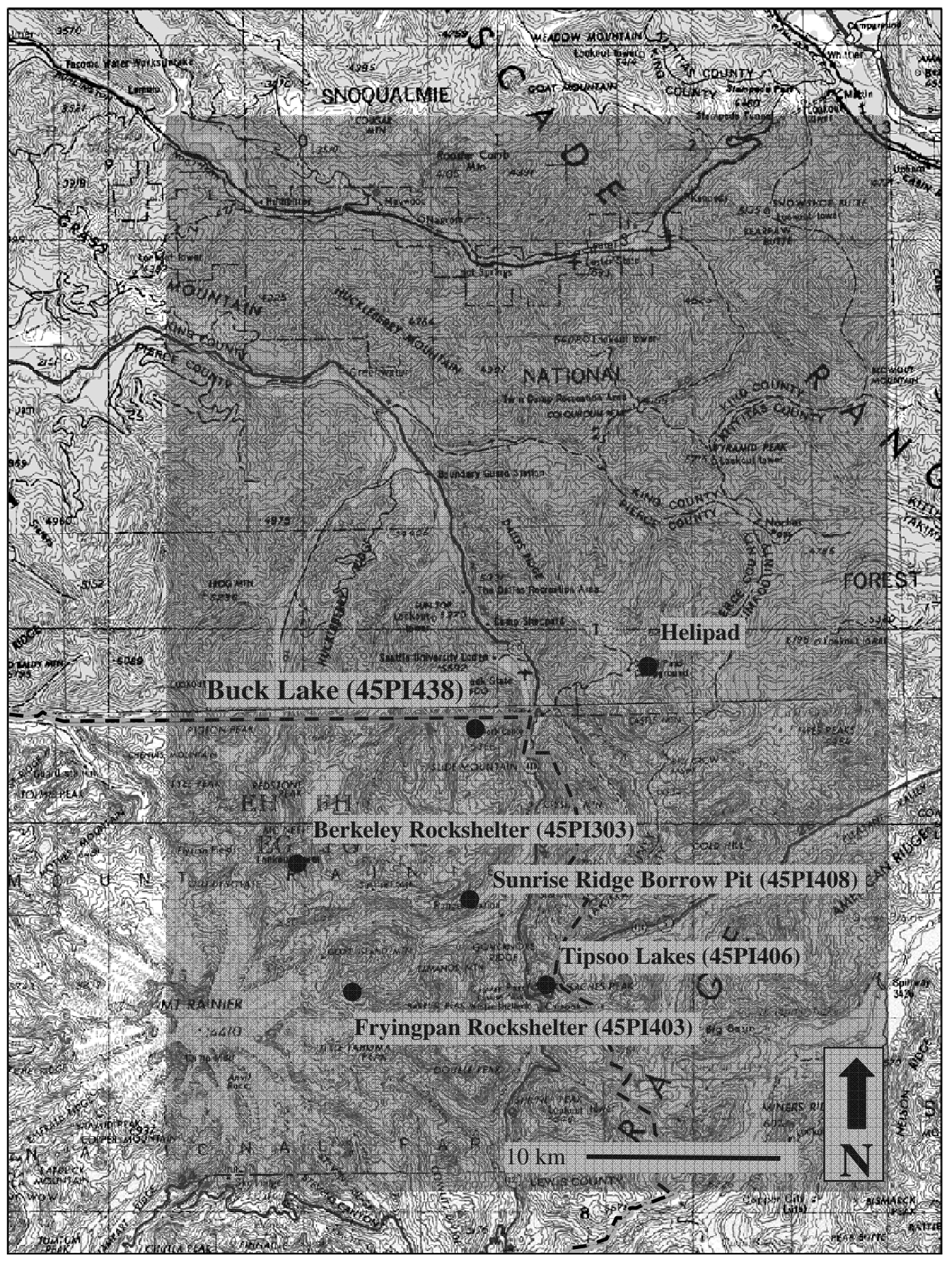

Figure 5. The Upper White River Basin (shaded) and archaeological sites mentioned in the text. 
Laboratory 2009b; Schuster 2005). A total of only 83 obsidian artifacts have been recovered at MORA (Burtchard 2003:54, 92; Northwest Research Obsidian Studies Laboratory 2009a).

Prehistoric sites in the Upper White River Basin provide some insight into what might be expected archaeologically at Buck Lake (45PI438). A summary of the Upper White River Drainage sites can be found in Table 1. Obsidian artifacts represented less than one percent of the total artifacts recovered from excavations at Sunrise Ridge Borrow Pit (45PI408) (Vaughn and McCutcheon 2008). At Tipsoo Lakes (45PI406), the obsidian artifacts represented close to five percent of the total artifacts recovered from excavations (Vaughn and McCutcheon 2008). Little use of obsidian is expected at Buck Lake (45PI438) and an obsidian source is not expected within MORA (Burtchard 2003:92).

In instances where the local raw material is of poor quality, such as at Buck Lake (45PI438), the better-quality nonlocal raw material will be used to manufacture transported formal tools (Andrefsky 1994b:381, 383, 388; MacDonald 2008:217, 218, 224). As Andrefsky (1994b:388) points out, "High quality lithic materials tend to have fewer flaws and are more easily chipped than lesser quality materials." This efficiency makes nonlocal, high-quality toolstone worthwhile for transport in "formal artifact shapes, and not as bulk raw-material cobbles or chunks" (Andrefsky 1994b:388). Transported formal tools made of higher-quality nonlocal toolstone will have a high degree of tool retouch (Andrefsky 1994b:381, 388; MacDonald 2008:217, 
Table 1. Summary of Upper White River Drainage Basin Prehistoric Sites.

\begin{tabular}{|c|c|c|c|c|c|}
\hline Site & $\begin{array}{l}\text { Distance } \\
\text { from } \\
\text { Buck } \\
\text { Lake } \\
\end{array}$ & Site Type & Age & Lithic Technology & Reference(s) \\
\hline Helipad & $8 \mathrm{~km} \mathrm{NE}$ & $\begin{array}{l}\text { Subalpine } \\
\text { logistical } \\
\text { task group } \\
\text { residential } \\
\text { base camp }\end{array}$ & $\begin{array}{l}\text { After } \\
5,000 \\
\text { years BP }\end{array}$ & $\begin{array}{l}\text { Late stage pressure } \\
\text { and percussion } \\
\text { bifacial thinning for } \\
\text { tool refurbishment; } \\
\text { scrapers; transported } \\
\text { preforms and finished } \\
\text { tools; mainly chert } \\
\text { toolstone }\end{array}$ & $\begin{array}{l}\text { Andrews et al. } \\
(2008)\end{array}$ \\
\hline $\begin{array}{l}\text { Sunrise } \\
\text { Ridge } \\
\text { Borrow Pit } \\
(45 P I 408)\end{array}$ & $8 \mathrm{~km} \mathrm{~S}$ & $\begin{array}{l}\text { Upper } \\
\text { maritime } \\
\text { forest multi- } \\
\text { task } \\
\text { residential } \\
\text { base camp }\end{array}$ & $\begin{array}{l}\text { Pre- and } \\
\text { post-2,300 } \\
\text { years BP }\end{array}$ & $\begin{array}{l}\text { Majority of chert } \\
\text { toolstone; lack of } \\
\text { cortex; mainly } \\
\text { terminal reduction } \\
\text { stage }\end{array}$ & $\begin{array}{l}\text { Burtchard (2003); } \\
\text { Dampf (2002); } \\
\text { Vaughn and } \\
\text { McCutcheon } \\
(2008)\end{array}$ \\
\hline $\begin{array}{l}\text { Berkeley } \\
\text { Park } \\
\text { Rockshelter } \\
(45 \text { PI303) }\end{array}$ & $\begin{array}{l}12 \mathrm{~km} \\
\mathrm{SW}\end{array}$ & $\begin{array}{l}\text { Upper forest } \\
\text { seasonal } \\
\text { hunting field } \\
\text { camp }\end{array}$ & $\begin{array}{l}300-1,000 \\
\text { years BP }\end{array}$ & $\begin{array}{l}\text { Majority of chert } \\
\text { toolstone; late-stage } \\
\text { debitage, arrow } \\
\text { points, bifaces, used } \\
\text { flakes, cores; some } \\
\text { evidence of bipolar } \\
\text { technology }\end{array}$ & $\begin{array}{l}\text { Bergland (2008); } \\
\text { Burtchard (2003); } \\
\text { Tofte (2009) }\end{array}$ \\
\hline $\begin{array}{l}\text { Tipsoo } \\
\text { Lakes } \\
\text { (45PI406) }\end{array}$ & $14 \mathrm{~km} \mathrm{SE}$ & $\begin{array}{l}\text { Subalpine } \\
\text { parkland } \\
\text { multi-task } \\
\text { residential } \\
\text { base camp }\end{array}$ & Unknown & $\begin{array}{l}\text { Majority of chert } \\
\text { toolstone; mainly } \\
\text { terminal reduction } \\
\text { stage }\end{array}$ & $\begin{array}{l}\text { Burtchard (2003); } \\
\text { Northwest } \\
\text { Research Obsidian } \\
\text { Studies } \\
\text { Laboratory } \\
\text { (2009a); Vaughn } \\
\text { and McCutcheon } \\
\text { (2008) }\end{array}$ \\
\hline $\begin{array}{l}\text { Fryingpan } \\
\text { Rockshelter } \\
(45 \mathrm{PI043)}\end{array}$ & $\begin{array}{l}16 \mathrm{~km} \\
\mathrm{SW}\end{array}$ & $\begin{array}{l}\text { Subalpine } \\
\text { seasonal } \\
\text { specialized } \\
\text { hunting } \\
\text { camp }\end{array}$ & $\begin{array}{l}300-1,000 \\
\text { years BP }\end{array}$ & $\begin{array}{l}\text { Knives, projectile } \\
\text { points, utilized core, } \\
\text { utilized flakes, } \\
\text { scrapers, blades, } \\
\text { bifaces; mainly small } \\
\text { late stage flakes from } \\
\text { maintenance; majority } \\
\text { of CCS toolstone }\end{array}$ & $\begin{array}{l}\text { Burtchard (2003); } \\
\text { Lubinski and } \\
\text { Burtchard (2005); } \\
\text { Rice (1965) }\end{array}$ \\
\hline
\end{tabular}


$218,224)$ as mobile hunter-gatherers mitigate the "risk [of] tool depletion" (MacDonald 2008:217, 218, 224).

Because of the distance the transported tools traveled and the amount of retouch and reduction, the size of the nonlocal versus local debitage will be predictably smaller (MacDonald 2008:228). If a usable local toolstone were nearby, debitage representing all stages of reduction would be expected. On the other hand, if this toolstone is obtained from a distance, debitage will be small $(<10 \mathrm{~mm}$ diameter and $<1.5 \mathrm{~mm}$ thick) and represent formal tool maintenance and use (Beck 2008:774775; Eerkens et al. 2007:586-587).

Burtchard (2003:iv) suggests that tools at MORA can be expected to be transported and show evidence of late-stage manufacture resulting in the deposition of small artifacts. When the local raw material is of poor knapping quality, it can be expected that formal tools would be made from nonlocal, high-quality toolstone despite hunter-gatherer mobility (Andrefsky 1994a:30-31). Also, in rough terrain such as at Buck Lake, it is expected that most of the early reduction of toolstone would occur at the toolstone source. Assemblages in this situation should include small and light debitage and represent "finished tools" (Wilson 2007:322).

Conservation of the limited number of tools in the toolkit and toolstone is important (Nelson 1991:74). Waste is kept to a minimum, and tools can be resharpened for reuse. Evidence of retouch and resharpening flakes will occur in higher proportions when toolstone conservation is important (Nelson 1991:74). Such 
situations are expected to be the case for all of the Buck Lake inhabitants experiencing the same raw material constraints regardless of mobility.

The shape and size of raw material can influence lithic technology as well (Andrefsky 1994b:384-387). Bipolar technology may be useful when the available toolstone is of low knapping quality and the investment required to procure high quality toolstone makes it an inefficient option (Andrefsky 1994b:384; Jeske and Lurie 1993:134). The bipolar technique is useful to conserve toolstone and can be expected to be used on small or pebbly raw material and existing stone tools (Andrefsky 1994b:384-387; Binford 1979:267; Kelly 2001:66). Fine-grained CCS or obsidian work best with the bipolar technique when a sharp flake is the desired product; coarsegrained material would not be preferred in this case (Kelly 2001:66). Coarse-grained igneous toolstone might have been preferred for processing hides because it will not cut through hides during softening and stretching (Hayden et al. 1996:29-30).

Igneous raw material of less than moderate knapping quality was the local toolstone available in the Buck Lake vicinity. The low frequencies of igneous tools and debitage recovered from Sunrise Ridge Borrow Pit (45PI408) (3.4\% and 4.56\%), Tipsoo Lakes (45PI406) (5.35\%), Fryingpan Rockshelter (45PI043) (0\%), and Berkeley Rockshelter (45PI303) (1\%) sites suggest that the locally available igneous raw material was not the preferred toolstone (Bergland 1988:16; Dampf 2002:83; Lubinski and Burtchard 2005:37; Rice 1965:4-7; Vaughn and McCutcheon 2008) (Table 1). The local igneous raw material was not preferred for even the simplest of tools. The high frequencies of nonlocal CCS tools and small or late stage reduction 
sequence CCS debitage at the Helipad, Sunrise Ridge Borrow Pit (45PI408), Tipsoo Lakes (45PI406), Fryingpan Rockshelter (45PI043), and Berkeley Rockshelter (45PI303) suggest that nonlocal CCS was the preferred transported toolstone in the Buck Lake vicinity (Andrews et al. 2008:4; Bergland 1988:15-19; Dampf 2002:79-80, 87-89; Lubinski and Burtchard 2005:37; Rice 1965:4-7; Vaughn and McCutcheon 2008) (Table 1).

Although bipolar debitage has been recovered at Berkeley Rockshelter (45PI303) (Burtchard 2007:28) (Table 1), evidence for the use of the bipolar technique at Buck Lake is not expected to occur in high frequencies. The locally available igneous material would not have been preferred to make expedient tools with the bipolar technique. The Buck Lake inhabitants might have used igneous bipolar flakes for hide processing; although there is little evidence in the vicinity that igneous material was preferred for use at all. The bipolar technique might have been used to conserve the nonlocal CCS to produce expedient flakes, but the preferred tools at Buck Lake would have been bifaces for hunting and butchering rather than smaller, expedient tools. Collectors might have used the bipolar technique on exhausted transported tools to produce expedient flakes for small-game hunting, but flakes from bifacial cores would have supplied this need.

Technological Organization and Tool Design. Based on the synthesis of past ethnoarchaeological and archaeological research, Nelson (1991:66) recognizes three main variables of tool and toolkit design that result from technological organization planning strategies: reliability, maintainability (flexibility and versatility), and 
transportability. Because of similar seasonal and terrain constraints, both foragers and collectors at Buck Lake relied on reliable, maintainable, and transportable tools.

Nelson (1991:66-67) defines a reliable tool as one that is readily available for the task at hand and is free of procurement, maintenance, and repair needs. Using a reliable tool leaves more time for the acquisition of prey and reduces the time required for tool preparation in the field. Time for the procurement of toolstone and the production of the tool is expended before the use of the tool, and time for maintenance is expended after the tool is used.

Some technological techniques and trends are often evident in a reliable design. Because of their high mobility, foragers typically use a more formal and standardized core technology for the production of reliable tool blanks for tasks on the go (Andrefsky 2005:227; Kooyman 2001:130). Standardized tools in a toolkit can have similar components to ensure that a backup tool is available if a tool in the toolkit breaks (Nelson 1991:69).

A tool or toolkit based on a maintainable design can be "flexible" or "versatile" (Nelson 1991:70). Flexible tools are "those which are changed in form to achieve multifunctional demands" (Nelson 1991:70). Versatile tools are "those which are maintained in a generalized form to meet a variety of needs" (Nelson 1991:70). Flexible tools require investment in time for reshaping and preparation, as the tool is fashioned for each particular task; versatile tools require time for preparation for a number of tasks. Both flexible and versatile tools are considered beneficial because they are multifunctional (Nelson 1991:71). 
There are three advantages to using a flexible or versatile tool, especially for foragers (Nelson 1991:71). First, a multifunctional tool can be used when the particular task the tool will be used for is unknown. Second, a multifunctional tool is useful when resource exploitation requires a variety of functions and tasks. Lastly, a multifunctional tool simplifies the toolkit; instead of having multiple tools for a number of tasks, one multifunctional tool can take the place of many. Such advantages would be important for highly mobile foragers who depend on lightweight gear. Multifunctional tools would also be beneficial in diverse environments where an array of resources would be exploited.

Highly mobile hunter-gatherers rely on tools and toolkits designed for transportability (Nelson 1991:73-74). This is especially important if toolstone is not available in the vicinity where a task will occur. In this instance, the tools and toolkits designed for transportability are carried to a task rather than made where the task will occur. A transportable toolkit is made up of a few resilient, lightweight, versatile, or flexible tools that can be used to extract a variety of resources from the environment while hunter-gatherers travel across the landscape. The weight of a transportable toolkit can be further reduced by using smaller tools with any excess removed (Nelson 1991:75).

Foragers and collectors at Buck Lake would have benefited from bifaces designed for reliability, maintainability, and transportability. There are two situations when reliable designs are particularly useful (Nelson 1991:67). Reliable tools are often used when hunting specific large animals at predictable places, at scheduled 
times, and that require little hunting time. Reliable tools would also be useful when hunting specific game in predictable places and variable times, when it would be beneficial to have a ready-to-use tool upon encountering prey (Nelson 1991:67).

One of the constraints at MORA that both foragers and collectors had to manage was seasonality. Tribal proto-historic and historic summer use of MORA involved small groups of men and women and "was seasonal, annual, of short duration, and primarily involved collecting and hunting" (Smith 2006:29, 123, 172). All hunter-gatherers using the subalpine areas in MORA throughout time are limited to resource procurement from June to October, when the weather is milder and there is less snow (Burtchard 2003:47). Both foragers and collectors at Buck Lake would have hunted subalpine fauna, such as ungulates, at predictable seasonal times.

Formal bifacial cores would have been reliable tools and sources of toolstone for mobile hunter-gatherers to reduce the risk of uncertainty. Bifacial cores would provide a toolstone that has predictable knapping qualities and predictable types of tools made from the core (Andrefsky 2005:157). Buck Lake hunter-gatherers would have used bifacial cores because local quality toolstone was not available.

Bifacial cores would have served as maintainable tools that would have been beneficial for hunter-gatherers at Buck Lake. A bifacial core would have served as a generalized multifunctional tool for mobile hunter-gatherers that can progressively transform from a core that produces a variety of flakes to a finished tool. A bifacial core can potentially be used for pounding, chopping, and slicing (Andrefsky 2005:31, 
157; Nelson 1991:72). A large biface has "several functional edges" and can produce flakes that can be used "for a wide variety of activities" (Nelson 1991:73).

Traveling within mountainous landscapes is not easy and presents a logistical challenge (Burtchard 2003:8-9; Burtchard 2007:7). As Burtchard (2007:24) points out, "Transportation difficulties [are] always inherent in using upland habitats." This would have been the case for both residentially mobile foragers and logistical-task oriented collectors. Therefore, tool design geared towards portability would seemingly be important for all inhabitants at Buck Lake, especially when quality toolstone had to be transported.

CCS toolstone is useful when a transportable design is employed as "it is easily shaped to a variety of forms, can be resharpened with minimal waste, and provides sharp tool edges" (Nelson 1991:75). Obsidian, on the other hand, is fragile and requires frequent resharpening (Nelson 1991:75). Bifacial cores would have conserved toolstone "because a large amount of tool edge can be produced in relation to the amount of material" (Nelson 1991:76-77).

Bifacial cores are highly portable and multifunctional, which reduces the number of tools needed in a toolkit and can conserve toolstone through reuse and reduction (Andrefsky 2005:157, 227; Nelson 1991:71, 77). They can produce a variety of thin and lightweight flakes with highly usable edges for a number of tasks. Also, a bifacial core can be transformed into a useful multifunctional tool as it is being reduced and results in little waste as it is resharpened, requiring fewer tools to be 
carried (Nelson 1991:74). Buck Lake hunter-gatherers are expected to have used bifacial cores made of nonlocal CCS because of their portability.

Blades are reliable tools because of their standardized form (Nelson 1991:68) and have a "high ratio of usable edge to total material," which conserves raw material (Nelson 1991:68, 77). Blade core technology involves modifying a core so that long and narrow blade flakes can be removed on an ongoing basis (Rasic and Andrefsky 2001:63). The blade flakes can then be used for modifying wood or butchering, and can also be fashioned into points (Whittaker 1993:219). Evidence of blade core use is often found in mobile hunter-gatherer archaeological assemblages (Rasic and Andrefsky 2001:62).

Microblades are smaller blades considered to be less than $5 \mathrm{~cm}$ long (Kooyman 2001:174). Microblade technology moved from Alaska to the Northwest Coast by the early Holocene and microblades have been documented in the Columbia Plateau between 8,000 and 5,000 years BP and in southern British Columbia between 5,000 and 6,000 years BP (Prentiss and Clarke 2008:267). Microblades could have been used for fine cutting and engraving, formed into tools, used as insets for projectile points, and hafted as knives (Rasic and Andrefsky 2001:76).

Although blades are reliable, they are considered to be "costly in material quality, training, and manufacture time" (Nelson 1991:68). Considering the expertise needed for successful blade core knapping, there is a risk of wasting blades made of high-quality toolstone (Hayden et al. 1996:17). Furthermore, blades add to toolstone procurement costs because they require toolstone of a particular shape, size, and 
quality (Hayden et al. 1996:17). Considering the toolstone and travel constraints the Buck Lake inhabitants had to endure, evidence for blade core technology is not expected to occur in high frequencies. It should be noted though that blades have been recovered at Fryingpan Rockshelter (45PI043) (Lubinski and Burtchard 2005:37) and a micro-blade core was recovered within the pre-Mazama component at Buck Lake Locus 4 (Burtchard 2007:19).

Technological Organization and Site Function. Both foragers and collectors are expected to have used residential bases or residential base camps, such as Buck Lake (45PI438), at MORA (Burtchard 2003:113; Burtchard 2007:26-27). Several inferences can be made about the technological organization at a residential base or residential base camp. Curated transportable tools are maintained at the residence to allow more time for resource acquisition in the field (Nelson 1991:78-79). Tool repair would have happened at camps between resource acquisition activities and late stage manufacture would have occurred if transportable tools were reused or shaped into cores (Nelson 1991:79-80).

Evidence of expedient technology use and discard can be expected at residences and camps when toolstone is available naturally or in a cache near an activity area (Nelson 1991:80). An increase in sedentism could cause the eventual use of expedient technology, as toolstone availability can be relied on in a continuously used place. Nelson (1991:80) recognizes three material expectations as a result of expedient technology. First, there would be little evidence of tool retouch as expedient tools are manufactured, used, and discarded at the activity area with little 
reuse. Second, there may be evidence of core preparation if the material is to be cached and if the toolmakers planned to use the area again in the future. Third, expedient cores discarded at residences and camps_-as opposed to being transported — could show various stages of reduction as they are continuously used.

A number of material trends can be expected at special-use sites where a specific task such as animal or plant processing occurs. As Burtchard (2003:ix) states, "Primary attractors to Mount Rainier are believed to have been large ungulatesprincipally elk and deer—supplemented by other animal and plant resources—such as goats, game birds, marmots, and huckleberries—-sharing the subablpine habitat." Considering this, a higher frequency of technology and tools geared toward ungulate hunting and processing can be expected at Buck Lake (45PI438).

Technological evidence at special-use sites should reflect a single task activity rather than the range of activities at residences (Nelson 1991:82-84). Curated tools must be transported to the activity area if they are not expediently made, and it's likely that these transported tools would be resharpened at the activity site as needed. Highly mobile foragers would most likely transport curated and prepared bifacial cores to special-use sites as sources of flake tools. Considering the prepared state of these bifacial cores, primary core reduction flake debris would not be expected. The overall shape of the flake population at special-use sites is expected to be consistent and would reflect the same bifacial reduction stage. Expedient tools are expected at special-use sites when toolstone is available near the task site and knowledge of the 
task area is known before task implementation. As argued above, local toolstone would not be available at Buck Lake for expedient tools unless it was cached.

Although a number of technology and tool types could have been a part of an ungulate hunting and processing toolkit, some types would be preferred over others. Tomka (2001:208) believes that processing requirements, and not mobility, determine a prehistoric technological strategy. He suggests that when a mass amount of processing is required in a short period of time, formal tools such as bifacial tools that are retouched are most effective (Tomka 2001:208-209). When a smaller amount of processing is required, an expedient technology that results in the manufacture of unmodified flakes or blades is most effective (Tomka 2001:208-209).

Research shows that hafted formal tools would be preferred over expedient flakes for processing larger animals and when a mass amount of processing was required (Tomka 2001:211-212). This is because of the comfort, control, and power a hafted formal tool such as a biface would provide compared with an expedient tool (Kuhn 1994:434; Tomka 2001:211-212). The Olympic elk that prehistoric huntergatherers in MORA would have hunted are large animals; males can weigh over 800 pounds and the females can weigh up to 600 pounds (Skinner 1936:32-33). Huntergatherers on seasonal logistical forays in MORA could have hunted and processed mass amounts of mountain goat wool to take back to the lowland residence for future storage (Burtchard 2007:26). Also, in seasonal situations such as at MORA, more formal tools designed for reliability are expected in an assemblage because of "increased processing requirements associated with bulk resource procurement" 
(Tomka 2001:223). Prehistoric hunter-gatherers at Buck Lake (45PI438) would have benefited from using bifaces to process large ungulates or mass amounts of ungulate hides during predictable seasonal times.

Technological Organization Expectations at Buck Lake (45PI438). Based on the premises in this theoretical background section, I propose that toolstone procurement, seasonality, and terrain constraints, along with a common resource acquisition goal and overlapping site function greatly influence the technological organization archaeological signatures of all the Buck Lake inhabitants through time regardless of the differences in mobility modeled for MORA. The Buck Lake inhabitants, whether foragers or collectors, relied heavily on transported bifaces made from nonlocal CCS for tools and cores. It is possible that collectors would have cached transported bifaces for future use as cores to produce expedient flakes for hunting smaller animals. As such, collector components could show evidence of biface production rather than the resharpening debitage expected of the forager components.

The transported biface expectation for Buck Lake (45PI438) is in tune with some of Burtchard's $(2003 ; 2007)$ expectations for MORA in general. Preliminary technological implications introduced for MORA show the use of a broad-based technology (Burtchard 2007:27-29). Based on the non-debitage MORA collections as of 1995, bifaces were used by mobile hunter-gatherers as cores to produce expedient flake tools where little toolstone was available (Burtchard 2003:90). Tertiary interior, biface, and retouch flakes imply the use of prepared cores or bifaces (Burtchard 
2003:91). Burtchard (2003:90) presents evidence of transported biface use in MORA when he makes the following observations:

In the non-debitage fraction of the Mount Rainier assemblages, bifaces appear to have played a primary role as cores for imported materials. Such a strategy reduces weight by minimizing nonfunctional stone. Replacement tools can be manufactured as needed on site, using only final retouch techniques. Flake debitage could be used for expedient cutting or scraping activities.... These larger, percussion bifaces are considered part of flexible biface technology, useful in mobile situations; particularly if raw materials are scarce...

\subsection{Chapter Summary}

This study uses artifacts from the three 1 x $1 \mathrm{~m}$ test units excavated between 2005 and 2007 at a Buck Lake (45PI438) Locus 4 activity area, in the northeast corner of MORA atop a mountain bench landform northeast of Mount Rainier at 5,400 ft ASL (Burtchard 2003:104; Burtchard 2007:19). The subalpine site has been interpreted as a residential base repeatedly used to exploit key upland faunal and floral resources such as elk and huckleberries during the late summer or early fall (Burtchard 2003:101, 112-113). Important faunal resources for hunter-gatherers at Buck Lake 
include: ungulates, small mammals, and birds (Burtchard 2003:25, 27; Smith 2006:146, 147-148, 170-171, 173, Figure 7.2).

In 1980, Lewis Binford presented the forager-collector mobility model (Binford 1980:5): foragers practice residential mobility and move their residence from resource patch to resource patch (Binford 1980:5), while collectors practice logistical mobility and send out specialized task groups to extract resources and return them to the residential base (Binford 1980:10). Burtchard (2003:124-127, 136-155; 2007:1336) uses an ecological approach grounded in forager-collector mobility to model changes in hunter-gatherer settlement and subsistence strategies through time in MORA. Burtchard (2007:22) suggests that a more forager-like strategy shifted to a more collector-like strategy between 4,500 and 3,500 RCYBP.

In general, foragers are expected to use tools that are curated, and collectors are expected to use expedient tools (Andrefsky 2008:8). A number of factors can influence the technological organization strategies employed regardless of mobility though, including toolstone availability, quality, size, and shape (Andrefsky 1994a:21; Andrefsky 1994b:377); tool design to accommodate reliability, maintainability, and transportability (Nelson 1991:66); and site function (Nelson 1991:78-80, 82-84).

Based on the expectations presented above, I propose the following technological organization expectations for the forager-like and collector-like Buck Lake (45PI438) cultural components: 
1) Both foragers and collectors used portable, nonlocal CCS toolstone and did not frequently use local igneous and nonlocal obsidian toolstone.

2) Both foragers and collectors used light and small finished transported bifaces to increase portability. Because of an increased reliance on expedient flakes, collector bifaces might be slightly heavier and larger.

3) Both foragers and collectors used transported bifacial tools and performed latestage bifacial reduction for resharpening and retouching tools.

4) Collectors used transported bifaces and middle-stage bifacial production to produce expedient flakes, and more frequently used expedient flakes.

5) Foragers and collectors seldom used blade and bipolar core technologies. 


\section{CHAPTER TWO}

\section{MATERIALS, METHODS, AND RESULTS}

\subsection{Materials}

This study uses a sample of lithic debitage from TUs 1-3 at Locus 4. Although overlooked in the past, debitage is recognized as a useful source of data for interpreting past human behavior such as lithic technological organization strategies (Andrefsky 2001:2; Bradbury and Carr 2004:66). From the analysis of a single debitage specimen or a population of specimens, inferences can be made about the technology, production stages, and the artifact type being produced (Andrefsky 2001:4-7, 9).

\subsubsection{Stratigraphy and Chronology}

Results of excavations at TUs 1-3 at Locus 4 indicate that Buck Lake's (45PI438) stratigraphy is intact because there has not been extensive pedoturbation (Figure 6). The site chronology is based on clearly visible deposits of volcanic material (tephra) and radiocarbon dates. The observed stratification contains thirteen

distinct strata. All but the bottommost stratum (stratum X) produced artifacts during the 2005-07 excavations. Table 2 and Figure 6 give stratum depths, general soil descriptions, and approximate artifact densities. Three distinct tephra deposits are 
visible within the site stratification and are used to infer relative dates for cultural deposits (see Table 2 and Figure 6 for stratigraphic locations).

Six radiocarbon samples from Locus Four were dated by the Beta Analytic Radiocarbon Dating Laboratory using accelerator mass spectrometry. One radiocarbon sample from the 2004 Buck Lake sediment core was dated by the Waikato Radiocarbon Dating Laboratory. The dates are listed in Table 1, and their stratigraphic locations are included in Figure 6.

Strata I-III predate the Mount Rainier C tephra deposited in Stratum IV and dated to $2340 \pm 200$ and $2460 \pm 200$ RCYBP. Strata V and VI predate the $3310 \pm 40$ and $3320 \pm 40$ RCYBP radiocarbon samples found in Stratum VIIa. Stratum VIIb contains the Mount St. Helens Yn tephra radiocarbon dated to $3500 \pm 250$ and $3510 \pm 250$ RCYBP. Stratum VIIIa has been radiocarbon dated to $3960 \pm 40,4650 \pm 40$, and $5220 \pm 50$ RCYBP. Stratum VIIIb predates the Mount Mazama O tephra deposited in Stratum VIIIc and radiocarbon dated to $6845 \pm 50$ RCYBP. Stratum IX has been radiocarbon dated to $6750 \pm 50$ and $7173 \pm 49$ RCYBP.

\subsubsection{Sampling and Cultural Components}

Sampling. Lithic debitage from strata I, II, III, IV, V, VIIIa, and VIIIb from TUs 1-3 at Locus 4 was analyzed. In the interest of time and considering the preliminary nature of this study, only the lithic debitage from stratum VIIa in TUs 1-2 at Locus 4 was analyzed for this stratum. Stratum VI was only identified in TU 3 
during excavation and was grouped with stratum VIIa for this test unit. No stratum VI/VIIa debitage specimens from TU 3 were included in the debitage population to greatly reduce the number of specimens to be analyzed. This resulted in a reduction of 1,239 specimens according to the fieldwork debitage counts recorded for this provenience. A total of 1,606 debitage specimens, or 56.4 percent of the total stratum VIIa lithic debitage collection, were analyzed; this is expected to be a representative sample for stratum VIIa. Debitage from strata VIIIc and IX within or below the Mount Mazama O tephra was not included in this study because the amount of debitage from this provenience was low.

All excavated soil from TUs 1-3 was screened through $1 / 8$ inch mesh for maximum recovery of cultural material. This study used specimens greater than $1 / 8$ inch for analysis that were shake-screened through $1 / 8$-inch hardware cloth. This method was used because $1 / 8$-inch field screens are typically used for archaeology in the Pacific Northwest for better artifact recovery (State of Oregon Parks and Recreation Department, State Historic Preservation Office 2007:2, 29), and allows the debitage sample to be comparable to other archaeological studies in the region.

Cultural Components. The Locus 4 lithic debitage collection from TUs 1-3, excavated between 2005 and 2007 and spanning to the Mount Mazama O tephra, is divided into two groups of components and assemblages based on Burtchard's (2007:Table 1) land-use model. The land-use model suggests that a more collectorlike hunter-gatherer mobility strategy was employed after 4,000 to $5,000{ }^{14} \mathrm{C}$ yr BP. Research suggests that at roughly the same time, a more collector-like strategy is 
expected to occur on the Southern Northwest Coast by around 1800 BC (Ames 2003:26-27) and on the Southern Plateau by around 1900 BC (Ames et al. 1998:111; Ames 2000). Before this, a more forager-like strategy is modeled in MORA (Burtchard 2007:Table 1).

The first group, labeled pre-MSH Yn, represents the forager-like strategy expected before the MSH Yn tephra deposit around 3500 RCYBP, consistent with Burtchard's (2007:Table 1) model. This sample includes 280 debitage specimens recovered from strata VIIIa and VIIIb in TUs 1-3.

The second group, labeled post-MSH Yn, represents a more collector-like strategy expected after the MSH Yn tephra deposit, consistent with Burtchard's (2007:Table 1) model, and includes 2,074 debitage specimens recovered from TUs 13. The debitage from this group came from strata I, II, III, IV, V, and VIIa, excluding stratum VI/VIIa from TU 3 (see Sampling section above). Debitage from stratum II, III, and IV were collected together during excavation.

Although mobility strategies might have varied during the multiple occupations within the pre-MSH Yn and post-MSH Yn group time periods, it is assumed that mobility strategies remained constant within each group: a forager mobility strategy for the pre-MSH Yn group and a collector strategy for the post-MSH Yn group. As discussed in Chapter One, the archaeological evidence from both groups is expected to appear similar through time because of toolstone availability, seasonality, and terrain constraints, as well as a common ungulate resource base and the use of Locus 4 at Buck Lake as a large ungulate processing area within the 
residential base camp. It is assumed that these constraints and commonalities did not drastically change through time.

The main differences between the pre-MSH Yn and post-MSH Yn groups are that collectors might have cached tools or cores and hunted small animals in addition to large ungulates. As mentioned in Chapter One, hunting large ungulates would have been the primary reason hunter-gatherers traveled to subalpine areas like Buck Lake. Hunting small animals would have been secondary to this. By caching tools or cores at repeatedly used areas, collectors might have produced expedient flakes for hunting and processing small animals. Bifaces for hunting and processing large ungulates would have been more important though and should be dominant in the archaeological record.

The MSH Yn tephra deposited around 3500 RCYBP in stratum VIIb will serve as a marker dividing the pre-MSH Yn from the post-MSH Yn components. The tephra is also a buffer; lithic artifacts within stratum VIIb are not included in this study to avoid the risk of mixed assemblages that might occur as a result of minimal pedoturbation and the vertical displacement of artifacts. 


\section{Table 2. Stratum Depths, Artifact Density, Radiocarbon Dates, and Tephra Layers for TUs 1-3.}

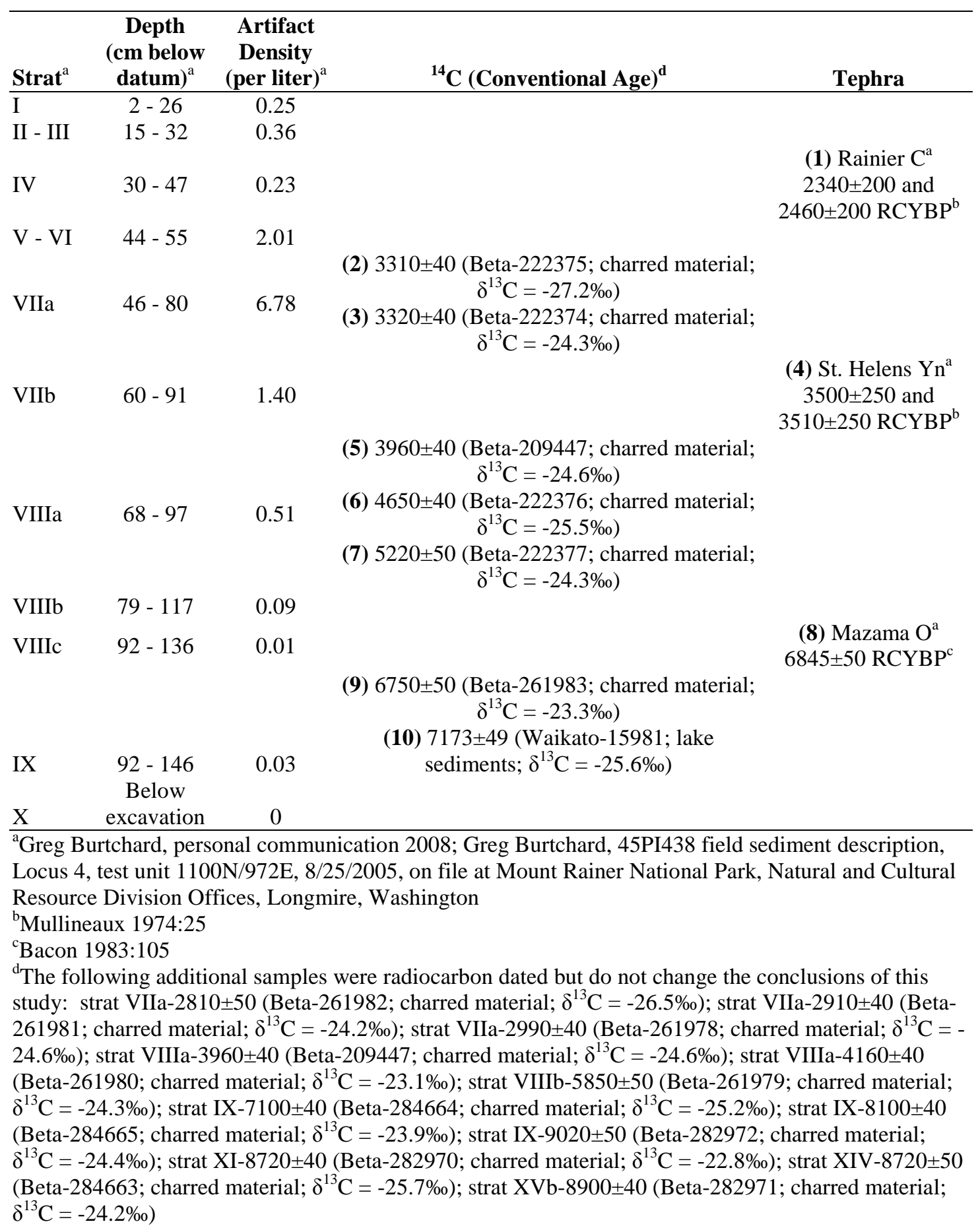




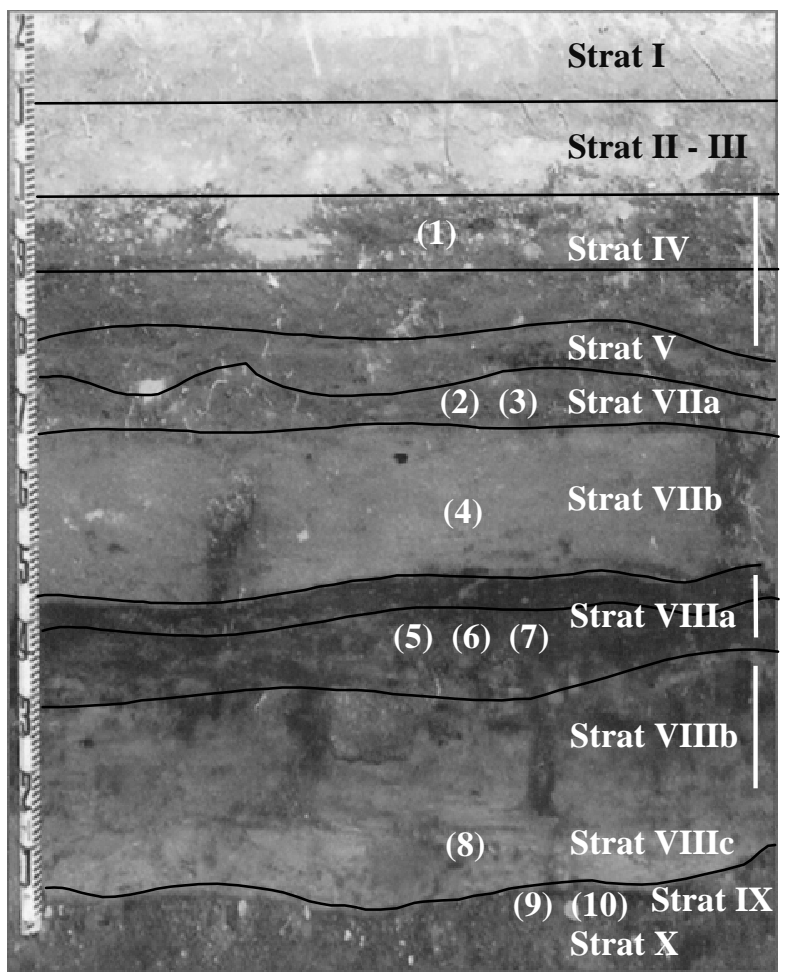

(1) Rainier C

$2340 \pm 200$ and $2460 \pm 200 \mathrm{RCYBP}$

(Mullineaux 1974:25)

(2) $3310 \pm 40$ (Beta-222375)

(3) $3320 \pm 40$ (Beta-222374)

(4) St. Helens Yn $3500 \pm 250$ and $3510 \pm 250$ RCYBP

(Mullineaux 1974:25)

(5) $3960 \pm 40$ (Beta-209447)

(6) $4650 \pm 40$ (Beta-222376)

(7) $5220 \pm 50$ (Beta-222377)

(8) Mazama $O$

$6845 \pm 50$ RCYBP

(Bacon 1983:105)

(9) $6750 \pm 50$ (Beta-261983)

(10) $7173 \pm 49$ (Waikato-15981)

Strat I Mixed sediment organic duff. Constituents include colluvially reworked Mt. Rainier C gravel sized tephra. Abundant roots and sand to coarse silt sized fine grained sediments.

Strat II Light gray to black speckled tephra. Fine to medium sand texture.

Strat III Yellowish gray fine to medium grained sand tephra. Probable tephra layer of unknown source.

Strat IV Dark to orangish brown gravely tephra. Mt. Rainier C primary deposit well expressed.

Strat V Medium brown sandy silt. Some charcoal. Abrupt wavy boundary. Cultural materials present. Pre-Rainier C / post-St. Helens Yn paleosol.

Strat VI Yellowish brown fine sand tephra layer. Clear wavy boundary conforms to upper St. Helens Yn cultural layer.

Strat VIIa Mottled brown to black slightly indurated medium sand tephra. St. Helens Yn cultural layer. Profuse charcoal, abundant lithic debris. Sediments most likely redeposited St. Helens Yn.

Strat VIIb Orangish brown sandy tephra, Mt. St. Helens Yn primary fall.

Strat VIIIa Dark brown to black mottled charcoal stained silt. Gradual boundary. Profuse charcoal. Cultural materials present. Probably redeposited Mazama tephra paleosol, reworked and blackened by human and natural causes.

Strat VIIIb Dark organic Mazama O silt sized tephra. Common rodent and root intrusions. Pre-cultural layer identified by color change.

Strat VIIIc Tan orange Mazama O tephra exposed in low area at base of excavation. Light color suggests limited oxidation possibly caused by marshy ground.

Strat IX Very thin black charcoal and organic rich layer at base of Mazama tephra and above angular cobble bedrock. Probably thin paleosol / marsh sediments predating the Mazama event.

Strat X Angular to subangular tabular cobbles and gravel. Probable decomposing bedrock or talus rubble. Generally present in the Buck Lake area. No cultural material.

Figure 6. Typical test unit soil profile, strata, tephra, and radiocarbon samples from Greg Burtchard, personal communication 2008 and Greg Burtchard, 45PI438 field sediment description, locus 4, test unit 1100N/972E, 8/25/2005, on file at Mount Rainer National Park, Natural and Cultural Resource Division Offices, Longmire, Washington. 


\subsection{Debitage Analysis Methods and Results}

The use of debitage analysis to investigate hunter-gatherer technological organization has improved in recent years, although no one particular method is standard (Carr and Bradbury 2001:126). What is important is that the methods are replicable (Andrefsky 2005:86). This study attempts to link lithic debitage characteristics and trends with the technological organization expectations for the forager-like and collector-like components. For each component, an attempt is made to: determine the frequency of local and nonlocal toolstone; determine the frequency of bifacial production and reduction; determine the frequency of lithic reduction and production stages; investigate debitage size as it relates to portability; determine the frequency of usable expedient flakes; and explore the frequency of bipolar and blade core technologies. The results of these methods will be compared to the expectations presented at the end of Chapter One.

Replicability is of upmost importance in debitage analysis and is stressed for this study. As Andrefsky (2005:86) states, "Replicability in flake debitage recording and measurement is...crucial for later analysis and interpretation." Typologies should be based on definitions that are "mutually exclusive" (Andrefsky 2001:7) and replicable along with any individual attribute method definitions (Andrefsky 2001:7-8, 10). The debitage methods used for this study are replicable and can be confidently measured by novice analyzers with some lithic analysis training (Andrefsky 2005:98; Bradbury and Carr 2004:69-70; Odell 2004:124, 126, 128; Prentiss 2001:158). 


\subsubsection{A Note on the Use of Technological Typologies}

Some lithic debitage analysis protocols, including those at MORA, use technological typologies to classify debitage into groups based on attributes believed to be byproducts of specific technological behaviors (Andrefsky 2001:6; Andrefsky 2005:120; Greg Burtchard, personal communication 2008; Odell 2004:121). Two common technological flake types applicable to this study are bifacial thinning flakes and bipolar flakes (Andrefsky 2001:6-7; Andrefsky 2005:120, 123). These technological types were not used for two reasons: first, as some lithic analysts have noted, the attributes used to classify a technological type are sometimes not consistently defined, making replicability questionable (Andrefsky 2001:7; Andrefsky 2005:123); second, the attributes used to define bifacial thinning and bipolar flakes cannot be easily identified or recorded by a novice lithic analyst like myself.

The presence of bifacial thinning flakes is believed to be an indicator of bifacial technology (Andrefsky 2005:123). Combinations of attributes used to define bifacial thinning flakes include: faceted striking platforms and dorsal flake scar ridges (Andrefsky 2005:123); and "curved longitudinal cross-sections, extremely acute lateral and distal edge angles, feathered flake terminations, narrow faceted striking platforms, a lip, little or no cortex, and a small flattened or diffuse bulb of force" (Andrefsky 2001:123). The debitage analysis protocol for MORA defines a bifacial thinning flake as having "narrow, multi-faceted or complex platform and longitudinal curving" and a "Dorsal surface [that] exhibits multiple flake scars" (Greg Burtchard, 
personal communication 2008). Without specific definitions, attributes such as lipping and flattened or diffused bulbs of force are too vague to be replicated between analysts (Andrefksy 2001:7). Longitudinal curving and narrow striking platforms also seem too vague and subjective to be replicated if they are not consistently defined. Despite their lack of replicability, experience is necessary to recognize attributes such as lipping and diffuse bulbs of force; this study relied on recording attributes that could be replicated and identified by a novice lithic analyst. Rather than identifying bifacial thinning flakes, this study used debitage size measurements and dorsal flake scar count to determine the presence of bifacial reduction.

Bipolar flakes, as the name indicates, are used as indicators of bipolar reduction technology (Andrefsky 2005:123). Attributes used to define bipolar flakes include: crushing at either or both distal and proximal flake ends; "crushed or sheared striking platforms" (Andrefsky 2005:125); and the presence of striking platforms and compression rings at both distal and proximal flake ends (Andrefsky 2005:124-125). The debitage protocol for MORA defines a bipolar flake as a "Bifacially reduced debitage identified by sheared or flattened bulb of percussion and/or platforms or percussion features on opposite ends of the artifact" (Greg Burtchard, personal communication 2008). Although these bipolar flake attributes could be specifically defined and replicated, they are not always positive indicators of bipolar technology. Based on experimental lithic studies, Jeske and Lurie (1993:141) found that attributes such as the number of compression rings, the presence of striking platforms on both flake ends, and the presence of "smooth" (Jeske and Lurie 1993:141) bulbs could not 
be used to differentiate free-hand core from bipolar core techniques because they are dependent on the type of raw material being reduced. Because these attributes cannot be consistently used to identify bipolar technology and there is not a comparable experimental bipolar technology sample for the raw materials used at Buck Lake, the bipolar flake technological type was not used for this study. Rather than identifying bipolar flakes, this study used the percentages of flake types to determine the use of bipolar cores.

\subsubsection{Statistical Methods}

This study used the SPSS 14.0 statistical package to perform descriptive statistics and statistical methods that test for: a normal distribution, the difference between two independent samples, the differences between an observed measurement with an expected one, and an association between two variables. The descriptive statistics presented for this study include the sample size, mean, median, minimum and maximum values, standard deviation, and frequency following the MORA protocol (Greg Burtchard, personal communication 2010).

Before choosing the appropriate statistical tests for this study, a KolmogorovSmirnov one-sample test (K-S) for the normal distribution of a quantitative variable was performed (cf. Fletcher and Lock 2006:80-81, 110-111; Green and Salkind 2005:364-365). An independent samples t-test was used to test the difference between two independent samples if a distribution was determined to be normal (cf. Fletcher 
and Lock 2006:83-85, 95-97; Green and Salkind 2005:167-172). If a distribution is not normal, the non-parametric Mann-Whitney test is appropriate to test the difference between two independent samples (cf. Fletcher and Lock 2006:97-98; Green and Salkind 2005:377-382). A one-sample t-test was used to compare an observed mean with an expected one from previous research (cf. Fletcher and Lock 2006:81-87; Green and Salkind 2005:155-160). Even if a distribution is not normal, the onesample t-test for mean can be used when the sample size is greater than 30 (Green and Salkind 2005:156). A chi-square test was used to test an association between two variables (cf. Fletcher and Lock 2006:129-134; Green and Salkind 2005:366-375).

\subsubsection{Interpretation-Free Typology}

Sullivan and Rozen's “interpretation-free” typology places specimens into "four mutually exclusive debitage categories" that attempt to encompass all possibilities of debitage condition (Sullivan and Rozen 1985:759). "Debris" lacks the characteristics of a single ventral surface such as "ripple marks, force lines, or a bulb of percussion" (Sullivan and Rozen 1985:758). A "flake fragment" has a single ventral surface, but lacks "a point of applied force... where the bulb of percussion intersects the striking platform" or "a point of applied force is indicated by the origin of force line radiation" (Sullivan and Rozen 1985:758). A "broken flake" has a single ventral surface and point of applied force, but lacks intact margins made evident by a step termination and the inability to accurately measure flake width (Sullivan and 
Rozen 1985:759). A "complete flake" has a single ventral surface, point of applied force, and intact margins (Sullivan and Rozen 1985:759). Flake terminations (step, feathered, plunging, or hinge) were recorded following the guidelines of Andrefsky (2005:88) to classify debitage specimens as broken or complete flakes. Flake characteristics were often identified with the aid of a 10X AmScope stereo microscope.

The interpretation-free typology is used here to divide the individual specimens into the four aforementioned mutually exclusive categories for further study. Broken and complete specimens were measured, dorsal scars counted, and platforms analyzed because of their completeness and the presence of a measurable platform. Analysis of the remaining debris and flake fragment categories was limited to raw material identification, weight, size class, or cortex analysis because of their incompleteness or lack of measurable attributes.

Results. The results of the interpretation-free typology can be found in Table 3. The highest percentage (41.4\%) of pre-MSH Yn debitage is debris, although flake fragments also represent a high percentage (38.2\%). Broken (7.9\%) and complete (12.5\%) flakes make up a smaller percentage of the pre-MSH Yn debitage. The majority (55.1\%) of post-MSH Yn debitage are flake fragments, while debris represents $30.5 \%$ of the post-MSH Yn debitage. Broken (5.2\%) and complete (9.3\%) flakes only represent a small percentage of the post-MSH Yn debitage.

Problems with the Typology. It should be noted that there were problems identifying points of applied force and debris during the analysis that might have 


\section{Table 3. Interpretation-Free Debitage Type Percentages and Frequencies (Italicized) for Pre- and Post-MSH Yn Cultural Components.}

\begin{tabular}{lcccccc}
\hline $\begin{array}{l}\text { Cultural } \\
\text { Component }\end{array}$ & Strat & $\mathrm{N}$ & Debris & $\begin{array}{c}\text { Flake } \\
\text { Fragment }\end{array}$ & $\begin{array}{c}\text { Broken } \\
\text { Flake }\end{array}$ & $\begin{array}{c}\text { Complete } \\
\text { Flake }\end{array}$ \\
\hline $\begin{array}{l}\text { Pre-MSH } \\
\text { Yn }\end{array}$ & VIIIa, VIIb & 280 & $41.4(116)$ & $38.2(107)$ & $7.9(22)$ & $12.5(35)$ \\
Post-MSH & & & & & & \\
Yn & & 2074 & $30.5(633)$ & $55.1(1142)$ & $5.2(107)$ & $9.3(192)$ \\
& I & 69 & 33.3 & 55.1 & 4.3 & 7.2 \\
& II, III, IV & 82 & 46.3 & 50 & 2.4 & 1.2 \\
& V & 317 & 40.4 & 52.7 & 2.8 & 4.1 \\
& VIIa & 1606 & 27.6 & 55.8 & 5.8 & 10.8 \\
\hline
\end{tabular}

affected the results of the debitage typology. Points of applied force on small specimens appeared flat and diffused, not bulbous as one would expect, which made them difficult to identify. As a result, there could be a greater number of flake fragments versus complete or broken flakes identified because the category-defining point of applied force attribute could not be seen. Therefore, the percentage of complete and broken flakes could be underrepresented in this study. The identification of fewer complete or broken flakes will also result in less data regarding flake size (maximum length and thickness), platform characteristics (type, width, and facet count), and dorsal scar count.

There was also a bias towards identifying specimens as debris. Some smaller raw material types were thin and prone to having ripple marks on both sides. This made it hard to determine a ventral side and forced the debitage into the debris category. Although the debitage actually represents a flake fragment or even complete or broken flakes, the debitage would have to be identified as debris. This could result in a slight misrepresentation of this category. 


\subsubsection{Method to Determine the Frequency of Local and Nonlocal Toolstone}

Raw material identification follows the procedures used by MORA based on general lithic material types known to exist there (Greg Burtchard, personal communication 2008). These material types are chert and chalcedony CCS, obsidian, andesite, other igneous, and other.

Raw Material Identification. The lithic material types were identified based on color, texture, and translucence using the naked eye and/or the aid of a 10X AmScope stereo microscope. A Hubbard Scientific Igneous Rock Study Kit and Phoenix Obsidian Designs Material Type Samples, Flintknapping Material Types Sampler, and Material Type Cards were used as comparative samples. CCS material was first inspected for translucency following the procedure presented by Kooyman (2001:30); specimens that appear translucent "when held $8 \mathrm{~cm}$ from the edge of the shade of a 75 watt light bulb" (Kooyman 2001:30) were identified as chalcedony, and opaque specimens were identified as chert.

Determining a more specific raw material type on small debitage specimens was difficult, because small specimens will appear translucent whether they are produced from chalcedony or chert. Chert specimens that are less than or equal to .5 mm thick will appear translucent (Kooyman 2001:30). This might result in a bias towards identifying chalcedony versus chert or other raw material types. Although identifying the raw material type of some specimens might be inaccurate, grouping the specimens by a broader raw material type (CCS, obsidian, igneous) is consistent. 
Therefore, this study used broad material type categories (CCS, obsidian, igneous, other) for making inferences about the use of local and nonlocal raw material.

Because it is assumed most of the raw material used to make stone tools comes from a distant source, and this is a preliminary study, the use of broad raw material types should not affect any results. In the future, after raw material sources in MORA are established, more precise identification that relies on raw material sourcing information could be used.

Results. The overwhelming majority of both the pre-MSH Yn and post-MSH Yn cultural components debitage were produced from nonlocal CCS (Table 4). For both the pre-MSH Yn and post-MSH Yn cultural components, the nonlocal CCS raw material was the preferred toolstone, and the locally available igneous raw material, including basalt, was minimally used as toolstone at Locus 4. The pre-MSH Yn cultural component has a higher percentage $(10.7 \%)$ of igneous raw material than the post-MSH Yn component (2.2\%). Obsidian was not observed in either of the cultural component samples.

Table 4. Debitage General Raw Material Type Percentages and Frequencies (Italicized) for Pre- and Post-MSH Yn Cultural Components.

\begin{tabular}{lcccc}
\hline Cultural & & & & \\
Component & Strat & N & CCS & Igneous \\
\hline Pre-MSH Yn & VIIIa, VIIIb & 280 & $89.3(250)$ & $10.7(30)$ \\
Post-MSH Yn & & 2074 & $97.8(2029)$ & $2.2(45)$ \\
& I & 69 & 92.8 & 7.2 \\
& II, III, IV & 82 & 95.1 & 4.9 \\
& V & 317 & 94.6 & 5.4 \\
& VIIa & 1606 & 98.8 & 1.2 \\
\hline
\end{tabular}


A chi-square test was conducted to determine if the relationship between general raw material type and cultural component was significant. The chi-square test resulted in a chi-square value of 58.39 and a significance level (p-value) of .00 with one degree of freedom. The results show that there is a significant relationship between the general raw material type and cultural component, and that the preferred use of nonlocal CCS raw material for toolstone and minimal use of the local igneous raw material toolstone is not coincidental. Also, the igneous raw material is more prevalent in the pre-MSH Yn component than the post-MSH Yn component.

Discussion. The expectation that both the pre- and post-MSH Yn cultural components will have a high occurrence of portable nonlocal CCS toolstone and a low frequency of local igneous and nonlocal obsidian toolstone (see expectation number one from Chapter One) is supported by the raw material identification results of this study. The majority of the pre-MSH Yn (89.3\%) and post-MSH Yn (97.8\%) cultural component debitage was made from nonlocal CCS. The Post-MSH Yn cultural component could have a higher percentage of CCS than the Pre-MSH Yn component because the post-MSH Yn hunter-gatherers were caching CCS toolstone at Buck Lake (45PI438) or in the vicinity as a result of repeated use of Locus 4. The local igneous raw material was minimally represented in the pre-MSH Yn (10.7\%) and post-MSH Yn $(2.2 \%)$ cultural components. The pre-MSH Yn hunter-gatherers could have relied on the local igneous material more because the supply of transported CCS raw material might have been extinguished. The post-MSH Yn hunter-gatherers would not have faced this problem if the CCS toolstone had been cached. Regardless, both 
foragers and collectors at Buck Lake relied heavily on nonlocal CCS for toolstone and made little or no use of the local igneous and nonlocal obsidian toolstone.

\subsubsection{Methods to Determine Debitage Size}

Debitage size decreases as the core reduction and tool production process progresses; debitage size is a good indicator of the size of the "objective piece" or the lithic piece from which the debitage was struck (Andrefsky 2005:98). The following methods to determine debitage size are used in this study.

Debitage Weight. Weight is a good indicator of debitage size that is easy to measure and replicate, even independent of debitage completeness (Andrefsky 2005:98-99; Odell 2004:126). For this study, debitage weight was measured to the .01 gram (g) using a My Weigh i201 digital scale. All four debitage types were weighed.

Results. Both the pre-MSH Yn and post-MSH Yn cultural components debitage are very light, with mean weights of less than $.30 \mathrm{~g}$ (Table 5). The post-MSH Yn mean debitage weight is almost twice as heavy, with a mean weight of $.29 \mathrm{~g}$ compared with the $.16 \mathrm{~g}$ mean weight of the pre-MSH Yn debitage.

The K-S normality test for the pre-MSH Yn component debitage weight resulted in a $\mathrm{z}$-value of 6.79 and a p-value of .00. Because the p-value is less than .05, the distribution is determined to be significantly different from a normal distribution. The normality test for the post-MSH Yn component debitage weight resulted in a $\mathrm{z}$ value of 18.88 and a p-value of .00 . Again, because the p-value is less than .05 , the 
Table 5. Debitage Weight Descriptive Statistics for Pre- and Post-MSH Yn Cultural Components.

\begin{tabular}{|c|c|c|c|c|c|c|c|}
\hline $\begin{array}{l}\text { Cultural } \\
\text { Component }\end{array}$ & Strat & $\mathrm{N}$ & $\begin{array}{c}\text { Mean } \\
(\mathrm{g})\end{array}$ & $\begin{array}{c}\text { Minimum } \\
(\mathrm{g})\end{array}$ & $\begin{array}{c}\text { Maximum } \\
(\mathrm{g})\end{array}$ & $\begin{array}{c}\text { Standard } \\
\text { Deviation } \\
(\mathrm{g})\end{array}$ & $\begin{array}{c}\text { Median } \\
(\mathrm{g})\end{array}$ \\
\hline \multirow{6}{*}{$\begin{array}{l}\text { Pre-MSH } \\
\text { Yn } \\
\text { Post-MSH } \\
\text { Yn }\end{array}$} & $\begin{array}{l}\text { VIIIIa, } \\
\text { VIIIb }\end{array}$ & 280 & .16 & .00 & 10.08 & .66 & .00 \\
\hline & & 2074 & .29 & .00 & 41.29 & 1.36 & .04 \\
\hline & I & 69 & .21 & .00 & 2.75 & .45 & .06 \\
\hline & II, III, IV & 82 & .26 & .00 & 3.29 & .55 & .08 \\
\hline & V & 317 & .31 & .00 & 41.29 & 2.43 & .00 \\
\hline & VIIa & 1606 & .30 & .00 & 30.16 & 1.09 & .04 \\
\hline
\end{tabular}

distribution is determined to be significantly different from a normal distribution.

A Mann-Whitney test was performed to test the difference in weight between the two cultural components, resulting in a z-value of -2.97 and a p-value of .00 , which suggests that the differences in the mean weights for the pre- and post-MSH Yn debitage are significantly different; the post-MSH Yn debitage is slightly, but significantly, heavier than the pre-MSH Yn debitage.

Debitage Size Class. Debitage size class is another useful method for determining debitage size on flake specimens regardless of completeness (Andrefsky 2005:99). All four debitage types were subjected to this method as an indication of the entire debitage population size. Circles are used to divide the debitage population into $10 \mathrm{~mm}$ to $75 \mathrm{~mm}$ size classes in $5 \mathrm{~mm}$ increments following Andrefsky and MORA procedures (Andrefsky 2005:102-103, Figure 5.10; Greg Burtchard, personal communication 2008). Each debitage specimen "is placed in the smallest diameter 
circle without touching the edge" flat side down and, whenever possible, ventral side down (Andrefsky 2005:102).

Results. The debitage diameter size class results for the pre- and post-MSH Yn cultural components can be found in Table 6. Both the pre-MSH Yn and post-MSH Yn cultural components debitage are very small, with the majority of the specimens falling in the less than $10 \mathrm{~mm}$ size class. The post-MSH Yn debitage occur in the larger diameter size classes than the pre-MSH Yn, although this could be attributed to differences in sample sizes.

Table 6. Debitage Diameter Size Class Percentages for Pre- and Post-MSH Yn Cultural Components.

\begin{tabular}{|c|c|c|c|c|c|c|c|c|c|c|c|c|c|c|}
\hline $\begin{array}{l}\text { Cultural } \\
\text { Component }\end{array}$ & Strat & $\mathrm{N}$ & $\begin{array}{l}\Xi \\
\Xi \\
\stackrel{\Xi}{\vee}\end{array}$ & $\begin{array}{c}\Xi \\
\Xi \\
\bar{v}\end{array}$ & 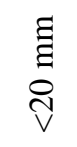 & 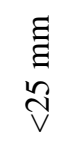 & $\begin{array}{l}\Xi \\
\Xi \\
\stackrel{్}{v}\end{array}$ & $\begin{array}{l}\Xi \\
\Xi \\
\tilde{\vartheta}\end{array}$ & $\begin{array}{l}\text { g } \\
\stackrel{g}{o} \\
\stackrel{+}{v}\end{array}$ & $\begin{array}{c}\Xi \\
\stackrel{\Xi}{~} \\
\stackrel{n}{v}\end{array}$ & $\begin{array}{l}\Xi \\
\Xi \\
0 \\
\vee\end{array}$ & $\begin{array}{l}\Xi \\
\vdots \\
n \\
v\end{array}$ & 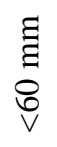 & \\
\hline \multirow{6}{*}{$\begin{array}{l}\text { Pre-MSH } \\
\text { Yn } \\
\text { Post-MSH } \\
\text { Yn }\end{array}$} & $\begin{array}{l}\text { VIIIa, } \\
\text { VIIIb }\end{array}$ & 280 & 62.9 & 21.4 & 10 & 4.3 & .7 & .4 & - & - & .4 & - & - & - \\
\hline & & 2074 & 56 & 24.4 & 9.3 & 4.2 & 2.9 & 1.5 & .9 & .5 & .1 & .0 & - & .0 \\
\hline & I & 69 & 50.7 & 30.4 & 10.1 & 4.3 & 4.3 & - & - & - & - & - & - & - \\
\hline & $\begin{array}{c}\text { II, III, } \\
\text { IV }\end{array}$ & 82 & 48.8 & 28 & 12.2 & 6.1 & 2.4 & 1.2 & 1.2 & - & - & - & - & - \\
\hline & V & 317 & 62.5 & 24 & 7.3 & 3.8 & 1.3 & .3 & - & .6 & - & .3 & - & .3 \\
\hline & VIIa & 1606 & 55.3 & 24.1 & 9.5 & 4.2 & 3.2 & 1.9 & 1.1 & .6 & .2 & - & .1 & \\
\hline
\end{tabular}

The K-S normality test for the pre-MSH Yn component diameter size class resulted in a z-value of 5.94 and a p-value of .00, which suggests that the distribution is significantly different from a normal distribution. The normality test for the post- 
MSH Yn component diameter size class resulted in a $\mathrm{z}$-value of 13.38 and a p-value of .00. Again, this indicates that the distribution is significantly different from a normal distribution.

A Mann-Whitney test was performed to test the difference in diameter size classes between the two cultural components and resulted in a z-value of -2.41 and a p-value of .02, which suggests that the differences in the diameter size classes for the pre- and post-MSH Yn debitage are significantly different; overall, the post-MSH Yn debitage is larger in size than the pre-MSH Yn debitage, although this could be attributed to differences in sample size.

Maximum Flake Length. Maximum flake length was measured in .01 mm using S-T Industries, Inc., electronic calipers. Maximum flake length was measured on broken and complete flake specimens following the procedures presented in Andrefsky (2005:99, Figure 5.8[c]). The maximum distance from the proximal to distal end of the flake specimen is measured following a line perpendicular to the width of the striking platform.

Results. The maximum flake length results for the pre- and post-MSH Yn cultural components can be found in Table 7. Both the pre-MSH Yn and post-MSH Yn cultural components flakes are very small, with mean maximum lengths that are less than $13 \mathrm{~mm}$. The post-MSH Yn mean maximum flake length is slightly longer.

The K-S normality test for the pre-MSH Yn component maximum flake length resulted in a $\mathrm{z}$-value of 1.17 and a $\mathrm{p}$-value of .13 . Because the $\mathrm{p}$-value is greater than .05 , the distribution is determined to not be significantly different from a normal 
Table 7. Broken and Complete Flake Maximum Length Descriptive Statistics for Pre- and Post-MSH Yn Cultural Components.

\begin{tabular}{|c|c|c|c|c|c|c|c|}
\hline $\begin{array}{l}\text { Cultural } \\
\text { Component }\end{array}$ & Strat & $\mathrm{N}$ & $\begin{array}{l}\text { Mean } \\
(\mathrm{mm})\end{array}$ & $\begin{array}{l}\text { Minimum } \\
(\mathrm{mm})\end{array}$ & $\begin{array}{l}\text { Maximum } \\
(\mathrm{mm})\end{array}$ & $\begin{array}{l}\text { Standard } \\
\text { Deviation } \\
(\mathrm{mm})\end{array}$ & $\begin{array}{c}\text { Median } \\
(\mathrm{mm})\end{array}$ \\
\hline \multirow{6}{*}{$\begin{array}{l}\text { Pre-MSH } \\
\text { Yn } \\
\text { Post-MSH } \\
\text { Yn }\end{array}$} & $\begin{array}{l}\text { VIIIa, } \\
\text { VIIIb }\end{array}$ & 57 & 9.47 & 3.17 & 21.15 & 4.55 & 8.11 \\
\hline & & 298 & 12.87 & 3.57 & 60.42 & 9.05 & 9.51 \\
\hline & I & 8 & 7.80 & 3.64 & 14.91 & 4.46 & 5.98 \\
\hline & II, III, IV & 3 & 6.98 & 5.14 & 10.30 & 2.88 & 5.50 \\
\hline & V & 22 & 17.25 & 5.47 & 60.42 & 12.75 & 12.55 \\
\hline & VIIa & 265 & 12.73 & 3.57 & 47.93 & 8.71 & 9.41 \\
\hline
\end{tabular}

distribution. The normality test for the post-MSH Yn component maximum flake length resulted in a z-value of 2.84 and a p-value of .00 , the distribution is determined to be significantly different than a normal distribution.

A Mann-Whitney test was performed to test the difference in maximum flake length between the two cultural components, resulting in a $\mathrm{z}$-value of -2.11 and a $\mathrm{p}$ value of .04 . Because the p-value is less than .05 , the differences in the mean lengths for the pre- and post-MSH Yn debitage are significantly different; the post-MSH Yn flakes are slightly longer than the pre-MSH Yn debitage.

Discussion. The expectation that both the pre- and post-MSH Yn cultural components will have evidence for the use of light and small finished transported bifaces to increase portability (see expectation number two from Chapter One) is supported by the debitage weight, debitage size class, and maximum flake length results of this study. The pre- and post- MSH Yn debitage had mean weights that were less than $.30 \mathrm{~g}$ and mean maximum flake lengths that were less than $13 \mathrm{~mm}$, 
considered light and small when compared to the range of debitage weights and lengths from experimental studies (cf. Odell 1989:Table 2). The majority of pre- and post-MSH Yn specimens also occurred in the smallest (less than $10 \mathrm{~mm}$ ) size class. Both foragers and collectors at Buck Lake produced light and small debitage from what can be inferred to be light and small objective pieces.

The results in this study support the expectation that the post-MSH Yn debitage and flakes will be slightly heavier and larger (see expectation number two from Chapter One). Although the differences are slight, the post-MSH Yn cultural component debitage has a mean weight that is $.13 \mathrm{~g}$ heavier, has more debitage specimens that occur in the larger size classes, and has a mean maximum flake length that is $3.4 \mathrm{~mm}$ longer than the post-MSH Yn specimens. All of these differences were determined to be statistically significant. Collectors at Buck Lake produced heavier and larger debitage from heavier and larger objective pieces than the foragers to manufacture expedient flakes. Another possibility for the differences in debitage size and weight between the pre- and post-MSH Yn components is the shape, size, and other physical properties of the specific raw materials used for toolstone. As explained earlier in this chapter, only broad material type categories (CCS, obsidian, igneous, other) were used given the difficulty of identifying more specific raw material types. Therefore, an investigation of the size and weight of debitage across specific material types was not possible. 


\subsubsection{Methods to Determine the Presence of Bifacial Reduction and Production Versus}

Core Reduction

I attempted to use the "aggregate trend analysis" method (cf. Bradbury and Carr 2004:67, 70-72) to investigate the percentage of lithic manufacturing techniques (core reduction, bifacial reduction, uniface reduction, and tool reduction) in the preand post-MSH Yn debitage samples. This method combines mass analysis, individual flake attribute analysis, and an interpretation-free typology to produce multiple lines of evidence for inferring lithic technology reduction techniques. This approach is easy with little need for training and little inter- and intra-observer error (Bradbury and Carr 2004:67).

I used the previously described diameter size classes to divide the debitage population rather than placing the individual debitage specimens into size classes by passing individual flakes through geologic sieves by hand (Andrew Bradbury, personal communication 2010; Bradbury and Carr 2004:71; Carr and Bradbury 2001:133). It was determined that my method of dividing the debitage population into diameter size classes was skewing the results making them incomparable to experimental lithic manufacturing debitage (Andrew Bradbury, personal communication 2010). Therefore, the aggregate trend analysis method was not used for this study. For further information on the aggregate trend analysis method, refer to Bradbury and Carr (2004) and Carr and Bradbury (2001). 
Weight, Maximum Flake Length, and Striking Platform Width. Based on the analysis of experimental lithic assemblages, Odell $(1989: 167,185)$ found that the weight, maximum length, and striking platform width of complete flakes greater than $10 \mathrm{~mm}$ in length could be used to differentiate core reduction from biface reduction. This study uses both complete and broken flake specimens in the greater than $10 \mathrm{~mm}$ size classes for these measurements to increase sample sizes. Using broken flakes will result in lower maximum flake length and weight values than if only complete flakes were measured. This is not expected to greatly affect the results because overall debitage maximum flake length and weight is expected to be low. Maximum flake length and weight were measured following Andrefsky (2005:99, Figure 5.8[c]) and Odell (1989:190-191). Striking platform width was measured in .01 mm using S-T Industries, Inc. electronic calipers, following Andrefsky (2005:94) and Odell (1989:190), where the measurement is taken across the platform from "lateral margin to lateral margin" (Andrefsky 2005:94).

The measurements from this study are compared with the measurements from Odell's (1989:166, Table 1, 174, Table 2) experimental bifacial projectile point lithic assemblage made from chert. The experimental assemblage included six reduction stages for making one projectile point (stages $\mathrm{H} 1$ through H6), five reduction stages for making another projectile point (stages S1 through S5), a stage one large biface reduction $(\mathrm{L} 1)$, and a stage one flake core reduction $(\mathrm{F} 1)$. The objective of this method is to determine if the pre- and post-MSH Yn debitage is significantly similar to core reduction or biface reduction experimental flakes to infer core reduction or 
biface reduction at Buck Lake (45PI438). Although the Buck Lake debitage population was produced from repeated occupations that might have resulted in the deposition of debitage representing a variety of reduction stages and lithic manufacturing techniques, it is expected that the primary lithic manufacturing technique was the reduction of mid- to late-stage bifaces.

Weight Results. The weight, K-S, and t-test results for the pre- and post-MSH Yn cultural components are presented in Table 8 and are used to determine whether core reduction or biface reduction can be inferred. The mean weight for the pre-MSH Yn specimens $(.33 \mathrm{~g}, \mathrm{n}=21)$ is most similar to the mean weight of the stage H6 (.14 g) experimental type when compared to the Odell (1989:166, Table 1, 174, Table 2) lithic assemblage production experiment results. Stage H6 involved "straight [ening] the lateral edges first with a round copper-tipped pressure flaker, then switch[ing] to an antler flaker for shallower indentations" (Odell 1989:164). The differences in the mean weights for the pre-MSH Yn (.33 g) and the stage H6 flakes (.14 g) experimental type from Odell (1989:174, Table 2) are significantly different as the pre-MSH Yn flakes are heavier. The next closest experimental type mean weight from the Odell (1989:174, Table 2) results is the stage S3 (.71 g). Stage S3 involved thinning the edges of a preform "with an antler billet... [and] required more edge preparation with chipping and grinding..." (Odell 1989:165). The differences in the mean weights for the pre-MSH Yn $(.33 \mathrm{~g})$ and the stage S3 (.71 g) flakes are also significantly different as the stage S3 flakes are heavier. The mean weight of the pre-MSH Yn cultural component flakes is significantly different from experimental biface debitage; 
therefore mean weight cannot be used to infer biface reduction. The differences in mean weight could be the result of different raw materials being reduced experimentally versus prehistorically or the mixing of lithic manufacturing techniques in the pre-MSH Yn cultural component occupations.

The mean weight for the post-MsH Yn specimens $(1.46 \mathrm{~g}, \mathrm{n}=140)$ is most similar to the stage H3/4 (1.24 g) experimental type when compared with the Odell (1989:166, Table 1, 174, Table 2) results. Stage H3 involved thinning a preform "with a moose antler billet" (Odell 1989:164). Stage H4 involved "basal thinning with a billet... [and] squar [ing] off the end in preparation for notching, preparing the edge with a bevelled antler pressure flaker" (Odell 1989:164). The differences in the mean weights for the post-MSH Yn and the stage H3/4 flakes $(1.24 \mathrm{~g})$ experimental type from Odell (1989:174, Table 2) are not significantly different. The mean weight of the post-MSH Yn cultural component flakes is not significantly different from experimental biface debitage; therefore biface reduction can be inferred.

Maximum Flake Length Results. The maximum flake length, K-S, and t-test results for the pre- and post-MSH Yn cultural components are presented in Table 8 and are used to determine whether core reduction or biface reduction can be inferred. The mean maximum flake length for the pre-MSH Yn specimens $(14.58 \mathrm{~mm}, \mathrm{n}=21)$ is most similar to the stage $\mathrm{S} 3(14.38 \mathrm{~mm})$ experimental type when compared with the Odell (1989:166, Table 1, 174, Table 2) results. The stage S3 technique is explained above. The differences in the mean maximum flake lengths for the pre-MSH Yn and the stage S3 flakes (14.38 mm) experimental type from Odell (1989:174, Table 2) are 
not significantly different from experimental biface debitage; therefore biface reduction can be inferred.

The mean maximum flake length for the post-MSH Yn specimens $(19.91 \mathrm{~mm}$, $\mathrm{n}=140)$ is most similar to the stage $\mathrm{H} 3 / 4(20.52 \mathrm{~mm})$ experimental type when compared to the Odell (1989:166, Table 1, 174, Table 2) results. The stage H3/4 technique is described above. The differences in the mean maximum flake lengths for the post-MSH Yn and the stage H3/4 flakes $(20.52 \mathrm{~mm})$ experimental type from Odell (1989:174, Table 2) are not significantly different; therefore biface reduction can be inferred.

Striking Platform Width Results. The striking platform width, K-S, and t-test results for the pre- and post-MSH Yn cultural components are presented in Table 8 and are used to determine whether core reduction or biface reduction can be inferred. The striking platform width for the pre-MSH Yn specimens $(5.26 \mathrm{~mm}, \mathrm{n}=21)$ is most similar to the stage $\mathrm{S} 4(6.31 \mathrm{~mm})$ experimental type when compared with the Odell (1989:166, Table 1, 174, Table 2) results. Stage S4 "was a notching and final edging operation, [where the knapper] used a flat copper-tipped pressure flaker for the notch and both a round copper and an antler tipped flaker for the edges" (Odell 1989:165). The differences in the mean striking platform widths for the pre-MSH Yn and the stage S4 flakes (6.31 mm) experimental type from Odell (1989:174, Table 2) are not significantly different; therefore biface reduction can be inferred.

The mean striking platform width for the post-MSH Yn specimens $(7.12 \mathrm{~mm}$, $\mathrm{n}=140)$ is most similar to the stage $\mathrm{H} 3 / 4(7.37 \mathrm{~mm})$ experimental type when 
Table 8. Greater Than $10 \mathrm{~mm}$ in Length Broken and Complete Flake Weight, Maximum Length, and Striking Platform Width for Pre- and Post-MSH Yn Cultural Components with K-S and T-test Results (Italicized).

\begin{tabular}{|c|c|c|c|c|c|}
\hline $\begin{array}{l}\text { Cultural } \\
\text { Component }\end{array}$ & Strat & $\mathrm{N}$ & $\begin{array}{c}\text { Mean Weight } \\
(\mathrm{g})\end{array}$ & $\begin{array}{c}\text { Mean } \\
\text { Maximum } \\
\text { Length (mm) }\end{array}$ & $\begin{array}{c}\text { Striking } \\
\text { Platform } \\
\text { Width }(\mathrm{mm}) \\
\end{array}$ \\
\hline Pre-MSH Yn & VIIIa, VIIIIb & 21 & $\begin{array}{c}.33 \\
z 1.03, p .24 \\
H 6: t 2.72, p \\
.01, d f 20 \\
\text { S3: } t 5.49, p \\
.00, d f 20\end{array}$ & $\begin{array}{c}14.58 \\
z .67, p .76 \\
S 3: t .29, p \\
.78, d f 20\end{array}$ & $\begin{array}{c}5.62 \\
z .88, .42 \\
S 4: t-.83, p \\
.42, d f 20\end{array}$ \\
\hline \multirow[t]{5}{*}{ Post-MSH Yn } & & 140 & $\begin{array}{c}1.46 \\
z 4.17, p .00 \\
H 3 / 4: t .69, p \\
.49,139 d f\end{array}$ & $\begin{array}{c}19.91 \\
\text { z 1.66, p.01 } \\
H 3 / 4: t-.81, p \\
.42, d f 139\end{array}$ & $\begin{array}{c}7.12 \\
z 2.64, p .00 \\
H 3 / 4: t-.54, p \\
.59, d f 139\end{array}$ \\
\hline & I & 2 & .18 & 14.57 & 4.79 \\
\hline & II, III, IV & 1 & .16 & 10.30 & 2.71 \\
\hline & V & 14 & 4.64 & 23.00 & 11.67 \\
\hline & VIIa & 123 & 1.13 & 19.73 & 6.68 \\
\hline
\end{tabular}

compared to the Odell (1989:166, Table 1, 174, Table 2) results. The differences in the mean striking platform width for the post-MSH Yn and the stage H3/4 flakes (7.37 mm) experimental type from Odell (1989:174, Table 2) are not significantly different; therefore biface reduction can be inferred.

Dorsal Flake Scar Count / Weight Ratio. Based on experimental lithic assemblages, Carr and Bradbury (2001:133) and Bradbury and Carr (1999:112) have determined that the dorsal flake scar count to weight (DSC/WT) ratio is a useful method for determining the amount of core reduction and tool production (biface and uniface) in an assemblage. This is based on the idea that debitage flakes will weigh 
less, and the number of dorsal scars will increase, as lithic reduction stages advance (Carr and Bradbury 2001:133). The ratio is calculated by dividing the number of dorsal flake scars by the flake weight (Bradbury and Carr 1999:112; Carr and Bradbury 2001:133). A low ratio indicates core reduction and a high ratio indicates tool production (Carr and Bradbury 2001:133). The DSC/WT ratios were calculated for all broken and complete flakes in this study.

The method of dorsal flake scar identification follows Andrefsky's (2005:109) procedures. Small flake removals related to "platform preparation, breaks, modification after detachment, and shattering" (Andrefsky 2005:109) will not be counted to eliminate scars that are not relevant to the lithic reduction stage. This is similar to the procedures used by Magne (1985:113), and later used by Bradbury and Carr (1999:109), where only scars greater than $5 \mathrm{~mm}$ in size were counted.

Dorsal flake scars were counted on broken and complete flakes, following the procedures of Carr and Bradbury (2001:132-133). Using an ordinal scale, “0” represents flakes where the dorsal surface has no flake scars and is completely covered with cortex, 1 indicates flakes with one dorsal flake scar, 2 indicates flakes with two dorsal flake scars, and 3 indicates flakes with more than two dorsal flake scars (Andrefsky 2005:109). This ordinal procedure is easy to use and reduces interobserver error (Andrefsky 2005:109). The number of dorsal flake scars was determined using a 10X AmScope stereo microscope. Weight measurements from the procedures above were used for broken and complete flakes to calculate the ratio value. 
Experimental lithic data results for flakes in the greater than $1 / 4$-inch size grade from 2001 produced by Andrew Bradbury and Phillip Carr (Andrew Bradbury, personal communication 2010) were provided for a comparison with the DSC/WT ratios in this study. DSC/WT ratios for the 2001 experimental data were calculated using Microsoft Excel 2007.

Results. The DSC/WT ratio results for the pre- and post-MSH Yn cultural components are presented in Table 9. The mean DSC/WT ratio for the pre-MSH Yn $(20.30, \mathrm{n}=24)$ and post-MSH Yn $(17.05, \mathrm{n}=198)$ cultural components are most

Table 9. Broken and Complete Flake Dorsal Scar Count to Weight (g) Ratio Descriptive Statistics for Pre- and Post-MSH Yn Cultural Components.

\begin{tabular}{|c|c|c|c|c|c|c|c|}
\hline $\begin{array}{l}\text { Cultural } \\
\text { Component }\end{array}$ & Strat & $\mathrm{N}$ & Mean & Minimum & Maximum & $\begin{array}{c}\text { Standard } \\
\text { Deviation }\end{array}$ & Median \\
\hline $\begin{array}{l}\text { Pre-MSH } \\
\text { Yn }\end{array}$ & $\begin{array}{l}\text { VIIIa, } \\
\text { VIIIb }\end{array}$ & 24 & 20.30 & 1.31 & 100 & 21.02 & 14.32 \\
\hline $\begin{array}{l}\text { Post-MSH } \\
\text { Yn }\end{array}$ & & 198 & 17.05 & 0 & 100 & 20.52 & 7.28 \\
\hline & I & 4 & 30.07 & 8 & 60 & 21.73 & 26.14 \\
\hline & II, III, IV & 2 & 23.01 & 18.75 & 27.27 & 6.03 & 23.01 \\
\hline & V & 18 & 13.51 & 0 & 75 & 20.13 & 3.67 \\
\hline & VIIa & 174 & 17.05 & 0 & 100 & 20.63 & 7.14 \\
\hline
\end{tabular}

similar to the mean DSC/WT ratio for the bifacial hafting reduction type (18.95) in the 2001 Bradbury and Carr experimental study.

The K-S normality test for the pre-MSH Yn component DSC/WT ratios resulted in a $\mathrm{z}$-value of 1.17 and a p-value of .13, representing a distribution that is not 
significantly different from a normal distribution. A one-sample t-test to compare the observed mean DSC/WT ratio of the pre-MSH Yn component (20.30) with the expected mean hafting reduction type DSC/WT ratio (18.95) from the 2001 experimental studies conducted by Bradbury and Carr resulted in a t-value of .32 and a p-value of .76 with 23 degrees of freedom. The p-value suggests that the differences in the DSC/WT ratios for the pre-MSH Yn and the bifacial hafting reduction type in the 2001 Bradbury and Carr experimental study are not significantly different.

The K-S normality test for the post-MSH Yn component DSC/WT ratios resulted in a $\mathrm{z}$-value of 2.86 and a p-value of .00 , representing a distribution that is significantly different from a normal distribution. A one-sample t-test to compare the observed mean DSC/WT ratio of the post-MSH Yn component (17.05) with the expected mean hafting reduction type DSC/WT ratio (18.95) from the 2001 experimental studies conducted by Bradbury and Carr resulted in a t-value of -1.30 and a p-value of .20 with 197 degrees of freedom. The p-value suggests that the differences in the DSC/WT ratios for the pre-MSH Yn and the bifacial hafting reduction type in the 2001 Bradbury and Carr experimental study are not significantly different.

Discussion. The expectation that both the forager- and collector-like cultural components will include evidence for the use of transported bifacial tools (see expectation number three from Chapter One) is partially supported by the results of this study. Although the mean weight of the pre-MSH Yn cultural component flakes was not significantly similar to experimental bifaces, the mean maximum flake length 
and striking platform width were comparable to those of stage three and four experimental bifaces versus those of an experimental flake core presented in Odell (1989:164, 166, Table 1, 174, Table 2). The mean weight, maximum flake length, and striking platform width of the post-MSH Yn flakes were comparable to those of stage three and four experimental bifaces versus those of an experimental flake core presented in Odell (1989:164, 166, Table 1, 174, Table 2). Mean DSC/WT ratios for both the pre- and post-MSH Yn cultural components (17.05 to 20.30) are most similar to experimental bifacial haft flakes (18.95) versus those of experimental cores (1.34). These similarities were determined to be statistically significant. As expected, bifacial technology, as opposed to flake core technology, was the primary lithic reduction type for both foragers and collectors at Buck Lake.

\subsubsection{Method to Determine the Frequency of Lithic Production and Reduction Stages}

Dorsal Cortex Coverage Percentage. It is recognized that the amount of cortex on a flake will decrease as the tool production and core reduction processes progress (Andrefksy 2005:103-104). However, the amount of cortex present on a flake can be dependent on a number of factors, including the amount of cortex present on the objective piece being reduced and the nature of the raw material (Andrefksy 2005:104). Following Andrefksy (2005:105-106), this study measured the amount of dorsal cortex on broken, complete, and fragment debitage using a replicable ordinal scale: If 100 percent of the dorsal surface is covered with cortex, a value of 3 is 
recorded; if less than 100 percent but greater than 50 percent, a value of 2 is recorded; if less than or equal to 50 percent but greater than 0 percent, a value of 1 is recorded; if 0 percent, a value of 0 is recorded. Because it is often difficult to determine if less than, greater than, or equal to 50 percent of the debitage dorsal surface is covered with cortex, a dot grid was used following the procedures of Andrefsky 2005:106-107, Figure 5.12). If more dots cover the dorsal cortex portion of a debitage specimen than the portion without cortex, a value of 2 is recorded.

The results from experimental studies by Mauldin and Amick (1989) and Odell (1989) indicate that the amount of dorsal cortex on debitage can be used to infer some stages of lithic reduction. Mauldin and Amick $(1989: 67,70)$ found that the presence of dorsal cortex on debitage from experimental lithic reduction to produce bifacial blanks could only be used to infer early lithic reduction stages. After 50 percent of reduction had been completed, 90-97 percent of the debitage had no cortex present. Odell (1989:185) found similar results; the extreme stages on either end of the reduction process can be differentiated based on the presence of dorsal cortex on debitage. This study uses similar inferences for early and late stages of lithic reduction based on the presence or absence of dorsal cortex.

Results. The dorsal cortex coverage percentage results for the pre- and postMSH Yn cultural components appear in Table 10. The overwhelming majority of both the pre-MSH Yn (98.2\%) and post-MSH Yn (96.3\%) cultural components flakes have no dorsal cortex. The post-MSH Yn cultural component has more flakes in the 1-50 percent and 51-99 percent dorsal cortex coverage classes. 
Table 10. Broken, Complete, and Fragment Flake Dorsal Cortex Coverage Percentages and Frequencies (Italicized) for Pre- and Post-MSH Yn Cultural Components.

\begin{tabular}{lcccccc}
\hline $\begin{array}{l}\text { Cultural } \\
\text { Component }\end{array}$ & Strat & $\mathrm{N}$ & $\begin{array}{c}0 \% \\
\text { Coverage }\end{array}$ & $\begin{array}{c}1-50 \% \\
\text { Coverage }\end{array}$ & $\begin{array}{c}51-99 \% \\
\text { Coverage }\end{array}$ & $\begin{array}{c}100 \% \\
\text { Coverage }\end{array}$ \\
\hline $\begin{array}{l}\text { Pre-MSH } \\
\text { Yn }\end{array}$ & VIIIa, VIIIb & 164 & $98.2(161)$ & $1.8(3)$ & - & - \\
Post-MSH & & & & & & \\
Yn & & 1441 & $96.3(1387)$ & $2.7(39)$ & $1.0(15)$ & - \\
& I & 46 & 100 & - & - & - \\
& II, III, IV & 44 & 95.5 & 4.5 & - & - \\
& V & 189 & 97.4 & 1.6 & 1.1 & - \\
& VIIa & 1162 & 96 & 2.9 & 1.1 & - \\
\hline
\end{tabular}

The K-S normality test for the pre-MSH Yn component dorsal cortex coverage percentage resulted in a $\mathrm{z}$-value of 6.86 and a p-value of .00, indicating a distribution that is not significantly different from a normal distribution. The K-S normality test for the post-MSH Yn component cortex coverage percentage resulted in a z-value of 20.36 and a p-value of .00 . Because the p-value is less than .05 , the distribution is determined to be significantly different from a normal distribution.

A Mann-Whitney test was performed to test the difference in dorsal cortex coverage between the two cultural components and resulted in a z-value of -1.27 and a p-value of .20, which suggests dorsal cortex coverage for the pre- and post-MSH Yn flakes are not significantly different.

Weight, Maximum Flake Length, Maximum Flake Thickness, and Platform Type. Based on the results of experimental biface reduction, Wilson and Andrefsky (2008:89-90) found that weight, maximum length, thickness, and platform type can be used to discriminate between biface production and resharpening. Biface production 
includes all the proximal (platform-bearing) flakes from lithic technological sequences that produce a biface that could be used as a cutting tool (Wilson and Andrefsky 2008:88). Biface resharpening includes all the proximal flakes from sequences after a biface was purposely dulled and then resharpened (Wilson and Andrefsky 2008:88). Wilson and Andrefsky's (2008:90, Table 4.1) experimental results show that biface production proximal flakes were heavier (12.784 $\mathrm{g}$ mean), longer (42.132 $\mathrm{mm}$ mean), and thicker (7.870 $\mathrm{mm}$ mean) than biface resharpening proximal flakes (1.193 g mean weight, $24.315 \mathrm{~mm}$ mean length, $2.308 \mathrm{~mm}$ mean thickness). Wilson and Andrefsky's (2008:90, Figure 4.1) experimental results also show that biface production resulted in more flat (35\%) and cortical (15\%) platforms than biface resharpening (5\% flat and $0 \%$ cortical); biface resharpening resulted in more complex (25-30\%) and abraded (65\%) platforms than biface production (15\% complex and 35\% abraded).

This study uses the same procedures discussed previously to measure weight and maximum length on proximal flakes (broken and complete flake specimens). The maximum thickness of proximal flakes was measured in $.01 \mathrm{~mm}$ increments following Andrefsky (2005:101, Figure 5.9f) and using S-T Industries, Inc. electronic calipers. The thickness of each proximal flake specimen was measured at its thickest point. Platform types follow the procedures presented in Andrefsky (2005:94-97, Figure 5.6) using a nominal scale (cortical, flat, complex, and abraded) that is simple and covers a range of variability. A cortical platform is completely covered in cortex. A flat platform has a smooth platform surface. A complex platform has a rounded surface or multiple flake scars. An abraded platform has a surface texture that shows grinding or 
abrasion. Broken and complete flake types will be used as proximal flake specimens for this study.

Results. The mean weight, mean length, mean thickness, and platform type percentages, K-S, and t-test results for the pre- and post-MSH Yn cultural components proximal flakes appear in Tables 11 and 12. The mean weight for the pre-MSH Yn specimens $(.12 \mathrm{~g}, \mathrm{n}=57)$ and post-MSH Yn specimens $(.70 \mathrm{~g}, \mathrm{n}=298)$ are most similar to the mean weight of the biface resharpening flakes (1.193 g) when compared with Wilson and Andrefsky's (2008:90, Table 4.1) experimental results. The mean weights for the pre-MSH Yn and the biface resharpening flakes (1.193 g) from Wilson and Andrefsky (2008:90, Table 4.1) are significantly different. The differences in the mean weights for the post-MSH Yn and the biface resharpening flakes $(1.193 \mathrm{~g})$ from Wilson and Andrefsky (2008:90, Table 4.1) are significantly different.

Table 11. Mean Weight, Maximum Length, and Maximum Thickness for Preand Post-MSH Yn Cultural Component Proximal Flakes with K-S and T-test Results (Italicized).

\begin{tabular}{lccccc}
\hline $\begin{array}{l}\text { Cultural } \\
\text { Component }\end{array}$ & Strat & $\mathrm{N}$ & Weight $(\mathrm{g})$ & Length $(\mathrm{mm})$ & $\begin{array}{c}\text { Thickness } \\
(\mathrm{mm})\end{array}$ \\
\hline & & & .12 & 9.47 & 1.42 \\
Pre-MSH Yn & VIIIa, VIIIb & 57 & $z 2.33, p .00$ & $z 1.17, p .13$ & $z 1.58, p .01$ \\
& & & $.72 .61, p .00$ & $t-23.91, p .00$ & $t-7.51, p .00$ \\
Post-MSH Yn & & & $z 6.84, p .00$ & $z 2.84, p .00$ & $z 3.16, p .00$ \\
& & 298 & $t-3.19, p .00$ & $t-21.87, p .00$ & $t-1.82, p .07$ \\
& I & 8 & .06 & 7.80 & 1.47 \\
& II, III, IV & 3 & .09 & 6.98 & 1.60 \\
& V & 22 & 2.97 & 17.25 & 2.96 \\
& VIIa & 265 & .54 & 12.73 & 2.08 \\
\hline
\end{tabular}




\section{Table 12. Platform Type Percentage for Pre- and Post-MSH Yn Cultural Component Proximal Flakes.}

\begin{tabular}{lccccccc}
\hline $\begin{array}{l}\text { Cultural } \\
\text { Component }\end{array}$ & Strat & $\mathrm{N}$ & $\begin{array}{c}\% \\
\text { Flat }\end{array}$ & $\begin{array}{c}\% \\
\text { Cortical }\end{array}$ & $\begin{array}{c}\% \\
\text { Complex }\end{array}$ & $\begin{array}{c}\% \\
\text { Abraded }\end{array}$ & $\begin{array}{c}\% \\
\text { Unknown }\end{array}$ \\
\hline $\begin{array}{l}\text { Pre-MSH } \\
\text { Yn }\end{array}$ & VIIIa, & 57 & 7.0 & - & 77.2 & 15.8 & - \\
Post-MSH & VIIIb & & & & & & \\
Yn & & 298 & 26.4 & 1.7 & 54.8 & 16.4 & .7 \\
& I & 8 & 25 & - & 75 & - & - \\
& II, III, IV & 3 & - & - & 66.7 & 33.3 & - \\
& V & 22 & 18.2 & - & 63.6 & 18.2 & - \\
& VIIa & 265 & 27.4 & 1.9 & 53.4 & 16.5 & .8 \\
\hline
\end{tabular}

The mean maximum flake length for the pre-MSH Yn specimens $(9.47 \mathrm{~mm}, \mathrm{n}$ $=57)$ and post-MSH Yn specimens $(12.87 \mathrm{~mm}, \mathrm{n}=298)$ are most similar to the mean maximum flake length of the biface resharpening flakes $(24.315 \mathrm{~mm})$ when compared with Wilson and Andrefsky's (2008:90, Table 4.1) experimental results. The differences in the mean flake lengths for the pre-MSH Yn and the biface resharpening flakes (24.315 mm) from Wilson and Andrefsky (2008:90, Table 4.1) are significantly different. The differences in the mean flake lengths for the post-MSH Yn and the biface resharpening flakes $(24.315 \mathrm{~mm})$ from Wilson and Andrefsky (2008:90, Table 4.1) are significantly different.

The mean maximum thickness for the pre-MSH Yn specimens $(1.42 \mathrm{~mm}, \mathrm{n}=$ 57) and post-MSH Yn specimens $(2.12 \mathrm{~mm}, \mathrm{n}=298)$ are most similar to the mean maximum flake thickness of the biface resharpening flakes $(2.308 \mathrm{~mm})$ when compared with Wilson and Andrefsky's (2008:90, Table 4.1) experimental results. The differences in the mean flake thicknesses for the pre-MSH Yn and the biface resharpening flakes (2.308 mm) from Wilson and Andrefsky (2008:90, Table 4.1) are 
significantly different. The differences in the mean flake thicknesses for the postMSH Yn and the biface resharpening flakes $(2.308 \mathrm{~mm})$ from Wilson and Andrefsky (2008:90, Table 4.1) are not significantly different.

The pre-MSH Yn distribution of cortical (0\%) and flat (7\%) platforms are similar to Wilson and Andrefsky's (2008:90, Figure 4.1) biface resharpening flat (5\%) and cortical (0\%) platform type results. All other platform type distributions are dissimilar to Wilson and Andrefsky's (2008:90, Figure 4.1) results. The post-MSH Yn distribution of flat (26.4\%) platforms are similar to Wilson and Andrefsky's (2008:90, Figure 4.1) biface production flat (35\%) platform type results. All other platform type distributions are dissimilar to Wilson and Andrefsky's (2008:90, Figure 4.1) results.

A chi-square test was conducted to determine if the relationship between platform type and cultural component was significant. The test resulted in a chisquare value of 23.80 and a p-value of 0.00 with six degrees of freedom. Because the $\mathrm{p}$-value is less than 0.05 , there is a significant relationship between platform type and cultural component. Although there could be sampling issues with these statistical results as some of the platform type percentages are zeros or low numbers.

Discussion. The expectation that forager- and collector-like cultural components will present evidence for late-stage bifacial reduction from resharpening and retouch (see expectation number three in Chapter One) is supported by the results of this study. The high percentage of flakes from the forager- (98.2\%) and collector-like (96.3\%) components have no dorsal cortex, indicating that flakes from 
both components are the result of later reduction stages, not early ones. Both foragers and collectors conducted later-stage lithic reduction at Buck Lake.

The expectation that the collector-like component will have a higher occurrence of evidence for middle-stage bifacial production for producing expedient flakes (see expectation number four in Chapter One) than the forager-like cultural component is not fully supported by the results of this study. The mean weight, maximum flake length, and maximum flake thickness of both the pre- and post-MSH Yn cultural components appear to be most similar to the biface resharpening flakes in Wilson and Andrefsky's (2008:90, Table 4.1) experimental results. Statistical tests show that these apparent similarities are not significant, except for the statistical test for differences in the mean flake thicknesses for the post-MSH Yn and the biface resharpening flakes from Wilson and Andrefsky's (2008:90, Table 4.1) experimental results, which show a statistically significant similarity.

The percentage of cortical and flat platform types for the pre-MSH Yn cultural component appear to be most similar to the cortical and flat platform types of biface resharpening flakes from Wilson and Andrefsky's (2008:90, Table 4.1) experimental results; whereas the percentage of flat platform types for the post-MSH Yn cultural component appear to be most similar to the flat platform type of biface production flakes from Wilson and Andrefsky's (2008:90, Table 4.1) experimental results. Statistical results support that these apparent relationships are significant.

Foragers were more likely to be involved in biface resharpening activities at Buck Lake as a result of transporting finished bifacial tools that required maintenance. 
Collectors, on the other hand, were more likely to be involved in biface production activities at Buck Lake as a result of transporting unfinished bifacial tools that could have been used as cores for producing expedient flakes.

\subsubsection{Method to Determine the Frequency of Usable Expedient Flakes}

Debitage Size Class. Andrefsky (2001:69) "arbitrarily" defines usable flakes as those that are greater than or equal to $25 \mathrm{~mm}$ in their "maximum dimension." The debitage size class method discussed previously was used to separate usable flakes (greater than or equal to $25 \mathrm{~mm}$ ) from those that most likely lack potential for being utilized (less than $25 \mathrm{~mm}$ ). Any broken flakes, complete flakes, or flake fragments in the greater than or equal to $25 \mathrm{~mm}$ size classes will be considered potential usable flakes.

Results. The greater than or equal to $25 \mathrm{~mm}$ flake diameter size class results for the pre- and post-MSH Yn cultural components can be found in Table 13. The pre-MSH Yn cultural component had no flake specimens in the greater than or equal to $25 \mathrm{~mm}$ diameter size classes; whereas, the post-MSH Yn cultural component had

small percentages of flakes in those diameter size classes. The post-MSH Yn cultural component has a higher occurrence of usable flakes than the pre-MSH Yn cultural component. 
Table 13. Broken, Complete, and Fragment Flake Greater Than or Equal to 25 mm Diameter Size Class Percentages for Pre- and Post-MSH Yn Cultural Components.

\begin{tabular}{|c|c|c|c|c|c|c|c|c|c|}
\hline $\begin{array}{l}\text { Cultural } \\
\text { Component }\end{array}$ & Strat & $\mathrm{N}$ & 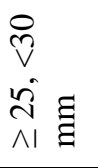 & $\stackrel{\sim}{\vartheta} \Xi$ & 守吉 & 守声 & $\stackrel{\circ}{\vee} \Xi$ & $\stackrel{8}{\nabla} \Xi$ & $\stackrel{\curvearrowleft}{\stackrel{\varpi}{\vee}}$ \\
\hline \multirow{6}{*}{$\begin{array}{l}\text { Pre-MSH } \\
\text { Yn } \\
\text { Post-MSH } \\
\text { Yn }\end{array}$} & $\begin{array}{l}\text { VIIIa, } \\
\text { VIIIb }\end{array}$ & 164 & - & - & - & - & - & - & - \\
\hline & & 1441 & 3.5 & 1.9 & 1.1 & .7 & .2 & .1 & .1 \\
\hline & I & 46 & 4.3 & - & - & - & - & - & - \\
\hline & $\begin{array}{l}\text { II, III, } \\
\text { IV }\end{array}$ & 44 & 2.3 & - & 2.3 & - & - & - & - \\
\hline & V & 189 & 1.6 & .5 & - & 1.1 & - & - & .5 \\
\hline & VIIa & 1162 & 3.9 & 2.3 & 1.3 & .7 & .3 & .1 & - \\
\hline
\end{tabular}

Discussion. The expectation that the collector-like cultural component will have a higher occurrence of usable expedient flakes than the forager-like component (see expectation number four in Chapter One) is supported by the results of this study. The post-MSH Yn cultural component has a small percentage of flakes in the greater than $25 \mathrm{~mm}$ size classes, whereas the pre-MSH Yn component has none. Collectors at Buck Lake made use of what have been determined to be usable flakes in what is likely to have been an expedient manner.

\subsubsection{Method to Determine the Frequency of Blade Core Technology}

Blade cores are a type of unidirectional core on which only one striking platform surface is used, and flakes are consistently removed in only one direction 
(Andrefsky 2005:15, 262). The following method is not used to directly test for the frequency of blade cores per se; rather, the method is a way of testing for unidirectional cores. If a high frequency of the debitage population was produced from unidirectional cores, the use of blade core technology can be inferred as a likely possibility.

Free-standing Typology. Andrefsky (2005:129-131) presents a "free-standing typology" (Andrefsky 2005:129) to determine whether a debitage population was more likely produced from unidirectional or multidirectional cores. His method divides a lithic debitage population into six types based on ratios of maximum length to maximum thickness, as well as weight classes. The length-to-thickness ratios are divided into two groups: one group includes ratios less than five, and the other includes ratios greater than or equal to five. Each of these two groups is then divided into three weight groups: less than $5 \mathrm{~g}, 5$ to $20 \mathrm{~g}$, and greater than $20 \mathrm{~g}$. The count and relative percentage for each of the six types in a debitage population is calculated.

Based on Andrefsky's (2005:129) analysis results, differences between unidirectional and multidirectional debitage were especially apparent in the group with a ratio greater than or equal to five that weigh less than five g. The relative percentage of this type for the unidirectional core was 11.1 percent, whereas it was 31.4 percent for the multidirectional core (Andrefksy 2005: Table 6.4; Figure 6.6). This study uses this freestanding typology and Andrefsky's (2005: Table 6.4; Figure 6.6) results for comparison to determine if the debitage population was more likely produced from unidirectional or multidirectional cores. The methods to measure the maximum 
length, maximum thickness, and weight on broken and complete flake specimens will be identical to those described previously and can be found above.

Results. The results of the freestanding typology can be found in Table 14 .

Both the pre-MSH Yn (84.2\%) and post-MSH Yn (73.4\%) cultural components have

Table 14. Percentages and Frequencies (Italicized) of Flakes in the Group with a Length-to-Thickness Ratio Greater Than or Equal to Five and that Weigh Less than Five Grams for Pre- and Post-MSH Yn Cultural Components.

\begin{tabular}{lccc}
\hline Cultural Component & N & $\begin{array}{c}\text { \% having length to } \\
\text { thickness ratio } \geq 5, \\
\text { weight }<5 \mathrm{~g}\end{array}$ \\
\hline Pre-MSH Yn & Strat & 57 & $84.2(48)$ \\
Post-MSH Yn & VIIIa, VIIIb & 293 & $73.4(215)$ \\
& I & 8 & 62.5 \\
& II, III, IV & 3 & 33.3 \\
& V & 20 & 75 \\
& VIIa & 262 & 74 \\
\hline
\end{tabular}

high percentages of flakes in the group with a length-to-thickness ratio greater than or equal to five that weigh less than five $\mathrm{g}$. This indicates that the use of unidirectional cores by both cultural components was most likely minimal. It is reasonable to infer that if use of unidirectional cores was minimal, then the use blade cores as a type of unidirectional core was also minimal. Blades can generally be defined as a flake that is twice as long as it is wide with parallel edges (Andrefsky 2005:253; Kooyman 2001:12; Odell 2004:45; Whittaker 1997:33). Although flakes were not recorded as blades as a technological type, and maximum width measurements were not recorded for flake specimens, few actual blades were recognized during this study, which 
supports the assertion that the use of blade technology was most likely minimal at Buck Lake.

Discussion. The expectation that both the forager- and collector-like cultural components will present little evidence for blade core technology (see expectation number five in Chapter One) is supported by the results of this study. Both the preand post-MSH Yn cultural components have low percentages of flakes that fall within what is considered to be a unidirectional core group. Unidirectional cores, presumed to represent blade cores, were not frequently used by the pre- and post-MSH Yn cultural components. Neither foragers nor collectors relied heavily on blade cores at Buck Lake.

\subsubsection{Method to Determine the Frequency of Bipolar Core Technology}

As stated before, the process bipolar reduction involves producing flakes by situating a core on an anvil and striking it with a hammer at a $90^{\circ}$ angle, which creates impact points on either side of the objective core (Jeske and Lurie 1993:132). The following method will be used to distinguish the frequency of bipolar core versus hard hammer core reduction techniques.

Percentage of Flakes. Jeske and Lurie (1993:138, 140) determined that 82.3

percent of the debitage created by experimental hard hammer core reduction were flakes (debitage with a striking platform, bulb of percussion, and flake termination), whereas 49.8 percent of the debitage created by experimental bipolar core techniques 
were flakes. These results were independent of raw material type and were confirmed at a 95 percent confidence interval (Jeske and Lurie 1993:140).

Based on Jeske and Lurie's (1993:140) results, Sievert and Wise (2001:92) inferred that bipolar core techniques were not used at a high frequency on the southcentral Andean coast of Peru, because 70.1 to 72.8 percent of the debitage population contained flakes. Flakes were defined as thin pieces of debitage with striking platforms, bulbs of percussion, or compression rings (Sievert and Wise 2001:90).

This study uses similar inferences based on Jeske and Lurie's $(1993: 138,140)$ and Sievert and Wise's $(2001: 90,92)$ definitions and results. Flake fragment, broken flake, and complete flake definitions for this study all fall within the definition of flakes in the Jeske and Lurie (1993) and Sievert and Wise (2001) studies. The percentage of these debitage types was calculated, and the technique for creating them (hard hammer core reduction versus bipolar core techniques) was inferred based on the percentages of flakes and debris.

Results. The results of the percentage of debris and flakes for the pre- and post-MSH Yn cultural components are shown in Table 15. The percentage of preMSH Yn cultural component flakes $(58.6 \%)$ is closer to the Jeske and Lurie (1993:140) bipolar technique flake percentage (49.8\%) results than the lower Sievert and Wise (2001:92) hard hammer technique flake percentage (70.1\%) results. Considering this, it would be reasonable to infer that the bipolar technique was used by the pre-MSH Yn inhabitants. The percentage of post-MSH Yn cultural component flakes $(69.5 \%)$ is much closer to the lower Sievert and Wise (2001:92) hard hammer 
technique flake percentage (70.1\%) results than the Jeske and Lurie (1993:140) bipolar technique flake percentage (49.8\%) results; therefore, the bipolar technique was most likely important to the post-MSH Yn inhabitants.

Table 15. Debris and Flake Percentages and Frequencies (Italicized) for Pre- and Post-MSH Yn Cultural Components.

\begin{tabular}{lcccc}
\hline Context & Strat & N & \% Debris & \% Flakes \\
\hline Pre-MSH Yn & VIIIa, VIIIb & 280 & $41.4(116)$ & $58.6(164)$ \\
Post-MSH Yn & & 2074 & $30.5(633)$ & $69.5(1441)$ \\
& I & 69 & 33.3 & 66.7 \\
& II, III, IV & 82 & 46.3 & 53.7 \\
& V & 317 & 40.4 & 59.6 \\
& VIIa & 1606 & 27.6 & 72.4 \\
\hline
\end{tabular}

A chi-square test was conducted to determine if the relationship between debitage type (flake and debris) and cultural component was significant. The test resulted in a chi-square value of 13.53 and a p-value of .00 with one degree of freedom, which indicates a significant relationship between object type and cultural component.

Discussion. The expectation that both the forager- and collector-like cultural components will have a low occurrence of evidence for bipolar core technology (see expectation number five in Chapter One) is not fully supported by the results of this study. The pre-MSH Yn cultural component has a high percentage of debris and low percentage of flakes, similar to what has been found for bipolar technology in experimental studies and archaeological research. The post-MSH Yn cultural 
component has a low percentage of debris and high percentage of flakes when compared with what is expected for bipolar technology in experimental studies and archaeological research. The relationship between object type and cultural component was determined to be statistically significant. Based on these results, unlike what was expected for this study, foragers appear to have used bipolar technology more frequently than collectors at Buck Lake.

The results of this study suggest that bipolar technology was important for foragers at Buck Lake, which is inconsistent with previous assumptions. As mentioned in Chapter One, bipolar technology may be used when local toolstone is of low knapping quality and acquiring nonlocal toolstone is not a viable option (Andrefsky 1994b:384; Jeske and Lurie 1993:134). This does not seem to be the case at Buck Lake, as the majority of debitage is made from nonlocal CCS. The bipolar technique could have been used at Buck Lake to conserve nonlocal CCS and might have been used on expended stone tools as suggested by Andrefsky (1994b:384-387) and Kelly (2001:66). Transporting bifaces and not nodules of CCS is more likely though, as suggested by Andrefsky (1994a:30-31) and Wilson (2007:322). The bipolar technique could have been used on expended tools to conserve CCS, but it would not be expected to be the primary lithic technology.

As Andrew Bradbury (personal communication 2010) suggests, there should be evidence of bipolar cores, anvils, and flakes at Buck Lake if bipolar technology were used. Although this study did not specifically analyze artifacts other than debitage, cores, and particularly bipolar cores, were not observed in high numbers. 
Anvils were also not observed. No flakes looked distinctively bipolar. With a lack of bipolar cores, anvils, and flakes, there are not strong indicators to suggest that bipolar technology was widely used at Buck Lake (Andrew Bradbury, personal communication 2010); although only a small area of the site has been studied.

It is possible that the pre-MSH Yn results are not entirely accurate. As mentioned in earlier in this chapter, there was a bias towards identifying specimens as debris that might have produced inflated debris percentages. The nature of the raw material could have also skewed the results of this study. Experimental lithic technology results suggest that the percentage of debris can be dependent on lithic raw material type with percentages below 46 percent (Andrew Bradbury, personal communication 2010).

\subsection{Chapter Summary}

This study used a sample of greater than $1 / 8$-inch lithic debitage from TUs 1-3 excavated between 2005 and 2007 as a source of data to investigate technological organization strategies through time at a Buck Lake activity area. Lithic debitage from the pre-MSH Yn tephra represents forager-like cultural components, whereas the post-MSH Yn tephra lithic debitage represents the collector-like cultural components.

This study relied on methods that are replicable and can be confidently measured by novice analyzers with some lithic analysis training (Andrefsky 2005:98; Bradbury and Carr 2004:69-70; Odell 2004:124, 126, 128; Prentiss 2001:158). 
Statistical methods were used to determine if results were significant. Tables 16 and 17 summarize the methods, expectations, and results of this study: 
Table 16. Summary of Analysis Methods.

\begin{tabular}{|c|c|c|}
\hline Analysis Method & Analysis Description & Analysis Objective \\
\hline $\begin{array}{l}\text { Sullivan and Rozen (1985) } \\
\text { Interpretation-Free Typology }\end{array}$ & $\begin{array}{l}\text { Places all debitage specimens into } \\
\text { four mutually exclusive } \\
\text { categories: flake fragment, debris, } \\
\text { broken flake, and complete flake. }\end{array}$ & $\begin{array}{l}\text { Debitage types were used } \\
\text { for further study. }\end{array}$ \\
\hline Raw Material Identification & $\begin{array}{l}\text { Places all debitage specimens into } \\
\text { broad material type categories } \\
\text { based on color, texture, and } \\
\text { translucence. }\end{array}$ & $\begin{array}{l}\text { Used to infer the use of } \\
\text { local and nonlocal } \\
\text { toolstone. }\end{array}$ \\
\hline Debitage Weight & $\begin{array}{l}\text { All debitage specimens were } \\
\text { weighed to } .01 \mathrm{~g} \text {. }\end{array}$ & $\begin{array}{l}\text { Used to infer objective } \\
\text { piece size. }\end{array}$ \\
\hline Debitage Size Class & $\begin{array}{l}\text { Places all debitage specimens into } \\
\text { diameter size classes using } 5 \mathrm{~mm} \\
\text { increment circles from } 5-65 \mathrm{~mm} \\
\text { diameter. }\end{array}$ & $\begin{array}{l}\text { Used to infer objective } \\
\text { piece size. } \\
\text { Used to infer the use of } \\
\text { expedient (greater than or } \\
\text { equal to } 25 \text { mm diameter } \\
\text { size class) flakes. }\end{array}$ \\
\hline Maximum Flake Length & $\begin{array}{l}\text { Maximum flake length was } \\
\text { measured on broken and complete } \\
\text { flake specimens to } .01 \mathrm{~mm} \text {. }\end{array}$ & $\begin{array}{l}\text { Used to infer objective } \\
\text { piece size. }\end{array}$ \\
\hline $\begin{array}{l}\text { Maximum Flake Length, Striking } \\
\text { Platform Width, and Weight }\end{array}$ & $\begin{array}{l}\text { Maximum flake length and } \\
\text { weight was measured on greater } \\
\text { than } 10 \mathrm{~mm} \text { diameter size class } \\
\text { broken and complete flake } \\
\text { specimens following the previous } \\
\text { procedures. Striking platform } \\
\text { width was measured on the same } \\
\text { specimens to } .01 \mathrm{~mm} \text {. }\end{array}$ & $\begin{array}{l}\text { Used to infer the presence } \\
\text { of bifacial reduction } \\
\text { versus core reduction. }\end{array}$ \\
\hline Dorsal Flake Scar / Weight Ratio & $\begin{array}{l}\text { The number of greater than } 5 \mathrm{~mm} \\
\text { dorsal flake scars was recorded on } \\
\text { broken and complete flake } \\
\text { specimens. The number of dorsal } \\
\text { flake scars was divided by the } \\
\text { weight of the specimens for } \\
\text { ratios. }\end{array}$ & $\begin{array}{l}\text { Used to infer the presence } \\
\text { of bifacial reduction } \\
\text { versus core reduction. }\end{array}$ \\
\hline Dorsal Cortex Percentage & $\begin{array}{l}\text { Dorsal cortex percentage was } \\
\text { measured on broken, complete, } \\
\text { and fragment flake specimens. }\end{array}$ & $\begin{array}{l}\text { Used to infer lithic } \\
\text { production and reduction } \\
\text { stages. }\end{array}$ \\
\hline
\end{tabular}


Table 16, Continued. Summary of Analysis Methods.

\begin{tabular}{|c|c|c|}
\hline Analysis Method & Analysis Description & Analysis Objective \\
\hline $\begin{array}{l}\text { Combined Weight, Maximum Flake } \\
\text { Length, Maximum Flake Thickness, } \\
\text { and Platform Type }\end{array}$ & $\begin{array}{l}\text { Weight and maximum flake } \\
\text { length was measured on broken } \\
\text { and complete flake specimens } \\
\text { following the previous } \\
\text { procedures. Maximum flake } \\
\text { thickness was measured on the } \\
\text { same specimens to } .01 \mathrm{~mm} \text {. } \\
\text { Platform type was measured on } \\
\text { the same specimens. }\end{array}$ & $\begin{array}{l}\text { Used to infer biface } \\
\text { production versus biface } \\
\text { resharpening stages. }\end{array}$ \\
\hline $\begin{array}{l}\text { Free-standing Typology Using } \\
\text { Maximum Flake Length to Maximum } \\
\text { Flake Thickness Ratios and Weight }\end{array}$ & $\begin{array}{l}\text { Maximum flake length, maximum } \\
\text { flake thickness, and weight were } \\
\text { measured on broken and complete } \\
\text { flake specimens. The maximum } \\
\text { flake length was divided by the } \\
\text { maximum flake thickness for } \\
\text { ratios. }\end{array}$ & $\begin{array}{l}\text { Used to infer the use of } \\
\text { unidirectional versus } \\
\text { multidirectional cores. } \\
\text { The use of unidirectional } \\
\text { cores was used to infer } \\
\text { the use of blade cores. }\end{array}$ \\
\hline Percentage of Flakes and Debris & $\begin{array}{l}\text { The percentage of debris and the } \\
\text { combined percentage of broken, } \\
\text { complete, and fragment flake } \\
\text { specimens were calculated. }\end{array}$ & $\begin{array}{l}\text { Used to infer the use of } \\
\text { bipolar cores. }\end{array}$ \\
\hline
\end{tabular}




\section{Table 17. Summary of Technological Organization Expectations and Analysis Results}

\begin{tabular}{|c|c|c|}
\hline Expectation & Result & Comments \\
\hline $\begin{array}{l}\text { Both the forager- and collector-like } \\
\text { cultural components will have a high } \\
\text { frequency of portable nonlocal CCS } \\
\text { toolstone and a low frequency of local } \\
\text { igneous and nonlocal obsidian toolstone. }\end{array}$ & Positive & $\begin{array}{l}\text { Majority ( } 89.3-97.8 \%) \text { of toolstone was nonlocal } \\
\text { CCS for both cultural components. }\end{array}$ \\
\hline $\begin{array}{l}\text { Both the forager- and collector-like } \\
\text { cultural components will present } \\
\text { evidence for the use of light and small } \\
\text { finished transported bifaces to increase } \\
\text { portability. Because of an increased } \\
\text { reliance on expedient flakes, collector- } \\
\text { like cultural component transported } \\
\text { bifaces might be slightly heavier and } \\
\text { larger. }\end{array}$ & Positive & $\begin{array}{l}\text { Both cultural components debitage were very } \\
\text { light (mean weight less than } .30 \mathrm{~g} \text { ), very small } \\
\text { (less than } 10 \mathrm{~mm} \text { size class and mean maximum } \\
\text { flake length less than } 13 \mathrm{~mm} \text { ). The collector-like } \\
\text { mean debitage weight is almost twice as heavy, } \\
\text { with a mean weight of } .29 \mathrm{~g} \text { compared with the } \\
.16 \mathrm{~g} \text { mean weight of the forager-like debitage. } \\
\text { The collector-like debitage occurs in the larger } \\
\text { diameter size classes and has a slightly }(3.4 \mathrm{~mm}) \\
\text { longer mean maximum flake length. }\end{array}$ \\
\hline $\begin{array}{l}\text { Both the forager- and collector-like } \\
\text { cultural components will present } \\
\text { evidence for the use of transported } \\
\text { bifacial tools and late stage bifacial } \\
\text { reduction from resharpening and } \\
\text { retouch. }\end{array}$ & Mixed & $\begin{array}{l}\text { Forager-like cultural component flakes mean } \\
\text { weight was not similar to experimental bifaces, } \\
\text { although mean maximum flake length and } \\
\text { striking platform width were comparable to stage } \\
\text { three and four experimental bifaces. The mean } \\
\text { weight, maximum flake length, and striking } \\
\text { platform width of the collector-like flakes were } \\
\text { comparable to those of stage three and four } \\
\text { experimental bifaces. Mean DSC/WT ratios for } \\
\text { both cultural components (17.05 to 20.30) are } \\
\text { most similar to experimental bifacial hafting } \\
\text { flakes (18.95) versus those of experimental cores } \\
\text { (1.34). The high percentage of flakes from the } \\
\text { forager- ( } 98.2 \% \text { ) and collector-like ( } 96.3 \%) \\
\text { components have no dorsal cortex, indicating that } \\
\text { flakes from both components are the result of late } \\
\text { reduction stages. The mean maximum flake } \\
\text { thickness for the collector-like cultural } \\
\text { component is similar to experimental biface } \\
\text { resharpening flakes. The percentage of cortical } \\
\text { and flat platform types for the forager-like } \\
\text { cultural component are similar to the platform } \\
\text { types of experimental biface resharpening flakes; } \\
\text { whereas the percentage of flat platform types for } \\
\text { the collector-like cultural component are similar } \\
\text { to platform types of experimental biface } \\
\text { production flakes. }\end{array}$ \\
\hline
\end{tabular}




\section{Table 17, Continued. Summary of Technological Organization Expectations and Analysis Results}

\begin{tabular}{l}
\hline Expectation \\
\hline The collector-like cultural \\
component will have present \\
evidence for the use of transported \\
bifaces and middle stage bifacial \\
production for producing expedient \\
flakes and a higher frequency of \\
usable expedient flakes.
\end{tabular}

Both the forager- and collector-like cultural components will have low frequencies of blade and bipolar core technologies.

\author{
Result Comments \\ Mixed The expectation that the collector-like component will \\ have a higher frequency of middle stage bifacial \\ production for producing expedient flakes than the \\ forager-like cultural component is not fully supported \\ by the results of this study. The mean maximum flake \\ thicknesses for the collector-like cultural components \\ are similar to experimental biface resharpening flakes. \\ The percentage of flat platform types for the collector- \\ like cultural component is similar to platform types of \\ experimental biface production flakes. The collector- \\ like cultural component has a small percentage of flakes \\ in the greater than $25 \mathrm{~mm}$ size classes, whereas the \\ forager-like component has none.
}

Mixed Both the forager-like and collector-like cultural components have low percentages of flakes that fall within what is considered to be a unidirectional core group presumed to represent blade cores. The foragerlike cultural component has a high percentage of debris and low percentage of flakes similar to what has been found for experimental bipolar technology. The collector-like cultural component has a low percentage of debris and high percentage of flakes when compared with experimental bipolar technology. The collectorlike cultural component has a low percentage of debris and high percentage of flakes unlike that of experimental bipolar technology. 


\section{CHAPTER THREE}

\section{SUMMARY, CONCLUSIONS, AND RECOMMENDATIONS}

\subsection{Thesis Summary}

This study used artifacts from the three $1 \times 1 \mathrm{~m}$ test units excavated between 2005 and 2007 at a Buck Lake (45PI438) Locus 4 activity area, in the northeast corner of MORA atop a mountain bench landform northeast of Mount Rainier at 5,400 ft ASL (Burtchard 2003:104; Burtchard 2007:19). The subalpine site has been interpreted as a residential base repeatedly used to exploit key upland faunal and floral resources such as elk and huckleberries during the late summer or early fall (Burtchard 2003:101, 112-113).

Buck Lake (45PI438) is within the Upper White River Basin (USGS 2009) in the southern Washington Cascades physiographic province $24 \mathrm{~km}$ west of the Cascade Range crest (Pringle 2008:6-7). Because of the treacherous mountain topography, the Mount Rainier area would have been a challenge to pass through, although east-west routes would have been available from the Northwest Coast and Plateau regions (Pringle 2008:6; Smith 2006:2). Igneous rock, primarily andesite, dominates the Buck Lake (45PI438) landscape (Pringle 2008:186-187).

Open forest conducive to optimal ungulate habitat would have been available in the Buck Lake area prior to the Hypsithermal Interval (7,800 to 4,500 B.P.); and, as defined by Burtchard (2003:39-43), during the Modern Interlude 2 (4,500 to 2,800 
B.P.), Burroughs Mountain Glacial Advance (2,800 to 2,100 B.P.), and Modern Interlude 3 (2,100 to 900 B.P.). Buck Lake inhabitants might have used fire to manage optimal habitat (Tweiten 2007:9). Important faunal resources for huntergatherers at Buck Lake include: ungulates, small mammals, and birds (Burtchard 2003:25, 27; Smith 2006:146, 147-148, 170-171, 173, Figure 7.2).

Both coastal and plateau groups likely used the Buck Lake area in protohistoric and historic times (Smith 2006:149). Buck Lake is within the Southern Plateau (Ames et al. 1998:104, Figure 1) and Southern Coast and Straight Coastline subregions of the Northwest Coast (Ames 2003:21, Figure 1). It is feasible that prehistoric groups from these areas used the Buck Lake vicinity for subsistence, especially if foraging habitat was more optimal (Burtchard 2003:41-42).

In 1980, Lewis Binford presented the forager-collector mobility model that categorized the world's present-day hunter-gatherers into two general types based on how they organized themselves to move about the landscape and exploit resources (Binford 1980:5). Foragers practice residential mobility and move their residence from resource patch to resource patch (Binford 1980:5). Collectors practice logistical mobility and send out specialized task groups to extract resources and return them to the residential base (Binford 1980:10). Researchers have recognized that the foragercollector model is not a simple dichotomy, but rather two opposite extremes with a number of factors that determine the strategies or combination of strategies they employ (Andrefksy 2005:212; Chatters 1987:337-338; Kelly 2007:117, 120; Kuhn 1995:26). 
The forager-collector mobility model is useful as a way to develop archaeological models and expectations to explore differences in hunter-gatherer resource acquisition strategies through time and across space (Ames 2000). The mobility model has been applied in the Pacific Northwest to develop temporal models that attempt to predict or explain the archaeological record in subalpine environments (e.g. Burtchard 1990; Burtchard 2007; Mierendorf 1986; Schalk 1988). Burtchard (2007:13-36) uses an ecological approach to model changes in hunter-gatherer settlement and subsistence strategies through time in MORA. Burtchard (2007:22) suggests that a more forager-like strategy shifted to a more collector-like strategy between 4,500 and 3,500 RCYBP.

Prehistoric hunter-gatherers are believed to have organized their technology in two general ways, which they sometimes combined, for planning purposes based on the mobility strategy employed (Nelson 1991:58, 62, 64-65). Curation involves the forethought of having prepared toolstone on-hand to counteract future conditions when materials and/or tool reduction and production time is not available when needed or the availability is unknown. An expedient strategy is used when future conditions conducive to the availability of needed materials and/or tool production and reduction time are known (Nelson 1991:62-64). In general, foragers are expected to use tools that are curated, and collectors are expected to use expedient tools (Andrefsky 2008:8), although there can be exceptions to this. A number of factors can influence the technological organization strategies employed regardless of mobility, including toolstone availability, quality, size, and shape (Andrefsky 1994a:21; 
Andrefsky 1994b:377); tool design to accommodate reliability, maintainability, and transportability (Nelson 1991:66); and site function (Nelson 1991:78-80, 82-84).

Based on the theoretical background presented above, the following technological organization expectations and results for the forager-like and collectorlike Buck Lake (45PI438) cultural components:

Expectation 1: Both foragers and collectors used portable, nonlocal CCS toolstone because of the relatively limited local availability and did not frequently use local igneous toolstone because of the coarse-grained nature. Nonlocal obsidian toolstone was also used infrequently.

Result: The majority (89.3-97.8\%) of toolstone was nonlocal CCS for both cultural components. Obsidian was not observed in either of the cultural component samples.

Expectation 2: Both foragers and collectors used light and small finished transported bifaces to increase portability. Because of an increased reliance on expedient flakes, collector bifaces might be slightly heavier and larger.

Result: Both cultural components debitage were very light (mean weight less than $.30 \mathrm{~g}$ ), very small (less than $10 \mathrm{~mm}$ size class and mean maximum flake length less than $13 \mathrm{~mm}$ ). The collector-like mean debitage weight is almost twice as heavy, 
with a mean weight of $.29 \mathrm{~g}$ compared with the $.16 \mathrm{~g}$ mean weight of the forager-like debitage. The collector-like debitage occurs in the larger diameter size classes and has a slightly longer (3.4 mm) mean maximum flake length.

Expectation 3: Both foragers and collectors used transported bifacial tools and performed late-stage bifacial reduction for resharpening and retouching tools.

Result: Forager-like cultural component flakes mean weight was not similar to experimental bifaces, although mean maximum flake length and striking platform width were comparable to stage three and four experimental bifaces. The mean weight, maximum flake length, and striking platform width of the collector-like flakes were comparable to those of stage three and four experimental bifaces. Mean DSC/WT ratios for both cultural components (17.05 to 20.30) are most similar to experimental bifacial hafting flakes (18.95) versus those of experimental cores (1.34). The high percentage of flakes from the forager- $(98.2 \%)$ and collector-like $(96.3 \%)$ components have no dorsal cortex, indicating that flakes from both components are the result of late reduction stages. The mean maximum flake thickness for the collectorlike cultural component is similar to experimental biface resharpening flakes. The percentage of cortical and flat platform types for the forager-like cultural component are similar to the platform types of experimental biface resharpening flakes; whereas the percentage of flat platform types for the collector-like cultural component are similar to platform types of experimental biface production flakes. 
Expectation 4: Collectors used transported bifaces and middle-stage bifacial production to produce expedient flakes, and used expedient flakes more frequently.

Result: The expectation that the collector-like component will have a higher frequency of middle stage bifacial production for producing expedient flakes than the forager-like cultural component is not fully supported by the results of this study. The mean maximum flake thicknesses for the collector-like cultural components are similar to experimental biface resharpening flakes. The percentage of flat platform types for the collector-like cultural component is similar to platform types of experimental biface production flakes. The collector-like cultural component has a small percentage of flakes in the greater than $25 \mathrm{~mm}$ size classes, whereas the foragerlike component has none.

Expectation 5: Both foragers and collectors did not frequently use blade and bipolar core technologies.

Result: Both the forager-like and collector-like cultural components have low percentages of flakes that fall within what is considered to be a unidirectional core group presumed to represent blade cores for the present study samples. The foragerlike cultural component has a high percentage of debris and low percentage of flakes similar to what has been found for experimental bipolar technology. Foragers could have been using bipolar techniques on exhausted bifaces or other artifacts to conserve 
transported nonlocal toolstone. The collector-like cultural component has a low percentage of debris and high percentage of flakes when compared with experimental bipolar technology. The collector-like cultural component has a low percentage of debris and high percentage of flakes unlike that of experimental bipolar technology.

This study used a sample of greater than $1 / 8$ inch $(3 \mathrm{~mm})$ lithic debitage from TUs 1-3 excavated between 2005 and 2007 as a source of data to investigate technological organization strategies through time at a Buck Lake activity area. Lithic debitage from the pre-MSH Yn tephra represented forager-like cultural components, whereas the post-MSH Yn tephra lithic debitage will represented the collector-like cultural components.

The lithic debitage analysis consisted of methods that are replicable and can be confidently measured by novice analyzers with some lithic analysis training (Andrefsky 2005:98; Bradbury and Carr 2004:69-70; Odell 2004:124, 126, 128; Prentiss 2001:158). Statistical methods were used to determine if results were significant. A summary of the methods, expectations, and results of this study can be found in Tables 16 and 17.

\subsection{Conclusions}

It has been suggested that ongoing MORA archaeological research should investigate changes in technological organization through time with larger samples and chronological control (Burtchard 2003:92). The purpose of this study was to 
investigate changes in hunter-gatherer technological organization through time at a subalpine prehistoric archaeological site in MORA using lithic analysis. Radiocarbon dates and tephra layers provided temporal control.

Only lithic debitage was analyzed for this study using replicable interpretationfree typology, individual attribute, and free-standing typology methods that could be used by a novice lithic analyst. As mentioned in Chapter Two, there were problems identifying points of applied force and ambiguous flake characteristics during the analysis that might have affected the results of the debitage interpretation-free typology. As a result, there could be a greater number of flake fragments versus complete or broken flakes and debris identified. In the future, the interpretation-free typology definitions should be reconsidered to accommodate the small and thin debitage and types of toolstone recovered at Buck Lake (45PI438).

Analysis results were used to test technological organization expectations by making inferences about the use of local and nonlocal toolstone, the use of bifacial production and reduction, lithic reduction and production stages, debitage size as it relates to portability, the use of expedient flakes, and to explore the use of bipolar and blade core technologies. Overall, the results of the lithic debitage analysis were mixed when compared to the technological organization expectations. Hunter-gatherers at Buck Lake heavily relied on nonlocal CCS raw material for their stone tool technology. The locally available igneous raw material apparently was not of a high enough knapping quality to be used for the tools associated with hunting and processing ungulates in the subalpine zone. The nonlocal CCS had to be transported 
from distances up to $56 \mathrm{~km}$ away and was reduced into small and light tools for the arduous journey from toolstone source to the subalpine areas at high elevations where they were used. These small and light tools were maintained in the subalpine areas after use resulting in the deposition of small and light debitage at Buck Lake. Collectors during the Late Holocene relied more on the reduction of heavier and larger tools to produce expedient flakes for hunting and processing smaller game when ungulate populations were reduced.

A majority of the analysis results support the expectation that both the foragerand collector-like cultural components would have a high occurrence of evidence for the use of bifacial tools and late stage bifacial reduction from resharpening and retouch. Only the weight of the forager-like component debitage was dissimilar to the weight of experimental bifaces. It is clear that hunter-gatherers at Buck Lake used late stage bifacial tools. Collectors produced a higher fraction of biface production flakes rather than just resharpening flakes. The production flakes were most likely used as expedient flakes.

The use of blade core and bipolar technology is not completely clear. My sample suggested that hunter-gatherers at Buck Lake did not rely on blade core technology. However, as Greg Burtchard (personal communication 2010) points out, "subsequent excavation at Buck Lake (45PI438) produced a higher fraction of large blades in the immediate vicinity of hearths dating to ca. 3500 RCYBP.” Greg Burtchard (personal communication 2010) also points out, as mentioned in Chapter One, "[A] core was also found in pre-Mazama sediments dating to ca. 6750 RCYBP. 
A clearer picture of blade use at Buck Lake (45PI438) awaits the results of continuing research at the site."

Whether or not hunter-gatherers at Buck Lake used bipolar technology is uncertain. Evidence shows that the forager-like cultural component has the same amount of debris and flakes as those resulting from experimental bipolar core reduction. The collector-like cultural component, on the other hand, has little evidence supporting a heavy reliance on bipolar technology. This unexpected result could be from the differences in raw material between the Buck Lake and the experimental bipolar collections. It's also possible that foragers could have been using bipolar techniques on exhausted bifaces or other artifacts to conserve transported nonlocal toolstone.

Several prehistoric sites have been excavated in the Upper White River Basin (Figure 5) and provide a means to compare and contrast with the results of this study (Table 1). Archaeological excavations at the Helipad, Berkeley Park Rockshelter (45PI303), Sunrise Ridge Borrow Pit (45PI408), Tipsoo Lakes (45PI406), and Fryingpan Rockshelter (45PI403) sites all resulted in the recovery of mainly late stage CCS debitage similar to Buck Lake (45PI438). These sites span 300 to 5,000 years BP. Similar to Buck Lake (45PI438), the Helipad site has evidence for transported preforms and finished tools. As mentioned previously in Chapter One, Fryingpan Rockshelter (45PI043) has evidence of blades which is not noticeably present at Buck Lake (45PI438). Berkeley Park Rockshelter (45PI303) has evidence of bipolar technology, which is also possible at Buck Lake (45PI438). It's possible that the 
similarities between Buck Lake (45PI438) and these other Upper White River Basin sites could be the result of coping with similar toolstone procurement, seasonality, and terrain constraints. It's worth noting that these sites have all been interpreted as residential bases, except Fryingpan Rockshelter (45PI403) and Berkeley Park Rockshelter (45PI303) which have been interpreted as specialized hunting camps. Overlapping site function can also account for the similarities between Buck Lake and other Upper White River Basin sites.

The study presented here is only preliminary. It does seem clear, though, that toolstone procurement, seasonality, and terrain constraints, along with a common resource acquisition goal and overlapping site function, greatly influence the technological organization archaeological signatures of all the Buck Lake inhabitants through time regardless of the differences in mobility modeled for MORA. Further research at Buck Lake should continue to investigate the technological organization of hunter-gatherers who used the site through time.

Recommendations for Further Research. A number of research studies will expand what has been presented here. First, the sourcing of raw material used at the Buck Lake site will determine what is indeed local and nonlocal toolstone. At this point, local and nonlocal toolstone has not been verified in the field. Second, the experimental lithic reduction of Buck Lake toolstone across a broad array of technological methods (e.g. bifacial, bipolar, blade, and core) will produce a comparative collection to determine what lithic technology was used at Buck Lake. Based on the results of this study, bipolar reduction and different stages of bifacial 
reduction and production would be especially insightful. Finally, future analysis should include the lithic artifacts recovered from the 2008 to 2009 excavations at Buck Lake. This could include not only debitage, but cores, flake tools, and bifacial tools which would provide further technological organization evidence. The analysis of cores could provide direct evidence for the use of bipolar and core technology. The analysis of flake tools could provide evidence for expedient technology. Retouch index studies of bifacial tools could be used to investigate tool curation. All of these recommended studies would broaden the knowledge of hunter-gatherer use of subalpine environments in the Pacific Northwest and MORA. 


\section{REFERENCES CITED}

Ames, Kenneth M.

2000 Cultural Affiliation Report, Chapter 2: Review of the Archaeological Data.

Report prepared for the National Park Service. Electronic document,

http://www.nps.gov/archeology/kennewick/AMES.htm, accessed June 11, 2009.

2003 The Northwest Coast. Evolutionary Anthropology 12:19-33.

Ames, Kenneth M., Don E. Dummond, Jerry R. Galm, and Rick Minor

1998 Prehistory of the Southern Plateau. Handbook of North American Indians

Vol. 9, The Plateau. Smithsonian Institute Press, Washington D.C.

Andrefsky, William, Jr.

1994a Raw-Material Availability and the Organization of Technology. American Antiquity 59:21-34.

1994b The Geological Occurrence of Lithic Material and Stone Tool Production Strategies. Geoarchaeology. An International Journal 9:345-362.

2005 Lithics: Macroscopic Approaches to Analysis. 2nd ed. Series edited by

Graeme Barker. Cambridge Manuals in Archaeology. Cambridge University

Press, New York.

2008 An Introduction to Stone Tool Life History and Technological Organization.

In Lithic Technology: Measures of Production, Use, and Curation, edited by

William Andrefsky, Jr., pp. 3-22. Cambridge University Press, New York.

Andrews, Bradford W., Hannah L. Tofte, and David R. Huelsbeck

2008 The Helipad Lithic Assemblage: Behavioral Implications and Occupational

Trends in the Southern Washington Cascades. Archaeology in Washington $14: 36-58$

Bacon, Charles R.

1983 Eruptive History of Mount Mazama and Crater Lake Caldera, Cascade

Range, U.S.A. Journal of Volcanology and Geothermal Research 18:57-115.

Baxter, Paul W.

1986 Archaic Upland Adaptations in the Central Oregon Cascades. Unpublished

Ph.D. dissertation, Department of Anthropology, University of Oregon, Eugene. 
Beck, R. Kelly

2008 Transport Distance and Debitage Assemblage Diversity: An Application of the Field Processing Model to Southern Utah Toolstone Procurement Sites. American Antiquity 73(4):759-780.

Bergland, Eric O.

1988 Archaeological Test Excavations at the Berkeley Rockshelter Site (45-PI303), Mount Rainier National Park, Washington. SRD Report of Investigations No. 1. Prepared for U.S. Department of Interior, National Park Service, Pacific Northwest Region, Seattle. Sidda Research and Development. Eugene, Oregon.

Binford, Lewis R.

1979 Organization and Formation Processes: Looking at Curated Technologies. Journal of Anthropological Research 35(3):255-273.

1980 Willow Smoke and Dogs' Tails: Hunter-Gatherer Settlement Systems and Archaeological Site Formation. American Antiquity 45:4-20.

2001 Constructing Frames of Reference: An Analytical Method for Archaeological Theory Building Using Hunter-Gatherer and Environmental Data Sets. University of California Press, Berkeley.

Bradbury, Andrew P., and Phillip J. Carr

1999 Examining Stage and Continuum Models of Flake Debris Analysis: An Experimental Approach. Journal of Archaeological Science 26:105-116.

2004 Combining Aggregate and Individual Methods of Flake Debris Analysis: Aggregate Trend Analysis. North American Archaeologist 25(1):65-90.

Burtchard, Greg C.

1990 The Posy Archaeological Project, Upland Use of the Central Cascades, Mt. Hood National Forest, Oregon. Prepared for the USDA Forest Service, Mt. Hood National Forest, Gresham, Oregon. Laboratory of Archaeology and Anthropology, Portland State University. Portland, Oregon.

2003 Environment, Prehistory \& Archaeology of Mount Rainier National Park, Washington. Reprinted. Originally published 1998, National Park Service, Seattle Washington. International Archaeological Research Institute, Inc., Honolulu, Hawai' i. Prepared for United States Department of the Interior, National Park Service, Columbia Cascades Support Office, Seattle, Washington. Copies available at the Mount Rainier National Park library, Longmire, Washington. 
2006 Buck Lake Archaeological and Paleoenvironmental Project Completion Report. Mount Rainier National Park, National Park Service.

2007 Holocene Subsistence and Settlement Patterns: Mount Rainier and the Montane Pacific Northwest. Archaeology in Washington 13:3-44.

Burtchard, Greg and Glen Lindeman (editors) 2006 Ethnography of Mount Rainier National Park, Takhoma. Washington State University Press, Pullman.

Burtchard, Greg C. and Christian J. Miss (editors) 1998 Identification and Evaluation of Heritage Resources on National Forest Parcels of the I-90 Land Exchange Project, Wenatchee, Mt. Baker-Snoqualmie and Gifford Pinchot National Forests, Washington. Northwest Archaeological Associates, Inc., Seattle, Washington and International Archaeological Research Institute, Inc., Honolulu, Hawai i. Prepared for Plum Creek Timber Company, L.P., Seattle Washington and Wenatchee, Mt. Baker-Snoqualmie and Gifford Pinchot National Forests, Washington.

Carr, Phillip J., and Andrew P. Bradbury

2001 Flake Debris Analysis, Levels of Production, and the Organization of Technology. In Lithic Debitage: Context, Form, Meaning, edited by William Andrefsky, Jr., pp. 126-146. University of Utah Press, Salt Lake City.

Centola, Lisa

2004 Deconstructing Lithic Technology: A Study from the Birch Creek Site (35ML181), Southeastern Oregon. Unpublished Master's thesis, Department of Anthropology, Washington State University, Pullman.

Chatters, James C.

1987 Hunter-Gatherer Adaptations and Assemblage Structure. Journal of Anthropological Archaeology 6(4):336-375.

2004 Safety in Numbers: The Influence of the Bow and Arrow on Village Formation on the Columbia Plateau. In Complex Hunter-Gatherers: Evolution and Organization of Prehistoric Communities on the Plateau of Northwestern North America, edited by William C. Prentiss and Ian Kujit, pp. 67-83. University of Utah Press, Salt Lake City.

Dampf, Steven K.

2002 The Sunrise Ridge Borrow Pit Site (45PI408): Subsurface Reconnaissance for a Significance Evaluation. Unpublished Master's thesis, Department of Anthropology, Central Washington University, Ellensburg. 
Eerkens, Jelmer W., Jeffrey R. Ferguson, Michael D. Glascock, Craig E. Skinner, and Sharon A. Waechter

2007 Reduction Strategies and Geochemical Characterization of Lithic

Assemblages: A Comparison of Three Case Studies from Western North

America. American Antiquity 72(3):585-597.

Fletcher, Mike and Gary R. Lock

2006 Digging Numbers: Elementary Statistics for Archaeologists. 2nd ed. Oxford

University School of Archaeology Monograph 33. Oxford University School of

Archaeology, Institute of Archaeology, Oxford.

Franklin, Jerry F. and C.T. Dyrness

1973 Natural Vegetation of Oregon and Washington. USDA Forest Service

General Technical Report PNW-8. Pacific Northwest Forest and Range

Experiment Station. Portland, Oregon.

Green, Samuel B. and Neil J. Salkind

2005 Using SPSS for Windows and Macintosh: Analyzing and Understanding Data.

4th ed. Pearson Prentice Hall, Upper Saddle River, New Jersey.

Hayden, Brian, Nora Franco, and Jim Spafford

1996 Evaluating Lithic Strategies and Design Criteria. In Stone Tools: Theoretical

Insights into Human Prehistory, edited by George H. Odell, pp. 9-45.

Interdisciplinary Contributions to Archaeology, Plenum Press, New York.

Jeske, Robert J. and Rochelle Lurie

1993 The Archaeological Visibility of Bipolar Technology: An Example from the

Koster Site. Midcontinental Journal of Archaeology 18:131-160.

Kelly, Robert L.

1992 Mobility/Sedentism: Concepts, Archaeological Measures, and Effects.

Annual Review of Anthropology 21: 43-66.

2001 Prehistory of the Carson Desert and Stillwater Mountains: Environment, Mobility, and Subsistence in a Great Basin Wetland. Univeristy of Utah Anthropological Papers Number 123, The University of Utah Press, Salt Lake City.

2007 The Foraging Spectrum: Diversity in Hunter-Gatherer Lifeways. Revised version. Percheron Press, Clinton Corners, New York. 
Kerwin, John

1999 Salmon Habitat Limiting Factors Report for the Puyallup River Basin (Water Resource Inventory Area 10). Electronic document, http://your.kingcounty.gov/dnrp/library/archive-documents/wlr/wrias/10/salmonhabitat-limiting-factors/pdf/wria-10-salmon-habitat-limiting-factors.pdf, accessed March 15, 2010.

Kooyman, Brian P.

2001 Understanding Stone Tools and Archaeological Sites. Reprinted. University of New Mexico Press, Albuquerque. Originally published 2000, University of Calgary Press, Alberta, Canada.

Kuhn, Steven L.

1994 A Formal Approach to the Design and Assembly of Mobile Toolkits. American Antiquity 59(3):426-442.

1995 Mousterian Lithic Technology: An Ecological Perspective. Princeton University Press, Princeton.

Lubinski, Patrick M. and Greg C. Burtchard 2005 Fryingpan Rockshelter (45PI43): A Subapline Fauna in Mount Rainier National Park. Archaeology in Washington 11:35-52.

MacDonald, Douglas H.

2008 The Role of Lithic Raw Material Availability and Quality in Determining

Tool Kit Size, Tool Function, and Degree of Retouch: A Case Study from Skink Rockshelter (46NI445), West Virginia. In Lithic Technology: Measures of

Production, Use, and Curation, edited by William Andrefsky, Jr., pp. 216-232. Cambridge University Press, New York.

Mack, Cheryl A.

1989 Prehistoric Upland Occupations in the Southern Washington Cascades.

Archaeology in Washington 1:49-57.

Magne, Martin P.R.

1985 Lithics and Livelihood: Stone Tool Technologies of Central and Southern Interior British Columbia. Archaeological Survey of Canada, Mercury Series, Paper no. 133. National Museum of Man, Ottawa.

Mauldin, Raymond P., and Daniel S. Amick

1989 Investigating Patterning in Debitage from Experimental Bifacial Core

Reduction. In Experiments in Lithic Technology, edited by Daniel S. Amick and Raymond P. Mauldin, pp. 67-88. BAR International Series 528. BAR, Oxford, England. 
McClure, Richard H., Jr.

1989 Alpine Obsidian Procurement in the Southern Washington Cascades:

Preliminary Research. Archaeology in Washington 1:59-69.

Mierendorf, Robert R.

1986 People of the North Cascades. National Park Service, Pacific Northwest

Region. University of Washington Press, Seattle.

Mierendorf, Robert R., David J. Harry, and Gregg M. Sullivan 1998 An Archaeological Site Survey and Evaluation in the Upper Skagit River

Valley, Whatcom County, Washington. National Park Service, Sedro-Woolley, Washington.

Mierendorf, Robert R., Franklin F. Foit, Jr., and Monika Nill

2006 Earth, Wind, Fire, and Stone at Cascade Pass. Paper presented at the 59th

Annual Northwest Anthropology Conference, Seattle, Washington.

Morgan, Christopher

2008 Reconstructing Prehistoric Hunter-Gatherer Foraging Radii: A Case Study from California's Southern Sierra Nevada. Journal of Archaeological Science $35: 247-258$.

Mullineaux, Donal R. 1974 Pumice and Other Pyroclastic Deposits in Mount Rainier National Park, Washington. United States Department of the Interior, Geological Survey Bulletin1326. U.S. Government Printing Office, Washington, D.C.

Nelson, Margaret C.

1991 The Study of Technological Organization. In Archaeological Method and

Theory, Vol. 3, edited by Michael B. Schiffer, pp. 57-100. University of Arizona Press, Tucson.

Nickels, Adam M.

2002 History Under Fire: Understanding Human Fire Modification of the Landscapes at Mount Rainier National Park. Unpublished Master's thesis, Department of Anthropology, Central Washington University, Ellensburg.

Northwest Research Obsidian Studies Laboratory 2009a 2008 Annual Laboratory Grant Recipients, Kevin Vaughn. Electronic document, http://www.obsidianlab.com/grant_list.html, accessed July 2, 2009.

2009b Washington Obsidian Sources Map. Electronic document, http://www.obsidianlab.com/image_maps/map_obsidian_washington.pdf, accessed March 18, 2009. 
Odell, George H.

1989 Experiments in Lithic Reduction. In Experiments in Lithic Technology, edited by Daniel S. Amick and Raymond P. Mauldin, pp. 163-198. BAR International Series 528. BAR, Oxford, England.

2001 Stone Tool Research at the End of the Millenium: Classification, Function, and Behavior. Journal of Archaeological Research 9(1):45-98.

2004 Lithic Analysis. Series edited by Charles E. Orser, Jr. and Michael B.

Schiffer. Manuals in Archaeological Method, Theory, and Technique. Springer, New York.

Prentiss, William C.

2001 Reliability and Validity of a "Distinctive Assemblage" Typology: Integrating Flake Size and Completeness. In Lithic Debitage: Context, Form, Meaning, edited by William Andrefsky, Jr., pp. 147-172. University of Utah Press, Salt Lake City.

Prentiss, Anna Marie and David S. Clarke

2008 Lithic Technological Organization in an Evolutionary Framework: Examples from North America's Pacific Northwest Region. In Lithic Technology:

Measures of Production, Use, and Curation, edited by William Andrefsky, Jr., pp. 257-285. Cambridge University Press, New York.

Pringle, Patrick T.

2008 Roadside Geology of Mount Rainier National Park and Vicinity. Washington Division of Geology and Earth Resources, Information Circular 107.

Rafferty, Janet E.

1985 The Archaeological Record of Sedentariness: Recognition, Development, and Implications. Advances in Archaeological Method and Theory. 8:113-156.

Rasic, Jeffrey and William Andrefsky Jr.

2001 Alaskan Blade Cores as Specialized Components of Mobile Toolkits:

Assessing Design Parameters and Toolkit Organization Through Debitage Analysis. In Lithic Debitage: Context, Form, Meaning, edited by William Andrefsky, Jr., pp. 61-79. University of Utah Press, Salt Lake City.

Reimer, Rudy

2000 Extreme Archaeology: The Results of Investigations at High Elevation Regions in the Northwest. Unpublished Master's thesis, Department of Archaeology, Simon Fraser University, Burnaby, B.C. 
Rice, David G.

1965 Archaeological Test Excavations in Fryingpan Rockshelter, Mount Rainier National Park. Washington State University Laboratory of Anthropology Report of Investigations No. 33. Pullman. Manuscript on file at Mount Rainer National Park library in Longmire.

Schalk, Randall

1988 The Evolution and Diversification of Native Landuse Systems on the Olympic Peninsula. National Park Service, Pacific Northwest Region. Institute for Environmental Studies.

Schalk, Randall F. and Greg Cleveland

1983 Cultural Resource Investigations for the Lyons Fish Hatchery, Lyons Ferry,

Washington, edited by Randall F.Schalk. Laboratory of Archaeology and History, Project Report No. 8. Washington State University, Pullman, Washington.

Schalk, Randall F., Ricky G. Atwell, Robert U. Bryson, Clayton G. Lebow, Nancy D. Sharp, Craig Skinner, and Andrew J. Bailey

1994 Archaeological Investigations PGT-PG\&E Pipeline Expansion Project Idaho, Washington, Oregon, and California, edited by Michael J. Moratto. INFOTECH Research, Inc., Davis, California. Submitted to Pacific Gas Transmission Company, Portland, Oregon.

Schasse, Henry W.

1987 Geologic Map of the Mount Rainier Quadrangle, Washington. Washington

Division of Geology and Earth Resources, Open File Report 87-16.

Schuster, J. Eric

2005 Geologic Map of Washington State. Washington Division of Geology and Earth Resources, Geologic Map GM-53.

Shott, Michael J.

1986 Technological Organization and Settlement Mobility: An Ethnographic

Examination. Journal of Anthropological Research. 42(1):15-51.

Sievert, April K. and Karen Wise

2001 A Generalized Technology for a Specialized Economy: Archaic Period Chipped Stone at Kilometer 4, Peru. In Lithic Debitage: Context, Form, Meaning, edited by William Andrefsky, Jr., pp. 80-105. University of Utah Press, Salt Lake City.

Skinner, Milton P. 1936 The Roosevelt Elk of the Olympic Peninsula. The Murrelet 17(2-3):30-35. 
Smith, Allan $\mathrm{H}$.

2006 Ethnography of Mount Rainier National Park, Takhoma. Washington State University Press, Pullman.

Smith, Nicholas James

2003 Toward a Scientific Approach to Significance Assessments of Prehistoric Archaeological Properties at Mount Rainier National Park. Unpublished Master's thesis, Department of Resource Management Central Washington University, Ellensburg, Washington.

Snyder, Sandra

1987 Prehistoric Land Use Patterns in the Central Oregon Cascade Range.

Unpublished Ph.D. dissertation, Department of Anthropology, University of Oregon, Eugene.

State of Oregon Parks and Recreation Department State Historic Preservation Office 2007 Guidelines for Conducting Field Archaeology in Oregon, April 2007.

Electronic document, http://www.oregon.gov/OPRD/HCD/ARCH/docs/draft_ field_guidelines.pdf, accessed March 25, 2009.

Sullivan, Alan P., III, and Kenneth C. Rozen

1985 Debitage Analysis and Archaeological Interpretation. American Antiquity 50:755-779.

Taylor, Walter P. and William T. Shaw 1927 Mammals and Birds of Mount Rainier National Park. United States Department of the Interior National Park Service. Washington, D.C.

Tofte, Hannah L.

2009 Berkeley Park Flakes: Inferring Prehistoric Technology, Subsistence, and Settlement on Mount Rainier. Paper presented at the 62nd Annual Northwest Anthropological Conference, Newport, Oregon.

Tomka, Steven A.

2001 The Effect of Processing Requirements on Reduction Stages and Tool Form:

A New Perspective. In Lithic Debitage: Context, Form, Meaning, edited by William Andrefsky, Jr., pp. 207-223. University of Utah Press, Salt Lake City. 
Tweiten, Michael A.

2007 The Interaction of Changing Patterns of Land Use, Sub-Alpine Composition and Fire Regime at Buck Lake, Mount Rainier National Park, USA. National Park Service, Seattle Washington. International Archaeological Research Institute, Inc., Honolulu, Hawai 'i. Prepared for United States Department of the Interior, National Park Service, Columbia Cascades Support Office, Seattle, Washington. Copies available at the Mount Rainier National Park Natural and Cultural Resource Division Offices, Longmire, Washington.

USGS Washington Water Science Center 2009 Upper White River Basin Study Area Map. Electronic document, http://wa.water.usgs.gov/projects/whiteriver/maps.htm, accessed Feburay 24, 2009.

Vaughn, Kevin, Todd Volkenand, and Patrick McCutcheon 2007 Technological \& Functional Variability in the Sunrise Ridge Borrow Pit (45PI408) Lithics. Paper presented at the 60th Annual Northwest Anthropology Conference, Pullman, Washington.

Vaughn, Kevin and Patrick McCutcheon 2008 Lithic Variability in Upland Sites in Mt Rainier National Park - Washington. Poster presented at the 73rd Annual Meeting of the Society for American Archaeology, Vancouver.

Walsh, Megan K., Cathy Whitlock, and Patrick J. Bartlein 2008 A 14,300-year-long Record of Fire-Vegetation-Climate Linkages at Battle Ground Lake, Southwestern Washington. Quaternary Research 70:251-264.

Whittaker, John C.

1997 Flintknapping: Making and Understanding Stone Tools. University of Texas Press, Austin.

Willis, Samuel C.

2005 Late Pleistocene Lithic Technological Organization on the Southern Oregon Coast: Investigations at Indian Sands (35-CU-67C). Unpublished Master's thesis, Department of Anthropology, Oregon State University, Corvallis.

Wilson, Jennifer and William Andrefsky, Jr.

2008 Exploring Retouch on Bifaces: Unpacking Production, Resharpening, and Hammer Type. In Lithic Technology: Measures of Production, Use, and Curation, edited by William Andrefsky, Jr., pp. 86-105. Cambridge University Press, New York. 
Wilson, Lucy

2007 Terrain Difficulty as a Factor in Raw Material Procurement in the Middle Paleolithic France. Journal of Field Archaeology 32:315-324.

Zobel, Donald B. and Joseph A. Antos 1997 A Decade of Recovery of Understory Vegetation Buried by Volcanic Tephra from Mount St. Helens. Ecological Monographs 67(3):317-344.

Zweifel, Matthew K. and Connie S. Reid 1991 Prehistoric Use of the Central Cascade Mountains of Eastern Washington State: An Overview of Site Types and Potential Resource Utilization. Archaeology in Washington 3:3-16. 
APPENDIX A

LITHIC DEBITAGE ANALYSIS DATA ENTRY CODES 


\begin{tabular}{|c|c|c|}
\hline Field & Code & Description \\
\hline Artifact Number (A\#) & & $\begin{array}{l}\text { Each debitage specimen was assigned an artifact } \\
\text { number in sequential order as it was analyzed. }\end{array}$ \\
\hline Inventory Number (I\#) & & $\begin{array}{l}\text { Each debitage specimen was assigned an inventory } \\
\text { number based on provenience separated by a } \\
\text { period: test unit.level.feature number. }\end{array}$ \\
\hline Weight (WT) & & Each debitage specimen was weighed to $.01 \mathrm{~g}$. \\
\hline \multirow[t]{5}{*}{ Object Type (OT) } & & $\begin{array}{l}\text { Each debitage specimen was placed into an object } \\
\text { type category following Sullivan and Rozen } \\
\text { (1985:758-759, Figure 2). }\end{array}$ \\
\hline & $\mathrm{d}$ & Debris \\
\hline & $\mathrm{f}$ & Flake fragment \\
\hline & $\mathrm{b}$ & Broken flake \\
\hline & $\mathrm{c}$ & Complete flake \\
\hline \multirow[t]{3}{*}{ Flake Termination $(\mathrm{T})$} & & $\begin{array}{l}\text { Flake termination was determined for broken and } \\
\text { complete flakes following Andrefsky (2005:87- } \\
\text { 88). }\end{array}$ \\
\hline & $\mathrm{s}$ & Step \\
\hline & o & Other (feathered, hinged, plunging) \\
\hline \multirow[t]{13}{*}{ Diameter Size Class (S) } & & $\begin{array}{l}\text { Each debitage specimen was placed into a } \\
\text { numbered diameter size class (1-12) using } 5 \mathrm{~mm} \\
\text { increment circles from 5-65 mm diameter } \\
\text { following Andrefsky (2005:102). }\end{array}$ \\
\hline & 1 & $<10 \mathrm{~mm}$ \\
\hline & 2 & 10 to $<15 \mathrm{~mm}$ \\
\hline & 3 & 15 to $<20 \mathrm{~mm}$ \\
\hline & 4 & 20 to $<25 \mathrm{~mm}$ \\
\hline & 5 & 25 to $<30 \mathrm{~mm}$ \\
\hline & 6 & 30 to $<35 \mathrm{~mm}$ \\
\hline & 7 & 35 to $<40 \mathrm{~mm}$ \\
\hline & 8 & 40 to $<45 \mathrm{~mm}$ \\
\hline & 9 & 45 to $<50 \mathrm{~mm}$ \\
\hline & 10 & 50 to $<55 \mathrm{~mm}$ \\
\hline & 11 & 55 to $<60 \mathrm{~mm}$ \\
\hline & 12 & 60 to $<65 \mathrm{~mm}$ \\
\hline \multirow[t]{6}{*}{ Platform Type (PT) } & & $\begin{array}{l}\text { Platform type was determined for broken and } \\
\text { complete flakes using a nominal scale following } \\
\text { Andrefsky (2005:94-97, Figure 5.6). }\end{array}$ \\
\hline & $\mathrm{c}$ & Cortical \\
\hline & $\mathrm{f}$ & Flat \\
\hline & $\mathrm{cx}$ & Complex \\
\hline & $\mathrm{a}$ & Abraded \\
\hline & $\mathrm{u}$ & Unknown \\
\hline
\end{tabular}




\begin{tabular}{|c|c|c|}
\hline \multirow[t]{4}{*}{ Platform Facet Count (PFC) } & & $\begin{array}{l}\text { Greater than } 2 \mathrm{~mm} \text { platform facets were counted } \\
\text { on broken and complete flakes using an ordinal } \\
\text { scale following Bradbury and Carr (2004:69, } 72 \text {, } \\
86 \text { ). }\end{array}$ \\
\hline & 0 & No facets \\
\hline & 1 & One facet \\
\hline & 2 & Two or more facets \\
\hline \multirow[t]{5}{*}{ Dorsal Flake Scar Count (DFSC) } & & $\begin{array}{l}\text { Dorsal flake scars were counted on broken and } \\
\text { complete flakes using an ordinal scale following } \\
\text { Andrefsky (2005:109). }\end{array}$ \\
\hline & 0 & Flakes with no flakes removed. \\
\hline & 1 & Flakes with one flake removed. \\
\hline & 2 & Flakes with two flakes removed. \\
\hline & 3 & Flakes with two or more flakes removed. \\
\hline \multirow[t]{5}{*}{ Dorsal Cortex Percentage (DC) } & & $\begin{array}{l}\text { Dorsal cortex percentage was determined on flake } \\
\text { fragments, broken flakes, and complete flakes } \\
\text { using an ordinal scale following Andrefsky } \\
\text { (2005:105-107, Figure 5.12). }\end{array}$ \\
\hline & 0 & $0 \%$ dorsal surface coverage \\
\hline & 1 & $\leq 50 \%,>0 \%$ dorsal surface coverage \\
\hline & 2 & $<100 \%,>50 \%$ dorsal surface coverage \\
\hline & 3 & $100 \%$ dorsal surface coverage \\
\hline Striking Platform Width (PW) & & $\begin{array}{l}\text { Platform width was measured on broken and } \\
\text { complete flakes in greater than } 10 \mathrm{~mm} \text { size classes } \\
\text { to } .01 \mathrm{~mm} \text { following Andrefsky }(2005: 94) \text {. }\end{array}$ \\
\hline Maximum Flake Length (ML) & & $\begin{array}{l}\text { Maximum flake length was measured on broken } \\
\text { and complete flakes to } .01 \mathrm{~mm} \text { following } \\
\text { Andrefsky }(2005: 99 \text {, Figure } 5.8[\mathrm{c}]) \text {. }\end{array}$ \\
\hline Maximum Flake Thickness (MT) & & $\begin{array}{l}\text { Maximum flake thickness was measured on } \\
\text { broken and complete flakes to } .01 \mathrm{~mm} \text { following } \\
\text { Andrefsky (2005:101, Figure 5.9f). }\end{array}$ \\
\hline \multirow[t]{13}{*}{ Raw Material Specific (RMS) } & & $\begin{array}{l}\text { The specific raw material type was determined for } \\
\text { each debitage specimen following Burtchard } \\
\text { 2003:205 and the 2006 MORA/JODA Lithic } \\
\text { Characterization Metadata and Field Metadata }\end{array}$ \\
\hline & $\mathrm{r}$ & Red-mottled chert \\
\hline & $\mathrm{y}$ & Yellow chert \\
\hline & $\mathrm{w}$ & White chert \\
\hline & g & Light gray-lavender chert \\
\hline & $\mathrm{b}$ & Dark gray-black chert \\
\hline & $\mathrm{t}$ & Tan/brown-mottled brown chert \\
\hline & oc & Other chert \\
\hline & $\mathrm{c}$ & Chalcedony \\
\hline & $\mathrm{ob}$ & Obsidian \\
\hline & $\mathrm{a}$ & Andesite \\
\hline & $\mathrm{i}$ & Fine-grained igneous \\
\hline & $\mathrm{o}$ & Other \\
\hline
\end{tabular}




\begin{tabular}{|l|l|l|}
\hline Raw Material General (RMG) & & $\begin{array}{l}\text { The general raw material type was determined for } \\
\text { each debitage specimen. }\end{array}$ \\
\hline & CCS & Cryptocrystalline silicate material \\
\hline & Igneous & Fine-grained igneous material \\
\hline
\end{tabular}


APPENDIX B

LITHIC DEBITAGE ANALYSIS DATA TABLE 


\begin{tabular}{|c|c|c|c|c|c|c|c|c|c|c|c|c|c|}
\hline A\# & I\# & WT & OT & \begin{tabular}{|l|l|}
$\mathbf{T}$ & $\mathbf{S}$ \\
\end{tabular} & PT & PFC & DFSC & DC & PW & ML & MT & RMS & RMG \\
\hline 1 & 1.06 & 0.40 & $\mathrm{f}$ & -3 & - & - & - & 0 & - & - & - & c & $\mathrm{CCS}$ \\
\hline 2 & 1.06 & 0.23 & c & \begin{tabular}{|l|l|} 
o & 2 \\
\end{tabular} & $\mathrm{cx}$ & 2 & 3 & 0 & 11.02 & 7.37 & 3.68 & $\mathrm{c}$ & CCS \\
\hline 3 & 1.06 & 0.29 & $\mathrm{f}$ & -4 & - & - & - & 0 & - & - & - & c & CCS \\
\hline 4 & 1.06 & 0.00 & d & -1 & - & - & - & - & - & - & - & c & CCS \\
\hline 5 & 1.06 & 0.10 & $\mathrm{f}$ & -2 & - & - & - & 1 & - & - & - & c & CCS \\
\hline 6 & 1.06 & 0.00 & $\mathrm{f}$ & -2 & - & - & - & 0 & - & - & - & c & CCS \\
\hline 7 & 1.06 & 0.00 & c & \begin{tabular}{l|l} 
o & 1 \\
\end{tabular} & $\mathrm{f}$ & 0 & 2 & 0 & 1.94 & 4.48 & 1.00 & $\mathrm{c}$ & CCS \\
\hline 8 & 1.06 & 0.13 & $\mathrm{~b}$ & \begin{tabular}{|l|l}
$\mathrm{s}$ & 2 \\
\end{tabular} & $\mathrm{f}$ & 0 & 2 & 0 & 5.72 & 12.92 & 1.34 & c & CCS \\
\hline 9 & 1.06 & 0.00 & $\mathrm{f}$ & -11 & - & - & - & 0 & - & - & - & $\mathrm{c}$ & CCS \\
\hline 10 & 1.06 & 0.18 & $\mathrm{f}$ & -3 & - & - & - & 0 & - & - & - & $\mathrm{c}$ & CCS \\
\hline 11 & 1.06 & 0.07 & $\mathrm{f}$ & -2 & - & - & - & 0 & - & - & - & c & CCS \\
\hline 12 & 1.06 & 0.00 & $\mathrm{~b}$ & \begin{tabular}{|l|l|}
$\mathrm{s}$ & 1 \\
\end{tabular} & $\mathrm{c}$ & 0 & 3 & 0 & 3.35 & 4.04 & 0.75 & c & CCS \\
\hline 13 & 1.06 & 0.00 & $\mathrm{f}$ & -11 & - & - & - & 0 & - & - & - & $\mathrm{c}$ & CCS \\
\hline 14 & 1.06 & 0.07 & $\mathrm{~d}$ & -2 & - & - & - & - & - & - & - & c & CCS \\
\hline 15 & 1.06 & 0.00 & $\mathrm{~b}$ & \begin{tabular}{|l|l|}
$\mathrm{s}$ & 1 \\
\end{tabular} & $\mathrm{cx}$ & 0 & 3 & 0 & 2.20 & 7.15 & 0.63 & c & CCS \\
\hline 16 & 1.06 & 0.04 & $\mathrm{f}$ & -1 & - & - & - & 0 & - & - & - & c & CCS \\
\hline 17 & 1.06 & 0.00 & $\mathrm{f}$ & -11 & - & - & - & 0 & - & - & - & c & CCS \\
\hline 18 & 1.06 & 0.00 & $\mathrm{f}$ & -1 & - & - & - & 0 & - & - & - & c & CCS \\
\hline 19 & 1.06 & 0.08 & $\mathrm{f}$ & -1 & - & - & - & 0 & - & - & - & c & CCS \\
\hline 20 & 1.06 & 0.11 & $\mathrm{f}$ & -2 & - & - & - & 2 & - & - & - & c & CCS \\
\hline 21 & 1.06 & 1.59 & c & \begin{tabular}{l|l} 
o & 4 \\
\end{tabular} & $\mathrm{cx}$ & 0 & 3 & 0 & 14.33 & 15.53 & 7.23 & c & CCS \\
\hline 23 & 1.06 & 0.07 & $\mathrm{c}$ & \begin{tabular}{l|l} 
o & 1 \\
\end{tabular} & $\mathrm{a}$ & 0 & 3 & 0 & 3.71 & 7.18 & 2.47 & c & $\mathrm{CCS}$ \\
\hline 24 & 1.06 & 0.20 & c & $\begin{array}{lll}\text { o } & 2 \\
\end{array}$ & $\mathrm{cx}$ & 1 & 0 & 0 & 4.78 & 9.48 & 1.91 & c & CCS \\
\hline 25 & 1.06 & 0.00 & $\mathrm{f}$ & -1 & - & - & - & 0 & - & - & - & c & CCS \\
\hline 26 & 1.06 & 0.00 & $\mathrm{f}$ & -1 & - & - & - & 0 & - & - & - & c & CCS \\
\hline 27 & 1.06 & 0.04 & $\mathrm{~d}$ & -2 & - & - & - & - & - & - & - & c & CCS \\
\hline 28 & 1.06 & 0.00 & $\mathrm{f}$ & \begin{tabular}{|l|l}
- & 1 \\
\end{tabular} & - & - & - & 0 & - & - & - & c & $\mathrm{CCS}$ \\
\hline 29 & 1.06 & 0.12 & $\mathrm{~d}$ & -2 & - & - & - & - & - & - & - & $\mathrm{c}$ & CCS \\
\hline 30 & 1.06 & 0.11 & $\mathrm{~d}$ & -2 & - & - & - & - & - & - & - & c & CCS \\
\hline 32 & 1.06 & 1.11 & $\mathrm{f}$ & -4 & - & - & - & 0 & - & - & - & c & $\mathrm{CCS}$ \\
\hline 33 & 1.06 & 0.05 & c & \begin{tabular}{|l|l|} 
o & 2 \\
\end{tabular} & $\mathrm{a}$ & 0 & 3 & 0 & 2.17 & 6.43 & 1.25 & c & CCS \\
\hline 34 & 1.06 & 1.18 & $\mathrm{f}$ & -3 & - & - & - & 1 & - & - & - & c & $\mathrm{CCS}$ \\
\hline 35 & 1.06 & 1.26 & $\mathrm{f}$ & -6 & - & - & - & 0 & - & - & - & c & $\mathrm{CCS}$ \\
\hline 36 & 1.06 & 0.26 & $\mathrm{~d}$ & -2 & - & - & - & - & - & - & - & c & CCS \\
\hline 37 & 1.06 & 0.15 & $\mathrm{f}$ & -3 & - & - & - & 0 & - & - & - & c & $\mathrm{CCS}$ \\
\hline 38 & 1.06 & 0.17 & $\mathrm{f}$ & -3 & - & - & - & 0 & - & - & - & c & $\mathrm{CCS}$ \\
\hline 39 & 1.06 & 0.32 & $\mathrm{~d}$ & -2 & - & - & - & - & - & - & - & c & $\mathrm{CCS}$ \\
\hline 40 & 1.06 & 0.29 & c & \begin{tabular}{l|l}
$\circ$ & 3 \\
\end{tabular} & $\mathrm{a}$ & 0 & 3 & 0 & 5.12 & 18.86 & 1.78 & $\mathrm{t}$ & $\mathrm{CCS}$ \\
\hline 41 & 1.06 & 1.31 & $\mathrm{f}$ & -5 & - & - & - & 0 & - & - & - & c & $\mathrm{CCS}$ \\
\hline 42 & 1.06 & 0.11 & $\mathrm{~d}$ & -2 & - & - & - & - & - & - & - & c & CCS \\
\hline 43 & 1.06 & 0.06 & $\mathrm{f}$ & -2 & - & - & - & 0 & - & - & - & c & $\mathrm{CCS}$ \\
\hline 44 & 1.06 & 1.81 & $\mathrm{f}$ & -4 & - & - & - & 0 & - & - & - & c & $\mathrm{CCS}$ \\
\hline
\end{tabular}




\begin{tabular}{|c|c|c|c|c|c|c|c|c|c|c|c|c|c|}
\hline 45 & 1.06 & 0.06 & $\mathrm{f}$ & \begin{tabular}{|l|l|}
-2 \\
\end{tabular} & - & - & - & 0 & - & - & - & c & CCS \\
\hline 46 & 1.06 & 3.04 & c & \begin{tabular}{|l|l} 
o & 6 \\
\end{tabular} & $\mathrm{a}$ & 2 & 3 & 0 & 7.98 & 28.41 & 4.25 & c & CCS \\
\hline 47 & 1.06 & 0.70 & $\mathrm{f}$ & -5 & - & - & - & 0 & - & - & - & $\mathrm{c}$ & CCS \\
\hline 48 & 1.06 & 0.00 & $\mathrm{~d}$ & -1 & - & - & - & - & - & - & - & $\mathrm{c}$ & CCS \\
\hline 49 & 1.06 & 0.77 & $\mathrm{f}$ & -4 & - & - & - & 2 & - & - & - & w & CCS \\
\hline 50 & 1.06 & 0.00 & $\mathrm{f}$ & -1 & - & - & - & 0 & - & - & - & c & CCS \\
\hline 51 & 1.06 & 0.11 & c & \begin{tabular}{|l|l|}
$\mathrm{o}$ & 2 \\
\end{tabular} & $\mathrm{cx}$ & 0 & 2 & 0 & 8.59 & 9.02 & 1.79 & c & CCS \\
\hline 52 & 1.06 & 0.40 & c & $\begin{array}{ll}\mathrm{o} & 2 \\
\end{array}$ & $\mathrm{f}$ & 0 & 2 & 1 & 10.69 & 8.63 & 4.45 & $\mathrm{t}$ & CCS \\
\hline 53 & 1.06 & 0.10 & $\mathrm{~b}$ & $\begin{array}{ll}s & 2 \\
\end{array}$ & $\mathrm{a}$ & 0 & 2 & 0 & 3.06 & 7.51 & 2.42 & $t$ & CCS \\
\hline 54 & 1.06 & 0.07 & $\mathrm{f}$ & -2 & - & - & - & 0 & - & - & - & c & CCS \\
\hline 55 & 1.06 & 0.47 & c & $\begin{array}{lll} & 3 \\
\end{array}$ & $\mathrm{f}$ & 0 & 3 & 0 & 11.92 & 9.90 & 3.14 & c & CCS \\
\hline 56 & 1.06 & 0.00 & $\mathrm{f}$ & -1 & - & - & - & 0 & - & - & - & c & CCS \\
\hline 57 & 1.06 & 0.19 & f & -2 & - & - & - & 0 & - & - & - & c & CCS \\
\hline 58 & 1.06 & 1.11 & $\mathrm{f}$ & -5 & - & - & - & 0 & - & - & - & c & CCS \\
\hline 59 & 1.06 & 0.00 & c & $\begin{array}{ll}\text { o } & 1 \\
\end{array}$ & $\mathrm{cx}$ & 0 & 3 & 0 & 1.64 & 4.60 & 0.74 & c & CCS \\
\hline 60 & 1.06 & 0.06 & f & -2 & - & - & - & 0 & - & - & - & c & CCS \\
\hline 61 & 1.06 & 0.00 & c & $\begin{array}{ll} & 1 \\
\end{array}$ & $\mathrm{cx}$ & 0 & 2 & 0 & 2.45 & 5.37 & 0.76 & c & CCS \\
\hline 62 & 1.06 & 0.16 & c & $\begin{array}{ll}0 & 3 \\
\end{array}$ & $\mathrm{a}$ & 0 & 2 & 0 & 3.60 & 19.04 & 1.60 & c & CCS \\
\hline 63 & 1.06 & 0.00 & c & $\begin{array}{ll} & 1 \\
\end{array}$ & f & 0 & - & 0 & - & - & - & c & CCS \\
\hline 64 & 1.06 & 0.00 & f & -1 & - & - & - & 0 & - & - & - & c & CCS \\
\hline 65 & 1.06 & 0.00 & d & -1 & - & - & - & - & - & - & - & c & CCS \\
\hline 66 & 1.06 & 0.06 & d & -2 & - & - & - & - & - & - & - & c & CCS \\
\hline 67 & 1.06 & 0.26 & f & -3 & - & - & - & 0 & - & - & - & c & CCS \\
\hline 68 & 1.06 & 0.16 & $\mathrm{f}$ & -2 & - & - & - & 0 & - & - & - & c & CCS \\
\hline 69 & 1.06 & 0.07 & $\mathrm{~d}$ & -1 & - & - & - & - & - & - & - & c & CCS \\
\hline 70 & 1.06 & 0.44 & c & $\begin{array}{ll}0 & 3 \\
\end{array}$ & f & 0 & 3 & 0 & 4.04 & 13.31 & 2.56 & c & CCS \\
\hline 71 & 1.06 & 0.39 & d & -2 & - & - & - & - & - & - & - & c & CCS \\
\hline 72 & 1.06 & 0.00 & c & $\begin{array}{ll}\text { o } & 1 \\
\end{array}$ & $\mathrm{f}$ & 0 & 2 & 0 & 4.94 & 5.41 & 0.76 & c & CCS \\
\hline 73 & 1.06 & 0.22 & $\mathrm{f}$ & -3 & - & - & - & 0 & - & - & - & c & CCS \\
\hline 74 & 1.06 & 0.09 & d & -2 & - & - & - & - & - & - & - & c & CCS \\
\hline 75 & 1.06 & 1.51 & d & -5 & - & - & - & - & - & - & - & c & CCS \\
\hline 76 & 1.06 & 0.00 & $\mathrm{f}$ & -1 & - & - & - & 0 & - & - & - & c & CCS \\
\hline 77 & 1.06 & 0.06 & $\mathrm{f}$ & -1 & - & - & - & 0 & - & - & - & c & CCS \\
\hline 78 & 1.06 & 0.00 & c & $\begin{array}{lll} & 1 \\
\end{array}$ & $\mathrm{cx}$ & 0 & 3 & 0 & 1.98 & 5.94 & 0.80 & c & CCS \\
\hline 79 & 1.06 & 0.00 & $\mathrm{f}$ & -1 & - & - & - & 0 & - & - & - & c & CCS \\
\hline 80 & 1.06 & 0.00 & d & -1 & - & - & - & - & - & - & - & c & CCS \\
\hline 81 & 1.06 & 0.00 & c & $\begin{array}{ll}\text { o } & 1\end{array}$ & $\mathrm{f}$ & 0 & 0 & 0 & 2.19 & 5.77 & 0.71 & c & CCS \\
\hline 82 & 1.06 & 0.00 & $\mathrm{~b}$ & $\begin{array}{ll}\mathrm{s} & 1 \\
\end{array}$ & $\mathrm{cx}$ & 0 & 2 & 0 & 3.02 & 3.57 & 0.71 & c & CCS \\
\hline 83 & 1.06 & 0.00 & c & $\begin{array}{lll} & 1 \\
\end{array}$ & $\mathrm{f}$ & 0 & 3 & 0 & 2.17 & 3.99 & 0.54 & c & CCS \\
\hline 84 & 1.06 & 0.00 & c & $\begin{array}{ll}\text { o } & 1 \\
\end{array}$ & cx & 0 & 3 & 0 & 3.51 & 7.04 & 1.17 & c & CCS \\
\hline 85 & 1.06 & 0.00 & $\mathrm{f}$ & -1 & - & - & - & 0 & - & - & - & c & CCS \\
\hline 86 & 1.06 & 0.00 & $\mathrm{f}$ & -1 & - & - & - & 0 & - & - & - & c & CCS \\
\hline 87 & 1.06 & 0.00 & $\mathrm{~b}$ & \begin{tabular}{|l|l}
$\mathrm{s}$ & 1 \\
\end{tabular} & $\mathrm{f}$ & 0 & 3 & 0 & 4.25 & 7.95 & 0.90 & c & CCS \\
\hline
\end{tabular}




\begin{tabular}{|c|c|c|c|c|c|c|c|c|c|c|c|c|c|}
\hline 88 & 1.06 & 0.03 & $\mathrm{~d}$ & \begin{tabular}{l|l|} 
& - \\
\end{tabular} & - & - & - & - & - & - & - & $\mathrm{c}$ & CCS \\
\hline 89 & 1.06 & 0.00 & c & $\begin{array}{lll}\text { o } & 1 \\
\end{array}$ & $\mathrm{cx}$ & 0 & 2 & 0 & 1.49 & 7.31 & 0.63 & c & CCS \\
\hline 90 & 1.06 & 0.04 & $\mathrm{~b}$ & $\begin{array}{ll}\text { s } & 1\end{array}$ & $\mathrm{cx}$ & 0 & 3 & 0 & 2.51 & 6.41 & 0.93 & c & CCS \\
\hline 91 & 1.06 & 0.00 & $\mathrm{f}$ & -2 & - & - & - & 0 & - & - & - & $\mathrm{c}$ & CCS \\
\hline 92 & 1.06 & 0.06 & $\mathrm{~d}$ & -1 & - & - & - & - & - & - & - & c & CCS \\
\hline 93 & 1.06 & 0.00 & $\mathrm{f}$ & -1 & - & - & - & 0 & - & - & - & c & CCS \\
\hline 94 & 1.06 & 0.04 & c & $\begin{array}{lll}\text { o } & 1 \\
\end{array}$ & $\mathrm{a}$ & 0 & 2 & 0 & 2.10 & 8.33 & 1.51 & $\mathrm{t}$ & CCS \\
\hline 95 & 1.06 & 0.00 & $\mathrm{~d}$ & -1 & - & - & - & - & - & - & - & c & CCS \\
\hline 96 & 1.06 & 0.11 & $b$ & $\begin{array}{ll}\mathrm{s} & 3 \\
\end{array}$ & $\mathrm{f}$ & 0 & 3 & 0 & 2.38 & 14.83 & 1.47 & c & CCS \\
\hline 97 & 1.06 & 0.00 & c & $\begin{array}{lll}\text { o } & 1 \\
\end{array}$ & $\mathrm{f}$ & 0 & 3 & 0 & 1.74 & 4.75 & 0.44 & c & CCS \\
\hline 98 & 1.06 & 0.00 & c & \begin{tabular}{l|l} 
o & 1 \\
\end{tabular} & $\mathrm{a}$ & 0 & 3 & 0 & 2.28 & 6.40 & 0.65 & c & CCS \\
\hline 99 & 1.06 & 0.03 & $\mathrm{f}$ & -2 & - & - & - & 0 & - & - & - & $\mathrm{c}$ & CCS \\
\hline 100 & 1.06 & 0.03 & $\mathrm{f}$ & -1 & - & - & - & 0 & - & - & - & $\mathrm{c}$ & CCS \\
\hline \begin{tabular}{|l|}
101 \\
\end{tabular} & 1.06 & 1.04 & $\mathrm{~d}$ & -4 & - & - & - & - & - & - & - & c & CCS \\
\hline 102 & 1.06 & 1.09 & c & $\begin{array}{ll}\text { o } & 4 \\
\end{array}$ & $\mathrm{f}$ & 0 & 3 & 0 & 9.64 & 21.49 & 2.50 & $\mathrm{c}$ & CCS \\
\hline 103 & 1.06 & 3.87 & $\mathrm{~b}$ & $\begin{array}{ll} \\
\text { s } 7\end{array}$ & $\mathrm{f}$ & 0 & 2 & 1 & 15.58 & 28.62 & 6.18 & c & CCS \\
\hline 104 & 1.06 & 0.00 & $\mathrm{~d}$ & -1 & - & - & - & - & - & - & - & c & CCS \\
\hline 105 & 1.06 & 0.08 & c & o 2 & $\mathrm{f}$ & 0 & 3 & 0 & 5.54 & 6.34 & 1.28 & $\mathrm{c}$ & CCS \\
\hline 106 & 1.06 & 0.84 & $\mathrm{f}$ & -3 & - & - & - & 0 & - & - & - & $\mathrm{c}$ & CCS \\
\hline 107 & 1.06 & 0.00 & c & $\begin{array}{lll}\text { o } & 1 \\
\end{array}$ & $\mathrm{cx}$ & 0 & 0 & 0 & 2.09 & 3.78 & 0.33 & c & CCS \\
\hline 108 & 1.06 & 1.93 & $\mathrm{c}$ & $\begin{array}{ll}\text { o } & 6 \\
\end{array}$ & \begin{tabular}{|l|l|} 
& $\mathrm{cx}$ \\
\end{tabular} & 0 & 3 & 0 & 5.72 & 30.41 & 4.26 & $\mathrm{c}$ & CCS \\
\hline 109 & 1.06 & 0.08 & c & o 2 & \begin{tabular}{|l|l|}
2 & $\mathrm{f}$ \\
\end{tabular} & 0 & 0 & 0 & 2.83 & 7.49 & 1.64 & $\mathrm{c}$ & CCS \\
\hline 110 & 1.06 & 0.00 & $\mathrm{f}$ & -1 & $1-$ & - & - & 0 & - & - & - & $\mathrm{c}$ & CCS \\
\hline 111 & 1.06 & 0.00 & $\mathrm{c}$ & \begin{tabular}{l|l} 
o & 1 \\
\end{tabular} & \begin{tabular}{l|l} 
& $\mathrm{cx}$ \\
\end{tabular} & \begin{tabular}{l|l|}
$x$ & 0 \\
\end{tabular} & 0 & 0 & 3.29 & 4.46 & 0.80 & $\mathrm{c}$ & CCS \\
\hline 112 & 1.06 & 0.03 & $\mathrm{f}$ & -2 & $2-$ & - & - & 0 & - & - & - & c & CCS \\
\hline 113 & 1.06 & 0.38 & $\mathrm{f}$ & -3 & \begin{tabular}{l|l}
3 & - \\
\end{tabular} & - & - & 0 & - & - & - & $\mathrm{c}$ & CCS \\
\hline 114 & 1.06 & 0.10 & $\mathrm{~b}$ & $\begin{array}{ll}\mathrm{s} & 2 \\
\end{array}$ & $2 \quad a$ & 0 & 3 & 0 & 8.54 & 9.94 & 0.96 & $\mathrm{c}$ & CCS \\
\hline 115 & 1.06 & 0.21 & $\mathrm{f}$ & -3 & \begin{tabular}{l|l}
3 & - \\
\end{tabular} & - & - & 0 & - & - & - & c & CCS \\
\hline 116 & 1.06 & 0.00 & c & $\begin{array}{lll}\text { o } & 1 \\
\end{array}$ & \begin{tabular}{|l|l}
$\mathrm{a}$ & $\mathrm{a}$ \\
\end{tabular} & 0 & 3 & 0 & 1.36 & 4.56 & 0.62 & $\mathrm{c}$ & CCS \\
\hline 117 & 1.06 & 0.24 & $\mathrm{f}$ & -3 & \begin{tabular}{l|l}
3 & - \\
\end{tabular} & - & - & 0 & - & - & - & $\mathrm{c}$ & CCS \\
\hline 118 & 1.06 & 0.33 & $\mathrm{~b}$ & $\begin{array}{lll}\mathrm{s} & 3 \\
\end{array}$ & \begin{tabular}{l|l}
3 & $\mathrm{cx}$ \\
\end{tabular} & \begin{tabular}{l|l}
$x$ & 0 \\
\end{tabular} & 2 & 0 & 9.83 & 13.61 & 3.29 & c & CCS \\
\hline 119 & 1.06 & 0.00 & c & \begin{tabular}{|l|l|} 
o & 1 \\
\end{tabular} & \begin{tabular}{|l|l|} 
& $\mathrm{cx}$ \\
\end{tabular} & \begin{tabular}{l|l}
$x$ & 0 \\
\end{tabular} & 3 & 0 & 4.20 & 4.59 & 1.45 & c & CCS \\
\hline 120 & 1.06 & 0.00 & $\mathrm{~b}$ & \begin{tabular}{|l|l}
$\mathrm{s}$ & 1 \\
\end{tabular} & \begin{tabular}{|l|l}
$\mathrm{a}$ \\
\end{tabular} & 0 & 3 & 0 & 2.49 & 6.07 & 1.60 & $\mathrm{c}$ & CCS \\
\hline 121 & 1.06 & 4.41 & $\mathrm{f}$ & -9 & \begin{tabular}{l|l}
9 & - \\
\end{tabular} & - & - & 0 & - & - & - & $\mathrm{c}$ & CCS \\
\hline 122 & 1.06 & 0.14 & $\mathrm{f}$ & -2 & \begin{tabular}{l|l}
2 & - \\
\end{tabular} & - & - & 0 & - & - & - & c & CCS \\
\hline 123 & 1.06 & 0.00 & $\mathrm{~d}$ & -1 & \begin{tabular}{l|l}
1 & - \\
\end{tabular} & - & - & - & - & - & - & $\mathrm{c}$ & CCS \\
\hline 124 & 1.06 & 0.22 & $\mathrm{f}$ & -3 & \begin{tabular}{l|l}
3 & - \\
\end{tabular} & - & - & 0 & - & - & - & $\mathrm{c}$ & CCS \\
\hline 125 & 1.06 & 0.07 & $\mathrm{~b}$ & $\begin{array}{lll}\mathrm{s} & 2 \\
\end{array}$ & \begin{tabular}{|l|l|}
2 & $\mathrm{cx}$ \\
\end{tabular} & \begin{tabular}{l|l|}
$x$ & 0 \\
\end{tabular} & 3 & 0 & 4.25 & 9.15 & 1.24 & c & CCS \\
\hline 126 & 1.06 & 0.23 & $\mathrm{c}$ & \begin{tabular}{ll|l} 
o 3 \\
\end{tabular} & \begin{tabular}{|l|l}
3 & $\mathrm{cx}$ \\
\end{tabular} & \begin{tabular}{l|l|}
$x$ & 0 \\
\end{tabular} & 3 & 0 & 4.14 & 17.08 & 1.33 & c & CCS \\
\hline 127 & 1.06 & 0.43 & $\mathrm{f}$ & -3 & \begin{tabular}{l|l}
3 & - \\
\end{tabular} & - & - & 0 & - & - & - & $\mathrm{c}$ & CCS \\
\hline 128 & 1.06 & 0.08 & $\mathrm{~d}$ & -2 & $2-$ & - & - & - & - & - & - & c & CCS \\
\hline 129 & 1.06 & 0.24 & $\mathrm{f}$ & -3 & \begin{tabular}{l|l}
3 & - \\
\end{tabular} & - & - & 0 & - & - & - & $\mathrm{c}$ & CCS \\
\hline 130 & 1.06 & 0.07 & $\mathrm{c}$ & o 2 & \begin{tabular}{|l|l}
2 & $\mathrm{cx}$ \\
\end{tabular} & \begin{tabular}{l|l}
$x$ & 2 \\
\end{tabular} & 3 & 0 & 8.12 & 6.71 & 1.31 & $\mathrm{c}$ & CCS \\
\hline
\end{tabular}




\begin{tabular}{|c|c|c|c|c|c|c|c|c|c|c|c|c|c|}
\hline 131 & 1.06 & 0.09 & $\mathrm{f}$ & \begin{tabular}{l|l}
- & 2 \\
\end{tabular} & - & - & - & 0 & - & - & - & c & CCS \\
\hline 132 & 1.06 & 0.61 & c & \begin{tabular}{l|l} 
o & 4 \\
\end{tabular} & $\mathrm{f}$ & 0 & 3 & 0 & 4.45 & 14.84 & 1.94 & c & CCS \\
\hline 133 & 1.06 & 2.99 & c & \begin{tabular}{l|l} 
o & 9 \\
\end{tabular} & $\mathrm{cx}$ & 0 & 3 & 0 & 5.29 & 47.93 & 4.84 & c & CCS \\
\hline 134 & 1.06 & 0.07 & $\mathrm{f}$ & -1 & - & - & - & 0 & - & - & - & c & CCS \\
\hline 135 & 1.06 & 0.61 & $\mathrm{f}$ & -5 & - & - & - & 0 & - & - & - & c & CCS \\
\hline 136 & 1.06 & 0.33 & c & $\begin{array}{lll}\text { o } & 3 \\
\end{array}$ & $\mathrm{f}$ & 0 & 3 & 0 & 6.42 & 15.71 & 1.72 & $\mathrm{t}$ & CCS \\
\hline 137 & 1.06 & 0.07 & f & -2 & - & - & - & 0 & - & - & - & c & CCS \\
\hline 138 & 1.06 & 1.87 & $\mathrm{f}$ & -7 & - & - & - & 0 & - & - & - & c & CCS \\
\hline 139 & 1.06 & 0.00 & f & -1 & - & - & - & 0 & - & - & - & c & CCS \\
\hline 140 & 1.06 & 6.15 & $\mathrm{c}$ & $\begin{array}{ll}\text { o } & 9 \\
\end{array}$ & $\mathrm{cx}$ & 2 & 3 & 0 & 13.16 & 45.02 & 9.70 & c & CCS \\
\hline 141 & 1.06 & 0.00 & d & -1 & - & - & - & - & - & - & - & c & CCS \\
\hline 142 & 1.06 & 0.92 & $\mathrm{f}$ & -5 & - & - & - & 0 & - & - & - & c & CCS \\
\hline 143 & 1.06 & 2.33 & $\mathrm{~b}$ & $\begin{array}{ll}\text { s } & 6 \\
\end{array}$ & $\mathrm{cx}$ & 2 & 3 & 0 & 7.57 & 33.01 & 4.74 & c & CCS \\
\hline 144 & 1.06 & 0.00 & f & -1 & - & - & - & 0 & - & - & - & c & CCS \\
\hline 145 & 1.06 & 0.10 & f & -2 & - & - & - & 0 & - & - & - & c & CCS \\
\hline 146 & 1.06 & 0.28 & f & -4 & - & - & - & 0 & - & - & - & c & CCS \\
\hline 147 & 1.06 & 0.06 & f & -2 & - & - & - & 0 & - & - & - & c & CCS \\
\hline 148 & 1.06 & 3.43 & $\mathrm{f}$ & -5 & - & - & - & 0 & - & - & - & c & CCS \\
\hline 149 & 1.06 & 0.33 & $\mathrm{~b}$ & $\begin{array}{ll}\mathrm{s} & 3 \\
\end{array}$ & $\mathrm{f}$ & 0 & 3 & 0 & 5.32 & 11.75 & 2.03 & c & CCS \\
\hline 150 & 1.06 & 1.49 & f & -5 & - & - & - & 0 & - & - & - & c & CCS \\
\hline 151 & 1.06 & 0.21 & $\mathrm{f}$ & -3 & - & - & - & 0 & - & - & - & c & CCS \\
\hline 152 & 1.06 & 0.30 & $\mathrm{f}$ & -3 & - & - & - & 0 & - & - & - & c & CCS \\
\hline 154 & 1.06 & 4.16 & c & $\begin{array}{ll}\text { o } & 8 \\
\end{array}$ & $\mathrm{f}$ & 0 & 3 & 0 & 6.26 & 39.53 & 4.83 & $\mathrm{t}$ & CCS \\
\hline 155 & 1.06 & 0.44 & c & $\begin{array}{ll}\text { o } & 3 \\
\end{array}$ & $\mathrm{f}$ & 0 & 2 & 0 & 4.91 & 15.98 & 1.58 & c & CCS \\
\hline 156 & 1.06 & 0.31 & f & -3 & - & - & - & 0 & - & - & - & c & CCS \\
\hline 157 & 1.06 & 0.13 & $\mathrm{f}$ & -2 & - & - & - & 0 & - & - & - & c & CCS \\
\hline 158 & 1.06 & 0.92 & $\mathrm{f}$ & -5 & - & - & - & 0 & - & - & - & c & CCS \\
\hline 159 & 1.06 & 0.12 & f & -2 & - & - & - & 0 & - & - & - & c & CCS \\
\hline 160 & 1.06 & 0.79 & $\mathrm{f}$ & -4 & - & - & - & 0 & - & - & - & c & CCS \\
\hline 161 & 1.06 & 1.59 & $\mathrm{~b}$ & $\begin{array}{ll}\mathrm{s} & 7 \\
\end{array}$ & $\mathrm{cx}$ & 0 & 2 & 0 & 5.11 & 18.19 & 2.78 & $\mathrm{t}$ & CCS \\
\hline 162 & 1.06 & 0.05 & $\mathrm{f}$ & -2 & - & - & - & 0 & - & - & - & c & CCS \\
\hline 164 & 1.06 & 1.70 & $\mathrm{f}$ & -5 & - & - & - & 0 & - & - & - & c & CCS \\
\hline 165 & 1.06 & 0.10 & c & $\begin{array}{ll}\text { o } & 2 \\
\end{array}$ & $\mathrm{f}$ & 0 & 3 & 0 & 1.89 & 12.85 & 1.24 & c & CCS \\
\hline 166 & 1.06 & 0.00 & d & -1 & - & - & - & - & - & - & - & c & CCS \\
\hline 167 & 1.06 & 0.07 & d & -1 & - & - & - & - & - & - & - & c & CCS \\
\hline 168 & 1.06 & 0.07 & d & -1 & - & - & - & - & - & - & - & W & CCS \\
\hline 169 & 1.06 & 0.05 & f & -2 & - & - & - & 0 & - & - & - & c & CCS \\
\hline 170 & 1.06 & 0.40 & d & -2 & - & - & - & - & - & - & - & c & CCS \\
\hline 171 & 1.06 & 0.72 & c & $\begin{array}{ll}\mathrm{o} & 3 \\
\end{array}$ & $\mathrm{f}$ & 0 & 3 & 0 & 6.44 & 14.75 & 3.65 & c & CCS \\
\hline 172 & 1.06 & 0.15 & $\mathrm{f}$ & -3 & - & - & - & 0 & - & - & - & c & CCS \\
\hline 173 & 1.06 & 0.28 & $\mathrm{~b}$ & $\begin{array}{lll}\mathrm{s} & 2 \\
\end{array}$ & $\mathrm{a}$ & 0 & 3 & 0 & 5.52 & 11.70 & 2.04 & c & CCS \\
\hline 174 & 1.06 & 1.51 & c & o 6 & $a$ & 0 & 3 & 0 & 7.11 & 29.75 & 2.82 & c & CCS \\
\hline 175 & 1.06 & 0.28 & $\mathrm{~d}$ & -3 & - & - & - & - & - & - & - & c & CCS \\
\hline
\end{tabular}




\begin{tabular}{|c|c|c|c|c|c|c|c|c|c|c|c|c|c|}
\hline 176 & 1.06 & 0.12 & $\mathrm{f}$ & \begin{tabular}{|l|l|}
-2 \\
\end{tabular} & - & - & - & 0 & - & - & - & c & CCS \\
\hline 177 & 1.06 & 0.00 & $\mathrm{~b}$ & \begin{tabular}{|l|l}
$\mathrm{s}$ & 1 \\
\end{tabular} & $\mathrm{a}$ & 0 & 2 & 1 & 3.16 & 6.80 & 0.85 & c & CCS \\
\hline 178 & 1.06 & 0.04 & d & -1 & - & - & - & - & - & - & - & c & CCS \\
\hline 179 & 1.06 & 0.06 & $\mathrm{f}$ & -2 & - & - & - & 0 & - & - & - & $\mathrm{c}$ & CCS \\
\hline 180 & 1.06 & 0.00 & $\mathrm{f}$ & -1 & - & - & - & 0 & - & - & - & c & CCS \\
\hline 181 & 1.06 & 0.00 & $\mathrm{f}$ & -1 & - & - & - & 0 & - & - & - & c & CCS \\
\hline 182 & 1.06 & 0.06 & d & -2 & - & - & - & - & - & - & - & c & CCS \\
\hline 183 & 1.06 & 0.00 & $\mathrm{~b}$ & $\begin{array}{ll}\text { s } & 1 \\
\end{array}$ & $\mathrm{cx}$ & 0 & 3 & 0 & 3.43 & 6.09 & 0.81 & c & CCS \\
\hline 184 & 1.06 & 0.00 & $\mathrm{~b}$ & $\begin{array}{ll}\mathrm{s} & 1 \\
\end{array}$ & $\mathrm{cx}$ & 0 & 2 & 0 & 0.86 & 5.39 & 0.65 & c & CCS \\
\hline 185 & 1.06 & 0.00 & $\mathrm{f}$ & -1 & - & - & - & 0 & - & - & - & c & CCS \\
\hline 186 & 1.06 & 0.14 & c & \begin{tabular}{l|l} 
o & 3 \\
\end{tabular} & $\mathrm{cx}$ & 2 & 3 & 0 & 7.14 & 10.08 & 1.86 & c & CCS \\
\hline 187 & 1.06 & 0.24 & c & $\begin{array}{lll} & 2 \\
\end{array}$ & $\mathrm{cx}$ & 2 & 3 & 0 & 4.70 & 15.07 & 1.59 & c & CCS \\
\hline 188 & 1.06 & 0.00 & $\mathrm{f}$ & -1 & - & - & - & 0 & - & - & - & c & CCS \\
\hline 189 & 1.06 & 0.06 & f & -2 & - & - & - & 0 & - & - & - & c & CCS \\
\hline 190 & 1.06 & 0.00 & f & -1 & - & - & - & 0 & - & - & - & c & CCS \\
\hline 191 & 1.06 & 0.10 & c & $\begin{array}{lll} & 2 \\
\end{array}$ & $\mathrm{a}$ & 0 & 3 & 0 & 3.38 & 9.16 & 1.50 & c & CCS \\
\hline 192 & 1.06 & 0.00 & c & $\begin{array}{ll} & 1 \\
\end{array}$ & $\mathrm{f}$ & 0 & 2 & 0 & 3.25 & 6.45 & 0.85 & c & CCS \\
\hline 193 & 1.06 & 0.09 & d & -2 & - & - & - & - & - & - & - & c & CCS \\
\hline 194 & 1.06 & 0.00 & $\mathrm{f}$ & -1 & - & - & - & 0 & - & - & - & c & CCS \\
\hline 195 & 1.06 & 0.04 & f & -1 & - & - & - & 0 & - & - & - & c & CCS \\
\hline 196 & 1.06 & 0.09 & $\mathrm{f}$ & -2 & - & - & - & 1 & - & - & - & c & CCS \\
\hline 197 & 1.06 & 0.15 & d & -2 & - & - & - & - & - & - & - & c & CCS \\
\hline 198 & 1.06 & 0.04 & f & -1 & - & - & - & 0 & - & - & - & c & CCS \\
\hline 199 & 1.06 & 0.00 & d & -1 & - & - & - & - & - & - & - & c & CCS \\
\hline 200 & 1.06 & 0.00 & c & $\begin{array}{ll}\text { o } & 1 \\
\end{array}$ & $\mathrm{cx}$ & 0 & 2 & 0 & 4.39 & 5.22 & 1.34 & $t$ & CCS \\
\hline 201 & 1.06 & 0.00 & $\mathrm{~b}$ & $\begin{array}{ll}\mathrm{s} & 1 \\
\end{array}$ & $\mathrm{cx}$ & 0 & 0 & 0 & 2.22 & 6.10 & 0.73 & c & CCS \\
\hline 202 & 1.06 & 0.00 & $\mathrm{f}$ & -1 & - & - & - & 0 & - & - & - & c & CCS \\
\hline 203 & 1.06 & 0.04 & d & -2 & - & - & - & - & - & - & - & c & CCS \\
\hline 204 & 1.06 & 0.00 & c & $\begin{array}{ll}0 & 2 \\
\end{array}$ & $\mathrm{a}$ & 0 & 2 & 2 & 0.99 & 9.06 & 1.19 & $t$ & CCS \\
\hline 205 & 1.06 & 0.00 & d & -1 & - & - & - & - & - & - & - & c & CCS \\
\hline 206 & 1.06 & 0.09 & c & $\begin{array}{ll}0 & 2 \\
\end{array}$ & $\mathrm{cx}$ & 0 & 3 & 0 & 7.72 & 7.52 & 1.70 & c & CCS \\
\hline 207 & 1.06 & 0.08 & $\mathrm{f}$ & -2 & - & - & - & 0 & - & - & - & c & CCS \\
\hline 208 & 1.06 & 0.00 & c & $\begin{array}{lll} & 1 \\
\end{array}$ & $\mathrm{f}$ & 0 & 0 & 0 & 2.88 & 8.52 & 1.01 & c & CCS \\
\hline 209 & 1.06 & 0.07 & $\mathrm{f}$ & -2 & - & - & - & 0 & - & - & - & $t$ & CCS \\
\hline 210 & 1.06 & 0.00 & $\mathrm{f}$ & -1 & - & - & - & 0 & - & - & - & c & CCS \\
\hline 211 & 1.06 & 0.00 & $\mathrm{f}$ & -1 & - & - & - & 0 & - & - & - & c & CCS \\
\hline 212 & 1.06 & 0.00 & c & $\begin{array}{ll}\text { o } & 2\end{array}$ & $\mathrm{a}$ & 0 & 3 & 0 & 2.31 & 5.42 & 0.75 & c & CCS \\
\hline 213 & 1.06 & 0.00 & $\mathrm{f}$ & -1 & - & - & - & 0 & - & - & - & c & CCS \\
\hline 214 & 1.06 & 0.00 & f & -1 & - & - & - & 0 & - & - & - & c & CCS \\
\hline 215 & 1.06 & 0.07 & $\mathrm{~b}$ & $\begin{array}{ll}\mathrm{s} & 1\end{array}$ & $\mathrm{a}$ & 0 & 3 & 0 & 4.50 & 5.58 & 1.91 & c & CCS \\
\hline 216 & 1.06 & 0.00 & f & -1 & - & - & - & 0 & - & - & - & c & CCS \\
\hline 217 & 1.06 & 0.00 & $\mathrm{~b}$ & \begin{tabular}{|l|l}
$\mathrm{s}$ & 1
\end{tabular} & $\mathrm{f}$ & 0 & 3 & 1 & 2.07 & 7.47 & 0.74 & c & CCS \\
\hline 218 & 1.06 & 0.00 & $\mathrm{~b}$ & \begin{tabular}{|l|l}
$\mathrm{s}$ & 1 \\
\end{tabular} & $\mathrm{a}$ & 0 & 2 & 0 & 1.91 & 5.71 & 0.64 & c & CCS \\
\hline
\end{tabular}




\begin{tabular}{|c|c|c|c|c|c|c|c|c|c|c|c|c|c|}
\hline 219 & 1.06 & 0.05 & c & $\begin{array}{ll}\text { o } & 2\end{array}$ & $\mathrm{f}$ & 0 & 2 & 0 & 1.27 & 10.70 & 1.35 & c & CCS \\
\hline 220 & 1.06 & 0.05 & $\mathrm{~b}$ & $\begin{array}{ll}\mathrm{s} & 2 \\
\end{array}$ & $\mathrm{f}$ & 0 & 2 & 0 & 1.69 & 10.62 & 1.48 & c & CCS \\
\hline 221 & 1.06 & 0.00 & $\mathrm{~b}$ & $\begin{array}{ll}\text { s } & 1\end{array}$ & $\mathrm{a}$ & 0 & 3 & 0 & 2.53 & 4.65 & 0.85 & c & CCS \\
\hline 222 & 1.06 & 0.00 & $\mathrm{c}$ & $\begin{array}{ll}\text { o } & 1 \\
\end{array}$ & $\mathrm{cx}$ & 0 & 2 & 0 & 1.95 & 7.03 & 0.64 & c & $\mathrm{CCS}$ \\
\hline 223 & 1.06 & 0.00 & $\mathrm{~b}$ & $\begin{array}{lll} & 1 \\
\end{array}$ & $\mathrm{cx}$ & 0 & 2 & 0 & 5.03 & 6.22 & 1.28 & c & CCS \\
\hline 224 & 1.06 & 0.07 & $\mathrm{~d}$ & -1 & - & - & - & - & - & - & - & c & CCS \\
\hline 225 & 1.06 & 0.00 & c & $\begin{array}{lll}\text { o } & 1 \\
\end{array}$ & $\mathrm{f}$ & 0 & 2 & 0 & 2.04 & 5.13 & 0.81 & c & CCS \\
\hline 226 & 1.06 & 0.00 & b & $\begin{array}{ll}\mathrm{s} & 1\end{array}$ & $\mathrm{a}$ & 0 & 2 & 0 & 3.71 & 5.01 & 1.10 & c & CCS \\
\hline 227 & 1.06 & 0.00 & c & $\begin{array}{ll}\mathrm{o} & 1\end{array}$ & cx & 0 & 2 & 0 & 2.08 & 4.97 & 0.67 & c & CCS \\
\hline 228 & 1.06 & 0.04 & b & $\begin{array}{ll}\text { s } & 1\end{array}$ & $\mathrm{a}$ & 0 & 3 & 0 & 3.90 & 6.65 & 1.20 & W & CCS \\
\hline 229 & 1.06 & 0.06 & $\mathrm{f}$ & -2 & - & - & - & 0 & - & - & - & c & CCS \\
\hline 230 & 1.06 & 0.00 & $\mathrm{f}$ & -1 & - & - & - & 0 & - & - & - & c & $\mathrm{CCS}$ \\
\hline 231 & 1.06 & 0.00 & $\mathrm{~b}$ & $\begin{array}{ll}\mathrm{s} & 1\end{array}$ & cx & 0 & 1 & 0 & 3.33 & 7.50 & 1.75 & c & CCS \\
\hline 232 & 1.06 & 0.00 & b & $\begin{array}{ll}\mathrm{s} & 1\end{array}$ & $\mathrm{f}$ & 0 & 2 & 0 & 0.95 & 5.48 & 0.92 & c & CCS \\
\hline 233 & 1.06 & 0.00 & $\mathrm{f}$ & -1 & - & - & - & 0 & - & - & - & c & $\mathrm{CCS}$ \\
\hline 234 & 1.06 & 0.00 & c & $\begin{array}{ll}\text { o } & 2 \\
\end{array}$ & $\mathrm{f}$ & 0 & 3 & 0 & 8.47 & 6.22 & 0.90 & c & CCS \\
\hline 235 & 1.06 & 0.00 & $\mathrm{~b}$ & $\begin{array}{ll}\mathrm{s} & 1\end{array}$ & $\mathrm{f}$ & 0 & 3 & 0 & 1.89 & 3.58 & 1.03 & c & CCS \\
\hline 236 & 1.06 & 0.00 & $\mathrm{~d}$ & -1 & - & - & - & - & - & - & - & c & CCS \\
\hline 237 & 1.06 & 0.72 & $\mathrm{~d}$ & -3 & - & - & - & - & - & - & - & $\mathrm{g}$ & CCS \\
\hline 238 & 1.06 & 0.13 & $\mathrm{f}$ & -2 & - & - & - & 0 & - & - & - & $\mathrm{g}$ & CCS \\
\hline 239 & 1.06 & 0.17 & f & -2 & - & - & - & 0 & - & - & - & $\mathrm{g}$ & CCS \\
\hline 240 & 1.06 & 0.51 & $b$ & \begin{tabular}{l|l} 
s & 4
\end{tabular} & f & 0 & 3 & 0 & 18.15 & 20.15 & 2.53 & w & CCS \\
\hline 241 & 1.06 & 0.28 & b & $\begin{array}{ll}\mathrm{s} \quad 3 \\
\end{array}$ & $\mathrm{u}$ & 0 & 3 & 0 & 6.69 & 14.54 & 1.81 & $\mathrm{~g}$ & CCS \\
\hline 242 & 1.06 & 0.95 & d & -4 & - & - & - & - & - & - & - & $\mathrm{g}$ & CCS \\
\hline 243 & 1.06 & 0.21 & $\mathrm{f}$ & -2 & - & - & - & 0 & - & - & - & $\mathrm{g}$ & CCS \\
\hline 244 & 1.06 & 0.78 & $\mathrm{f}$ & -4 & - & - & - & 0 & - & - & - & $\mathrm{g}$ & CCS \\
\hline 245 & 1.06 & 0.74 & $\mathrm{f}$ & -4 & - & - & - & 0 & - & - & - & w & CCS \\
\hline 246 & 1.06 & 0.04 & b & $\begin{array}{ll}\mathrm{s} & 2 \\
\end{array}$ & $\mathrm{a}$ & 0 & 3 & 0 & 7.34 & 6.08 & 2.11 & $\mathrm{~g}$ & CCS \\
\hline 247 & 1.06 & 0.13 & $\mathrm{f}$ & -2 & - & - & - & 0 & - & - & - & $\mathrm{g}$ & CCS \\
\hline 248 & 1.06 & 0.29 & $\mathrm{f}$ & -2 & - & - & - & 0 & - & - & - & $\mathrm{g}$ & CCS \\
\hline 249 & 1.06 & 0.13 & $\mathrm{f}$ & -2 & - & - & - & 0 & - & - & - & $\mathrm{g}$ & CCS \\
\hline 250 & 1.06 & 0.10 & $\mathrm{~d}$ & -2 & - & - & - & - & - & - & - & $\mathrm{g}$ & CCS \\
\hline 251 & 1.06 & 0.05 & d & -1 & - & - & - & - & - & - & - & w & CCS \\
\hline 252 & 1.06 & 0.10 & d & -2 & - & - & - & - & - & - & - & $\mathrm{g}$ & CCS \\
\hline 253 & 1.06 & 0.07 & $\mathrm{~b}$ & $\begin{array}{ll}\mathrm{s} & 2 \\
\end{array}$ & $\mathrm{cx}$ & 0 & 2 & 0 & 2.24 & 11.02 & 1.37 & $\mathrm{~g}$ & $\mathrm{CCS}$ \\
\hline 254 & 1.06 & 0.20 & f & -3 & - & - & - & 0 & - & - & - & W & CCS \\
\hline 255 & 1.06 & 0.34 & f & -2 & - & - & - & 0 & - & - & - & $\mathrm{g}$ & CCS \\
\hline 256 & 1.06 & 0.07 & d & -1 & - & - & - & - & - & - & - & $\mathrm{g}$ & CCS \\
\hline 257 & 1.06 & 0.07 & $\mathrm{f}$ & -1 & - & - & - & 0 & - & - & - & $\mathrm{g}$ & CCS \\
\hline 258 & 1.06 & 0.13 & d & -2 & - & - & - & - & - & - & - & W & CCS \\
\hline 259 & 1.06 & 0.11 & $\mathrm{~d}$ & -2 & - & - & - & - & - & - & - & $\mathrm{W}$ & CCS \\
\hline 260 & 1.06 & 0.06 & d & -1 & - & - & - & - & - & - & - & $\mathrm{g}$ & CCS \\
\hline 261 & 1.06 & 0.06 & $\mathrm{~d}$ & -1 & - & - & - & - & - & - & - & $\mathrm{g}$ & CCS \\
\hline
\end{tabular}




\begin{tabular}{|c|c|c|c|c|c|c|c|c|c|c|c|c|c|}
\hline 262 & 1.06 & 0.03 & b & $\begin{array}{ll}\mathrm{s} & 1\end{array}$ & \begin{tabular}{|l|l|}
1 & $\mathrm{cx}$ \\
\end{tabular} & 0 & 2 & 0 & 2.23 & 7.59 & 0.87 & g & CCS \\
\hline 263 & 1.06 & 0.18 & $\mathrm{~d}$ & -2 & 2 & - & - & - & - & - & - & w & CCS \\
\hline 264 & 1.06 & 0.00 & $\mathrm{~b}$ & \begin{tabular}{|l|l}
$\mathrm{S}$ & 1 \\
\end{tabular} & \begin{tabular}{l|l}
1 & $\mathrm{cx}$ \\
\end{tabular} & 0 & 1 & 0 & 2.22 & 7.17 & 1.06 & c & CCS \\
\hline 265 & 1.06 & 0.09 & $\mathrm{f}$ & -2 & 2 & - & - & 0 & - & - & - & $\mathrm{g}$ & CCS \\
\hline 266 & 1.06 & 0.97 & $\mathrm{f}$ & -5 & 5 & - & - & 0 & - & - & - & $\mathrm{g}$ & CCS \\
\hline 267 & 1.06 & 0.03 & $\mathrm{~d}$ & -1 & $1-$ & - & - & - & - & - & - & $\mathrm{g}$ & CCS \\
\hline 268 & 1.06 & 0.04 & d & -1 & $1-$ & - & - & - & - & - & - & W & CCS \\
\hline 269 & 1.06 & 0.00 & $\mathrm{f}$ & -1 & $1-$ & - & - & 0 & - & - & - & $\mathrm{g}$ & CCS \\
\hline 270 & 1.06 & 0.09 & $\mathrm{~b}$ & $\begin{array}{ll}\mathrm{s} & 1 \\
\end{array}$ & l cx & 0 & 2 & 0 & 3.99 & 8.50 & 2.14 & $\mathrm{t}$ & CCS \\
\hline 271 & 1.06 & 0.18 & d & -3 & $3-$ & - & - & - & - & - & - & $\mathrm{g}$ & CCS \\
\hline 272 & 1.06 & 0.88 & d & -2 & $2-$ & - & - & - & - & - & - & c & CCS \\
\hline 273 & 1.06 & 0.12 & $\mathrm{~b}$ & $\begin{array}{ll}\mathrm{s} & 2 \\
\end{array}$ & $\begin{array}{ll}2 & \mathrm{f} \\
\end{array}$ & 0 & 3 & 0 & 4.53 & 12.71 & 1.56 & W & CCS \\
\hline 274 & 1.06 & 0.42 & $\mathrm{~b}$ & $\begin{array}{ll}\mathrm{s} \quad 3 \\
\end{array}$ & $3 \mathrm{f}$ & 0 & 3 & 0 & 7.76 & 15.97 & 2.40 & W & CCS \\
\hline 275 & 1.06 & 0.33 & $\mathrm{f}$ & -2 & $2-$ & - & - & 0 & - & - & - & W & CCS \\
\hline 276 & 1.06 & 0.10 & c & $\begin{array}{ll}\mathrm{o} & 2 \\
\end{array}$ & $2 \quad a$ & 0 & 0 & 0 & 5.46 & 7.77 & 1.78 & W & CCS \\
\hline 277 & 1.06 & 0.27 & d & -2 & $2-$ & - & - & - & - & - & - & W & CCS \\
\hline 278 & 1.06 & 0.23 & $\mathrm{~d}$ & -2 & $2-$ & - & - & - & - & - & - & $\mathrm{g}$ & CCS \\
\hline 279 & 1.06 & 0.17 & $\mathrm{~d}$ & -2 & $2-$ & - & - & - & - & - & - & W & CCS \\
\hline 280 & 1.06 & 0.28 & d & -3 & $3-$ & - & - & - & - & - & - & w & CCS \\
\hline 281 & 1.06 & 0.07 & c & $\begin{array}{ll}\text { o } & 1 \\
\end{array}$ & $\mathrm{cx}$ & 0 & 3 & 0 & 2.05 & 8.42 & 1.18 & $\mathrm{~g}$ & CCS \\
\hline 282 & 1.06 & 0.08 & $\mathrm{f}$ & -2 & $2-$ & - & - & 0 & - & - & - & $\mathrm{g}$ & CCS \\
\hline 283 & 1.06 & 0.14 & c & o 2 & $2 \quad \mathrm{cx}$ & 0 & 3 & 0 & 8.66 & 5.91 & 2.76 & $\mathrm{~g}$ & CCS \\
\hline 284 & 1.06 & 0.17 & $\mathrm{f}$ & -2 & $2-$ & - & - & 0 & - & - & - & $\mathrm{g}$ & CCS \\
\hline 285 & 1.06 & 0.22 & b & $\begin{array}{lll}\mathrm{s} & 2 \\
\end{array}$ & $\begin{array}{ll}2 & \mathrm{f} \\
\end{array}$ & 0 & 3 & 0 & 6.23 & 8.60 & 2.42 & $\mathrm{~g}$ & CCS \\
\hline 286 & 1.06 & 0.06 & $\mathrm{f}$ & -1 & $1-$ & - & - & 0 & - & - & - & $\mathrm{g}$ & CCS \\
\hline 287 & 1.06 & 0.10 & c & o 2 & $2 \quad \mathrm{cx}$ & 0 & 3 & 0 & 4.91 & 10.16 & 1.48 & $\mathrm{~g}$ & CCS \\
\hline 288 & 1.06 & 0.00 & $\mathrm{f}$ & -1 & $1-$ & - & - & 0 & - & - & - & $\mathrm{g}$ & CCS \\
\hline 289 & 1.06 & 0.22 & $\mathrm{f}$ & -2 & $2-$ & - & - & 0 & - & - & - & $\mathrm{g}$ & CCS \\
\hline 290 & 1.06 & 0.08 & $\mathrm{f}$ & -2 & 2 & - & - & 0 & - & - & - & $\mathrm{g}$ & CCS \\
\hline 291 & 1.06 & 0.09 & c & o 2 & $2 \quad \mathrm{cx}$ & 0 & 2 & 0 & 1.80 & 9.53 & 0.22 & $\mathrm{~g}$ & CCS \\
\hline 292 & 1.06 & 0.00 & d & -1 & $1-$ & - & - & - & - & - & - & W & CCS \\
\hline 293 & 1.06 & 0.21 & $\mathrm{~d}$ & -3 & $3-$ & - & - & - & - & - & - & $\mathrm{g}$ & CCS \\
\hline 294 & 1.06 & 0.19 & $\mathrm{f}$ & -2 & $2-$ & - & - & 0 & - & - & - & $\mathrm{g}$ & CCS \\
\hline 295 & 1.06 & 0.14 & $\mathrm{f}$ & -2 & $2-$ & - & - & 0 & - & - & - & $\mathrm{g}$ & CCS \\
\hline 296 & 1.06 & 0.15 & $\mathrm{~d}$ & -2 & $2-$ & - & - & - & - & - & - & W & CCS \\
\hline 297 & 1.06 & 0.08 & d & -2 & $2-$ & - & - & - & - & - & - & W & CCS \\
\hline 298 & 1.06 & 0.09 & f & -1 & $1-$ & - & - & 0 & - & - & - & w & CCS \\
\hline 299 & 1.06 & 0.04 & d & -1 & $1-$ & - & - & - & - & - & - & W & CCS \\
\hline 300 & 1.06 & 0.00 & $\mathrm{f}$ & -1 & $1-$ & - & - & 0 & - & - & - & $\mathrm{g}$ & CCS \\
\hline 301 & 1.06 & 0.07 & d & -2 & 2 & - & - & - & - & - & - & $\mathrm{g}$ & CCS \\
\hline 302 & 1.06 & 0.08 & $\mathrm{~d}$ & -2 & $2-$ & - & - & - & - & - & - & c & CCS \\
\hline 303 & 1.06 & 0.03 & f & -1 & $1-$ & - & - & 0 & - & - & - & $\mathrm{g}$ & CCS \\
\hline 304 & 1.06 & 0.13 & $\mathrm{~d}$ & -2 & 2 & - & - & - & - & - & - & $\mathrm{t}$ & CCS \\
\hline
\end{tabular}




\begin{tabular}{|c|c|c|c|c|c|c|c|c|c|c|c|c|c|}
\hline 305 & 1.06 & 0.15 & $\mathrm{f}$ & $-1-3$ & - & - & - & 0 & - & - & - & $\mathrm{t}$ & CCS \\
\hline 306 & 1.06 & 0.18 & d & -1 & - & - & - & - & - & - & - & $\mathrm{g}$ & CCS \\
\hline 307 & 1.06 & 0.03 & $\mathrm{f}$ & -1 & - & - & - & 0 & - & - & - & w & CCS \\
\hline 308 & 1.06 & 0.11 & $\mathrm{f}$ & -2 & - & - & - & 0 & - & - & - & w & CCS \\
\hline 309 & 1.06 & 0.04 & d & -1 & - & - & - & - & - & - & - & $\mathrm{g}$ & CCS \\
\hline 310 & 1.06 & 0.04 & f & -1 & - & - & - & 0 & - & - & - & $\mathrm{g}$ & CCS \\
\hline 311 & 1.06 & 0.00 & $\mathrm{c}$ & $\begin{array}{lll}0 & 1 \\
\end{array}$ & $\mathrm{cx}$ & 0 & 3 & 0 & 2.68 & 7.95 & 0.95 & w & CCS \\
\hline 312 & 1.06 & 0.04 & $\mathrm{f}$ & -1 & - & - & - & 0 & - & - & - & $\mathrm{g}$ & CCS \\
\hline 313 & 1.06 & 0.00 & $\mathrm{f}$ & -1 & - & - & - & 0 & - & - & - & $\mathrm{w}$ & CCS \\
\hline 314 & 1.06 & 0.00 & f & -1 & - & - & - & 0 & - & - & - & w & CCS \\
\hline 315 & 1.06 & 0.00 & $\mathrm{f}$ & -1 & - & - & - & 0 & - & - & - & $\mathrm{g}$ & CCS \\
\hline 316 & 1.06 & 0.05 & c & \begin{tabular}{l|l} 
o & 1 \\
\end{tabular} & $\mathrm{cx}$ & 0 & 3 & 0 & 1.95 & 9.06 & 1.05 & w & CCS \\
\hline 317 & 1.06 & 0.00 & f & -1 & - & - & - & 0 & - & - & - & w & CCS \\
\hline 318 & 1.06 & 0.12 & d & -1 & - & - & - & - & - & - & - & $\mathrm{g}$ & CCS \\
\hline 319 & 1.06 & 0.00 & c & \begin{tabular}{l|l} 
o & 1 \\
\end{tabular} & $\mathrm{f}$ & 0 & 0 & 0 & 3.63 & 7.43 & 1.28 & c & CCS \\
\hline 320 & 1.06 & 0.06 & d & -2 & - & - & - & - & - & - & - & $\mathrm{g}$ & CCS \\
\hline 321 & 1.06 & 0.09 & d & -1 & - & - & - & - & - & - & - & $\mathrm{i}$ & Igneous \\
\hline 322 & 1.06 & 0.00 & d & -1 & - & - & - & - & - & - & - & w & CCS \\
\hline 323 & 1.06 & 0.00 & d & -1 & - & - & - & - & - & - & - & w & CCS \\
\hline 324 & 1.06 & 0.00 & f & -1 & - & - & - & 0 & - & - & - & $\mathrm{g}$ & CCS \\
\hline 325 & 1.06 & 0.00 & f & -1 & - & - & - & 0 & - & - & - & w & CCS \\
\hline 326 & 1.06 & 0.00 & f & -1 & - & - & - & 0 & - & - & - & $\mathrm{g}$ & CCS \\
\hline 327 & 1.06 & 0.06 & $\mathrm{~d}$ & -1 & - & - & - & - & - & - & - & W & CCS \\
\hline 328 & 1.06 & 0.04 & d & -2 & - & - & - & - & - & - & - & w & CCS \\
\hline 329 & 1.06 & 0.00 & $\mathrm{~d}$ & -1 & - & - & - & - & - & - & - & $\mathrm{g}$ & CCS \\
\hline 330 & 1.06 & 0.06 & f & -1 & - & - & - & 0 & - & - & - & $\mathrm{g}$ & CCS \\
\hline 331 & 1.06 & 0.00 & $\mathrm{f}$ & -1 & - & - & - & 0 & - & - & - & $\mathrm{g}$ & CCS \\
\hline 332 & 1.06 & 0.00 & f & -1 & - & - & - & 0 & - & - & - & $\mathrm{g}$ & CCS \\
\hline 333 & 1.06 & 0.00 & $\mathrm{f}$ & -1 & - & - & - & 0 & - & - & - & $\mathrm{g}$ & CCS \\
\hline 334 & 1.06 & 0.00 & $\mathrm{f}$ & -1 & - & - & - & 0 & - & - & - & W & CCS \\
\hline 335 & 1.06 & 0.00 & $\mathrm{f}$ & -1 & - & - & - & 0 & - & - & - & $\mathrm{g}$ & CCS \\
\hline 336 & 1.06 & 0.17 & c & $\begin{array}{ll} & 3 \\
\end{array}$ & $\mathrm{cx}$ & 1 & 3 & 0 & 4.22 & 18.46 & 1.74 & W & CCS \\
\hline 337 & 1.06 & 0.05 & d & -1 & - & - & - & - & - & - & - & w & CCS \\
\hline 338 & 1.06 & 0.10 & $\mathrm{f}$ & -2 & - & - & - & 0 & - & - & - & c & CCS \\
\hline 339 & 1.06 & 0.00 & $\mathrm{~b}$ & $\begin{array}{ll}\mathrm{s} & 1 \\
\end{array}$ & $\mathrm{cx}$ & 0 & 3 & 0 & 5.60 & 6.78 & 0.86 & w & CCS \\
\hline 340 & 1.06 & 3.00 & d & -1 & - & - & - & - & - & - & - & w & CCS \\
\hline 341 & 1.06 & 0.05 & $\mathrm{~b}$ & $\begin{array}{ll}\mathrm{s} & 2 \\
\end{array}$ & $\mathrm{a}$ & 0 & 2 & 0 & 6.13 & 8.36 & 1.14 & c & CCS \\
\hline 342 & 1.06 & 0.04 & $\mathrm{f}$ & -2 & - & - & - & 0 & - & - & - & $\mathrm{g}$ & CCS \\
\hline 343 & 1.06 & 0.09 & $\mathrm{~d}$ & -1 & - & - & - & - & - & - & - & $\mathrm{w}$ & CCS \\
\hline 344 & 1.06 & 0.08 & d & -2 & - & - & - & - & - & - & - & $\mathrm{g}$ & CCS \\
\hline 345 & 1.06 & 0.04 & $\mathrm{~d}$ & -1 & - & - & - & - & - & - & - & $\mathrm{w}$ & CCS \\
\hline 346 & 1.06 & 0.16 & $\mathrm{~d}$ & -2 & - & - & - & - & - & - & - & $\mathrm{g}$ & CCS \\
\hline 347 & 1.06 & 0.00 & $\mathrm{~d}$ & -2 & - & - & - & - & - & - & - & $\mathrm{c}$ & CCS \\
\hline
\end{tabular}




\begin{tabular}{|c|c|c|c|c|c|c|c|c|c|c|c|c|c|c|}
\hline 348 & 1.06 & 0.00 & $\mathrm{f}$ & -1 & $1-$ & - & - & - & 0 & - & - & - & $\mathrm{g}$ & CCS \\
\hline 349 & 1.06 & 0.00 & c & $\begin{array}{lll}\text { o } & 1 \\
\end{array}$ & \begin{tabular}{l|l}
1 & $\mathrm{c} x$ \\
\end{tabular} & \begin{tabular}{l|l}
$\mathrm{x}$ & 0 \\
\end{tabular} & 0 & 3 & 0 & 2.05 & 9.26 & 0.65 & $\mathrm{~g}$ & CCS \\
\hline 350 & 1.06 & 0.04 & f & -1 & $1-$ & - & - & - & 0 & - & - & - & $\mathrm{g}$ & CCS \\
\hline 351 & 1.06 & 0.00 & $\mathrm{~d}$ & -1 & $1-$ & - & - & - & - & - & - & - & $\mathrm{g}$ & CCS \\
\hline 352 & 1.06 & 0.00 & c & $\begin{array}{lll}\text { o } & 1 \\
\end{array}$ & \begin{tabular}{l|l}
1 & $\mathrm{c} x$ \\
\end{tabular} & \begin{tabular}{l|l}
$\mathrm{x}$ & 0 \\
\end{tabular} & 0 & 3 & 0 & 4.28 & 6.61 & 0.84 & $\mathrm{~g}$ & CCS \\
\hline 353 & 1.06 & 0.00 & c & $\begin{array}{lll}\text { o } & 1 \\
\end{array}$ & \begin{tabular}{l|l}
1 & $\mathrm{c} x$ \\
\end{tabular} & \begin{tabular}{l|l}
$\mathrm{x}$ & 0 \\
\end{tabular} & 0 & 3 & 0 & 3.13 & 4.89 & 0.94 & $\mathrm{~g}$ & CCS \\
\hline 354 & 1.06 & 0.00 & c & $\begin{array}{ll}\text { o } & 1 \\
\end{array}$ & $\begin{array}{lll}1 & \mathrm{c} x \\
\end{array}$ & \begin{tabular}{l|l}
$\mathrm{x}$ & 0 \\
\end{tabular} & 0 & 3 & 0 & 0.42 & 6.86 & 1.03 & c & CCS \\
\hline 355 & 1.06 & 0.00 & $\mathrm{~d}$ & -1 & $1-$ & - & - & - & - & - & - & - & $\mathrm{g}$ & CCS \\
\hline 356 & 1.06 & 0.00 & $\mathrm{f}$ & -1 & $1-$ & - & - & - & 0 & - & - & - & $\mathrm{g}$ & CCS \\
\hline 357 & 1.06 & 0.11 & d & -2 & $2-$ & - & - & - & - & - & - & - & $\mathrm{g}$ & CCS \\
\hline 358 & 1.06 & 0.04 & $\mathrm{f}$ & -1 & $1-$ & & - & - & 0 & - & - & - & $\mathrm{g}$ & $\mathrm{CCS}$ \\
\hline 359 & 1.06 & 0.03 & c & $\begin{array}{ll}\text { o } & 1 \\
\end{array}$ & $\begin{array}{lll}1 & \mathrm{c} x \\
\end{array}$ & \begin{tabular}{l|l}
$\mathrm{xx}$ & 0 \\
\end{tabular} & 0 & 3 & 0 & 4.03 & 6.19 & 1.45 & $\mathrm{~g}$ & CCS \\
\hline 360 & 1.06 & 0.00 & $\mathrm{~d}$ & -1 & $1-$ & -1 & - & - & - & - & - & - & $\mathrm{b}$ & CCS \\
\hline 361 & 1.06 & 0.07 & $\mathrm{~d}$ & -2 & $2-$ & -1 & - & - & - & - & - & - & $\mathrm{w}$ & $\mathrm{CCS}$ \\
\hline 362 & 1.06 & 0.00 & f & -1 & $1-$ & - & - & - & 0 & - & - & - & $\mathrm{g}$ & $\mathrm{CCS}$ \\
\hline 363 & 1.06 & 0.00 & $\mathrm{f}$ & -1 & $1-$ & - & - & - & 0 & - & - & - & $\mathrm{c}$ & CCS \\
\hline 364 & 1.06 & 0.00 & $\mathrm{f}$ & -1 & $1-$ & - & - & - & 0 & - & - & - & $t$ & $\mathrm{CCS}$ \\
\hline 365 & 1.06 & 0.00 & c & \begin{tabular}{|l|l|} 
o & 1 \\
\end{tabular} & \begin{tabular}{l|l} 
& $\mathrm{f}$ \\
\end{tabular} & 0 & 0 & 3 & 0 & 2.17 & 7.22 & 0.94 & $\mathrm{~g}$ & $\mathrm{CCS}$ \\
\hline 366 & 1.06 & 0.00 & d & -1 & $1-$ & - & - & - & - & - & - & - & $\mathrm{g}$ & CCS \\
\hline 367 & 1.06 & 0.00 & $\mathrm{~d}$ & -1 & $1-$ & -1 & - & - & - & - & - & - & $\mathrm{g}$ & CCS \\
\hline 368 & 1.06 & 0.00 & f & -1 & $1-$ & - & - & - & 0 & - & - & - & c & $\mathrm{CCS}$ \\
\hline 369 & 1.06 & 0.00 & $\mathrm{f}$ & -1 & $1-$ & -1 & - & - & 0 & - & - & - & $\mathrm{g}$ & $\mathrm{CCS}$ \\
\hline 370 & 1.06 & 0.00 & f & -1 & $1-$ & - & - & - & 0 & - & - & - & $\mathrm{g}$ & $\mathrm{CCS}$ \\
\hline 371 & 1.06 & 0.05 & d & -1 & $1-$ & -1 & - & - & - & - & - & - & c & $\mathrm{CCS}$ \\
\hline 372 & 1.06 & 0.00 & d & -1 & $1-$ & - & - & - & - & - & - & - & $\mathrm{g}$ & CCS \\
\hline 373 & 1.06 & 0.00 & $f$ & -1 & $1-$ & -1 & - & - & 0 & - & - & - & $\mathrm{g}$ & $\mathrm{CCS}$ \\
\hline 374 & 1.06 & 0.06 & $\mathrm{f}$ & -2 & 2 & - & - & - & 0 & - & - & - & $\mathrm{g}$ & CCS \\
\hline 375 & 1.06 & 0.04 & $\mathrm{~b}$ & $\begin{array}{lll}\mathrm{s} & 2 \\
\end{array}$ & $\begin{array}{ll}2 & \mathrm{f} \\
\end{array}$ & 0 & 0 & 3 & 0 & 1.67 & 10.41 & 1.04 & $\mathrm{~g}$ & CCS \\
\hline 376 & 1.06 & 0.07 & d & -1 & $1-$ & -1 & - & - & - & - & - & - & $\mathrm{g}$ & CCS \\
\hline 377 & 1.06 & 0.05 & d & -1 & $1-$ & -1 & - & - & - & - & - & - & w & CCS \\
\hline 378 & 1.06 & 0.07 & d & -1 & $1-$ & - & - & - & - & - & - & - & $\mathrm{g}$ & CCS \\
\hline 379 & 1.06 & 0.00 & d & -1 & - & -1 & - & - & - & - & - & - & $\mathrm{g}$ & $\mathrm{CCS}$ \\
\hline 380 & 1.06 & 0.13 & d & -2 & & - & - & - & - & - & - & - & $\mathrm{g}$ & CCS \\
\hline 381 & 1.06 & 0.00 & d & -1 & - & - & - & - & - & - & - & - & $\mathrm{g}$ & CCS \\
\hline 382 & 1.06 & 0.00 & d & -1 & $1-$ & - & - & - & - & - & - & - & $\mathrm{g}$ & CCS \\
\hline 383 & 1.06 & 0.00 & d & -1 & - & - & - & - & - & - & - & - & $\mathrm{g}$ & $\mathrm{CCS}$ \\
\hline 384 & 1.06 & 0.00 & d & -1 & $1-$ & - & - & - & - & - & - & - & $\mathrm{g}$ & CCS \\
\hline 385 & 1.06 & 0.09 & $\mathrm{~d}$ & -1 & - & - & - & - & - & - & - & - & W & CCS \\
\hline 386 & 1.06 & 0.00 & d & -1 & $1-$ & - & - & - & - & - & - & - & $\mathrm{g}$ & CCS \\
\hline 387 & 1.06 & 0.04 & d & -1 & - & - & - & - & - & - & - & - & $\mathrm{g}$ & $\mathrm{CCS}$ \\
\hline 388 & 1.06 & 0.00 & $\mathrm{~b}$ & \begin{tabular}{l|l} 
s & 1 \\
\end{tabular} & $\mathrm{f}$ & 0 & 0 & 2 & 0 & 1.61 & 4.66 & 0.97 & $\mathrm{~g}$ & CCS \\
\hline 389 & 1.06 & 0.00 & d & -1 & - & - & - & - & - & - & - & - & c & CCS \\
\hline 390 & 1.06 & 0.00 & f & -1 & $1-$ & - & - & - & 0 & - & - & - & w & CCS \\
\hline
\end{tabular}




\begin{tabular}{|c|c|c|c|c|c|c|c|c|c|c|c|c|c|c|}
\hline 391 & 1.06 & 0.00 & b & $\mathrm{s}$ & 1 & $\mathrm{f}$ & 0 & 2 & 0 & 3.04 & 8.60 & 1.15 & $\mathrm{~g}$ & CCS \\
\hline 392 & 1.06 & 0.04 & $\mathrm{~b}$ & $\mathrm{~s}$ & 1 & f & 0 & 2 & 0 & 2.08 & 6.17 & 1.81 & $\mathrm{~g}$ & CCS \\
\hline 393 & 1.06 & 0.00 & $\mathrm{~d}$ & - & 1 & - & - & - & - & - & - & - & $\mathrm{g}$ & CCS \\
\hline 394 & 1.06 & 0.00 & $\mathrm{~d}$ & - & 1 & - & - & - & - & - & - & - & $\mathrm{g}$ & CCS \\
\hline 395 & 1.06 & 0.00 & $\mathrm{f}$ & - & 1 & - & - & - & 0 & - & - & - & $\mathrm{g}$ & CCS \\
\hline 396 & 1.06 & 0.00 & $\mathrm{f}$ & - & 1 & - & - & - & 0 & - & - & - & W & CCS \\
\hline 397 & 1.06 & 0.00 & d & - & 1 & - & - & - & - & - & - & - & b & CCS \\
\hline 398 & 1.06 & 0.00 & d & - & 1 & - & - & - & - & - & - & - & $\mathrm{g}$ & CCS \\
\hline 399 & 1.06 & 0.00 & $\mathrm{f}$ & - & 1 & - & - & - & 0 & - & - & - & W & CCS \\
\hline 400 & 1.06 & 0.00 & d & - & 1 & - & - & - & - & - & - & - & $\mathrm{g}$ & CCS \\
\hline 401 & 1.06 & 0.04 & $\mathrm{f}$ & - & 1 & - & - & - & 0 & - & - & - & $\mathrm{g}$ & CCS \\
\hline 402 & 1.06 & 0.00 & $\mathrm{f}$ & - & 1 & - & - & - & 0 & - & - & - & W & CCS \\
\hline 403 & 1.06 & 0.00 & $\mathrm{f}$ & - & 1 & - & - & - & 0 & - & - & - & w & CCS \\
\hline 404 & 1.06 & 0.00 & d & - & 1 & - & - & - & - & - & - & - & W & CCS \\
\hline 405 & 1.06 & 0.00 & $\mathrm{~d}$ & - & 1 & - & - & - & - & - & - & - & $\mathrm{g}$ & CCS \\
\hline 406 & 1.06 & 0.00 & b & $\mathrm{s}$ & 1 & $\mathrm{u}$ & 0 & 2 & 0 & 3.74 & 4.63 & 0.99 & $\mathrm{t}$ & CCS \\
\hline 407 & 1.06 & 0.00 & $\mathrm{~b}$ & $\mathrm{~s}$ & 1 & f & 0 & 3 & 0 & 3.04 & 5.12 & 1.18 & $\mathrm{~g}$ & CCS \\
\hline 408 & 1.06 & 0.00 & $\mathrm{f}$ & - & 1 & - & - & - & 0 & - & - & - & $\mathrm{b}$ & CCS \\
\hline 409 & 1.06 & 0.00 & $\mathrm{f}$ & - & 1 & - & - & - & 0 & - & - & - & w & CCS \\
\hline 410 & 1.06 & 0.00 & $\mathrm{f}$ & - & 1 & - & - & - & 0 & - & - & - & $\mathrm{g}$ & CCS \\
\hline 411 & 1.06 & 0.00 & $\mathrm{f}$ & - & 1 & - & - & - & 0 & - & - & - & $\mathrm{g}$ & CCS \\
\hline 412 & 1.06 & 0.00 & $\mathrm{f}$ & - & 1 & - & - & - & 0 & - & - & - & $\mathrm{g}$ & CCS \\
\hline 413 & 1.06 & 0.00 & $\mathrm{f}$ & - & 1 & - & - & - & 0 & - & - & - & $\mathrm{g}$ & CCS \\
\hline 414 & 1.06 & 0.00 & d & - & 1 & - & - & - & - & - & - & - & w & CCS \\
\hline 415 & 1.06 & 0.00 & $\mathrm{~d}$ & - & 1 & - & - & - & - & - & - & - & $b$ & CCS \\
\hline 416 & 1.06 & 0.00 & $\mathrm{f}$ & - & 1 & - & - & - & 0 & - & - & - & $\mathrm{g}$ & CCS \\
\hline 417 & 1.06 & 0.00 & c & o & 1 & $\mathrm{cx}$ & 0 & 3 & 0 & 1.68 & 4.82 & 0.86 & W & CCS \\
\hline 418 & 1.06 & 0.00 & d & - & 1 & - & - & - & - & - & - & - & $\mathrm{g}$ & CCS \\
\hline 419 & 1.06 & 0.00 & $\mathrm{f}$ & - & 1 & - & - & - & 0 & - & - & - & c & CCS \\
\hline 420 & 1.06 & 0.00 & $\mathrm{f}$ & - & 1 & - & - & - & 0 & - & - & - & $\mathrm{g}$ & CCS \\
\hline 421 & 1.06 & 0.00 & $\mathrm{f}$ & - & 1 & - & - & - & 0 & - & - & - & $\mathrm{t}$ & CCS \\
\hline 422 & 1.06 & 0.00 & $\mathrm{f}$ & - & 1 & - & - & - & 0 & - & - & - & $b$ & CCS \\
\hline 423 & 1.06 & 0.00 & $\mathrm{f}$ & - & 1 & - & - & - & 0 & - & - & - & $\mathrm{g}$ & CCS \\
\hline 424 & 1.06 & 0.00 & $\mathrm{f}$ & - & 1 & - & - & - & 0 & - & - & - & $\mathrm{g}$ & CCS \\
\hline 425 & 1.06 & 0.00 & c & o & 1 & $\mathrm{cx}$ & 0 & 2 & 0 & 1.29 & 5.43 & 0.72 & $\mathrm{~g}$ & CCS \\
\hline 426 & 1.06 & 0.00 & d & - & 1 & - & - & - & - & - & - & - & $\mathrm{g}$ & CCS \\
\hline 427 & 1.06 & 0.00 & f & - & 1 & - & - & - & 0 & - & - & - & w & CCS \\
\hline 428 & 1.06 & 0.00 & $\mathrm{f}$ & - & 1 & - & - & - & 0 & - & - & - & $\mathrm{g}$ & CCS \\
\hline 429 & 1.06 & 0.00 & d & - & 1 & - & - & - & - & - & - & - & $\mathrm{g}$ & CCS \\
\hline 430 & 1.06 & 0.00 & d & - & 1 & - & - & - & - & - & - & - & $\mathrm{g}$ & CCS \\
\hline 431 & 1.06 & 0.00 & $\mathrm{f}$ & - & 1 & - & - & - & 0 & - & - & - & $\mathrm{g}$ & CCS \\
\hline 432 & 1.06 & 0.00 & d & - & 1 & - & - & - & - & - & - & - & $\mathrm{g}$ & CCS \\
\hline 433 & 1.06 & 0.00 & $\mathrm{~d}$ & - & 1 & - & - & - & - & - & - & - & $\mathrm{g}$ & CCS \\
\hline
\end{tabular}




\begin{tabular}{|c|c|c|c|c|c|c|c|c|c|c|c|c|c|}
\hline 434 & 1.06 & 1.62 & d & \begin{tabular}{|l|l}
- & 4 \\
\end{tabular} & - & - & - & - & - & - & - & $\mathrm{t}$ & CCS \\
\hline 435 & 1.06 & 3.36 & $\mathrm{~b}$ & $\begin{array}{lll}\text { s } & 7 \\
\end{array}$ & $\mathrm{f}$ & 0 & 3 & 0 & 7.70 & 33.40 & 6.70 & $\mathrm{y}$ & CCS \\
\hline 436 & 1.06 & 0.19 & f & -4 & - & - & - & 0 & - & - & - & $\mathrm{t}$ & CCS \\
\hline 437 & 1.06 & 1.75 & $\mathrm{~d}$ & -4 & - & - & - & - & - & - & - & $\mathrm{g}$ & CCS \\
\hline 438 & 1.06 & 0.57 & $\mathrm{f}$ & -4 & - & - & - & 0 & - & - & - & w & CCS \\
\hline 439 & 1.06 & 0.67 & $\mathrm{~d}$ & -3 & - & - & - & - & - & - & - & c & CCS \\
\hline 440 & 1.06 & 0.21 & f & -3 & - & - & - & 0 & - & - & - & c & CCS \\
\hline 441 & 1.06 & 0.65 & $\mathrm{~b}$ & $\begin{array}{lll}\mathrm{s} & 3 \\
\end{array}$ & cx & 0 & 3 & 0 & 3.78 & 15.83 & 3.61 & $\mathrm{~g}$ & CCS \\
\hline 442 & 1.06 & 1.67 & f & -4 & - & - & - & 0 & - & - & - & $\mathrm{g}$ & CCS \\
\hline 443 & 1.06 & 0.10 & $\mathrm{f}$ & -2 & - & - & - & 0 & - & - & - & $\mathrm{g}$ & CCS \\
\hline 444 & 1.06 & 0.11 & d & -2 & - & - & - & - & - & - & - & $\mathrm{t}$ & CCS \\
\hline 445 & 1.06 & 0.43 & $\mathrm{~b}$ & $\begin{array}{ll}\mathrm{s} & 3 \\
\end{array}$ & $\mathrm{cx}$ & 2 & 3 & 2 & 5.83 & 13.71 & 3.83 & $t$ & CCS \\
\hline 446 & 1.06 & 0.31 & d & -2 & - & - & - & - & - & - & - & $\mathrm{t}$ & CCS \\
\hline 447 & 1.06 & 0.18 & f & -2 & - & - & - & 0 & - & - & - & $\mathrm{r}$ & CCS \\
\hline 448 & 1.06 & 0.11 & d & -2 & - & - & - & - & - & - & - & $\mathrm{g}$ & CCS \\
\hline 449 & 1.06 & 0.05 & $\mathrm{~b}$ & \begin{tabular}{l|l}
$\mathrm{s}$ & 1 \\
\end{tabular} & $\mathrm{cx}$ & 0 & 3 & 0 & 4.29 & 6.71 & 1.85 & $\mathrm{~g}$ & CCS \\
\hline 450 & 1.06 & 0.08 & d & -1 & - & - & - & - & - & - & - & $\mathrm{t}$ & CCS \\
\hline 451 & 1.06 & 0.03 & d & -1 & - & - & - & - & - & - & - & $\mathrm{g}$ & CCS \\
\hline 452 & 1.06 & 0.04 & $\mathrm{f}$ & -2 & - & - & - & 0 & - & - & - & $\mathrm{g}$ & CCS \\
\hline 453 & 1.06 & 0.05 & $\mathrm{f}$ & -2 & - & - & - & 0 & - & - & - & $t$ & CCS \\
\hline 454 & 1.06 & 0.06 & $\mathrm{~d}$ & -1 & - & - & - & - & - & - & - & $\mathrm{g}$ & CCS \\
\hline 455 & 1.06 & 0.07 & d & -2 & - & - & - & - & - & - & - & c & CCS \\
\hline 456 & 1.06 & 0.11 & $\mathrm{f}$ & -2 & - & - & - & 0 & - & - & - & c & CCS \\
\hline 457 & 1.06 & 0.09 & $\mathrm{f}$ & -2 & - & - & - & 0 & - & - & - & c & CCS \\
\hline 458 & 1.06 & 0.03 & $\mathrm{~d}$ & -1 & - & - & - & - & - & - & - & c & CCS \\
\hline 459 & 1.06 & 0.00 & $\mathrm{~b}$ & $\begin{array}{ll} & 2 \\
\end{array}$ & $\mathrm{f}$ & 0 & 1 & 0 & 1.14 & 8.02 & 0.77 & c & CCS \\
\hline 460 & 1.06 & 0.00 & $\mathrm{f}$ & -1 & - & - & - & 0 & - & - & - & $\mathrm{g}$ & CCS \\
\hline 461 & 1.06 & 0.00 & f & -1 & - & - & - & 0 & - & - & - & c & CCS \\
\hline 462 & 1.06 & 0.00 & d & -1 & - & - & - & - & - & - & - & c & CCS \\
\hline 463 & 1.06 & 0.00 & $\mathrm{f}$ & -1 & - & - & - & 0 & - & - & - & c & CCS \\
\hline 464 & 1.06 & 0.00 & d & -1 & - & - & - & - & - & - & - & c & CCS \\
\hline 465 & 1.06 & 0.00 & d & -2 & - & - & - & - & - & - & - & c & CCS \\
\hline 466 & 1.06 & 0.00 & c & \begin{tabular}{l|l} 
o & 1 \\
\end{tabular} & $\mathrm{a}$ & 0 & 0 & 0 & 2.70 & 4.45 & 0.91 & c & CCS \\
\hline 467 & 1.06 & 0.00 & $\mathrm{f}$ & -1 & - & - & - & 0 & - & - & - & c & CCS \\
\hline 468 & 1.06 & 4.22 & $\mathrm{f}$ & -5 & - & - & - & 0 & - & - & - & $\mathrm{a}$ & Igneous \\
\hline 469 & 1.06 & 0.79 & $\mathrm{f}$ & -4 & - & - & - & 0 & - & - & - & $\mathrm{g}$ & CCS \\
\hline 470 & 1.06 & 0.21 & f & -3 & - & - & - & 0 & - & - & - & c & CCS \\
\hline 471 & 1.06 & 0.59 & $\mathrm{f}$ & -5 & - & - & - & 0 & - & - & - & c & $\mathrm{CCS}$ \\
\hline 472 & 1.06 & 0.44 & $\mathrm{~d}$ & -3 & - & - & - & - & - & - & - & c & CCS \\
\hline 473 & 1.06 & 0.18 & $\mathrm{f}$ & -2 & - & - & - & 0 & - & - & - & $\mathrm{g}$ & CCS \\
\hline 474 & 1.06 & 0.22 & f & -3 & - & - & - & 0 & - & - & - & $\mathrm{g}$ & CCS \\
\hline 475 & 1.06 & 0.18 & d & -2 & - & - & - & - & - & - & - & $\mathrm{g}$ & CCS \\
\hline 476 & 1.06 & 0.65 & $\mathrm{f}$ & -3 & - & - & - & 0 & - & - & - & $\mathrm{c}$ & CCS \\
\hline
\end{tabular}




\begin{tabular}{|c|c|c|c|c|c|c|c|c|c|c|c|c|c|}
\hline 477 & 1.06 & 0.20 & $\mathrm{~d}$ & -2 & - & - & - & - & - & - & - & $\mathrm{t}$ & CCS \\
\hline 478 & 1.06 & 0.04 & f & -2 & - & - & - & 0 & - & - & - & c & CCS \\
\hline 479 & 1.06 & 0.13 & $\mathrm{~b}$ & $\begin{array}{ll}\mathrm{s} & 2 \\
\end{array}$ & $\mathrm{cx}$ & 0 & 2 & 0 & 4.75 & 10.36 & 1.44 & c & CCS \\
\hline 480 & 1.06 & 0.07 & $\mathrm{f}$ & -2 & - & - & - & 0 & - & - & - & $\mathrm{c}$ & CCS \\
\hline 481 & 1.06 & 0.06 & $\mathrm{f}$ & -2 & - & - & - & 0 & - & - & - & c & CCS \\
\hline 482 & 1.06 & 0.00 & c & \begin{tabular}{l|l} 
o & 1 \\
\end{tabular} & $\mathrm{a}$ & 0 & 3 & 0 & 2.54 & 8.36 & 0.65 & c & CCS \\
\hline 483 & 1.06 & 0.05 & $\mathrm{f}$ & -2 & - & - & - & 0 & - & - & - & c & CCS \\
\hline \begin{tabular}{|l|}
484 \\
\end{tabular} & 1.06 & 0.06 & $\mathrm{f}$ & -2 & - & - & - & 0 & - & - & - & c & CCS \\
\hline 485 & 1.06 & 0.08 & $\mathrm{f}$ & -2 & - & - & - & 0 & - & - & - & $\mathrm{g}$ & CCS \\
\hline \begin{tabular}{|l|}
486 \\
\end{tabular} & 1.06 & 0.00 & $\mathrm{~d}$ & -1 & - & - & - & - & - & - & - & c & CCS \\
\hline \begin{tabular}{|l|}
487 \\
\end{tabular} & 1.06 & 1.57 & c & $\begin{array}{ll}\text { o } & 6 \\
\end{array}$ & $\mathrm{a}$ & 2 & 3 & 1 & 7.88 & 25.08 & 3.89 & $\mathrm{r}$ & CCS \\
\hline \begin{tabular}{|l|l|}
488 \\
\end{tabular} & 1.06 & 0.26 & $\mathrm{f}$ & -3 & - & - & - & 0 & - & - & - & c & CCS \\
\hline \begin{tabular}{|l|}
489 \\
\end{tabular} & 1.06 & 0.39 & $\mathrm{f}$ & -3 & - & - & - & 2 & - & - & - & c & CCS \\
\hline 490 & 1.06 & 0.23 & $\mathrm{~d}$ & -2 & - & - & - & - & - & - & - & $\mathrm{t}$ & CCS \\
\hline 491 & 1.06 & 0.00 & c & $\begin{array}{lll}\text { o } & 1 \\
\end{array}$ & $\mathrm{a}$ & 0 & 3 & 0 & 0.93 & 9.58 & 1.23 & c & CCS \\
\hline 4992 & 1.06 & 0.01 & $\mathrm{~d}$ & -1 & - & - & - & - & - & - & - & $\mathrm{r}$ & CCS \\
\hline 4993 & 1.06 & 0.05 & $\mathrm{f}$ & -1 & - & - & - & 0 & - & - & - & $\mathrm{r}$ & CCS \\
\hline 4994 & 1.06 & 0.00 & $\mathrm{f}$ & -1 & - & - & - & 0 & - & - & - & $\mathrm{r}$ & CCS \\
\hline 495 & 1.06 & 0.00 & $\mathrm{~b}$ & \begin{tabular}{l|l}
$\mathrm{s}$ & 1 \\
\end{tabular} & $\mathrm{f}$ & 0 & 2 & 0 & 3.59 & 5.36 & 0.99 & $\mathrm{~g}$ & CCS \\
\hline 496 & 1.06 & 0.00 & $\mathrm{f}$ & -1 & - & - & - & 0 & - & - & - & $\mathrm{r}$ & CCS \\
\hline \begin{tabular}{|l|}
497 \\
\end{tabular} & 1.06 & 0.00 & $\mathrm{f}$ & -1 & - & - & - & 0 & - & - & - & $\mathrm{r}$ & CCS \\
\hline 4998 & 1.06 & 0.00 & $\mathrm{f}$ & -1 & - & - & - & 0 & - & - & - & $\mathrm{r}$ & CCS \\
\hline 499 & 1.06 & 0.00 & $\mathrm{f}$ & -1 & - & - & - & 0 & - & - & - & $\mathrm{r}$ & CCS \\
\hline 500 & 1.06 & 0.00 & $\mathrm{f}$ & -1 & - & - & - & 0 & - & - & - & $\mathrm{r}$ & CCS \\
\hline 501 & 1.06 & 0.00 & c & $\begin{array}{ll}\text { o } & 1 \\
\end{array}$ & $\mathrm{cx}$ & 0 & 3 & 0 & 2.11 & 4.40 & 0.52 & $\mathrm{r}$ & CCS \\
\hline 502 & 1.06 & 3.38 & $\mathrm{~d}$ & -5 & - & - & - & - & - & - & - & c & CCS \\
\hline 503 & 1.06 & 1.07 & $\mathrm{f}$ & -6 & - & - & - & 0 & - & - & - & $\mathrm{r}$ & CCS \\
\hline 504 & 1.06 & 0.61 & c & \begin{tabular}{ll|l} 
o & 4 \\
\end{tabular} & $\mathrm{cx}$ & 0 & 3 & 0 & 2.55 & 20.94 & 2.45 & $\mathrm{r}$ & CCS \\
\hline 505 & 1.06 & 0.27 & $\mathrm{f}$ & -3 & - & - & - & 0 & - & - & - & $\mathrm{r}$ & CCS \\
\hline 506 & 1.06 & 0.09 & $\mathrm{c}$ & o 2 & $\mathrm{a}$ & 0 & 3 & 0 & 2.20 & 9.15 & 1.80 & $\mathrm{t}$ & $\mathrm{CCS}$ \\
\hline 507 & 1.06 & 0.03 & $\mathrm{~d}$ & -1 & - & - & - & - & - & - & - & $\mathrm{r}$ & CCS \\
\hline 508 & 1.06 & 0.00 & $\mathrm{f}$ & -1 & - & - & - & 0 & - & - & - & $\mathrm{r}$ & CCS \\
\hline 509 & 1.06 & 0.00 & $\mathrm{~d}$ & -1 & - & - & - & - & - & - & - & $\mathrm{r}$ & $\mathrm{CCS}$ \\
\hline 510 & 1.06 & 0.00 & $\mathrm{f}$ & -2 & - & - & - & 0 & - & - & - & $\mathrm{r}$ & $\mathrm{CCS}$ \\
\hline 511 & 1.06 & 0.00 & $\mathrm{c}$ & $\begin{array}{ll}\text { o } & 1 \\
\end{array}$ & $\mathrm{cx}$ & 0 & 3 & 0 & 2.29 & 6.05 & 1.09 & $\mathrm{r}$ & CCS \\
\hline 512 & 1.06 & 4.60 & $\mathrm{c}$ & o 7 & $\mathrm{cx}$ & 2 & 3 & 1 & 3.05 & 35.30 & 8.53 & $\mathrm{t}$ & $\mathrm{CCS}$ \\
\hline 513 & 1.06 & 1.68 & $\mathrm{c}$ & \begin{tabular}{l|l}
05 \\
\end{tabular} & $\mathrm{f}$ & 0 & 3 & 0 & 6.28 & 16.19 & 6.08 & $\mathrm{t}$ & CCS \\
\hline 519 & 1.06 & 0.73 & $\mathrm{~d}$ & -3 & - & - & - & - & - & - & - & $\mathrm{i}$ & Igneous \\
\hline 520 & 1.06 & 4.48 & $\mathrm{~d}$ & -6 & - & - & - & - & - & - & - & $\mathrm{i}$ & Igneous \\
\hline 521 & 1.06 & 0.71 & $\mathrm{~d}$ & -4 & - & - & - & - & - & - & - & $\mathrm{i}$ & Igneous \\
\hline 522 & 1.06 & 0.37 & c & o 3 & $\mathrm{f}$ & 0 & 3 & 0 & 6.22 & 14.68 & 1.97 & $\mathrm{i}$ & Igneous \\
\hline 523 & 1.06 & 0.14 & $\mathrm{f}$ & -2 & - & - & - & 0 & - & - & - & $\mathrm{r}$ & $\mathrm{CCS}$ \\
\hline 524 & 1.06 & 0.00 & $\mathrm{~d}$ & -1 & - & - & - & - & - & - & - & $\mathrm{r}$ & CCS \\
\hline
\end{tabular}




\begin{tabular}{|c|c|c|c|c|c|c|c|c|c|c|c|c|c|}
\hline 525 & 1.06 & 0.07 & c & \begin{tabular}{l|l} 
o & 2 \\
\end{tabular} & $\mathrm{cx}$ & 0 & 3 & 0 & 2.24 & 9.16 & 2.02 & $\mathrm{r}$ & CCS \\
\hline 526 & 1.06 & 0.00 & $\mathrm{~d}$ & -1 & - & - & - & - & - & - & - & $\mathrm{r}$ & CCS \\
\hline 527 & 1.06 & 0.00 & $\mathrm{f}$ & -1 & - & - & - & 0 & - & - & - & $\mathrm{r}$ & CCS \\
\hline 528 & 1.06 & 0.00 & c & \begin{tabular}{l|l} 
o & 1 \\
\end{tabular} & $\mathrm{cx}$ & 2 & 0 & 0 & 6.08 & 4.49 & 0.70 & $\mathrm{r}$ & CCS \\
\hline 529 & 1.06 & 0.00 & c & $\begin{array}{ll} & 1 \\
\end{array}$ & $\mathrm{cx}$ & 0 & 3 & 0 & 2.70 & 5.82 & 0.53 & $\mathrm{r}$ & CCS \\
\hline 530 & 1.06 & 0.00 & $\mathrm{f}$ & -1 & - & - & - & 0 & - & - & - & $\mathrm{r}$ & CCS \\
\hline 531 & 1.06 & 0.00 & c & $\begin{array}{ll} & 1 \\
\end{array}$ & $\mathrm{cx}$ & 0 & 2 & 0 & 2.62 & 6.23 & 0.73 & $\mathrm{r}$ & CCS \\
\hline 532 & 1.06 & 2.28 & c & $\begin{array}{ll} & 6 \\
\end{array}$ & cx & 2 & 3 & 0 & 9.36 & 30.23 & 6.71 & $\mathrm{t}$ & CCS \\
\hline 533 & 1.06 & 4.31 & f & -5 & - & - & - & 0 & - & - & - & $\mathrm{t}$ & CCS \\
\hline 534 & 1.06 & 3.76 & d & -7 & - & - & - & - & - & - & - & b & CCS \\
\hline 535 & 1.06 & 3.50 & $\mathrm{f}$ & -7 & - & - & - & 0 & - & - & - & $\mathrm{t}$ & CCS \\
\hline 536 & 1.06 & 1.06 & c & \begin{tabular}{l|l} 
o & 5 \\
\end{tabular} & $\mathrm{a}$ & 0 & 0 & 0 & 6.95 & 20.72 & 3.85 & $\mathrm{t}$ & CCS \\
\hline 537 & 1.06 & 0.90 & $\mathrm{~b}$ & \begin{tabular}{l|l}
$\mathrm{s}$ & 5 \\
\end{tabular} & $\mathrm{cx}$ & 2 & 3 & 0 & 11.87 & 18.45 & 2.61 & c & CCS \\
\hline 538 & 1.06 & 0.98 & $\mathrm{f}$ & -4 & - & - & - & 0 & - & - & - & $\mathrm{b}$ & CCS \\
\hline 539 & 1.06 & 0.82 & f & -3 & - & - & - & 0 & - & - & - & $t$ & CCS \\
\hline 540 & 1.06 & 0.51 & f & -4 & - & - & - & 0 & - & - & - & $t$ & CCS \\
\hline 541 & 1.06 & 0.28 & $\mathrm{~d}$ & -2 & - & - & - & - & - & - & - & $t$ & CCS \\
\hline 542 & 1.06 & 0.62 & $\mathrm{f}$ & -3 & - & - & - & 0 & - & - & - & $t$ & CCS \\
\hline 543 & 1.06 & 0.34 & $\mathrm{f}$ & -2 & - & - & - & 0 & - & - & - & $t$ & CCS \\
\hline 544 & 1.06 & 0.90 & d & -4 & - & - & - & - & - & - & - & $t$ & CCS \\
\hline 545 & 1.06 & 0.73 & $\mathrm{f}$ & -4 & - & - & - & 0 & - & - & - & c & CCS \\
\hline 546 & 1.06 & 0.10 & $\mathrm{~d}$ & -2 & - & - & - & - & - & - & - & $t$ & CCS \\
\hline 547 & 1.06 & 0.19 & d & -2 & - & - & - & - & - & - & - & c & CCS \\
\hline 548 & 1.06 & 0.99 & c & $\begin{array}{ll}\text { lo } & 3 \\
\end{array}$ & $\mathrm{cx}$ & 0 & 3 & 0 & 8.40 & 16.29 & 4.60 & $t$ & CCS \\
\hline 549 & 1.06 & 0.48 & d & -3 & - & - & - & - & - & - & - & $\mathrm{t}$ & CCS \\
\hline 550 & 1.06 & 0.06 & c & o 2 & $\mathrm{a}$ & 0 & 3 & 0 & 3.39 & 9.75 & 2.23 & $t$ & CCS \\
\hline 551 & 1.06 & 0.00 & $\mathrm{f}$ & -1 & - & - & - & 0 & - & - & - & $\mathrm{b}$ & CCS \\
\hline 552 & 1.06 & 2.44 & b & \begin{tabular}{l|l} 
s 5 \\
\end{tabular} & $\mathrm{a}$ & 0 & 3 & 0 & 10.36 & 21.56 & 4.79 & $\mathrm{r}$ & CCS \\
\hline 555 & 1.06 & 0.89 & d & -3 & - & - & - & - & - & - & - & $\mathrm{r}$ & CCS \\
\hline 556 & 1.06 & 1.20 & d & -3 & - & - & - & - & - & - & - & $t$ & CCS \\
\hline 557 & 1.06 & 1.05 & c & o 5 & cx & 2 & 3 & 0 & 7.38 & 22.48 & 3.22 & $t$ & CCS \\
\hline 558 & 1.06 & 0.40 & c & $\begin{array}{ll}\text { o } 3 \\
\end{array}$ & $\mathrm{f}$ & 0 & 3 & 0 & 6.15 & 13.79 & 2.24 & $\mathrm{r}$ & CCS \\
\hline 559 & 1.06 & 0.62 & c & o 5 & cx & 2 & 3 & 0 & 5.09 & 24.75 & 2.44 & $\mathrm{r}$ & CCS \\
\hline 560 & 1.06 & 0.56 & $\mathrm{~b}$ & $\begin{array}{ll}\mathrm{s} & 4 \\
\end{array}$ & $\mathrm{a}$ & 0 & 3 & 0 & 5.29 & 12.34 & 2.93 & $\mathrm{~g}$ & CCS \\
\hline 561 & 1.06 & 0.34 & d & -2 & - & - & - & - & - & - & - & $t$ & CCS \\
\hline 562 & 1.06 & 0.04 & c & \begin{tabular}{l|l} 
& 1 \\
\end{tabular} & $\mathrm{a}$ & 0 & 3 & 0 & 3.97 & 8.82 & 1.70 & $\mathrm{i}$ & Igneous \\
\hline 563 & 1.06 & 0.09 & f & -2 & - & - & - & 0 & - & - & - & $\mathrm{g}$ & CCS \\
\hline 564 & 1.06 & 0.31 & $\mathrm{f}$ & -2 & - & - & - & 0 & - & - & - & $t$ & CCS \\
\hline 565 & 1.06 & 0.18 & $\mathrm{f}$ & -3 & - & - & - & 0 & - & - & - & c & CCS \\
\hline 566 & 1.06 & 0.23 & d & -2 & - & - & - & - & - & - & - & $t$ & CCS \\
\hline 567 & 1.06 & 0.08 & d & -2 & - & - & - & - & - & - & - & $\mathrm{r}$ & CCS \\
\hline 568 & 1.06 & 0.03 & f & -1 & - & - & - & 0 & - & - & - & $\mathrm{b}$ & CCS \\
\hline 569 & 1.06 & 0.19 & d & -3 & - & - & - & - & - & - & - & $\mathrm{g}$ & CCS \\
\hline
\end{tabular}




\begin{tabular}{|c|c|c|c|c|c|c|c|c|c|c|c|c|c|}
\hline 570 & 1.06 & 0.21 & b & \begin{tabular}{|l|l}
$\mathrm{s}$ & 3 \\
\end{tabular} & $\begin{array}{ll}3 & \mathrm{cx} \\
\end{array}$ & 1 & 3 & 0 & 4.37 & 17.58 & 1.44 & $\mathrm{t}$ & CCS \\
\hline 571 & 1.06 & 0.22 & d & -2 & 2 & - & - & - & - & - & - & c & CCS \\
\hline 572 & 1.06 & 0.14 & $\mathrm{f}$ & -2 & $2-$ & - & - & 0 & - & - & - & $t$ & CCS \\
\hline 573 & 1.06 & 0.04 & $\mathrm{f}$ & -2 & 2 & - & - & 0 & - & - & - & $\mathrm{r}$ & $\mathrm{CCS}$ \\
\hline 574 & 1.06 & 0.00 & d & -1 & $1-$ & - & - & - & - & - & - & $\mathrm{g}$ & CCS \\
\hline 575 & 1.06 & 0.00 & d & -1 & $1-$ & - & - & - & - & - & - & c & CCS \\
\hline 576 & 1.06 & 0.17 & $\mathrm{f}$ & -2 & $2-$ & - & - & 0 & - & - & - & $\mathrm{t}$ & CCS \\
\hline 577 & 1.06 & 0.07 & $\mathrm{~b}$ & \begin{tabular}{l|l}
$\mathrm{s}$ & 1 \\
\end{tabular} & $1 \quad \mathrm{cx}$ & 0 & 3 & 0 & 3.09 & 7.51 & 1.47 & $\mathrm{~g}$ & CCS \\
\hline 578 & 1.06 & 0.00 & $\mathrm{f}$ & -2 & $2-$ & - & - & 0 & - & - & - & $\mathrm{b}$ & CCS \\
\hline 579 & 1.06 & 0.00 & c & $\begin{array}{lll}\text { o } & 1 \\
\end{array}$ & $\begin{array}{ll}\mathrm{a} \\
\mathrm{a}\end{array}$ & 0 & 2 & 0 & 4.21 & 5.58 & 1.38 & $\mathrm{t}$ & $\mathrm{CCS}$ \\
\hline 580 & 1.06 & 0.00 & $\mathrm{f}$ & -1 & $1-$ & - & - & 0 & - & - & - & $t$ & CCS \\
\hline 581 & 1.06 & 0.11 & $\mathrm{f}$ & -2 & $2-$ & - & - & 0 & - & - & - & $t$ & $\mathrm{CCS}$ \\
\hline 582 & 1.06 & 0.03 & $\mathrm{f}$ & -1 & $1-$ & - & - & 0 & - & - & - & $\mathrm{t}$ & CCS \\
\hline 583 & 1.06 & 0.00 & d & -1 & $1-$ & - & - & - & - & - & - & c & CCS \\
\hline 584 & 1.06 & 0.04 & d & -2 & $2-$ & - & - & - & - & - & - & $\mathrm{g}$ & CCS \\
\hline 585 & 1.06 & 0.07 & d & -2 & $2-$ & - & - & - & - & - & - & $t$ & CCS \\
\hline 586 & 1.06 & 0.00 & $\mathrm{~d}$ & -1 & $1-$ & - & - & - & - & - & - & $\mathrm{g}$ & CCS \\
\hline 587 & 1.06 & 0.20 & d & -2 & $2-$ & - & - & - & - & - & - & $t$ & CCS \\
\hline 588 & 1.06 & 0.12 & $\mathrm{f}$ & -2 & 2 & - & - & 0 & - & - & - & $\mathrm{g}$ & CCS \\
\hline 589 & 1.06 & 0.07 & c & o 2 & $2 \quad \mathrm{cx}$ & 0 & 3 & 0 & 3.57 & 13.95 & 1.77 & $t$ & CCS \\
\hline 590 & 1.06 & 0.00 & $\mathrm{f}$ & -1 & $1-$ & - & - & 0 & - & - & - & $\mathrm{g}$ & CCS \\
\hline 591 & 1.06 & 0.00 & $\mathrm{~d}$ & -2 & 2 & - & - & - & - & - & - & $\mathrm{b}$ & CCS \\
\hline 592 & 1.06 & 0.00 & $\mathrm{~d}$ & -1 & $1-$ & - & - & - & - & - & - & $\mathrm{g}$ & CCS \\
\hline 593 & 1.06 & 0.00 & $\mathrm{f}$ & -1 & $1-$ & - & - & 0 & - & - & - & b & CCS \\
\hline 594 & 1.06 & 0.00 & $\mathrm{f}$ & -1 & $1-$ & - & - & 0 & - & - & - & $\mathrm{b}$ & CCS \\
\hline 595 & 1.06 & 0.00 & $\mathrm{~d}$ & -1 & $1-$ & - & - & - & - & - & - & $\mathrm{b}$ & CCS \\
\hline 598 & 1.09 & 0.90 & $\mathrm{~d}$ & -4 & $4-$ & - & - & - & - & - & - & $\mathrm{r}$ & CCS \\
\hline 599 & 1.09 & 0.46 & $\mathrm{f}$ & -4 & $4-$ & - & - & 0 & - & - & - & $t$ & CCS \\
\hline 600 & 1.09 & 0.43 & b & $\begin{array}{ll}\mathrm{s} & 3 \\
\end{array}$ & $3 \quad \mathrm{cx}$ & 0 & 3 & 0 & 3.69 & 17.98 & 2.93 & $t$ & CCS \\
\hline 601 & 1.09 & 0.29 & $\mathrm{~b}$ & $\begin{array}{ll}\mathrm{s} & 3 \\
\end{array}$ & $3 \quad \mathrm{cx}$ & 0 & 3 & 0 & 5.48 & 11.95 & 2.43 & $\mathrm{~g}$ & CCS \\
\hline 603 & 1.09 & 0.58 & c & \begin{tabular}{l|l} 
o & 4 \\
\end{tabular} & $\begin{array}{l}4 \quad \mathrm{a} \\
\end{array}$ & 0 & 3 & 0 & 10.12 & 15.07 & 3.19 & c & CCS \\
\hline 604 & 1.09 & 0.42 & $\mathrm{f}$ & -3 & $3-$ & - & - & 0 & - & - & - & $t$ & CCS \\
\hline 606 & 1.09 & 0.18 & $\mathrm{~b}$ & s 2 & $2 \quad \mathrm{cx}$ & 0 & 3 & 0 & 6.70 & 12.32 & 1.87 & c & CCS \\
\hline 607 & 1.09 & 0.26 & $\mathrm{f}$ & -2 & $2-$ & - & - & 0 & - & - & - & $\mathrm{r}$ & CCS \\
\hline 609 & 1.09 & 0.22 & c & o 22 & $2 \quad \mathrm{cx}$ & 0 & 3 & 0 & 2.74 & 10.40 & 1.59 & $\mathrm{~b}$ & CCS \\
\hline 611 & 1.09 & 0.25 & $\mathrm{~d}$ & -2 & $2-$ & - & - & - & - & - & - & $\mathrm{g}$ & CCS \\
\hline 612 & 1.09 & 0.03 & c & o 1 & $\mathrm{f}$ & 0 & 3 & 0 & 1.77 & 7.18 & 1.21 & $y$ & CCS \\
\hline 613 & 1.09 & 0.14 & $\mathrm{f}$ & -2 & $2-$ & - & - & 0 & - & - & - & $\mathrm{t}$ & CCS \\
\hline 614 & 1.09 & 0.00 & $\mathrm{f}$ & -1 & $1-$ & - & - & 0 & - & - & - & $\mathrm{t}$ & CCS \\
\hline 615 & 1.09 & 0.00 & $\mathrm{f}$ & -1 & $1-$ & - & - & 0 & - & - & - & c & CCS \\
\hline 617 & 1.09 & 0.11 & $\mathrm{f}$ & -2 & $2-$ & - & - & 0 & - & - & - & $t$ & CCS \\
\hline 618 & 1.09 & 0.00 & c & $\begin{array}{ll} & 1\end{array}$ & $1 \quad \mathrm{cx}$ & 0 & 2 & 0 & 3.82 & 5.81 & 1.00 & $\mathrm{y}$ & CCS \\
\hline 619 & 1.09 & 0.00 & $\mathrm{~b}$ & \begin{tabular}{l|l} 
s & 1
\end{tabular} & $1 \quad c x$ & 0 & 1 & 0 & 6.30 & 5.09 & 1.34 & $t$ & CCS \\
\hline
\end{tabular}




\begin{tabular}{|c|c|c|c|c|c|c|c|c|c|c|c|c|c|c|}
\hline 620 & 1.09 & 0.00 & c & o & 1 & cx & 0 & 2 & 0 & 2.06 & 6.72 & 0.99 & b & CCS \\
\hline 621 & 1.09 & 0.00 & $\mathrm{~d}$ & - & 1 & - & - & - & - & - & - & - & $\mathrm{t}$ & CCS \\
\hline 622 & 1.09 & 0.00 & f & - & 1 & - & - & - & 0 & - & - & - & $\mathrm{w}$ & CCS \\
\hline 623 & 1.09 & 0.07 & $\mathrm{f}$ & - & 1 & - & - & - & 0 & - & - & - & $\mathrm{t}$ & CCS \\
\hline 624 & 1.09 & 0.00 & c & o & 1 & $\mathrm{f}$ & 0 & 3 & 0 & 2.68 & 7.55 & 0.99 & $\mathrm{~b}$ & CCS \\
\hline 625 & 1.09 & 0.00 & $\mathrm{f}$ & - & 1 & - & - & - & 0 & - & - & - & $\mathrm{g}$ & CCS \\
\hline 626 & 1.09 & 0.00 & $\mathrm{f}$ & - & 1 & - & - & - & 0 & - & - & - & b & CCS \\
\hline 627 & 1.09 & 0.00 & $\mathrm{~b}$ & $\mathrm{~s}$ & 1 & $\mathrm{cx}$ & 0 & 2 & 0 & 2.06 & 7.35 & 0.93 & b & CCS \\
\hline 629 & 1.09 & 0.00 & $\mathrm{f}$ & - & 1 & - & - & - & 0 & - & - & - & c & CCS \\
\hline 631 & 1.09 & 0.78 & d & - & 3 & - & - & - & - & - & - & - & $\mathrm{r}$ & CCS \\
\hline 633 & 1.09 & 0.27 & c & o & 3 & $\mathrm{a}$ & 0 & 3 & 0 & 4.66 & 16.26 & 1.96 & $t$ & CCS \\
\hline 634 & 1.09 & 0.48 & c & $\mathrm{o}$ & 4 & $\mathrm{cx}$ & 0 & 3 & 0 & 6.74 & 21.15 & 2.90 & $t$ & CCS \\
\hline 635 & 1.09 & 0.41 & $\mathrm{~b}$ & $\mathrm{~s}$ & 4 & $\mathrm{cx}$ & 0 & 2 & 0 & 9.03 & 19.24 & 2.83 & $t$ & CCS \\
\hline 636 & 1.09 & 0.26 & $\mathrm{f}$ & - & 3 & - & - & - & 1 & - & - & - & c & CCS \\
\hline 637 & 1.09 & 0.32 & $\mathrm{~b}$ & $\mathrm{~s}$ & 3 & $\mathrm{a}$ & 0 & 3 & 0 & 4.96 & 16.37 & 2.71 & $t$ & CCS \\
\hline 639 & 1.09 & 0.14 & c & o & 3 & $\mathrm{a}$ & 0 & 3 & 0 & 2.43 & 14.99 & 1.04 & $\mathrm{t}$ & CCS \\
\hline 640 & 1.09 & 0.11 & c & o & 2 & $\mathrm{cx}$ & 0 & 2 & 0 & 2.72 & 12.26 & 1.11 & $\mathrm{~b}$ & CCS \\
\hline 641 & 1.09 & 0.00 & $\mathrm{f}$ & - & 1 & - & - & - & 0 & - & - & - & $t$ & CCS \\
\hline 642 & 1.09 & 0.07 & c & o & 2 & $\mathrm{cx}$ & 0 & 3 & 0 & 2.28 & 10.33 & 1.43 & $\mathrm{~g}$ & CCS \\
\hline 643 & 1.09 & 0.06 & c & o & 2 & $\mathrm{cx}$ & 0 & 3 & 0 & 3.09 & 9.84 & 1.50 & $t$ & CCS \\
\hline 644 & 1.09 & 0.00 & c & $\mathrm{o}$ & 1 & $\mathrm{cx}$ & 0 & 2 & 0 & 2.17 & 8.11 & 0.96 & $\mathrm{t}$ & CCS \\
\hline 646 & 1.09 & 0.00 & $\mathrm{f}$ & - & 1 & - & - & - & 0 & - & - & - & $b$ & CCS \\
\hline 647 & 1.09 & 0.00 & $\mathrm{~d}$ & - & 1 & - & - & - & - & - & - & - & $\mathrm{t}$ & CCS \\
\hline 648 & 1.09 & 0.00 & c & o & 1 & $\mathrm{cx}$ & 0 & 3 & 0 & 1.36 & 6.22 & 0.83 & $\mathrm{~b}$ & CCS \\
\hline 649 & 1.09 & 0.00 & $\mathrm{f}$ & - & 1 & - & - & - & 0 & - & - & - & $\mathrm{t}$ & CCS \\
\hline 650 & 1.09 & 0.00 & c & o & 1 & $\mathrm{cx}$ & 0 & 2 & 0 & 2.02 & 6.70 & 0.67 & $b$ & CCS \\
\hline 651 & 1.09 & 0.00 & $\mathrm{~b}$ & $\mathrm{~s}$ & 1 & $\mathrm{cx}$ & 0 & 2 & 0 & 3.21 & 8.22 & 0.83 & $\mathrm{t}$ & CCS \\
\hline 652 & 1.09 & 0.00 & d & - & 1 & - & - & - & - & - & - & - & $\mathrm{w}$ & CCS \\
\hline 653 & 1.09 & 0.00 & d & - & 1 & - & - & - & - & - & - & - & $t$ & CCS \\
\hline 654 & 1.09 & 0.00 & d & - & 1 & - & - & - & - & - & - & - & $\mathrm{w}$ & CCS \\
\hline 655 & 1.09 & 0.00 & c & 0 & 1 & $\mathrm{cx}$ & 0 & 3 & 0 & 3.68 & 6.72 & 0.65 & w & CCS \\
\hline 656 & 1.09 & 0.00 & $\mathrm{f}$ & - & 1 & - & - & - & 0 & - & - & - & $\mathrm{w}$ & CCS \\
\hline 657 & 1.09 & 0.00 & $\mathrm{~b}$ & $\mathrm{~s}$ & 1 & $\mathrm{cx}$ & 0 & 3 & 0 & 2.71 & 7.53 & 0.70 & w & CCS \\
\hline 658 & 1.09 & 0.00 & $\mathrm{f}$ & - & 1 & - & - & - & 0 & - & - & - & $t$ & CCS \\
\hline 659 & 1.09 & 0.00 & $\mathrm{~b}$ & $\mathrm{~s}$ & 1 & $\mathrm{cx}$ & 0 & 2 & 0 & 3.09 & 4.67 & 0.96 & $\mathrm{w}$ & CCS \\
\hline 660 & 1.09 & 0.00 & c & $\mathrm{o}$ & 1 & $\mathrm{cx}$ & 0 & 3 & 0 & 2.71 & 6.63 & 1.02 & $\mathrm{w}$ & CCS \\
\hline 661 & 1.09 & 0.00 & f & - & 1 & - & - & - & 0 & - & - & - & $\mathrm{t}$ & CCS \\
\hline 662 & 1.09 & 0.00 & d & - & 1 & - & - & - & - & - & - & - & $\mathrm{i}$ & Igneous \\
\hline 664 & 1.09 & 0.00 & $\mathrm{~b}$ & $\mathrm{~s}$ & 1 & cx & 0 & 2 & 0 & 1.58 & 4.54 & 0.52 & $\mathrm{w}$ & CCS \\
\hline 665 & 1.05 & 3.57 & c & o & 8 & f & 0 & 3 & 0 & 24.64 & 27.18 & 3.61 & $\mathrm{~g}$ & CCS \\
\hline 666 & 1.05 & 11.42 & c & o & 8 & $\mathrm{cx}$ & 2 & 3 & 0 & 27.56 & 33.14 & 9.25 & $\mathrm{i}$ & Igneous \\
\hline 667 & 1.05 & 3.04 & $\mathrm{f}$ & -4 & 4 & - & - & - & 1 & - & - & - & $t$ & CCS \\
\hline 668 & 1.05 & 1.09 & c & o: & 5 & $\mathrm{a}$ & 0 & 3 & 0 & 7.57 & 25.97 & 3.52 & $\mathrm{t}$ & CCS \\
\hline
\end{tabular}




\begin{tabular}{|c|c|c|c|c|c|c|c|c|c|c|c|c|c|}
\hline 669 & 1.05 & 0.60 & f & \begin{tabular}{l|l}
- & 4 \\
\end{tabular} & - & - & - & 0 & - & - & - & $\mathrm{g}$ & CCS \\
\hline 670 & 1.05 & 0.28 & $\mathrm{f}$ & -3 & - & - & - & 0 & - & - & - & $\mathrm{r}$ & CCS \\
\hline 671 & 1.05 & 0.70 & c & \begin{tabular}{|l|l|} 
o & 4 \\
\end{tabular} & $\mathrm{a}$ & 0 & 3 & 0 & 7.93 & 19.17 & 2.38 & c & CCS \\
\hline 672 & 1.05 & 0.34 & $\mathrm{f}$ & -3 & - & - & - & 0 & - & - & - & $\mathrm{g}$ & CCS \\
\hline 673 & 1.05 & 0.09 & $\mathrm{~b}$ & \begin{tabular}{|l|l}
$\mathrm{s}$ & 2 \\
\end{tabular} & $\mathrm{a}$ & 0 & 3 & 0 & 7.15 & 9.03 & 1.06 & $\mathrm{~g}$ & CCS \\
\hline 674 & 1.05 & 0.07 & $\mathrm{f}$ & -1 & - & - & - & 0 & - & - & - & c & CCS \\
\hline 675 & 1.05 & 0.19 & d & -2 & - & - & - & - & - & - & - & $t$ & CCS \\
\hline 676 & 1.05 & 0.07 & c & $\begin{array}{ll} \\
\end{array}$ & $c x$ & 0 & 3 & 0 & 6.31 & 6.19 & 1.56 & c & CCS \\
\hline 677 & 1.05 & 0.00 & $\mathrm{f}$ & -1 & - & - & - & 0 & - & - & - & $\mathrm{r}$ & CCS \\
\hline 678 & 1.05 & 0.00 & d & -1 & - & - & - & - & - & - & - & c & CCS \\
\hline 679 & 1.05 & 0.00 & c & \begin{tabular}{l|l} 
& 1 \\
\end{tabular} & $\mathrm{cx}$ & 0 & 2 & 0 & 2.77 & 6.78 & 0.92 & c & CCS \\
\hline 680 & 1.05 & 0.00 & d & -1 & - & - & - & - & - & - & - & c & CCS \\
\hline 681 & 1.05 & 0.03 & $\mathrm{f}$ & -1 & - & - & - & 0 & - & - & - & c & CCS \\
\hline 682 & 1.05 & 0.00 & d & -1 & - & - & - & - & - & - & - & $\mathrm{g}$ & CCS \\
\hline 683 & 1.05 & 0.00 & f & -1 & - & - & - & 0 & - & - & - & c & CCS \\
\hline 684 & 1.08 & 0.62 & c & $\begin{array}{ll}\text { o } & 4 \\
\end{array}$ & $\mathrm{cx}$ & 0 & 3 & 0 & 7.26 & 19.10 & 4.07 & $t$ & CCS \\
\hline 685 & 1.05 & 41.29 & c & $\begin{array}{lll}\text { o } & 14 \\
\end{array}$ & $\mathrm{cx}$ & 2 & 3 & 0 & 37.61 & 60.42 & 11.53 & $t$ & CCS \\
\hline 686 & 1.05 & 0.87 & $\mathrm{~b}$ & \begin{tabular}{|l|l}
$\mathrm{s}$ & 4 \\
\end{tabular} & $\mathrm{f}$ & 0 & 2 & 0 & 7.74 & 17.75 & 3.21 & w & CCS \\
\hline 687 & 1.05 & 2.21 & $\mathrm{f}$ & -5 & - & - & - & 0 & - & - & - & $\mathrm{g}$ & CCS \\
\hline 688 & 1.05 & 0.98 & $\mathrm{f}$ & -4 & - & - & - & 0 & - & - & - & c & CCS \\
\hline 689 & 1.05 & 1.23 & d & -4 & - & - & - & - & - & - & - & $\mathrm{g}$ & CCS \\
\hline 690 & 1.05 & 0.67 & d & -4 & - & - & - & - & - & - & - & b & CCS \\
\hline 691 & 1.05 & 0.26 & d & -2 & - & - & - & - & - & - & - & $\mathrm{g}$ & CCS \\
\hline 693 & 1.05 & 0.27 & b & $\begin{array}{ll}\mathrm{s} & 2 \\
\end{array}$ & $\mathrm{cx}$ & 0 & 3 & 0 & 6.40 & 9.83 & 2.02 & $\mathrm{~g}$ & CCS \\
\hline 694 & 1.05 & 0.10 & $\mathrm{f}$ & -2 & - & - & - & 0 & - & - & - & $\mathrm{r}$ & CCS \\
\hline 695 & 1.05 & 0.07 & $\mathrm{f}$ & -1 & - & - & - & 0 & - & - & - & c & CCS \\
\hline 696 & 1.05 & 0.13 & $\mathrm{~b}$ & $\begin{array}{ll}\mathrm{s} & 2 \\
\end{array}$ & $\mathrm{cx}$ & 0 & 2 & 0 & 6.96 & 10.73 & 2.56 & $\mathrm{~g}$ & CCS \\
\hline 697 & 1.05 & 0.05 & $\mathrm{f}$ & -2 & - & - & - & 0 & - & - & - & W & CCS \\
\hline 698 & 1.05 & 0.00 & d & -1 & - & - & - & - & - & - & - & c & CCS \\
\hline 699 & 1.05 & 0.00 & $\mathrm{f}$ & -1 & - & - & - & 0 & - & - & - & W & CCS \\
\hline 700 & 1.05 & 0.02 & $\mathrm{f}$ & -2 & - & - & - & 0 & - & - & - & c & CCS \\
\hline 701 & 1.05 & 0.00 & $\mathrm{f}$ & -1 & - & - & - & 0 & - & - & - & $\mathrm{g}$ & CCS \\
\hline 702 & 1.05 & 0.00 & $\mathrm{f}$ & -1 & - & - & - & 0 & - & - & - & c & CCS \\
\hline 703 & 1.05 & 0.00 & $\mathrm{f}$ & -1 & - & - & - & 0 & - & - & - & c & CCS \\
\hline 704 & 1.05 & 0.00 & $\mathrm{f}$ & -1 & - & - & - & 0 & - & - & - & $\mathrm{g}$ & CCS \\
\hline 705 & 1.08 & 0.33 & d & -3 & - & - & - & - & - & - & - & $\mathrm{r}$ & CCS \\
\hline 706 & 1.08 & 0.18 & f & -2 & - & - & - & 0 & - & - & - & $\mathrm{g}$ & CCS \\
\hline 707 & 1.08 & 0.15 & c & $\begin{array}{ll}\text { o } & 3 \\
\end{array}$ & $\mathrm{cx}$ & 1 & 3 & 0 & 3.95 & 14.81 & 1.79 & $\mathrm{t}$ & CCS \\
\hline 708 & 1.08 & 0.07 & $\mathrm{f}$ & -2 & - & - & - & 0 & - & - & - & $\mathrm{g}$ & CCS \\
\hline 709 & 1.08 & 0.05 & f & -2 & - & - & - & 0 & - & - & - & c & CCS \\
\hline 710 & 1.08 & 0.00 & d & -1 & - & - & - & - & - & - & - & w & CCS \\
\hline 711 & 1.08 & 0.00 & b & $\begin{array}{ll}\mathrm{s} & 1\end{array}$ & cx & 0 & 2 & 0 & 2.99 & 4.30 & 0.83 & w & CCS \\
\hline 712 & 1.08 & 0.00 & f & -1 & - & E & - & 0 & - & - & - & w & CCS \\
\hline
\end{tabular}




\begin{tabular}{|c|c|c|c|c|c|c|c|c|c|c|c|c|c|c|}
\hline 713 & 1.08 & 0.00 & c & o & 1 & $\mathrm{f}$ & 0 & 3 & 0 & 2.79 & 6.59 & 0.78 & w & CCS \\
\hline 714 & 1.08 & 0.00 & $\mathrm{~b}$ & $\mathrm{~s}$ & 1 & cx & 0 & 2 & 0 & 3.17 & 5.38 & 0.62 & w & CCS \\
\hline 715 & 1.08 & 0.00 & c & o & 1 & $\mathrm{a}$ & 0 & 3 & 0 & 1.78 & 6.32 & 1.07 & $b$ & CCS \\
\hline 716 & 1.08 & 0.00 & $\mathrm{~b}$ & $\mathrm{~s}$ & 1 & $\mathrm{a}$ & 0 & 3 & 0 & 3.57 & 5.49 & 1.02 & $b$ & CCS \\
\hline 717 & 1.01 & 1.96 & $\mathrm{f}$ & -5 & 5 & - & - & - & 0 & - & - & - & $\mathrm{y}$ & CCS \\
\hline 719 & 1.01 & 0.29 & $\mathrm{f}$ & -3 & 3 & - & - & - & 0 & - & - & - & $\mathrm{r}$ & CCS \\
\hline 720 & 1.01 & 0.72 & $\mathrm{f}$ & -3 & 3 & - & - & - & 0 & - & - & - & c & CCS \\
\hline 721 & 1.01 & 0.14 & $\mathrm{f}$ & -3 & 3 & - & - & - & 0 & - & - & - & c & CCS \\
\hline 722 & 1.01 & 0.19 & f & -2 & 2 & - & - & - & 0 & - & - & - & c & CCS \\
\hline 723 & 1.01 & 0.11 & d & - & 1 & - & - & - & - & - & - & - & c & CCS \\
\hline 724 & 1.01 & 0.08 & $\mathrm{~b}$ & $\mathrm{~s}$ & 1 & cx & 0 & 2 & 0 & 4.28 & 6.43 & 2.21 & c & CCS \\
\hline 725 & 1.01 & 0.11 & $\mathrm{f}$ & -2 & 2 & - & - & - & 0 & - & - & - & c & CCS \\
\hline 726 & 1.01 & 0.25 & $\mathrm{~b}$ & $\mathrm{~s}$ & 3 & f & 0 & 2 & 0 & 6.78 & 14.23 & 2.21 & $\mathrm{~g}$ & CCS \\
\hline 727 & 1.01 & 0.05 & c & o 2 & 2 & cx & 0 & 3 & 0 & 3.21 & 8.54 & 1.18 & b & CCS \\
\hline 728 & 1.01 & 0.11 & f & -2 & 2 & - & - & - & 0 & - & - & - & c & CCS \\
\hline 729 & 1.01 & 0.00 & c & o & 1 & $\mathrm{f}$ & 0 & 0 & 0 & 5.90 & 3.64 & 1.22 & $\mathrm{~g}$ & CCS \\
\hline 730 & 1.01 & 0.03 & f & -2 & 2 & - & - & - & 0 & - & - & - & $\mathrm{g}$ & CCS \\
\hline 731 & 1.01 & 0.11 & c & o & 2 & $\mathrm{cx}$ & 0 & 3 & 0 & 2.79 & 14.91 & 1.63 & c & CCS \\
\hline 732 & 1.01 & 0.05 & $\mathrm{f}$ & -2 & 2 & - & - & - & 0 & - & - & - & c & CCS \\
\hline 733 & 1.01 & 0.00 & c & o & 1 & $\mathrm{cx}$ & 0 & 3 & 0 & 3.67 & 3.67 & 2.08 & c & CCS \\
\hline 734 & 1.01 & 0.00 & c & o & 1 & cx & 0 & 3 & 0 & 2.07 & 5.42 & 0.66 & c & CCS \\
\hline 735 & 1.01 & 0.00 & $\mathrm{~b}$ & $\mathrm{~s}$ & 1 & $\mathrm{cx}$ & 0 & 3 & 0 & 1.40 & 5.52 & 0.55 & $\mathrm{r}$ & CCS \\
\hline 736 & 1.02 & 0.15 & $\mathrm{f}$ & -3 & 3 & - & - & - & 0 & - & - & - & c & CCS \\
\hline 737 & 1.02 & 0.16 & $\mathrm{f}$ & -3 & 3 & - & - & - & 0 & - & - & - & c & CCS \\
\hline 738 & 1.02 & 0.40 & $\mathrm{f}$ & -3 & 3 & - & - & - & 0 & - & - & - & c & CCS \\
\hline 739 & 1.02 & 0.21 & $\mathrm{f}$ & -2 & 2 & - & - & - & 0 & - & - & - & $t$ & CCS \\
\hline 740 & 1.02 & 0.20 & d & -2 & 2 & - & - & - & - & - & - & - & $\mathrm{g}$ & CCS \\
\hline 741 & 1.02 & 0.08 & d & - & 1 & - & - & - & - & - & - & - & $\mathrm{g}$ & CCS \\
\hline 742 & 1.02 & 0.07 & d & - & 1 & - & - & - & - & - & - & - & $\mathrm{g}$ & CCS \\
\hline 743 & 1.02 & 0.16 & d & -3 & 3 & - & - & - & - & - & - & - & W & CCS \\
\hline 744 & 1.02 & 0.11 & c & o & 2 & $\mathrm{cx}$ & 0 & 3 & 0 & 6.57 & 5.50 & 1.92 & c & CCS \\
\hline 745 & 1.02 & 0.16 & $\mathrm{~b}$ & $\mathrm{~s}$ & 2 & $\mathrm{a}$ & 0 & 3 & 0 & 2.71 & 10.30 & 2.28 & c & CCS \\
\hline 746 & 1.02 & 0.00 & $\mathrm{f}$ & - & 1 & - & - & - & 0 & - & - & - & c & CCS \\
\hline 747 & 1.10 & 10.08 & d & - & 9 & - & - & - & - & - & - & - & $\mathrm{t}$ & CCS \\
\hline 748 & 1.10 & 0.20 & c & o 3 & 3 & $c x$ & 1 & 3 & 0 & 3.81 & 14.87 & 1.32 & $\mathrm{y}$ & $\mathrm{CCS}$ \\
\hline 749 & 1.10 & 0.37 & $\mathrm{f}$ & -3 & 3 & - & - & - & 0 & - & - & - & $\mathrm{t}$ & CCS \\
\hline 751 & 1.10 & 0.18 & f & -2 & 2 & - & - & - & 0 & - & - & - & $\mathrm{t}$ & CCS \\
\hline 752 & 1.10 & 0.16 & d & -2 & 2 & - & - & - & - & - & - & - & $\mathrm{i}$ & Igneous \\
\hline 753 & 1.10 & 0.15 & f & -2 & 2 & - & - & - & 0 & - & - & - & $\mathrm{t}$ & CCS \\
\hline 754 & 1.10 & 0.07 & d & -3 & 3 & - & - & - & - & - & - & - & $\mathrm{t}$ & CCS \\
\hline 755 & 1.10 & 0.00 & $\mathrm{~d}$ & - & 1 & - & - & - & - & - & - & - & $t$ & CCS \\
\hline 756 & 1.10 & 0.00 & $\mathrm{~d}$ & - & 1 & - & - & - & - & - & - & - & $t$ & CCS \\
\hline 757 & 1.10 & 0.00 & $\mathrm{f}$ & - & & - & - & - & 0 & - & - & - & $\mathrm{b}$ & CCS \\
\hline
\end{tabular}




\begin{tabular}{|c|c|c|c|c|c|c|c|c|c|c|c|c|c|}
\hline 758 & 2.06 & 0.42 & $\mathrm{f}$ & \begin{tabular}{|l|l|}
-3 \\
\end{tabular} & - & - & - & 0 & - & - & - & $\mathrm{c}$ & CCS \\
\hline 759 & 2.06 & 0.50 & $\mathrm{f}$ & -4 & - & - & - & 0 & - & - & - & $\mathrm{t}$ & CCS \\
\hline 760 & 2.06 & 0.48 & $\mathrm{f}$ & -3 & - & - & - & 0 & - & - & - & $\mathrm{c}$ & CCS \\
\hline 761 & 2.06 & 0.21 & $\mathrm{~b}$ & \begin{tabular}{|l|l|}
$\mathrm{s}$ & 2 \\
\end{tabular} & $\mathrm{cx}$ & 0 & 3 & 0 & 2.50 & 14.13 & 1.90 & $\mathrm{t}$ & CCS \\
\hline 762 & 2.06 & 0.15 & $\mathrm{f}$ & -2 & - & - & - & 0 & - & - & - & $\mathrm{b}$ & CCS \\
\hline 763 & 2.06 & 0.49 & $\mathrm{~d}$ & -2 & - & - & - & - & - & - & - & c & CCS \\
\hline 764 & 2.06 & 0.23 & $\mathrm{f}$ & -2 & - & - & - & 0 & - & - & - & c & CCS \\
\hline 765 & 2.06 & 0.08 & $\mathrm{f}$ & -2 & - & - & - & 0 & - & - & - & c & CCS \\
\hline 766 & 2.06 & 0.17 & $\mathrm{f}$ & -2 & - & - & - & 0 & - & - & - & c & CCS \\
\hline 767 & 2.06 & 0.09 & $\mathrm{f}$ & -2 & - & - & - & 0 & - & - & - & $\mathrm{c}$ & CCS \\
\hline 768 & 2.06 & 0.09 & $\mathrm{f}$ & -2 & - & - & - & 1 & - & - & - & c & CCS \\
\hline 769 & 2.06 & 0.17 & $\mathrm{f}$ & -2 & - & - & - & 0 & - & - & - & $\mathrm{c}$ & CCS \\
\hline \begin{tabular}{|l|}
770 \\
\end{tabular} & 2.06 & 0.09 & $\mathrm{f}$ & -2 & - & - & - & 0 & - & - & - & $\mathrm{b}$ & CCS \\
\hline \begin{tabular}{|l|}
771 \\
\end{tabular} & 2.06 & 0.00 & c & \begin{tabular}{|l|l|} 
o & 1 \\
\end{tabular} & $\mathrm{cx}$ & 0 & 3 & 0 & 1.76 & 8.01 & 1.20 & $\mathrm{~g}$ & CCS \\
\hline \begin{tabular}{|l|l|}
772 \\
\end{tabular} & 2.06 & 0.21 & $\mathrm{f}$ & -3 & - & - & - & 0 & - & - & - & $\mathrm{c}$ & CCS \\
\hline \begin{tabular}{|l|l|}
773 \\
\end{tabular} & 2.06 & 0.07 & $\mathrm{f}$ & -2 & - & - & - & 0 & - & - & - & c & CCS \\
\hline \begin{tabular}{|l|}
774 \\
\end{tabular} & 2.06 & 0.08 & $\mathrm{f}$ & -2 & - & - & - & 0 & - & - & - & $\mathrm{r}$ & CCS \\
\hline 775 & 2.06 & 0.04 & $\mathrm{~b}$ & \begin{tabular}{|l|l}
$\mathrm{s}$ & 1 \\
\end{tabular} & $\mathrm{cx}$ & 0 & 2 & 0 & 2.49 & 8.98 & 1.13 & $\mathrm{c}$ & CCS \\
\hline 776 & 2.06 & 0.07 & $\mathrm{f}$ & -1 & - & - & - & 0 & - & - & - & $\mathrm{b}$ & CCS \\
\hline \begin{tabular}{|l}
777 \\
\end{tabular} & 2.06 & 0.05 & $\mathrm{f}$ & -1 & - & - & - & 0 & - & - & - & W & CCS \\
\hline \begin{tabular}{|l|}
778 \\
\end{tabular} & 2.06 & 0.00 & $\mathrm{f}$ & -1 & - & - & - & 0 & - & - & - & $\mathrm{c}$ & CCS \\
\hline 779 & 2.06 & 0.03 & $\mathrm{f}$ & -1 & - & - & - & 0 & - & - & - & W & CCS \\
\hline 780 & 2.06 & 0.00 & $\mathrm{~d}$ & -1 & - & - & - & - & - & - & - & $\mathrm{c}$ & CCS \\
\hline \begin{tabular}{|l|l|}
781 \\
\end{tabular} & 2.06 & 0.00 & $\mathrm{f}$ & -1 & - & - & - & 0 & - & - & - & $\mathrm{c}$ & CCS \\
\hline 782 & 2.06 & 0.00 & d & -2 & - & - & - & - & - & - & - & c & CCS \\
\hline 783 & 2.06 & 0.10 & $d$ & -1 & - & - & - & - & - & - & - & $\mathrm{c}$ & CCS \\
\hline 784 & 2.06 & 0.00 & $\mathrm{~d}$ & -1 & - & - & - & - & - & - & - & $\mathrm{g}$ & CCS \\
\hline 785 & 2.06 & 0.03 & $\mathrm{~d}$ & -1 & - & - & - & - & - & - & - & $\mathrm{r}$ & CCS \\
\hline 786 & 2.06 & 0.00 & $\mathrm{f}$ & -2 & - & - & - & 0 & - & - & - & c & CCS \\
\hline 787 & 2.06 & 2.90 & c & $\begin{array}{ll}0 & 8 \\
\end{array}$ & $\mathrm{cx}$ & 2 & 3 & 0 & 7.75 & 34.63 & 3.52 & $\mathrm{c}$ & CCS \\
\hline 788 & 2.06 & 2.91 & $\mathrm{f}$ & -7 & - & - & - & 1 & - & - & - & c & CCS \\
\hline 789 & 2.06 & 3.76 & $\mathrm{~b}$ & $\begin{array}{ll}\mathrm{s} & 6 \\
\end{array}$ & $\mathrm{a}$ & 0 & 3 & 0 & 13.15 & 19.84 & 6.11 & $\mathrm{t}$ & CCS \\
\hline 790 & 2.06 & 1.10 & $\mathrm{f}$ & -5 & - & - & - & 0 & - & - & - & $\mathrm{c}$ & $\mathrm{CCS}$ \\
\hline 791 & 2.06 & 1.54 & $\mathrm{f}$ & -6 & - & - & - & 0 & - & - & - & $\mathrm{c}$ & $\mathrm{CCS}$ \\
\hline 792 & 2.06 & 12.06 & $\mathrm{f}$ & -8 & - & - & - & 0 & - & - & - & $\mathrm{i}$ & Igneous \\
\hline 793 & 2.06 & 30.16 & $\mathrm{f}$ & -1 & $1-$ & - & - & 1 & - & - & - & $\mathrm{t}$ & CCS \\
\hline 794 & 2.06 & 4.11 & c & o 7 & $\mathrm{cx}$ & 2 & 3 & 0 & 22.13 & 33.32 & 7.29 & $\mathrm{c}$ & CCS \\
\hline 795 & 2.06 & 6.07 & $\mathrm{f}$ & -6 & - & - & - & 0 & - & - & - & $\mathrm{r}$ & CCS \\
\hline 796 & 2.06 & 1.43 & c & $\begin{array}{ll}\mathrm{o} & 6 \\
\end{array}$ & $\mathrm{a}$ & 0 & 3 & 0 & 6.74 & 28.94 & 2.74 & $\mathrm{~g}$ & CCS \\
\hline 797 & 2.06 & 4.36 & c & o 8 & $\mathrm{cx}$ & 2 & 3 & 1 & 8.76 & 41.16 & 5.10 & c & CCS \\
\hline 798 & 2.06 & 1.02 & c & o 5 & $\mathrm{cx}$ & 0 & 3 & 0 & 4.99 & 24.86 & 1.97 & $\mathrm{r}$ & CCS \\
\hline 799 & 2.06 & 2.49 & $\mathrm{f}$ & -5 & - & - & - & 0 & - & - & - & $t$ & CCS \\
\hline 800 & 2.06 & 4.62 & $\mathrm{~b}$ & \begin{tabular}{l|l} 
s 7 \\
\end{tabular} & $\mathrm{cx}$ & 2 & 3 & 0 & 20.67 & 28.93 & 4.43 & $\mathrm{t}$ & CCS \\
\hline
\end{tabular}




\begin{tabular}{|c|c|c|c|c|c|c|c|c|c|c|c|c|c|}
\hline 801 & 2.06 & 2.32 & c & $\begin{array}{ll} & 6 \\
\end{array}$ & $\mathrm{f}$ & 0 & 3 & 0 & 4.97 & 29.18 & 2.92 & $\mathrm{t}$ & CCS \\
\hline 802 & 2.06 & 3.57 & d & -8 & - & - & - & - & - & - & - & i & Igneous \\
\hline 803 & 2.06 & 1.78 & c & $\begin{array}{ll}\text { lo } & 6\end{array}$ & f & 0 & 3 & 0 & 7.12 & 24.09 & 3.93 & $\mathrm{r}$ & CCS \\
\hline 804 & 2.06 & 5.95 & $\mathrm{~b}$ & \begin{tabular}{l|l}
$\mathrm{s}$ & 7
\end{tabular} & $\mathrm{cx}$ & 2 & 2 & 2 & 24.62 & 21.99 & 0.80 & $\mathrm{~g}$ & CCS \\
\hline 805 & 2.06 & 2.01 & $\mathrm{f}$ & -5 & - & - & - & 0 & - & - & - & $\mathrm{t}$ & CCS \\
\hline 806 & 2.06 & 11.32 & f & -7 & - & - & - & 0 & - & - & - & $\mathrm{r}$ & CCS \\
\hline 807 & 2.06 & 1.09 & f & -6 & - & - & - & 0 & - & - & - & $\mathrm{t}$ & CCS \\
\hline 808 & 2.06 & 0.89 & f & -5 & - & - & - & 0 & - & - & - & $t$ & CCS \\
\hline 809 & 2.06 & 2.96 & f & -5 & - & - & - & 0 & - & - & - & $t$ & CCS \\
\hline 810 & 2.06 & 0.43 & c & \begin{tabular}{l|l} 
o & 4 \\
\end{tabular} & $\mathrm{f}$ & 0 & 3 & 0 & 4.81 & 19.67 & 1.17 & c & CCS \\
\hline 811 & 2.06 & 2.25 & c & o 5 & $\mathrm{cx}$ & 0 & 3 & 0 & 8.79 & 20.55 & 5.63 & $\mathrm{t}$ & CCS \\
\hline 812 & 2.06 & 0.41 & c & $\begin{array}{ll}\text { o } 5 \\
\end{array}$ & $\mathrm{cx}$ & 0 & 0 & 0 & 4.41 & 24.13 & 1.36 & c & CCS \\
\hline 813 & 2.06 & 1.46 & f & -5 & - & - & - & 0 & - & - & - & c & CCS \\
\hline 814 & 2.06 & 2.58 & c & $\begin{array}{ll}\text { o } & 6 \\
\end{array}$ & $\mathrm{cx}$ & 0 & 3 & 0 & 4.17 & 32.82 & 3.09 & $\mathrm{t}$ & CCS \\
\hline 815 & 2.06 & 1.28 & c & o 5 & $\mathrm{cx}$ & 2 & 3 & 0 & 9.46 & 20.57 & 3.72 & $\mathrm{r}$ & CCS \\
\hline 816 & 2.06 & 2.78 & d & -5 & - & - & - & - & - & - & - & $\mathrm{i}$ & Igneous \\
\hline 817 & 2.06 & 1.94 & $\mathrm{f}$ & -7 & - & - & - & 1 & - & - & - & $\mathrm{r}$ & CCS \\
\hline 818 & 2.06 & 1.05 & d & -4 & - & - & - & - & - & - & - & $\mathrm{g}$ & CCS \\
\hline 819 & 2.06 & 0.53 & f & -3 & - & - & - & 0 & - & - & - & c & CCS \\
\hline 820 & 2.06 & 0.60 & d & -4 & - & - & - & - & - & - & - & $\mathrm{i}$ & Igneous \\
\hline 821 & 2.06 & 0.17 & f & -3 & - & - & - & 0 & - & - & - & $\mathrm{g}$ & CCS \\
\hline 822 & 2.06 & 1.49 & c & $\begin{array}{ll}\text { o } & 4\end{array}$ & $\mathrm{cx}$ & 1 & 3 & 0 & 19.37 & 15.64 & 5.19 & $t$ & CCS \\
\hline 823 & 2.06 & 0.66 & $\mathrm{f}$ & -4 & - & - & - & 2 & - & - & - & $\mathrm{g}$ & CCS \\
\hline 824 & 2.06 & 0.72 & d & -3 & - & - & - & - & - & - & - & w & CCS \\
\hline 825 & 2.06 & 0.59 & $\mathrm{~b}$ & \begin{tabular}{l|l}
$\mathrm{s}$ & 4 \\
\end{tabular} & $\mathrm{a}$ & 0 & 3 & 0 & 3.23 & 20.37 & 2.73 & c & CCS \\
\hline 826 & 2.06 & 0.44 & c & $\begin{array}{lll} & \text { o } \\
\end{array}$ & $\mathrm{cx}$ & 0 & 3 & 0 & 5.49 & 23.47 & 1.69 & c & CCS \\
\hline 827 & 2.06 & 0.54 & $\mathrm{f}$ & -3 & - & - & - & 0 & - & - & - & c & CCS \\
\hline 828 & 2.06 & 0.51 & c & \begin{tabular}{l|l} 
o & 4 \\
\end{tabular} & $\mathrm{cx}$ & 0 & 3 & 0 & 3.81 & 21.89 & 1.97 & c & CCS \\
\hline 829 & 2.06 & 0.55 & $\mathrm{f}$ & -3 & - & - & - & 0 & - & - & - & $\mathrm{t}$ & CCS \\
\hline 830 & 2.06 & 0.62 & $\mathrm{f}$ & -3 & - & - & - & 0 & - & - & - & c & CCS \\
\hline 831 & 2.06 & 0.33 & $\mathrm{~b}$ & $\begin{array}{ll}\mathrm{s} & 3 \\
\end{array}$ & $\mathrm{cx}$ & 0 & 3 & 0 & 4.40 & 12.61 & 2.30 & c & CCS \\
\hline 832 & 2.06 & 0.58 & d & -4 & - & - & - & - & - & - & - & $\mathrm{b}$ & CCS \\
\hline 833 & 2.06 & 0.58 & d & -3 & - & - & - & - & - & - & - & $\mathrm{i}$ & Igneous \\
\hline 834 & 2.06 & 0.15 & c & o 22 & $\mathrm{f}$ & 0 & 0 & 0 & 9.43 & 11.44 & 1.68 & c & CCS \\
\hline 835 & 2.06 & 0.36 & d & -2 & - & - & - & - & - & - & - & w & CCS \\
\hline 836 & 2.06 & 2.12 & $\mathrm{f}$ & -5 & - & - & - & 0 & - & - & - & $t$ & CCS \\
\hline 837 & 2.06 & 0.40 & $\mathrm{~b}$ & \begin{tabular}{l|l}
$\mathrm{s}$ & 3 \\
\end{tabular} & $\mathrm{cx}$ & 0 & 3 & 1 & 7.76 & 13.87 & 1.60 & c & CCS \\
\hline 838 & 2.06 & 0.32 & f & -5 & - & - & - & 0 & - & - & - & c & CCS \\
\hline 839 & 2.06 & 0.17 & f & -4 & - & - & - & 0 & - & - & - & c & CCS \\
\hline 840 & 2.06 & 0.28 & $\mathrm{f}$ & -3 & - & - & - & 0 & - & - & - & $\mathrm{g}$ & CCS \\
\hline 841 & 2.06 & 0.09 & d & -2 & - & - & - & - & - & - & - & c & CCS \\
\hline 842 & 2.06 & 0.24 & $\mathrm{~b}$ & \begin{tabular}{l|l} 
s & 3
\end{tabular} & $\mathrm{cx}$ & 1 & 2 & 0 & 2.77 & 11.18 & 1.61 & c & CCS \\
\hline 843 & 2.06 & 0.42 & c & o 3 & $\mathrm{cx}$ & 0 & 3 & 0 & 4.86 & 15.53 & 2.74 & c & CCS \\
\hline
\end{tabular}




\begin{tabular}{|c|c|c|c|c|c|c|c|c|c|c|c|c|c|}
\hline 844 & 2.06 & 1.88 & c & \begin{tabular}{|l|l|} 
o & 6 \\
\end{tabular} & $\mathrm{a}$ & 0 & 3 & 1 & 7.15 & 25.51 & 5.48 & $\mathrm{r}$ & CCS \\
\hline 845 & 2.06 & 0.56 & $\mathrm{f}$ & -3 & - & - & - & 0 & - & - & - & $t$ & CCS \\
\hline 846 & 2.06 & 0.61 & $\mathrm{f}$ & -2 & - & - & - & 0 & - & - & - & c & CCS \\
\hline 847 & 2.06 & 0.19 & c & o 2 & $\mathrm{cx}$ & 0 & 3 & 0 & 2.43 & 10.26 & 1.50 & $\mathrm{~g}$ & CCS \\
\hline 848 & 2.06 & 2.33 & $\mathrm{f}$ & -6 & - & - & - & 0 & - & - & - & c & CCS \\
\hline 849 & 2.06 & 0.31 & $\mathrm{f}$ & -4 & - & - & - & 0 & - & - & - & c & CCS \\
\hline 850 & 2.06 & 0.31 & $\mathrm{f}$ & -3 & - & - & - & 0 & - & - & - & c & CCS \\
\hline 851 & 2.06 & 0.44 & $\mathrm{f}$ & -4 & - & - & - & 1 & - & - & - & $\mathrm{r}$ & CCS \\
\hline 852 & 2.06 & 0.63 & c & $\begin{array}{lll}\text { o } & 4 \\
\end{array}$ & $\mathrm{cx}$ & 0 & 3 & 0 & 3.23 & 21.45 & 1.98 & $\mathrm{t}$ & CCS \\
\hline 853 & 2.06 & 0.70 & c & $\begin{array}{lll}\text { o } & 4 \\
\end{array}$ & $\mathrm{cx}$ & 0 & 3 & 0 & 2.51 & 24.19 & 4.08 & $t$ & CCS \\
\hline 854 & 2.06 & 1.27 & c & $\begin{array}{ll}\text { o } & 4 \\
\end{array}$ & $\mathrm{f}$ & 0 & 3 & 0 & 3.12 & 21.06 & 2.82 & c & CCS \\
\hline 855 & 2.06 & 0.26 & $\mathrm{f}$ & -3 & - & - & - & 0 & - & - & - & $\mathrm{t}$ & CCS \\
\hline 856 & 2.06 & 0.57 & $\mathrm{~b}$ & \begin{tabular}{l|l}
$\mathrm{s}$ & 5 \\
\end{tabular} & $\mathrm{f}$ & 0 & 3 & 0 & 2.63 & 17.82 & 2.30 & $\mathrm{t}$ & CCS \\
\hline \begin{tabular}{|l|}
857 \\
\end{tabular} & 2.06 & 0.25 & c & o 3 & $\mathrm{cx}$ & 0 & 3 & 0 & 2.04 & 13.42 & 2.03 & c & CCS \\
\hline 858 & 2.06 & 0.09 & $\mathrm{f}$ & -2 & - & - & - & 0 & - & - & - & $t$ & CCS \\
\hline \begin{tabular}{|l|}
859 \\
\end{tabular} & 2.06 & 1.29 & $\mathrm{~d}$ & -6 & - & - & - & - & - & - & - & $t$ & CCS \\
\hline 860 & 2.06 & 0.95 & $\mathrm{~d}$ & -3 & - & - & - & - & - & - & - & w & CCS \\
\hline 861 & 2.06 & 0.63 & $\mathrm{f}$ & -6 & - & - & - & 0 & - & - & - & $\mathrm{t}$ & CCS \\
\hline 862 & 2.06 & 0.40 & c & o 3 & $\mathrm{cx}$ & 2 & 3 & 0 & 9.44 & 7.81 & 2.94 & c & CCS \\
\hline 863 & 2.06 & 0.69 & $\mathrm{f}$ & -3 & - & - & - & 0 & - & - & - & w & CCS \\
\hline 864 & 2.06 & 0.30 & $\mathrm{~d}$ & -2 & - & - & - & - & - & - & - & $\mathrm{i}$ & Igneous \\
\hline 865 & 2.06 & 0.20 & $\mathrm{~d}$ & -3 & - & - & - & - & - & - & - & c & CCS \\
\hline 866 & 2.06 & 0.53 & c & o 3 & cx & 1 & 1 & 0 & 4.52 & 16.08 & 2.43 & c & CCS \\
\hline 867 & 2.06 & 0.62 & $\mathrm{f}$ & -3 & - & - & - & 0 & - & - & - & c & CCS \\
\hline 868 & 2.06 & 0.08 & $\mathrm{~d}$ & -2 & - & - & - & - & - & - & - & c & CCS \\
\hline 869 & 2.06 & 0.50 & $\mathrm{f}$ & -4 & - & - & - & 0 & - & - & - & c & CCS \\
\hline 870 & 2.06 & 0.42 & c & o 3 & $\mathrm{f}$ & 0 & 2 & 0 & 3.08 & 16.04 & 3.16 & c & $\mathrm{CCS}$ \\
\hline 871 & 2.06 & 1.18 & $\mathrm{~d}$ & -3 & - & - & - & - & - & - & - & $t$ & CCS \\
\hline 872 & 2.06 & 0.55 & $\mathrm{~d}$ & -3 & - & - & - & - & - & - & - & $t$ & CCS \\
\hline 873 & 2.06 & 0.37 & $\mathrm{c}$ & o 3 & $\mathrm{f}$ & 0 & 0 & 2 & 3.13 & 15.17 & 1.63 & $\mathrm{~g}$ & CCS \\
\hline 874 & 2.06 & 0.69 & c & \begin{tabular}{ll|l} 
o & 4 \\
\end{tabular} & cx & 0 & 3 & 0 & 3.37 & 15.87 & 3.58 & c & CCS \\
\hline 875 & 2.06 & 0.83 & c & $\begin{array}{ll} \\
\end{array}$ & c & 0 & 0 & 1 & 7.93 & 12.92 & 3.62 & $\mathrm{~b}$ & CCS \\
\hline 876 & 2.06 & 0.28 & $\mathrm{f}$ & -3 & - & - & - & 0 & - & - & - & $\mathrm{g}$ & CCS \\
\hline 877 & 2.06 & 0.99 & $\mathrm{f}$ & -4 & - & - & - & 0 & - & - & - & $\mathrm{y}$ & CCS \\
\hline 878 & 2.06 & 0.49 & $\mathrm{f}$ & -2 & - & - & - & 1 & - & - & - & $\mathrm{r}$ & CCS \\
\hline 879 & 2.06 & 0.27 & $\mathrm{~b}$ & $\begin{array}{ll}\mathrm{s} & 3 \\
\end{array}$ & $\mathrm{a}$ & 0 & 2 & 0 & 3.89 & 14.82 & 2.08 & c & CCS \\
\hline 880 & 2.06 & 0.14 & $\mathrm{~d}$ & -2 & - & - & - & - & - & - & - & c & CCS \\
\hline 881 & 2.06 & 0.12 & $\mathrm{~d}$ & -2 & - & - & - & - & - & - & - & c & CCS \\
\hline 882 & 2.06 & 0.28 & $\mathrm{f}$ & -2 & - & - & - & 0 & - & - & - & c & CCS \\
\hline 883 & 2.06 & 0.21 & $f$ & -2 & - & - & - & 0 & - & - & - & c & CCS \\
\hline 884 & 2.06 & 0.52 & $\mathrm{f}$ & -3 & - & - & - & 0 & - & - & - & c & CCS \\
\hline 885 & 2.06 & 0.18 & $\mathrm{~d}$ & -2 & - & - & - & - & - & - & - & c & CCS \\
\hline 886 & 2.06 & 0.60 & $\mathrm{f}$ & -4 & - & - & - & 1 & - & - & - & $\mathrm{r}$ & CCS \\
\hline
\end{tabular}




\begin{tabular}{|c|c|c|c|c|c|c|c|c|c|c|c|c|c|}
\hline 887 & 2.06 & 0.14 & $\mathrm{f}$ & -2 & - & - & - & 0 & - & - & - & $\mathrm{c}$ & CCS \\
\hline 888 & 2.06 & 0.00 & $\mathrm{f}$ & -1 & - & - & - & 0 & - & - & - & c & CCS \\
\hline 889 & 2.06 & 0.24 & $\mathrm{f}$ & -2 & - & - & - & 0 & - & - & - & c & CCS \\
\hline 890 & 2.06 & 0.12 & $\mathrm{f}$ & -2 & - & - & - & 0 & - & - & - & c & CCS \\
\hline 891 & 2.06 & 0.20 & $\mathrm{f}$ & -2 & - & - & - & 0 & - & - & - & c & CCS \\
\hline 892 & 2.06 & 0.25 & $\mathrm{f}$ & -3 & - & - & - & 0 & - & - & - & c & CCS \\
\hline 893 & 2.06 & 0.10 & $\mathrm{f}$ & -2 & - & - & - & 0 & - & - & - & c & CCS \\
\hline 894 & 2.06 & 0.00 & $\mathrm{f}$ & -2 & - & - & - & 0 & - & - & - & c & CCS \\
\hline 895 & 2.06 & 0.77 & c & $\begin{array}{ll}0 & 3 \\
\end{array}$ & $\mathrm{cx}$ & 2 & 2 & 0 & 9.35 & 16.41 & 2.44 & c & CCS \\
\hline 896 & 2.06 & 0.13 & $\mathrm{f}$ & -2 & - & - & - & 0 & - & - & - & c & CCS \\
\hline 897 & 2.06 & 0.33 & $\mathrm{f}$ & -3 & - & - & - & 0 & - & - & - & c & CCS \\
\hline 898 & 2.06 & 0.08 & $\mathrm{f}$ & -2 & - & - & - & 0 & - & - & - & c & CCS \\
\hline 899 & 2.06 & 0.16 & d & -2 & - & - & - & - & - & - & - & c & CCS \\
\hline 900 & 2.06 & 0.15 & d & -2 & - & - & - & - & - & - & - & c & CCS \\
\hline 901 & 2.06 & 0.09 & $\mathrm{f}$ & -2 & - & - & - & 1 & - & - & - & c & CCS \\
\hline 902 & 2.06 & 0.08 & $\mathrm{f}$ & -2 & - & - & - & 0 & - & - & - & c & CCS \\
\hline 903 & 2.06 & 0.11 & $\mathrm{f}$ & -3 & - & - & - & 0 & - & - & - & c & CCS \\
\hline 904 & 2.06 & 0.09 & $\mathrm{~d}$ & -2 & - & - & - & - & - & - & - & W & CCS \\
\hline 905 & 2.06 & 1.07 & c & $\begin{array}{ll}\text { o } & 6 \\
\end{array}$ & $\mathrm{cx}$ & 0 & 3 & 0 & 3.22 & 32.42 & 1.25 & c & CCS \\
\hline 906 & 2.06 & 0.09 & c & \begin{tabular}{|l|l} 
o & 1 \\
\end{tabular} & $\mathrm{f}$ & 0 & 2 & 0 & 2.87 & 6.83 & 2.85 & $\mathrm{c}$ & CCS \\
\hline 907 & 2.06 & 1.54 & $\mathrm{f}$ & -4 & - & - & - & 1 & - & - & - & c & CCS \\
\hline 908 & 2.06 & 0.23 & d & -2 & - & - & - & - & - & - & - & $\mathrm{c}$ & CCS \\
\hline 909 & 2.06 & 0.06 & d & -1 & - & - & - & - & - & - & - & $b$ & CCS \\
\hline 910 & 2.06 & 0.05 & d & -1 & - & - & - & - & - & - & - & $\mathrm{g}$ & CCS \\
\hline 911 & 2.06 & 0.06 & d & -2 & - & - & - & - & - & - & - & c & CCS \\
\hline 912 & 2.06 & 0.07 & b & \begin{tabular}{|l|l}
$\mathrm{s}$ & 2 \\
\end{tabular} & $c x$ & 0 & 3 & 0 & 2.45 & 10.77 & 1.29 & c & CCS \\
\hline 913 & 2.06 & 0.07 & $\mathrm{f}$ & -3 & - & - & - & 0 & - & - & - & c & CCS \\
\hline 914 & 2.06 & 0.31 & c & $\begin{array}{lll}0 & 3 \\
\end{array}$ & $\mathrm{cx}$ & 0 & 3 & 0 & 5.84 & 15.15 & 2.54 & c & CCS \\
\hline 915 & 2.06 & 0.56 & d & -3 & - & - & - & - & - & - & - & c & CCS \\
\hline 916 & 2.06 & 0.09 & $\mathrm{f}$ & -2 & - & - & - & 0 & - & - & - & $\mathrm{r}$ & CCS \\
\hline 917 & 2.06 & 0.12 & d & -2 & - & - & - & - & - & - & - & c & CCS \\
\hline 918 & 2.06 & 0.21 & $\mathrm{f}$ & -3 & - & - & - & 0 & - & - & - & c & CCS \\
\hline 919 & 2.06 & 0.22 & d & -2 & - & - & - & - & - & - & - & $\mathrm{g}$ & CCS \\
\hline 920 & 2.06 & 0.00 & $\mathrm{f}$ & -1 & - & - & - & 0 & - & - & - & c & CCS \\
\hline 921 & 2.06 & 0.04 & d & -1 & - & - & - & - & - & - & - & c & CCS \\
\hline 922 & 2.06 & 0.00 & d & -1 & - & - & - & - & - & - & - & $\mathrm{g}$ & CCS \\
\hline 923 & 2.06 & 0.15 & $\mathrm{~b}$ & $\begin{array}{ll} & 2 \\
\end{array}$ & $c x$ & 0 & 3 & 0 & 2.66 & 14.60 & 1.60 & c & CCS \\
\hline 924 & 2.06 & 0.12 & $\mathrm{f}$ & -3 & - & - & - & 0 & - & - & - & c & CCS \\
\hline 925 & 2.06 & 0.00 & $\mathrm{f}$ & -2 & - & - & - & 0 & - & - & - & c & CCS \\
\hline 926 & 2.06 & 0.05 & $\mathrm{f}$ & -2 & - & - & - & 0 & - & - & - & c & CCS \\
\hline 927 & 2.06 & 0.05 & d & -1 & - & - & - & - & - & - & - & c & CCS \\
\hline 928 & 2.06 & 0.09 & $\mathrm{~b}$ & $\begin{array}{ll}\mathrm{s} & 1 \\
\end{array}$ & $\mathrm{f}$ & 0 & 3 & 0 & 4.15 & 7.31 & 2.29 & c & CCS \\
\hline 929 & 2.06 & 0.28 & $\mathrm{f}$ & -3 & - & - & - & 0 & - & - & - & c & CCS \\
\hline
\end{tabular}




\begin{tabular}{|c|c|c|c|c|c|c|c|c|c|c|c|c|c|}
\hline 930 & 2.06 & 0.09 & $\mathrm{f}$ & -2 & - & - & - & 1 & - & - & - & $\mathrm{y}$ & CCS \\
\hline 931 & 2.06 & 0.09 & d & -1 & - & - & - & - & - & - & - & $\mathrm{g}$ & CCS \\
\hline 932 & 2.06 & 0.10 & c & $\begin{array}{lll}\text { o } & 2 \\
\end{array}$ & $\mathrm{f}$ & 0 & 3 & 0 & 7.78 & 6.32 & 2.13 & $\mathrm{c}$ & CCS \\
\hline 933 & 2.06 & 0.07 & $\mathrm{~d}$ & -2 & - & - & - & - & - & - & - & $\mathrm{c}$ & CCS \\
\hline 934 & 2.06 & 0.33 & $\mathrm{~d}$ & -3 & - & - & - & - & - & - & - & $\mathrm{b}$ & CCS \\
\hline 935 & 2.06 & 0.19 & d & -2 & - & - & - & - & - & - & - & W & CCS \\
\hline 936 & 2.06 & 0.05 & d & -1 & - & - & - & - & - & - & - & c & CCS \\
\hline 937 & 2.06 & 0.15 & $\mathrm{f}$ & -3 & - & - & - & 0 & - & - & - & $\mathrm{c}$ & CCS \\
\hline 938 & 2.06 & 0.12 & d & -2 & - & - & - & - & - & - & - & c & CCS \\
\hline 939 & 2.06 & 0.11 & $\mathrm{f}$ & -2 & - & - & - & 0 & - & - & - & $\mathrm{c}$ & CCS \\
\hline 940 & 2.06 & 0.05 & $\mathrm{f}$ & -1 & - & - & - & 0 & - & - & - & $\mathrm{r}$ & CCS \\
\hline 941 & 2.06 & 0.08 & $\mathrm{f}$ & -2 & - & - & - & 0 & - & - & - & $\mathrm{c}$ & CCS \\
\hline 942 & 2.06 & 0.24 & $\mathrm{f}$ & -2 & - & - & - & 0 & - & - & - & $\mathrm{c}$ & CCS \\
\hline 943 & 2.06 & 0.00 & $\mathrm{~d}$ & -1 & - & - & - & - & - & - & - & $\mathrm{w}$ & CCS \\
\hline 944 & 2.06 & 0.10 & $\mathrm{f}$ & -2 & - & - & - & 0 & - & - & - & $\mathrm{c}$ & CCS \\
\hline 945 & 2.06 & 0.07 & $\mathrm{~d}$ & -1 & - & - & - & - & - & - & - & $\mathrm{g}$ & CCS \\
\hline 946 & 2.06 & 0.12 & $\mathrm{~b}$ & $\begin{array}{lll}\mathrm{s} & 2 \\
\end{array}$ & $\mathrm{cx}$ & 2 & 3 & 0 & 4.31 & 9.39 & 1.39 & $\mathrm{~g}$ & CCS \\
\hline 947 & 2.06 & 0.00 & c & \begin{tabular}{l|l}
$\mathrm{o}$ & 2 \\
\end{tabular} & $\mathrm{cx}$ & 0 & 2 & 0 & 3.08 & 9.80 & 0.84 & $\mathrm{~g}$ & CCS \\
\hline 948 & 2.06 & 0.06 & $d$ & -2 & - & - & - & - & - & - & - & c & CCS \\
\hline 949 & 2.06 & 0.10 & d & -2 & - & - & - & - & - & - & - & c & CCS \\
\hline 950 & 2.06 & 0.06 & $\mathrm{~b}$ & \begin{tabular}{l|l}
$\mathrm{s}$ & 2 \\
\end{tabular} & $\mathrm{cx}$ & 0 & 2 & 0 & 2.46 & 10.22 & 1.24 & $\mathrm{c}$ & CCS \\
\hline 951 & 2.06 & 0.11 & $\mathrm{f}$ & -2 & - & - & - & 0 & - & - & - & $\mathrm{c}$ & CCS \\
\hline 952 & 2.06 & 0.04 & $\mathrm{~d}$ & -2 & - & - & - & - & - & - & - & $\mathrm{c}$ & CCS \\
\hline 953 & 2.06 & 0.10 & $\mathrm{~d}$ & -2 & - & - & - & - & - & - & - & $\mathrm{c}$ & CCS \\
\hline 954 & 2.06 & 0.00 & $\mathrm{~d}$ & -1 & - & - & - & - & - & - & - & $\mathrm{c}$ & CCS \\
\hline 955 & 2.06 & 0.00 & $\mathrm{f}$ & -1 & - & - & - & 0 & - & - & - & $\mathrm{c}$ & CCS \\
\hline 956 & 2.06 & 0.15 & $\mathrm{f}$ & -3 & - & - & - & 0 & - & - & - & $\mathrm{c}$ & CCS \\
\hline 957 & 2.06 & 0.12 & $\mathrm{c}$ & $\begin{array}{lll}\mathrm{O} & 2 \\
\end{array}$ & $\mathrm{cx}$ & 0 & 3 & 0 & 2.86 & 11.78 & 1.95 & $\mathrm{t}$ & CCS \\
\hline 958 & 2.06 & 0.14 & $\mathrm{f}$ & -2 & - & - & - & 1 & - & - & - & $\mathrm{w}$ & CCS \\
\hline 959 & 2.06 & 0.20 & $\mathrm{f}$ & -3 & - & - & - & 0 & - & - & - & $\mathrm{c}$ & CCS \\
\hline 960 & 2.06 & 0.34 & $\mathrm{f}$ & -2 & - & - & - & 0 & - & - & - & $\mathrm{c}$ & CCS \\
\hline 961 & 2.06 & 0.19 & $\mathrm{~b}$ & \begin{tabular}{l|l}
$\mathrm{s}$ & 2 \\
\end{tabular} & $\mathrm{cx}$ & 1 & 2 & 0 & 7.56 & 12.95 & 1.24 & $\mathrm{c}$ & CCS \\
\hline 962 & 2.06 & 0.66 & $\mathrm{~d}$ & -3 & - & - & - & - & - & - & - & $\mathrm{t}$ & CCS \\
\hline 963 & 2.06 & 0.00 & $\mathrm{f}$ & -2 & - & - & - & 0 & - & - & - & $\mathrm{c}$ & CCS \\
\hline 965 & 2.06 & 0.04 & $\mathrm{f}$ & -1 & - & - & - & 0 & - & - & - & $\mathrm{b}$ & CCS \\
\hline 966 & 2.06 & 0.04 & $\mathrm{f}$ & -2 & - & - & - & 0 & - & - & - & $\mathrm{c}$ & CCS \\
\hline 967 & 2.06 & 0.42 & $\mathrm{c}$ & $\begin{array}{ll}\text { o } 2 \\
\end{array}$ & $\mathrm{f}$ & 0 & 3 & 0 & 11.94 & 10.07 & 3.56 & $\mathrm{c}$ & CCS \\
\hline 968 & 2.06 & 0.03 & $\mathrm{f}$ & -1 & - & - & - & 0 & - & - & - & c & CCS \\
\hline 969 & 2.06 & 0.07 & $\mathrm{f}$ & -1 & - & - & - & 0 & - & - & - & $\mathrm{c}$ & CCS \\
\hline 970 & 2.06 & 0.10 & $\mathrm{f}$ & -2 & - & - & - & 0 & - & - & - & $\mathrm{g}$ & CCS \\
\hline 971 & 2.06 & 0.08 & $\mathrm{~d}$ & -2 & - & - & - & - & - & - & - & $\mathrm{r}$ & CCS \\
\hline 972 & 2.06 & 0.10 & $\mathrm{f}$ & -2 & - & - & - & 0 & - & - & - & $\mathrm{c}$ & CCS \\
\hline 973 & 2.06 & 0.08 & $\mathrm{~d}$ & -2 & - & - & - & - & - & - & - & $\mathrm{c}$ & CCS \\
\hline
\end{tabular}




\begin{tabular}{|c|c|c|c|c|c|c|c|c|c|c|c|c|c|}
\hline 974 & 2.06 & 0.10 & c & \begin{tabular}{|l|l|l|l|l|l|l} 
o & . \\
\end{tabular} & $\mathrm{cx}$ & 1 & 2 & 0 & 4.10 & 11.98 & 0.99 & c & CCS \\
\hline 975 & 2.06 & 0.18 & d & -2 & - & - & - & - & - & - & - & $\mathrm{g}$ & CCS \\
\hline 976 & 2.06 & 0.00 & $\mathrm{f}$ & -1 & - & - & - & 0 & - & - & - & $\mathrm{g}$ & CCS \\
\hline 977 & 2.06 & 0.00 & $\mathrm{f}$ & -1 & - & - & - & 0 & - & - & - & c & CCS \\
\hline 978 & 2.06 & 0.25 & $\mathrm{~b}$ & $\begin{array}{ll}\mathrm{s} & 2 \\
\end{array}$ & $\mathrm{f}$ & 0 & 3 & 0 & 5.02 & 12.00 & 2.88 & c & CCS \\
\hline 979 & 2.06 & 0.10 & $\mathrm{f}$ & -2 & - & - & - & 0 & - & - & - & w & CCS \\
\hline 980 & 2.06 & 0.19 & d & -2 & - & - & - & - & - & - & - & c & CCS \\
\hline 981 & 2.06 & 0.03 & d & -1 & - & - & - & - & - & - & - & $\mathrm{b}$ & CCS \\
\hline 982 & 2.06 & 0.00 & d & -2 & - & - & - & - & - & - & - & c & CCS \\
\hline 983 & 2.06 & 0.08 & $\mathrm{f}$ & -2 & - & - & - & 0 & - & - & - & c & CCS \\
\hline 984 & 2.06 & 0.08 & c & \begin{tabular}{l|l} 
o & 1 \\
\end{tabular} & $\mathrm{cx}$ & 0 & 3 & 0 & 3.18 & 8.70 & 1.36 & $t$ & CCS \\
\hline 985 & 2.06 & 0.05 & $\mathrm{f}$ & -2 & - & - & - & 0 & - & - & - & c & CCS \\
\hline 986 & 2.06 & 0.00 & $\mathrm{f}$ & -1 & - & - & - & 0 & - & - & - & $\mathrm{b}$ & CCS \\
\hline 987 & 2.06 & 0.04 & $\mathrm{~d}$ & -1 & - & - & - & - & - & - & - & c & CCS \\
\hline 988 & 2.06 & 0.05 & $\mathrm{f}$ & -1 & - & - & - & 0 & - & - & - & c & CCS \\
\hline 989 & 2.06 & 0.07 & $\mathrm{~d}$ & -1 & - & - & - & - & - & - & - & c & CCS \\
\hline 990 & 2.06 & 0.06 & $\mathrm{f}$ & -2 & - & - & - & 0 & - & - & - & c & CCS \\
\hline 991 & 2.06 & 0.00 & $\mathrm{~d}$ & -1 & - & - & - & - & - & - & - & c & CCS \\
\hline 992 & 2.06 & 0.09 & $d$ & -2 & - & - & - & - & - & - & - & $\mathrm{b}$ & CCS \\
\hline 993 & 2.06 & 0.00 & $\mathrm{f}$ & -1 & - & - & - & 0 & - & - & - & c & CCS \\
\hline 994 & 2.06 & 0.00 & $\mathrm{f}$ & -1 & - & - & - & 0 & - & - & - & c & CCS \\
\hline 995 & 2.06 & 0.09 & $\mathrm{~d}$ & -1 & - & - & - & - & - & - & - & c & CCS \\
\hline 996 & 2.06 & 0.07 & $\mathrm{~d}$ & -1 & - & - & - & - & - & - & - & $\mathrm{g}$ & CCS \\
\hline 997 & 2.06 & 0.00 & $\mathrm{f}$ & -1 & - & - & - & 0 & - & - & - & c & CCS \\
\hline 998 & 2.06 & 0.00 & $\mathrm{~d}$ & -1 & - & - & - & - & - & - & - & c & CCS \\
\hline 999 & 2.06 & 0.04 & $\mathrm{f}$ & -2 & - & - & - & 0 & - & - & - & w & CCS \\
\hline 1,000 & 2.06 & 0.08 & $\mathrm{c}$ & $\begin{array}{ll}0 & 1 \\
\end{array}$ & $\mathrm{cx}$ & 1 & 3 & 0 & 3.37 & 7.85 & 1.39 & $\mathrm{t}$ & CCS \\
\hline 1,001 & 2.06 & 0.00 & $\mathrm{~d}$ & -1 & - & - & - & - & - & - & - & $\mathrm{g}$ & CCS \\
\hline 1,002 & 2.06 & 0.07 & $\mathrm{f}$ & -2 & - & - & - & 0 & - & - & - & c & CCS \\
\hline 1,003 & 2.06 & 0.00 & $\mathrm{f}$ & -1 & - & - & - & 0 & - & - & - & c & CCS \\
\hline 1,004 & 2.06 & 0.08 & $\mathrm{f}$ & -2 & - & - & - & 0 & - & - & - & c & CCS \\
\hline 1,005 & 2.06 & 0.06 & $\mathrm{f}$ & -1 & - & - & - & 0 & - & - & - & c & CCS \\
\hline 1,006 & 2.06 & 0.07 & $\mathrm{f}$ & -2 & - & - & - & 0 & - & - & - & c & CCS \\
\hline 1,007 & 2.06 & 0.31 & $\mathrm{~d}$ & -2 & - & - & - & - & - & - & - & c & CCS \\
\hline 1,008 & 2.06 & 0.04 & $\mathrm{c}$ & \begin{tabular}{ll|} 
o & 1 \\
\end{tabular} & $\mathrm{cx}$ & 0 & 2 & 0 & 1.97 & 7.53 & 0.85 & $\mathrm{~b}$ & $\mathrm{CCS}$ \\
\hline 1,009 & 2.06 & 0.04 & $\mathrm{f}$ & -1 & - & - & - & 0 & - & - & - & c & CCS \\
\hline 1,010 & 2.06 & 0.32 & $\mathrm{f}$ & -2 & - & - & - & 0 & - & - & - & c & $\mathrm{CCS}$ \\
\hline 1,011 & 2.06 & 0.09 & $\mathrm{~d}$ & -2 & - & - & - & - & - & - & - & c & CCS \\
\hline 1,012 & 2.06 & 0.08 & $\mathrm{f}$ & -1 & - & - & - & 0 & - & - & - & $t$ & $\mathrm{CCS}$ \\
\hline 1,013 & 2.06 & 0.04 & $\mathrm{f}$ & -2 & - & - & - & 0 & - & - & - & c & CCS \\
\hline 1,014 & 2.06 & 0.05 & $\mathrm{f}$ & -1 & - & - & - & 0 & - & - & - & c & CCS \\
\hline 1,015 & 2.06 & 0.08 & $\mathrm{f}$ & -1 & - & - & - & 0 & - & - & - & w & CCS \\
\hline 1,016 & 2.06 & 0.06 & $\mathrm{f}$ & -1 & - & - & - & 0 & - & - & - & $\mathrm{t}$ & CCS \\
\hline
\end{tabular}




\begin{tabular}{|c|c|c|c|c|c|c|c|c|c|c|c|c|c|}
\hline 1,017 & 2.06 & 0.00 & $\mathrm{~d}$ & \begin{tabular}{|l|l}
- & 1 \\
\end{tabular} & - & - & - & - & - & - & - & $\mathrm{c}$ & CCS \\
\hline 1,018 & 2.06 & 0.03 & f & -1 & - & - & - & 0 & - & - & - & W & CCS \\
\hline 1,019 & 2.06 & 0.04 & $\mathrm{f}$ & -1 & - & - & - & 0 & - & - & - & $\mathrm{c}$ & CCS \\
\hline 1,020 & 2.06 & 0.00 & $\mathrm{f}$ & -1 & - & - & - & 0 & - & - & - & $\mathrm{c}$ & CCS \\
\hline 1,021 & 2.06 & 0.00 & $\mathrm{f}$ & -1 & - & - & - & 0 & - & - & - & c & CCS \\
\hline 1,022 & 2.06 & 0.00 & $\mathrm{f}$ & -1 & - & - & - & 0 & - & - & - & c & CCS \\
\hline 1,023 & 2.06 & 0.00 & $\mathrm{f}$ & -11 & - & - & - & 0 & - & - & - & c & CCS \\
\hline 1,024 & 2.06 & 0.00 & d & -1 & - & - & - & - & - & - & - & c & CCS \\
\hline 1,025 & 2.06 & 0.00 & $\mathrm{f}$ & -1 & - & - & - & 0 & - & - & - & $t$ & CCS \\
\hline 1,026 & 2.06 & 0.05 & $\mathrm{f}$ & -2 & - & - & - & 0 & - & - & - & $\mathrm{c}$ & CCS \\
\hline 1,027 & 2.06 & 0.00 & $\mathrm{~d}$ & -1 & - & - & - & - & - & - & - & c & CCS \\
\hline 1,028 & 2.06 & 0.00 & $\mathrm{f}$ & -1 & - & - & - & 0 & - & - & - & w & CCS \\
\hline 1,029 & 2.06 & 0.00 & $\mathrm{~d}$ & -1 & - & - & - & - & - & - & - & $\mathrm{g}$ & CCS \\
\hline 1,030 & 2.06 & 0.00 & $\mathrm{~d}$ & -2 & - & - & - & - & - & - & - & $\mathrm{t}$ & CCS \\
\hline 1,031 & 2.06 & 0.00 & $\mathrm{f}$ & -1 & - & - & - & 0 & - & - & - & $\mathrm{c}$ & CCS \\
\hline 1,032 & 2.06 & 0.06 & $\mathrm{f}$ & -2 & - & - & - & 0 & - & - & - & c & CCS \\
\hline 1,033 & 2.06 & 0.04 & $\mathrm{f}$ & -2 & - & - & - & 0 & - & - & - & c & CCS \\
\hline 1,034 & 2.06 & 0.00 & $\mathrm{~d}$ & -1 & - & - & - & - & - & - & - & $\mathrm{c}$ & CCS \\
\hline 1,035 & 2.06 & 0.05 & $\mathrm{f}$ & -1 & - & - & - & 0 & - & - & - & $\mathrm{t}$ & CCS \\
\hline 1,036 & 2.06 & 0.04 & $\mathrm{f}$ & -2 & - & - & - & 0 & - & - & - & c & CCS \\
\hline 1,037 & 2.06 & 0.06 & $\mathrm{f}$ & -2 & - & - & - & 0 & - & - & - & $\mathrm{c}$ & CCS \\
\hline 1,038 & 2.06 & 0.03 & $\mathrm{f}$ & -1 & - & - & - & 0 & - & - & - & $\mathrm{c}$ & CCS \\
\hline 1,039 & 2.06 & 0.05 & $\mathrm{f}$ & -2 & - & - & - & 0 & - & - & - & $\mathrm{c}$ & CCS \\
\hline 1,040 & 2.06 & 0.00 & $\mathrm{f}$ & -1 & - & - & - & 0 & - & - & - & $\mathrm{c}$ & CCS \\
\hline 1,041 & 2.06 & 0.09 & $\mathrm{f}$ & -2 & - & - & - & 0 & - & - & - & $\mathrm{c}$ & CCS \\
\hline 1,042 & 2.06 & 0.12 & $\mathrm{f}$ & -2 & - & - & - & 0 & - & - & - & $\mathrm{c}$ & CCS \\
\hline 1,043 & 2.06 & 0.00 & $\mathrm{~b}$ & \begin{tabular}{|l|l}
$\mathrm{s}$ & 1 \\
\end{tabular} & $\mathrm{f}$ & 0 & 2 & 0 & 5.72 & 5.78 & 0.64 & $\mathrm{c}$ & CCS \\
\hline 1,044 & 2.06 & 0.06 & $\mathrm{f}$ & \begin{tabular}{|l|l}
- & 1 \\
\end{tabular} & - & - & - & 0 & - & - & - & $\mathrm{c}$ & CCS \\
\hline 1,045 & 2.06 & 0.06 & $\mathrm{c}$ & \begin{tabular}{|l|l} 
o & 2 \\
\end{tabular} & $\mathrm{cx}$ & 2 & 3 & 0 & 5.48 & 12.00 & 1.84 & $\mathrm{c}$ & CCS \\
\hline 1,046 & 2.06 & 0.04 & $\mathrm{f}$ & -1 & - & - & - & 0 & - & - & - & $\mathrm{c}$ & CCS \\
\hline 1,047 & 2.06 & 0.13 & $\mathrm{f}$ & -2 & - & - & - & 0 & - & - & - & $\mathrm{t}$ & CCS \\
\hline 1,048 & 2.06 & 0.06 & $\mathrm{f}$ & -1 & - & - & - & 0 & - & - & - & $\mathrm{c}$ & CCS \\
\hline 1,049 & 2.06 & 0.00 & $\mathrm{f}$ & -1 & - & - & - & 0 & - & - & - & c & CCS \\
\hline 1,050 & 2.06 & 0.00 & $\mathrm{f}$ & \begin{tabular}{|l|l|} 
& 1 \\
\end{tabular} & - & - & - & 0 & - & - & - & $\mathrm{c}$ & CCS \\
\hline 1,051 & 2.06 & 0.09 & $\mathrm{f}$ & -2 & - & - & - & 0 & - & - & - & $\mathrm{c}$ & CCS \\
\hline 1,052 & 2.06 & 0.00 & $\mathrm{f}$ & -2 & - & - & - & 0 & - & - & - & $\mathrm{g}$ & CCS \\
\hline 1,053 & 2.06 & 0.00 & $\mathrm{~d}$ & -1 & - & - & - & - & - & - & - & c & CCS \\
\hline 1,054 & 2.06 & 0.03 & $\mathrm{f}$ & -1 & - & - & - & 0 & - & - & - & $\mathrm{t}$ & CCS \\
\hline 1,055 & 2.06 & 0.00 & $\mathrm{f}$ & -1 & - & - & - & 0 & - & - & - & $\mathrm{c}$ & CCS \\
\hline 1,056 & 2.06 & 0.00 & $\mathrm{f}$ & -1 & - & - & - & 0 & - & - & - & $\mathrm{c}$ & CCS \\
\hline 1,057 & 2.06 & 0.07 & $\mathrm{f}$ & -1 & - & - & - & 0 & - & - & - & c & CCS \\
\hline 1,058 & 2.06 & 0.02 & $\mathrm{f}$ & -1 & - & - & - & 0 & - & - & - & $\mathrm{c}$ & CCS \\
\hline 1,059 & 2.06 & 0.07 & $\mathrm{f}$ & -1 & - & - & - & 0 & - & - & - & $\mathrm{c}$ & CCS \\
\hline
\end{tabular}




\begin{tabular}{|c|c|c|c|c|c|c|c|c|c|c|c|c|c|}
\hline 1,060 & 2.06 & 0.00 & $\mathrm{f}$ & -1 & $1-$ & \begin{tabular}{l|l}
- & - \\
\end{tabular} & - & 0 & - & - & - & $\mathrm{c}$ & CCS \\
\hline 1,061 & 2.06 & 0.03 & $\mathrm{~d}$ & -1 & - & - & - & - & - & - & - & $\mathrm{g}$ & CCS \\
\hline 1,062 & 2.06 & 0.04 & $\mathrm{~d}$ & -1 & - & $-1-$ & - & - & - & - & - & c & CCS \\
\hline 1,063 & 2.06 & 0.00 & $\mathrm{~d}$ & -1 & - & $-\quad-$ & - & - & - & - & - & $\mathrm{g}$ & CCS \\
\hline 1,064 & 2.06 & 0.05 & $\mathrm{~d}$ & -1 & - & $-1-$ & - & - & - & - & - & c & CCS \\
\hline 1,065 & 2.06 & 0.00 & $\mathrm{f}$ & -1 & - & $-1-$ & - & 0 & - & - & - & W & CCS \\
\hline 1,066 & 2.06 & 0.00 & $\mathrm{f}$ & -1 & $1-$ & $-1-$ & - & 0 & - & - & - & $\mathrm{r}$ & CCS \\
\hline 1,067 & 2.06 & 0.06 & $\mathrm{f}$ & -2 & 2 & $-\quad-$ & - & 0 & - & - & - & c & CCS \\
\hline 1,068 & 2.06 & 0.08 & f & -2 & $2-$ & $-\quad-$ & - & 0 & - & - & - & c & CCS \\
\hline 1,069 & 2.06 & 0.00 & $\mathrm{~d}$ & -1 & - & $-\quad-$ & - & - & - & - & - & $\mathrm{g}$ & CCS \\
\hline 1,070 & 2.06 & 0.00 & $\mathrm{f}$ & -1 & - & $-1-$ & - & 0 & - & - & - & c & CCS \\
\hline 1,071 & 2.06 & 0.00 & $\mathrm{~d}$ & -1 & - & $-\quad-$ & - & - & - & - & - & c & CCS \\
\hline 1,072 & 2.06 & 0.00 & f & -1 & - & $-\quad-$ & - & 0 & - & - & - & c & CCS \\
\hline 1,073 & 2.06 & 0.06 & $\mathrm{~d}$ & -2 & - & -1 & - & - & - & - & - & W & CCS \\
\hline 1,074 & 2.06 & 0.00 & $\mathrm{f}$ & -1 & - & $-\quad-$ & - & 0 & - & - & - & c & CCS \\
\hline 1,075 & 2.06 & 0.00 & $\mathrm{~d}$ & -1 & - & $-\quad-$ & - & - & - & - & - & $\mathrm{t}$ & CCS \\
\hline 1,076 & 2.06 & 0.05 & $\mathrm{~d}$ & -1 & - & $-\quad-$ & - & - & - & - & - & w & CCS \\
\hline 1,077 & 2.06 & 0.03 & $\mathrm{~d}$ & -1 & - & $-\quad-$ & - & - & - & - & - & $\mathrm{g}$ & CCS \\
\hline 1,078 & 2.06 & 0.07 & $\mathrm{~d}$ & -1 & - & $-1-$ & - & - & - & - & - & c & CCS \\
\hline 1,079 & 2.06 & 0.00 & $\mathrm{f}$ & -1 & - & $-\quad-$ & - & 0 & - & - & - & c & CCS \\
\hline 1,080 & 2.06 & 0.00 & $\mathrm{f}$ & -1 & - & $-\quad-$ & - & 0 & - & - & - & c & CCS \\
\hline 1,081 & 2.06 & 0.00 & $\mathrm{f}$ & -1 & - & $-1-$ & - & 0 & - & - & - & $\mathrm{g}$ & CCS \\
\hline 1,082 & 2.06 & 0.03 & $\mathrm{f}$ & -1 & - & $-\quad-$ & - & 0 & - & - & - & c & CCS \\
\hline 1,083 & 2.06 & 0.00 & $\mathrm{~d}$ & -1 & - & $-\quad-$ & - & - & - & - & - & $\mathrm{r}$ & CCS \\
\hline 1,084 & 2.06 & 0.15 & $\mathrm{f}$ & -2 & - & $-\quad-$ & - & 0 & - & - & - & $\mathrm{r}$ & CCS \\
\hline 1,085 & 2.06 & 0.00 & $\mathrm{f}$ & -1 & - & $-1-$ & - & 0 & - & - & - & c & CCS \\
\hline 1,086 & 2.06 & 0.00 & $\mathrm{f}$ & -1 & - & $-\quad-$ & - & 0 & - & - & - & c & CCS \\
\hline 1,087 & 2.06 & 0.00 & $\mathrm{f}$ & -1 & - & $-\quad-$ & - & 0 & - & - & - & c & CCS \\
\hline 1,088 & 2.06 & 0.06 & $\mathrm{~d}$ & -2 & - & $-\quad-$ & - & - & - & - & - & c & CCS \\
\hline 1,089 & 2.06 & 0.07 & $\mathrm{~d}$ & -2 & - & $-\quad-$ & - & - & - & - & - & $t$ & CCS \\
\hline 1,090 & 2.06 & 0.04 & $\mathrm{~d}$ & -2 & - & - & - & - & - & - & - & $\mathrm{t}$ & CCS \\
\hline 1,091 & 2.06 & 0.00 & $\mathrm{f}$ & -2 & - & $-\quad-$ & - & 0 & - & - & - & c & CCS \\
\hline 1,092 & 2.06 & 0.00 & $\mathrm{f}$ & -1 & - & - & - & 0 & - & - & - & $\mathrm{b}$ & CCS \\
\hline 1,093 & 2.06 & 0.04 & $\mathrm{f}$ & -1 & - & $-\quad-$ & - & 0 & - & - & - & c & CCS \\
\hline 1,094 & 2.06 & 0.00 & $\mathrm{~d}$ & -1 & - & - & - & - & - & - & - & $\mathrm{W}$ & CCS \\
\hline 1,095 & 2.06 & 0.00 & $\mathrm{f}$ & -1 & - & $-\quad-$ & - & 0 & - & - & - & c & CCS \\
\hline 1,096 & 2.06 & 0.00 & $\mathrm{~d}$ & -1 & - & - & - & - & - & - & - & $\mathrm{t}$ & CCS \\
\hline 1,097 & 2.06 & 0.00 & $\mathrm{f}$ & -1 & - & - & - & 0 & - & - & - & W & CCS \\
\hline 1,098 & 2.06 & 0.00 & $\mathrm{~d}$ & -1 & - & - & - & - & - & - & - & $\mathrm{r}$ & CCS \\
\hline 1,099 & 2.06 & 0.04 & $\mathrm{~d}$ & -1 & - & $-1-$ & - & - & - & - & - & w & CCS \\
\hline 1,100 & 2.06 & 0.00 & $\mathrm{f}$ & -1 & - & - & - & 0 & - & - & - & $\mathrm{r}$ & CCS \\
\hline 1,101 & 2.06 & 0.00 & c & \begin{tabular}{|l|l} 
o & 1 \\
\end{tabular} & l f & 0 & 2 & 0 & 1.24 & 5.40 & 0.59 & c & CCS \\
\hline 1,102 & 2.06 & 0.00 & c & \begin{tabular}{|l|l} 
o & 1 \\
\end{tabular} & $1 \quad a$ & 0 & 0 & 0 & 3.38 & 9.10 & 1.43 & $\mathrm{c}$ & CCS \\
\hline
\end{tabular}




\begin{tabular}{|c|c|c|c|c|c|c|c|c|c|c|c|c|c|}
\hline 1,103 & 2.06 & 0.00 & $\mathrm{f}$ & \begin{tabular}{l|l} 
& 1 \\
\end{tabular} & - & - & - & 0 & - & - & - & $\mathrm{w}$ & CCS \\
\hline 1,104 & 2.06 & 0.00 & d & -1 & - & - & - & - & - & - & - & $\mathrm{b}$ & CCS \\
\hline 1,105 & 2.06 & 0.00 & $\mathrm{f}$ & -1 & - & - & - & 0 & - & - & - & $\mathrm{c}$ & CCS \\
\hline 1,106 & 2.06 & 0.00 & $\mathrm{f}$ & -1 & - & - & - & 0 & - & - & - & $\mathrm{c}$ & CCS \\
\hline 1,107 & 2.06 & 0.02 & d & -1 & - & - & - & - & - & - & - & W & CCS \\
\hline 1,108 & 2.06 & 0.00 & c & $\begin{array}{ll}\text { o } & 1 \\
\end{array}$ & $\mathrm{cx}$ & 0 & 0 & 0 & 1.68 & 7.75 & 0.60 & c & CCS \\
\hline 1,109 & 2.06 & 0.00 & d & -1 & - & - & - & - & - & - & - & c & CCS \\
\hline 1,110 & 2.06 & 0.05 & $\mathrm{f}$ & -1 & - & - & - & 0 & - & - & - & c & CCS \\
\hline 1,111 & 2.06 & 0.00 & c & $\begin{array}{ll}\text { o } & 1 \\
\end{array}$ & $\mathrm{cx}$ & 0 & 3 & 0 & 3.24 & 8.26 & 0.83 & $\mathrm{r}$ & CCS \\
\hline 1,112 & 2.06 & 0.00 & $\mathrm{f}$ & -1 & - & - & - & 0 & - & - & - & $\mathrm{c}$ & CCS \\
\hline 1,113 & 2.06 & 0.00 & $\mathrm{f}$ & -1 & - & - & - & 0 & - & - & - & c & CCS \\
\hline 1,114 & 2.06 & 0.00 & $\mathrm{f}$ & -1 & - & - & - & 0 & - & - & - & $\mathrm{c}$ & CCS \\
\hline 1,115 & 2.06 & 0.06 & c & o 2 & $\mathrm{f}$ & 0 & 0 & 0 & 3.46 & 10.92 & 1.09 & $\mathrm{c}$ & CCS \\
\hline 1,116 & 2.06 & 0.00 & $\mathrm{f}$ & -2 & - & - & - & 0 & - & - & - & c & CCS \\
\hline 1,117 & 2.06 & 0.00 & $\mathrm{f}$ & -1 & - & - & - & 0 & - & - & - & $\mathrm{c}$ & CCS \\
\hline 1,118 & 2.06 & 0.07 & $\mathrm{f}$ & -1 & - & - & - & 0 & - & - & - & c & CCS \\
\hline 1,119 & 2.06 & 0.00 & $\mathrm{f}$ & -1 & - & - & - & 0 & - & - & - & c & CCS \\
\hline 1,120 & 2.06 & 0.00 & $\mathrm{f}$ & -1 & - & - & - & 0 & - & - & - & $\mathrm{t}$ & CCS \\
\hline 1,121 & 2.06 & 0.00 & $\mathrm{f}$ & -1 & - & - & - & 0 & - & - & - & $\mathrm{c}$ & CCS \\
\hline 1,122 & 2.06 & 0.00 & $\mathrm{f}$ & -1 & - & - & - & 0 & - & - & - & c & CCS \\
\hline 1,123 & 2.06 & 0.00 & $\mathrm{~d}$ & -1 & - & - & - & - & - & - & - & $\mathrm{c}$ & CCS \\
\hline 1,124 & 2.06 & 0.00 & $\mathrm{f}$ & -1 & - & - & - & 0 & - & - & - & $\mathrm{c}$ & CCS \\
\hline 1,125 & 2.06 & 0.00 & $\mathrm{~d}$ & -1 & - & - & - & - & - & - & - & $\mathrm{c}$ & CCS \\
\hline 1,126 & 2.06 & 0.00 & $\mathrm{f}$ & -2 & - & - & - & 0 & - & - & - & $\mathrm{c}$ & CCS \\
\hline 1,127 & 2.06 & 0.00 & $\mathrm{~d}$ & -1 & - & - & - & - & - & - & - & $\mathrm{r}$ & CCS \\
\hline 1,128 & 2.06 & 0.00 & $\mathrm{f}$ & -1 & - & - & - & 0 & - & - & - & $\mathrm{c}$ & CCS \\
\hline 1,129 & 2.06 & 0.00 & $\mathrm{f}$ & -1 & - & - & - & 0 & - & - & - & $\mathrm{g}$ & CCS \\
\hline 1,130 & 2.06 & 0.00 & $\mathrm{f}$ & -1 & - & - & - & 0 & - & - & - & $\mathrm{c}$ & CCS \\
\hline 1,131 & 2.06 & 0.00 & $\mathrm{f}$ & -1 & - & - & - & 0 & - & - & - & $\mathrm{c}$ & CCS \\
\hline 1,132 & 2.06 & 0.00 & $\mathrm{f}$ & -1 & - & - & - & 0 & - & - & - & $\mathrm{c}$ & CCS \\
\hline 1,133 & 2.06 & 0.00 & $\mathrm{f}$ & -1 & - & - & - & 0 & - & - & - & $\mathrm{c}$ & CCS \\
\hline 1,134 & 2.06 & 0.00 & $\mathrm{c}$ & \begin{tabular}{|l|l|} 
o & 1 \\
\end{tabular} & $\mathrm{f}$ & 0 & 2 & 0 & 2.19 & 6.70 & 0.64 & $\mathrm{c}$ & CCS \\
\hline 1,135 & 2.06 & 0.00 & $\mathrm{f}$ & -1 & - & - & - & 0 & - & - & - & c & CCS \\
\hline 1,136 & 2.06 & 0.00 & $\mathrm{f}$ & -1 & - & - & - & 0 & - & - & - & $\mathrm{c}$ & CCS \\
\hline 1,137 & 2.06 & 0.00 & $\mathrm{~d}$ & -1 & - & - & - & - & - & - & - & $\mathrm{c}$ & CCS \\
\hline 1,138 & 2.06 & 0.00 & $\mathrm{f}$ & -1 & - & - & - & 0 & - & - & - & $\mathrm{c}$ & CCS \\
\hline 1,139 & 2.06 & 0.00 & $\mathrm{f}$ & -2 & - & - & - & 0 & - & - & - & $\mathrm{c}$ & CCS \\
\hline 1,140 & 2.06 & 0.00 & $\mathrm{f}$ & -1 & - & - & - & 0 & - & - & - & c & CCS \\
\hline 1,141 & 2.06 & 0.00 & c & \begin{tabular}{l|l} 
o & 1 \\
\end{tabular} & $\mathrm{cx}$ & 0 & 2 & 0 & 2.53 & 6.20 & 0.75 & $\mathrm{c}$ & CCS \\
\hline 1,142 & 2.06 & 0.00 & $\mathrm{f}$ & -1 & - & - & - & 0 & - & - & - & $\mathrm{c}$ & CCS \\
\hline 1,143 & 2.06 & 0.00 & $\mathrm{f}$ & -1 & - & - & - & 0 & - & - & - & $\mathrm{r}$ & CCS \\
\hline 1,144 & 2.06 & 0.00 & $\mathrm{~d}$ & -1 & - & - & - & - & - & - & - & $\mathrm{g}$ & CCS \\
\hline 1,145 & 2.06 & 0.00 & $\mathrm{~b}$ & \begin{tabular}{l|l} 
s & 1
\end{tabular} & $\mathrm{cx}$ & 0 & 3 & 0 & 2.35 & 5.20 & 0.67 & $\mathrm{c}$ & CCS \\
\hline
\end{tabular}




\begin{tabular}{|c|c|c|c|c|c|c|c|c|c|c|c|c|c|}
\hline 1,146 & 2.06 & 0.00 & $\mathrm{f}$ & -1 & - & - & - & 0 & - & - & - & $\mathrm{r}$ & CCS \\
\hline 1,147 & 2.06 & 0.00 & $\mathrm{f}$ & -1 & - & - & - & 0 & - & - & - & $\mathrm{g}$ & CCS \\
\hline 1,148 & 2.06 & 0.00 & $\mathrm{f}$ & -1 & - & - & - & 0 & - & - & - & c & CCS \\
\hline 1,149 & 2.06 & 0.00 & $\mathrm{f}$ & -1 & - & - & - & 0 & - & - & - & $\mathrm{g}$ & CCS \\
\hline 1,150 & 2.06 & 0.00 & $\mathrm{f}$ & -1 & - & - & - & 0 & - & - & - & $\mathrm{r}$ & CCS \\
\hline 1,151 & 2.06 & 0.00 & $\mathrm{f}$ & -1 & - & - & - & 0 & - & - & - & c & CCS \\
\hline 1,152 & 2.06 & 0.00 & d & -1 & - & - & - & - & - & - & - & c & CCS \\
\hline 1,153 & 2.06 & 0.00 & $\mathrm{f}$ & -1 & - & - & - & 0 & - & - & - & c & CCS \\
\hline 1,154 & 2.06 & 0.00 & $\mathrm{f}$ & -1 & - & - & - & 0 & - & - & - & c & CCS \\
\hline 1,155 & 2.06 & 0.00 & $\mathrm{f}$ & -1 & - & - & - & 0 & - & - & - & c & CCS \\
\hline 1,156 & 2.06 & 0.00 & $\mathrm{f}$ & -1 & - & - & - & 0 & - & - & - & $\mathrm{r}$ & CCS \\
\hline 1,157 & 2.06 & 0.00 & $\mathrm{f}$ & -1 & - & - & - & 0 & - & - & - & c & CCS \\
\hline 1,158 & 2.06 & 0.00 & $\mathrm{f}$ & -1 & - & - & - & 0 & - & - & - & c & CCS \\
\hline 1,159 & 2.06 & 0.00 & $\mathrm{f}$ & -1 & - & - & - & 0 & - & - & - & $t$ & CCS \\
\hline 1,160 & 2.06 & 0.00 & $\mathrm{f}$ & -1 & - & - & - & 0 & - & - & - & c & CCS \\
\hline 1,161 & 2.06 & 0.00 & $\mathrm{f}$ & -1 & - & - & - & 0 & - & - & - & c & CCS \\
\hline 1,162 & 2.06 & 0.04 & $\mathrm{f}$ & -1 & - & - & - & 0 & - & - & - & c & CCS \\
\hline 1,163 & 2.06 & 0.00 & $\mathrm{f}$ & -1 & - & - & - & 0 & - & - & - & w & CCS \\
\hline 1,164 & 2.06 & 0.00 & $\mathrm{f}$ & -1 & - & - & - & 0 & - & - & - & $\mathrm{g}$ & CCS \\
\hline 1,165 & 2.06 & 0.00 & $\mathrm{f}$ & -1 & - & - & - & 0 & - & - & - & $\mathrm{b}$ & CCS \\
\hline 1,166 & 2.06 & 0.00 & d & -1 & - & - & - & - & - & - & - & w & CCS \\
\hline 1,167 & 2.06 & 0.00 & $\mathrm{f}$ & -1 & - & - & - & 0 & - & - & - & $\mathrm{c}$ & CCS \\
\hline 1,168 & 2.06 & 0.00 & c & $\begin{array}{ll} & 1 \\
\end{array}$ & $\mathrm{cx}$ & 0 & 3 & 0 & 2.90 & 5.84 & 1.03 & $\mathrm{c}$ & CCS \\
\hline 1,169 & 2.06 & 0.00 & $\mathrm{f}$ & -1 & - & - & - & 0 & - & - & - & c & CCS \\
\hline 1,170 & 2.06 & 0.00 & $\mathrm{f}$ & -1 & - & - & - & 0 & - & - & - & c & CCS \\
\hline 1,171 & 2.06 & 0.00 & $\mathrm{f}$ & -1 & - & - & - & 0 & - & - & - & $\mathrm{b}$ & CCS \\
\hline 1,172 & 2.06 & 0.00 & $\mathrm{f}$ & -1 & - & - & - & 0 & - & - & - & c & CCS \\
\hline 1,173 & 2.06 & 0.00 & $\mathrm{f}$ & -1 & - & - & - & 0 & - & - & - & $\mathrm{r}$ & CCS \\
\hline 1,174 & 2.06 & 0.00 & $\mathrm{f}$ & -1 & - & - & - & 0 & - & - & - & $\mathrm{t}$ & CCS \\
\hline 1,175 & 2.06 & 0.00 & $\mathrm{f}$ & -2 & - & - & - & 0 & - & - & - & c & CCS \\
\hline 1,176 & 2.06 & 0.00 & $\mathrm{f}$ & -1 & - & - & - & 0 & - & - & - & c & CCS \\
\hline 1,177 & 2.06 & 0.00 & $\mathrm{f}$ & -1 & - & - & - & 0 & - & - & - & $\mathrm{c}$ & CCS \\
\hline 1,178 & 2.06 & 0.00 & $\mathrm{f}$ & -1 & - & - & - & 0 & - & - & - & $\mathrm{g}$ & CCS \\
\hline 1,179 & 2.06 & 0.00 & $\mathrm{f}$ & -1 & - & - & - & 0 & - & - & - & c & CCS \\
\hline 1,180 & 2.06 & 0.00 & $\mathrm{f}$ & -1 & - & - & - & 0 & - & - & - & $\mathrm{g}$ & CCS \\
\hline 1,181 & 2.06 & 0.00 & $\mathrm{f}$ & -1 & - & - & - & 0 & - & - & - & c & CCS \\
\hline 1,182 & 2.06 & 0.00 & $\mathrm{f}$ & -1 & - & - & - & 0 & - & - & - & b & CCS \\
\hline 1,183 & 2.06 & 0.00 & $\mathrm{f}$ & -1 & - & - & - & 0 & - & - & - & c & CCS \\
\hline 1,184 & 2.06 & 0.00 & $\mathrm{f}$ & -1 & - & - & - & 0 & - & - & - & c & CCS \\
\hline 1,185 & 2.06 & 0.00 & $\mathrm{f}$ & -1 & - & - & - & 0 & - & - & - & c & CCS \\
\hline 1,186 & 2.06 & 0.00 & d & -1 & - & - & - & - & - & - & - & c & CCS \\
\hline 1,187 & 2.06 & 0.00 & d & -1 & - & - & - & - & - & - & - & c & CCS \\
\hline 1,188 & 2.06 & 0.00 & $\mathrm{f}$ & -1 & - & - & - & 0 & - & - & - & c & CCS \\
\hline
\end{tabular}




\begin{tabular}{|c|c|c|c|c|c|c|c|c|c|c|c|c|c|}
\hline 1,189 & 2.06 & 0.00 & $\mathrm{f}$ & -1 & - & - & - & 0 & - & - & - & c & CCS \\
\hline 1,190 & 2.06 & 0.00 & $\mathrm{f}$ & -1 & - & - & - & 0 & - & - & - & c & CCS \\
\hline 1,191 & 2.06 & 0.03 & $\mathrm{f}$ & -1 & - & - & - & 0 & - & - & - & $t$ & CCS \\
\hline 1,192 & 2.06 & 0.00 & $\mathrm{f}$ & -1 & - & - & - & 0 & - & - & - & c & CCS \\
\hline 1,193 & 2.06 & 0.00 & $\mathrm{f}$ & -1 & - & - & - & 0 & - & - & - & $t$ & CCS \\
\hline 1,194 & 2.06 & 0.00 & $\mathrm{f}$ & -1 & - & - & - & 0 & - & - & - & c & CCS \\
\hline 1,195 & 2.06 & 0.00 & d & -2 & - & - & - & - & - & - & - & c & CCS \\
\hline 1,196 & 2.06 & 0.00 & d & -1 & - & - & - & - & - & - & - & c & CCS \\
\hline 1,197 & 2.06 & 0.00 & $\mathrm{f}$ & -1 & - & - & - & 0 & - & - & - & c & CCS \\
\hline 1,198 & 2.06 & 0.00 & $\mathrm{f}$ & -1 & - & - & - & 0 & - & - & - & c & CCS \\
\hline 1,199 & 2.06 & 0.00 & $\mathrm{f}$ & -1 & - & - & - & 0 & - & - & - & c & CCS \\
\hline 1,200 & 2.06 & 0.00 & $\mathrm{f}$ & -1 & - & - & - & 0 & - & - & - & c & CCS \\
\hline 1,201 & 2.06 & 0.00 & $\mathrm{f}$ & -1 & - & - & - & 0 & - & - & - & c & CCS \\
\hline 1,202 & 2.06 & 0.00 & $\mathrm{f}$ & -1 & - & - & - & 0 & - & - & - & $\mathrm{r}$ & CCS \\
\hline 1,203 & 2.06 & 0.00 & $\mathrm{f}$ & -1 & - & - & - & 0 & - & - & - & $\mathrm{t}$ & CCS \\
\hline 1,204 & 2.06 & 0.00 & $\mathrm{f}$ & -1 & - & - & - & 0 & - & - & - & $\mathrm{g}$ & CCS \\
\hline 1,205 & 2.06 & 0.00 & $\mathrm{f}$ & -1 & - & - & - & 0 & - & - & - & c & CCS \\
\hline 1,206 & 2.06 & 0.00 & $\mathrm{f}$ & -1 & - & - & - & 0 & - & - & - & c & CCS \\
\hline 1,207 & 2.06 & 0.00 & $\mathrm{f}$ & -1 & - & - & - & 0 & - & - & - & c & CCS \\
\hline 1,208 & 2.06 & 0.00 & $\mathrm{f}$ & -1 & - & - & - & 0 & - & - & - & $b$ & CCS \\
\hline 1,209 & 2.06 & 0.00 & $\mathrm{f}$ & -1 & - & - & - & 0 & - & - & - & c & CCS \\
\hline 1,210 & 2.06 & 0.00 & $\mathrm{f}$ & -1 & - & - & - & 0 & - & - & - & c & CCS \\
\hline 1,211 & 2.06 & 0.00 & $\mathrm{f}$ & -1 & - & - & - & 0 & - & - & - & $\mathrm{b}$ & CCS \\
\hline 1,212 & 2.06 & 0.00 & c & \begin{tabular}{|l|l|} 
o & 1 \\
\end{tabular} & $\mathrm{cx}$ & 0 & 3 & 0 & 2.34 & 5.25 & 0.78 & c & CCS \\
\hline 1,213 & 2.06 & 0.00 & d & -1 & - & - & - & - & - & - & - & c & CCS \\
\hline 1,214 & 2.06 & 0.00 & $\mathrm{f}$ & -1 & - & - & - & 0 & - & - & - & c & CCS \\
\hline 1,215 & 2.06 & 0.04 & $\mathrm{~b}$ & $\begin{array}{ll}\mathrm{s} & 1 \\
\end{array}$ & $\mathrm{cx}$ & 1 & 3 & 0 & 3.84 & 4.58 & 1.28 & $\mathrm{~b}$ & CCS \\
\hline 1,216 & 2.06 & 0.00 & d & -1 & - & - & - & - & - & - & - & $t$ & CCS \\
\hline 1,217 & 2.06 & 0.00 & $\mathrm{f}$ & -1 & - & - & - & 0 & - & - & - & c & CCS \\
\hline 1,218 & 2.06 & 0.00 & $\mathrm{f}$ & -1 & - & - & - & 0 & - & - & - & c & CCS \\
\hline 1,219 & 2.06 & 0.00 & $\mathrm{f}$ & -1 & - & - & - & 0 & - & - & - & c & CCS \\
\hline 1,220 & 2.06 & 0.00 & $\mathrm{f}$ & -1 & - & - & - & 0 & - & - & - & c & CCS \\
\hline 1,221 & 2.06 & 0.00 & $\mathrm{f}$ & -1 & - & - & - & 0 & - & - & - & c & CCS \\
\hline 1,222 & 2.06 & 0.00 & $\mathrm{f}$ & -1 & - & - & - & 0 & - & - & - & c & CCS \\
\hline 1,223 & 2.06 & 0.00 & d & -1 & - & - & - & - & - & - & - & $t$ & CCS \\
\hline 1,224 & 2.06 & 0.00 & d & -1 & - & - & - & - & - & - & - & $\mathrm{g}$ & CCS \\
\hline 1,225 & 2.06 & 0.00 & $\mathrm{f}$ & -1 & - & - & - & 0 & - & - & - & w & CCS \\
\hline 1,226 & 2.06 & 0.00 & $\mathrm{f}$ & -1 & - & - & - & 0 & - & - & - & c & CCS \\
\hline 1,227 & 2.06 & 0.00 & d & -1 & - & - & - & - & - & - & - & $\mathrm{g}$ & CCS \\
\hline 1,228 & 2.06 & 0.00 & d & -1 & - & - & - & - & - & - & - & c & CCS \\
\hline 1,229 & 2.06 & 0.00 & $\mathrm{f}$ & -1 & - & - & - & 0 & - & - & - & c & CCS \\
\hline 1,230 & 2.06 & 0.00 & $\mathrm{f}$ & -1 & - & - & - & 0 & - & - & - & c & CCS \\
\hline 1,231 & 2.06 & 0.00 & $\mathrm{f}$ & -1 & - & - & - & 0 & - & - & - & $\mathrm{r}$ & CCS \\
\hline
\end{tabular}




\begin{tabular}{|c|c|c|c|c|c|c|c|c|c|c|c|c|c|}
\hline 1,232 & 2.06 & 0.00 & $\mathrm{f}$ & \begin{tabular}{|l|l|}
- & 1 \\
\end{tabular} & - & - & - & 0 & - & - & - & c & CCS \\
\hline 1,233 & 2.06 & 0.00 & $\mathrm{f}$ & -1 & - & - & - & 0 & - & - & - & c & CCS \\
\hline 1,234 & 2.06 & 0.00 & f & -1 & - & - & - & 0 & - & - & - & c & CCS \\
\hline 1,235 & 2.06 & 0.00 & d & -1 & - & - & - & - & - & - & - & c & CCS \\
\hline 1,236 & 2.06 & 0.00 & $\mathrm{f}$ & -1 & - & - & - & 0 & - & - & - & c & CCS \\
\hline 1,237 & 2.06 & 0.00 & f & -1 & - & - & - & 0 & - & - & - & c & CCS \\
\hline 1,238 & 2.06 & 0.00 & f & -1 & - & - & - & 0 & - & - & - & c & CCS \\
\hline 1,239 & 2.06 & 0.00 & d & -1 & - & - & - & - & - & - & - & c & CCS \\
\hline 1,240 & 2.06 & 0.00 & $\mathrm{f}$ & -1 & - & - & - & 0 & - & - & - & c & CCS \\
\hline 1,241 & 2.06 & 0.00 & d & -1 & - & - & - & - & - & - & - & c & CCS \\
\hline 1,242 & 2.06 & 0.00 & d & -1 & - & - & - & - & - & - & - & c & CCS \\
\hline 1,243 & 2.06 & 0.00 & $\mathrm{~d}$ & -1 & - & - & - & - & - & - & - & c & CCS \\
\hline 1,244 & 2.06 & 0.00 & $\mathrm{f}$ & -1 & - & - & - & 0 & - & - & - & $\mathrm{g}$ & CCS \\
\hline 1,245 & 2.06 & 0.00 & $\mathrm{~d}$ & -1 & - & - & - & - & - & - & - & c & CCS \\
\hline 1,246 & 2.06 & 0.00 & f & -2 & - & - & - & 0 & - & - & - & c & CCS \\
\hline 1,247 & 2.06 & 0.00 & $\mathrm{f}$ & -1 & - & - & - & 0 & - & - & - & c & CCS \\
\hline 1,248 & 2.06 & 0.00 & d & -1 & - & - & - & - & - & - & - & $\mathrm{g}$ & CCS \\
\hline 1,249 & 2.06 & 0.00 & $\mathrm{f}$ & -1 & - & - & - & 0 & - & - & - & c & CCS \\
\hline 1,250 & 2.06 & 0.00 & $\mathrm{~b}$ & \begin{tabular}{l|l}
$\mathrm{s}$ & 1 \\
\end{tabular} & $\mathrm{cx}$ & 0 & 2 & 0 & 3.89 & 5.22 & 1.42 & $\mathrm{~g}$ & CCS \\
\hline 1,251 & 2.06 & 0.00 & $\mathrm{f}$ & -1 & - & - & - & 0 & - & - & - & $\mathrm{r}$ & CCS \\
\hline 1,252 & 2.06 & 0.00 & d & -1 & - & - & - & - & - & - & - & c & CCS \\
\hline 1,253 & 2.06 & 0.00 & $\mathrm{f}$ & -1 & - & - & - & 0 & - & - & - & c & CCS \\
\hline 1,254 & 2.06 & 0.00 & d & -1 & - & - & - & - & - & - & - & c & CCS \\
\hline 1,255 & 2.06 & 0.00 & $\mathrm{f}$ & -1 & - & - & - & 0 & - & - & - & c & CCS \\
\hline 1,256 & 2.06 & 0.00 & $\mathrm{f}$ & -1 & - & - & - & 0 & - & - & - & c & CCS \\
\hline 1,257 & 2.06 & 0.00 & $\mathrm{~b}$ & $\begin{array}{ll}\text { s } & 1 \\
\end{array}$ & cx & 0 & 2 & 0 & 1.84 & 5.83 & 0.73 & c & CCS \\
\hline 1,258 & 2.06 & 0.00 & $\mathrm{f}$ & -1 & - & - & - & 0 & - & - & - & $\mathrm{g}$ & CCS \\
\hline 1,259 & 2.06 & 0.00 & $\mathrm{f}$ & -1 & - & - & - & 0 & - & - & - & c & CCS \\
\hline 1,260 & 2.06 & 0.00 & $\mathrm{f}$ & -1 & - & - & - & 0 & - & - & - & $\mathrm{t}$ & CCS \\
\hline 1,261 & 2.06 & 0.00 & d & -1 & - & - & - & - & - & - & - & c & CCS \\
\hline 1,262 & 2.06 & 0.00 & $\mathrm{f}$ & -1 & - & - & - & 0 & - & - & - & c & CCS \\
\hline 1,263 & 2.06 & 0.00 & $\mathrm{f}$ & -1 & - & - & - & 0 & - & - & - & c & CCS \\
\hline 1,264 & 2.06 & 0.00 & $\mathrm{f}$ & -1 & - & - & - & 0 & - & - & - & c & CCS \\
\hline 1,265 & 2.06 & 0.00 & $\mathrm{f}$ & -1 & - & - & - & 0 & - & - & - & c & CCS \\
\hline 1,266 & 2.06 & 0.00 & $\mathrm{f}$ & -1 & - & - & - & 0 & - & - & - & c & CCS \\
\hline 1,267 & 2.06 & 0.00 & d & -1 & - & - & - & - & - & - & - & $\mathrm{g}$ & CCS \\
\hline 1,268 & 2.06 & 0.00 & $\mathrm{f}$ & -1 & - & - & - & 0 & - & - & - & $\mathrm{t}$ & CCS \\
\hline 1,269 & 2.06 & 0.00 & $\mathrm{f}$ & -1 & - & - & - & 0 & - & - & - & $\mathrm{g}$ & CCS \\
\hline 1,270 & 2.06 & 0.00 & f & -1 & - & - & - & 0 & - & - & - & $\mathrm{g}$ & CCS \\
\hline 1,271 & 2.06 & 0.00 & $\mathrm{f}$ & -1 & - & - & - & 0 & - & - & - & c & CCS \\
\hline 1,272 & 2.06 & 0.00 & f & -1 & - & - & - & 0 & - & - & - & c & CCS \\
\hline 1,273 & 2.06 & 0.00 & $\mathrm{f}$ & -1 & - & - & - & 0 & - & - & - & w & CCS \\
\hline 1,274 & 2.06 & 0.00 & f & -1 & - & - & - & 0 & - & - & - & c & CCS \\
\hline
\end{tabular}




\begin{tabular}{|c|c|c|c|c|c|c|c|c|c|c|c|c|c|}
\hline 1,275 & 2.06 & 0.00 & $\mathrm{f}$ & \begin{tabular}{|l|l|}
- & 1 \\
\end{tabular} & - & - & - & 0 & - & - & - & $\mathrm{c}$ & CCS \\
\hline 1,276 & 2.06 & 0.00 & $\mathrm{f}$ & -1 & - & - & - & 0 & - & - & - & c & CCS \\
\hline 1,277 & 2.06 & 0.00 & $\mathrm{f}$ & \begin{tabular}{|l|l}
- & 1 \\
\end{tabular} & - & - & - & 0 & - & - & - & $\mathrm{c}$ & CCS \\
\hline 1,278 & 2.06 & 0.00 & $\mathrm{f}$ & -1 & - & - & - & 0 & - & - & - & $\mathrm{c}$ & CCS \\
\hline 1,279 & 2.06 & 0.00 & $\mathrm{f}$ & -1 & - & - & - & 0 & - & - & - & c & CCS \\
\hline 1,280 & 2.06 & 0.00 & c & \begin{tabular}{|l|l}
$\mathrm{o}$ & 1 \\
\end{tabular} & $\mathrm{cx}$ & 0 & 2 & 0 & 2.02 & 3.80 & 0.64 & c & CCS \\
\hline 1,281 & 2.06 & 0.00 & $\mathrm{f}$ & -1 & - & - & - & 0 & - & - & - & c & CCS \\
\hline 1,282 & 2.06 & 0.00 & $\mathrm{f}$ & -1 & - & - & - & 0 & - & - & - & c & CCS \\
\hline 1,283 & 2.06 & 0.00 & $\mathrm{~d}$ & -1 & - & - & - & - & - & - & - & $\mathrm{g}$ & CCS \\
\hline 1,284 & 2.06 & 0.00 & $\mathrm{f}$ & -1 & - & - & - & 0 & - & - & - & $\mathrm{c}$ & CCS \\
\hline 1,285 & 2.06 & 0.00 & $\mathrm{f}$ & -1 & - & - & - & 0 & - & - & - & $\mathrm{c}$ & CCS \\
\hline 1,286 & 2.06 & 0.00 & $\mathrm{f}$ & -1 & - & - & - & 0 & - & - & - & c & CCS \\
\hline 1,287 & 2.06 & 0.00 & $\mathrm{f}$ & -1 & - & - & - & 0 & - & - & - & $\mathrm{t}$ & CCS \\
\hline 1,288 & 2.06 & 0.00 & $\mathrm{f}$ & -1 & - & - & - & 0 & - & - & - & $\mathrm{r}$ & CCS \\
\hline 1,289 & 2.06 & 0.00 & $\mathrm{f}$ & -1 & - & - & - & 0 & - & - & - & c & CCS \\
\hline 1,290 & 2.06 & 0.00 & $\mathrm{f}$ & -1 & - & - & - & 0 & - & - & - & $\mathrm{c}$ & CCS \\
\hline 1,291 & 2.06 & 0.00 & $\mathrm{~d}$ & -1 & - & - & - & - & - & - & - & c & CCS \\
\hline 1,292 & 2.06 & 0.00 & $\mathrm{f}$ & -1 & - & - & - & 0 & - & - & - & $\mathrm{r}$ & CCS \\
\hline 1,293 & 2.06 & 0.00 & $\mathrm{f}$ & -1 & - & - & - & 0 & - & - & - & c & CCS \\
\hline 1,294 & 2.06 & 0.00 & $\mathrm{~d}$ & -1 & - & - & - & - & - & - & - & c & CCS \\
\hline 1,295 & 2.06 & 0.00 & $\mathrm{f}$ & -1 & - & - & - & 0 & - & - & - & c & CCS \\
\hline 1,296 & 2.06 & 0.00 & $\mathrm{f}$ & -1 & - & - & - & 0 & - & - & - & $\mathrm{r}$ & CCS \\
\hline 1,297 & 2.06 & 0.00 & $\mathrm{f}$ & -1 & - & - & - & 0 & - & - & - & c & CCS \\
\hline 1,298 & 2.06 & 0.00 & $\mathrm{f}$ & -1 & - & - & - & 0 & - & - & - & $\mathrm{c}$ & CCS \\
\hline 1,299 & 2.06 & 0.00 & $\mathrm{f}$ & -1 & - & - & - & 0 & - & - & - & c & CCS \\
\hline 1,300 & 2.06 & 0.00 & $\mathrm{f}$ & -1 & - & - & - & 0 & - & - & - & c & CCS \\
\hline 1,301 & 2.06 & 0.00 & $\mathrm{~d}$ & -1 & - & - & - & - & - & - & - & $\mathrm{r}$ & CCS \\
\hline 1,302 & 2.06 & 0.00 & $\mathrm{f}$ & -1 & - & - & - & 0 & - & - & - & $\mathrm{t}$ & CCS \\
\hline 1,303 & 2.06 & 0.00 & $\mathrm{f}$ & -1 & - & - & - & 0 & - & - & - & $\mathrm{g}$ & CCS \\
\hline 1,304 & 2.06 & 0.00 & $\mathrm{f}$ & -1 & - & - & - & 0 & - & - & - & $\mathrm{c}$ & CCS \\
\hline 1,305 & 2.06 & 0.00 & $\mathrm{f}$ & -1 & - & - & - & 0 & - & - & - & $\mathrm{c}$ & CCS \\
\hline 1,306 & 2.06 & 0.00 & $\mathrm{f}$ & -1 & - & - & - & 0 & - & - & - & c & CCS \\
\hline 1,307 & 2.06 & 0.00 & $\mathrm{f}$ & -1 & - & - & - & 0 & - & - & - & $\mathrm{t}$ & CCS \\
\hline 1,308 & 2.06 & 0.00 & $\mathrm{f}$ & -1 & - & - & - & 0 & - & - & - & $\mathrm{c}$ & CCS \\
\hline 1,309 & 2.06 & 0.00 & $\mathrm{~d}$ & -1 & - & - & - & - & - & - & - & $\mathrm{t}$ & CCS \\
\hline 1,310 & 2.06 & 0.00 & $\mathrm{f}$ & -1 & - & - & - & 0 & - & - & - & $\mathrm{c}$ & CCS \\
\hline 1,311 & 2.06 & 0.00 & $\mathrm{f}$ & -1 & - & - & - & 0 & - & - & - & $\mathrm{c}$ & CCS \\
\hline 1,312 & 2.06 & 0.00 & $\mathrm{f}$ & -1 & - & - & - & 0 & - & - & - & $\mathrm{c}$ & CCS \\
\hline 1,313 & 2.06 & 0.00 & $\mathrm{f}$ & -1 & - & - & - & 0 & - & - & - & $\mathrm{c}$ & CCS \\
\hline 1,314 & 2.06 & 0.00 & $\mathrm{f}$ & -1 & - & - & - & 0 & - & - & - & $\mathrm{c}$ & CCS \\
\hline 1,315 & 2.06 & 0.00 & $\mathrm{f}$ & -1 & - & - & - & 0 & - & - & - & $\mathrm{g}$ & CCS \\
\hline 1,316 & 2.06 & 0.00 & $\mathrm{f}$ & -1 & - & - & - & 0 & - & - & - & $\mathrm{c}$ & CCS \\
\hline 1,317 & 2.06 & 0.00 & f & -1 & - & - & - & 0 & - & - & - & $\mathrm{g}$ & CCS \\
\hline
\end{tabular}




\begin{tabular}{|c|c|c|c|c|c|c|c|c|c|c|c|c|c|}
\hline 1,318 & 2.06 & 0.00 & $\mathrm{f}$ & \begin{tabular}{l|l}
- & 1 \\
\end{tabular} & - & - & - & 0 & - & - & - & $\mathrm{b}$ & CCS \\
\hline 1,319 & 2.06 & 0.00 & f & -1 & - & - & - & 0 & - & - & - & c & CCS \\
\hline 1,320 & 2.06 & 0.00 & $\mathrm{f}$ & -1 & - & - & - & 0 & - & - & - & c & $\mathrm{CCS}$ \\
\hline 1,321 & 2.06 & 0.00 & $\mathrm{f}$ & -1 & - & - & - & 0 & - & - & - & c & CCS \\
\hline 1,322 & 2.06 & 0.00 & d & -1 & - & - & - & - & - & - & - & c & CCS \\
\hline 1,323 & 2.06 & 0.03 & d & -1 & - & - & - & - & - & - & - & $\mathrm{g}$ & CCS \\
\hline 1,324 & 2.06 & 0.00 & $\mathrm{f}$ & -1 & - & - & - & 0 & - & - & - & c & CCS \\
\hline 1,325 & 2.06 & 0.00 & c & $\begin{array}{lll}\text { o } & 1 \\
\end{array}$ & $\mathrm{cx}$ & 0 & 3 & 0 & 2.37 & 4.19 & 0.62 & $\mathrm{t}$ & CCS \\
\hline 1,326 & 2.06 & 0.00 & $\mathrm{f}$ & -1 & - & - & - & 0 & - & - & - & c & CCS \\
\hline 1,327 & 2.06 & 0.00 & $\mathrm{f}$ & -1 & - & - & - & 0 & - & - & - & $\mathrm{c}$ & $\mathrm{CCS}$ \\
\hline 1,328 & 2.06 & 0.00 & $\mathrm{f}$ & -1 & - & - & - & 0 & - & - & - & c & CCS \\
\hline 1,329 & 2.06 & 0.00 & $\mathrm{f}$ & -1 & - & - & - & 0 & - & - & - & c & CCS \\
\hline 1,330 & 2.06 & 0.00 & c & \begin{tabular}{l|l} 
o & 1 \\
\end{tabular} & $\mathrm{cx}$ & 0 & 0 & 0 & 3.55 & 3.76 & 0.77 & $\mathrm{c}$ & CCS \\
\hline 1,331 & 2.06 & 0.00 & $\mathrm{f}$ & -1 & - & - & - & 0 & - & - & - & $\mathrm{c}$ & CCS \\
\hline 1,332 & 2.06 & 0.00 & $\mathrm{f}$ & -1 & - & - & - & 0 & - & - & - & c & CCS \\
\hline 1,333 & 2.06 & 0.00 & $\mathrm{f}$ & -1 & - & - & - & 0 & - & - & - & c & CCS \\
\hline 1,334 & 2.06 & 0.00 & $\mathrm{f}$ & -1 & - & - & - & 0 & - & - & - & c & CCS \\
\hline 1,336 & 2.06 .3 & 3.60 & $\mathrm{f}$ & -7 & - & - & - & 0 & - & - & - & $t$ & CCS \\
\hline 1,337 & 2.06 .3 & 1.77 & c & o 6 & $\mathrm{f}$ & 0 & 2 & 0 & 5.85 & 29.64 & 4.62 & c & CCS \\
\hline 1,339 & 2.06 .3 & 1.96 & $\mathrm{~b}$ & $\begin{array}{ll}\mathrm{s} & 6 \\
\end{array}$ & c & 0 & 0 & 2 & 3.99 & 26.85 & 4.05 & $\mathrm{r}$ & CCS \\
\hline 1,342 & 2.06 .3 & 1.70 & $\mathrm{f}$ & -7 & - & - & - & 0 & - & - & - & c & CCS \\
\hline 1,343 & 2.06 .3 & 3.85 & $\mathrm{c}$ & $\begin{array}{ll}\text { o } 8 \\
\end{array}$ & $\mathrm{a}$ & 0 & 3 & 0 & 7.33 & 37.58 & 6.95 & c & CCS \\
\hline 1,344 & 2.06 .3 & 2.72 & $\mathrm{~d}$ & -5 & - & - & - & - & - & - & - & c & CCS \\
\hline 1,345 & 2.06 .3 & 4.50 & $\mathrm{f}$ & -6 & - & - & - & 0 & - & - & - & c & CCS \\
\hline 1,346 & 2.06 .3 & 5.15 & $\mathrm{f}$ & -6 & - & - & - & 0 & - & - & - & $\mathrm{t}$ & CCS \\
\hline 1,347 & 2.06 .3 & 2.49 & $\mathrm{f}$ & -8 & - & - & - & 0 & - & - & - & c & CCS \\
\hline 1,348 & 2.06 .3 & 2.27 & $\mathrm{f}$ & -5 & - & - & - & 1 & - & - & - & c & CCS \\
\hline 1,349 & 2.06 .3 & 1.59 & c & $\begin{array}{ll}\mathrm{O} & 5 \\
\end{array}$ & $\mathrm{cx}$ & 0 & 3 & 0 & 7.54 & 28.69 & 5.40 & $\mathrm{c}$ & CCS \\
\hline 1,350 & 2.06 .3 & 1.57 & $\mathrm{c}$ & $\begin{array}{ll}\text { o } & 5 \\
\end{array}$ & $\mathrm{cx}$ & 0 & 3 & 0 & 17.05 & 23.12 & 8.13 & $t$ & CCS \\
\hline 1,351 & 2.06 .3 & 1.54 & $\mathrm{~d}$ & -6 & - & - & - & - & - & - & - & $\mathrm{t}$ & CCS \\
\hline 1,353 & 2.06 .3 & 2.53 & $\mathrm{f}$ & -5 & - & - & - & 0 & - & - & - & $\mathrm{c}$ & CCS \\
\hline 1,354 & 2.06 .3 & 1.68 & $\mathrm{f}$ & -4 & - & - & - & 0 & - & - & - & c & CCS \\
\hline 1,355 & 2.06 .3 & 0.55 & $\mathrm{c}$ & $\begin{array}{ll}0 & 5 \\
\end{array}$ & $\mathrm{cx}$ & 1 & 3 & 1 & 6.89 & 21.85 & 8.42 & $\mathrm{c}$ & CCS \\
\hline 1,356 & 2.06 .3 & 1.55 & $\mathrm{~d}$ & -4 & - & - & - & - & - & - & - & $\mathrm{c}$ & CCS \\
\hline 1,357 & 2.06 .3 & 0.98 & $\mathrm{f}$ & -4 & - & - & - & 0 & - & - & - & $\mathrm{c}$ & CCS \\
\hline 1,358 & 2.06 .3 & 1.13 & $\mathrm{f}$ & -4 & - & - & - & 2 & - & - & - & $\mathrm{r}$ & CCS \\
\hline 1,359 & 2.06 .3 & 0.51 & $\mathrm{c}$ & \begin{tabular}{l|l} 
o & 4 \\
\end{tabular} & $\mathrm{cx}$ & 0 & 3 & 0 & 7.60 & 20.47 & 1.61 & $\mathrm{c}$ & $\mathrm{CCS}$ \\
\hline 1,360 & 2.06 .3 & 0.64 & $\mathrm{~d}$ & -4 & - & - & - & - & - & - & - & $\mathrm{t}$ & CCS \\
\hline 1,361 & 2.06 .3 & 0.27 & $\mathrm{f}$ & -3 & - & - & - & 0 & - & - & - & $\mathrm{c}$ & CCS \\
\hline 1,362 & 2.06 .3 & 0.59 & $\mathrm{f}$ & -3 & - & - & - & 0 & - & - & - & $\mathrm{c}$ & CCS \\
\hline 1,363 & 2.06 .3 & 0.81 & c & o 3 & $\mathrm{f}$ & 0 & 0 & 0 & 15.88 & 14.37 & 5.96 & $\mathrm{c}$ & CCS \\
\hline 1,364 & 2.06 .3 & 0.46 & $\mathrm{f}$ & -3 & - & - & - & 0 & - & - & - & $\mathrm{c}$ & CCS \\
\hline 1,365 & 2.06 .3 & 0.30 & $\mathrm{~d}$ & -3 & - & - & - & - & - & - & - & $\mathrm{c}$ & CCS \\
\hline
\end{tabular}




\begin{tabular}{|c|c|c|c|c|c|c|c|c|c|c|c|c|c|}
\hline 1,366 & 2.06 .3 & 0.43 & c & \begin{tabular}{|l|l|} 
o & 4 \\
\end{tabular} & $\mathrm{cx}$ & 0 & 3 & 0 & 4.29 & 17.10 & 1.81 & $\mathrm{t}$ & CCS \\
\hline 1,367 & 2.06 .3 & 0.46 & $\mathrm{f}$ & -3 & - & - & - & 0 & - & - & - & w & $\mathrm{CCS}$ \\
\hline 1,368 & 2.06 .3 & 0.53 & $\mathrm{f}$ & -3 & - & - & - & 2 & - & - & - & c & $\mathrm{CCS}$ \\
\hline 1,369 & 2.06 .3 & 0.81 & $\mathrm{f}$ & -3 & - & - & - & 0 & - & - & - & $\mathrm{r}$ & $\mathrm{CCS}$ \\
\hline 1,370 & 2.06 .3 & 0.39 & $\mathrm{f}$ & -3 & - & - & - & 0 & - & - & - & c & $\mathrm{CCS}$ \\
\hline 1,371 & 2.06 .3 & 0.32 & $\mathrm{~d}$ & -3 & - & - & - & - & - & - & - & c & CCS \\
\hline 1,372 & 2.06 .3 & 0.26 & $\mathrm{f}$ & -3 & - & - & - & 0 & - & - & - & c & $\mathrm{CCS}$ \\
\hline 1,373 & 2.06 .3 & 0.86 & $\mathrm{f}$ & -4 & - & - & - & 0 & - & - & - & c & CCS \\
\hline 1,374 & 2.06 .3 & 1.07 & d & -5 & - & - & - & - & - & - & - & c & $\mathrm{CCS}$ \\
\hline 1,375 & 2.06 .3 & 0.14 & $\mathrm{f}$ & -3 & - & - & - & 0 & - & - & - & c & $\mathrm{CCS}$ \\
\hline 1,376 & 2.06 .3 & 0.40 & $\mathrm{f}$ & -5 & - & - & - & 1 & - & - & - & c & $\mathrm{CCS}$ \\
\hline 1,377 & 2.06.3 & 0.15 & $\mathrm{f}$ & -2 & - & - & - & 0 & - & - & - & c & $\mathrm{CCS}$ \\
\hline 1,378 & 2.06.3 & 0.09 & $\mathrm{f}$ & -3 & - & - & - & 0 & - & - & - & c & $\mathrm{CCS}$ \\
\hline 1,379 & 2.06 .3 & 0.28 & $\mathrm{f}$ & -3 & - & - & - & 0 & - & - & - & c & $\mathrm{CCS}$ \\
\hline 1,380 & 2.06.3 & 0.08 & c & $\begin{array}{ll} & 2 \\
\end{array}$ & $\mathrm{f}$ & 0 & 0 & 0 & 7.23 & 9.58 & 1.50 & c & $\mathrm{CCS}$ \\
\hline 1,381 & 2.06.3 & 0.29 & $\mathrm{f}$ & -3 & - & - & - & 0 & - & - & - & c & $\mathrm{CCS}$ \\
\hline 1,382 & 2.06 .3 & 0.15 & $\mathrm{f}$ & -2 & - & - & - & 1 & - & - & - & c & $\mathrm{CCS}$ \\
\hline 1,383 & 2.06.3 & 0.56 & $\mathrm{~d}$ & -3 & - & - & - & - & - & - & - & c & $\mathrm{CCS}$ \\
\hline 1,384 & 2.06 .3 & 0.14 & $\mathrm{f}$ & -3 & - & - & - & 0 & - & - & - & c & CCS \\
\hline 1,385 & 2.06 .3 & 0.14 & $\mathrm{f}$ & -3 & - & - & - & 0 & - & - & - & c & $\mathrm{CCS}$ \\
\hline 1,386 & 2.06 .3 & 0.26 & $\mathrm{f}$ & -3 & - & - & - & 0 & - & - & - & $t$ & $\mathrm{CCS}$ \\
\hline 1,387 & 2.06 .3 & 0.07 & d & -2 & - & - & - & - & - & - & - & c & CCS \\
\hline 1,388 & 2.06 .3 & 0.23 & d & -2 & - & - & - & - & - & - & - & b & CCS \\
\hline 1,389 & 2.06 .3 & 0.35 & $\mathrm{f}$ & -2 & - & - & - & 0 & - & - & - & c & CCS \\
\hline 1,390 & 2.06 .3 & 0.11 & d & -3 & - & - & - & - & - & - & - & c & $\mathrm{CCS}$ \\
\hline 1,391 & 2.06 .3 & 0.13 & $\mathrm{f}$ & -2 & - & - & - & 0 & - & - & - & c & CCS \\
\hline 1,392 & 2.06 .3 & 0.00 & $\mathrm{f}$ & -1 & - & - & - & 0 & - & - & - & c & CCS \\
\hline 1,393 & 2.06 .3 & 0.20 & $\mathrm{f}$ & -3 & - & - & - & 0 & - & - & - & c & $\mathrm{CCS}$ \\
\hline 1,394 & 2.06 .3 & 0.49 & d & -2 & - & - & - & - & - & - & - & c & CCS \\
\hline 1,395 & 2.06 .3 & 0.17 & f & -3 & - & - & - & 0 & - & - & - & c & CCS \\
\hline 1,396 & 2.06 .3 & 0.09 & $\mathrm{f}$ & -2 & - & - & - & 0 & - & - & - & c & $\mathrm{CCS}$ \\
\hline 1,397 & 2.06 .3 & 0.09 & $\mathrm{f}$ & -3 & - & - & - & 0 & - & - & - & c & CCS \\
\hline 1,398 & 2.06 .3 & 0.16 & $\mathrm{f}$ & -3 & - & - & - & 0 & - & - & - & $\mathrm{r}$ & CCS \\
\hline 1,399 & 2.06 .3 & 0.12 & $\mathrm{f}$ & -2 & - & - & - & 0 & - & - & - & $\mathrm{r}$ & CCS \\
\hline 1,400 & 2.06 .3 & 0.16 & $\mathrm{f}$ & -3 & - & - & - & 1 & - & - & - & c & $\mathrm{CCS}$ \\
\hline 1,401 & 2.06 .3 & 0.23 & f & -2 & - & - & - & 0 & - & - & - & $\mathrm{c}$ & CCS \\
\hline 1,402 & 2.06 .3 & 0.10 & $\mathrm{f}$ & -2 & - & - & - & 0 & - & - & - & c & $\mathrm{CCS}$ \\
\hline 1,403 & 2.06 .3 & 0.15 & f & -2 & - & - & - & 0 & - & - & - & $t$ & CCS \\
\hline 1,404 & 2.06 .3 & 0.04 & $\mathrm{~d}$ & -1 & - & - & - & - & - & - & - & c & CCS \\
\hline 1,405 & 2.06 .3 & 0.12 & d & -2 & - & - & - & - & - & - & - & w & CCS \\
\hline 1,406 & 2.06 .3 & 0.13 & $\mathrm{f}$ & -2 & - & - & - & 0 & - & - & - & $\mathrm{t}$ & CCS \\
\hline 1,407 & 2.06 .3 & 0.12 & f & -2 & - & - & - & 0 & - & - & - & t & CCS \\
\hline 1,408 & 2.06 .3 & 0.17 & $\mathrm{~d}$ & -2 & - & - & - & - & - & - & - & $t$ & CCS \\
\hline
\end{tabular}




\begin{tabular}{|c|c|c|c|c|c|c|c|c|c|c|c|c|c|}
\hline 1,409 & 2.06 .3 & 0.23 & $\mathrm{f}$ & -1 & - & - & - & 0 & - & - & - & c & $\mathrm{CCS}$ \\
\hline 1,410 & 2.06 .3 & 0.24 & d & -2 & - & - & - & - & - & - & - & c & $\mathrm{CCS}$ \\
\hline 1,411 & 2.06 .3 & 0.14 & d & -2 & - & - & - & - & - & - & - & c & $\mathrm{CCS}$ \\
\hline 1,412 & 2.06 .3 & 0.07 & $\mathrm{f}$ & -2 & - & - & - & 0 & - & - & - & c & CCS \\
\hline 1,413 & 2.06 .3 & 0.00 & $\mathrm{f}$ & -1 & - & - & - & 0 & - & - & - & c & CCS \\
\hline 1,414 & 2.06 .3 & 0.11 & d & -2 & - & - & - & - & - & - & - & c & $\mathrm{CCS}$ \\
\hline 1,415 & 2.06 .3 & 0.11 & d & -1 & - & - & - & - & - & - & - & c & CCS \\
\hline 1,416 & 2.06 .3 & 0.04 & $\mathrm{f}$ & -2 & - & - & - & 0 & - & - & - & c & $\mathrm{CCS}$ \\
\hline 1,417 & 2.06 .3 & 0.08 & c & \begin{tabular}{|l|l|} 
o & 1 \\
\end{tabular} & cx & 0 & 3 & 0 & 6.61 & 7.63 & 1.55 & c & $\mathrm{CCS}$ \\
\hline 1,418 & 2.06 .3 & 0.12 & $\mathrm{f}$ & -2 & - & - & - & 0 & - & - & - & c & $\mathrm{CCS}$ \\
\hline 1,419 & 2.06 .3 & 0.03 & $\mathrm{f}$ & -11 & - & - & - & 0 & - & - & - & c & $\mathrm{CCS}$ \\
\hline 1,420 & 2.06 .3 & 0.00 & $\mathrm{~d}$ & -1 & - & - & - & - & - & - & - & c & $\mathrm{CCS}$ \\
\hline 1,421 & 2.06 .3 & 0.00 & $\mathrm{f}$ & -11 & - & - & - & 1 & - & - & - & c & $\mathrm{CCS}$ \\
\hline 1,422 & 2.06 .3 & 0.08 & d & -2 & - & - & - & - & - & - & - & $\mathrm{r}$ & $\mathrm{CCS}$ \\
\hline 1,423 & 2.06 .3 & 0.07 & $\mathrm{f}$ & -2 & - & - & - & 0 & - & - & - & c & $\mathrm{CCS}$ \\
\hline 1,424 & 2.06 .3 & 0.03 & $\mathrm{f}$ & -1 & - & - & - & 0 & - & - & - & c & $\mathrm{CCS}$ \\
\hline 1,425 & 2.06 .3 & 0.09 & $\mathrm{f}$ & -2 & - & - & - & 0 & - & - & - & $\mathrm{t}$ & CCS \\
\hline 1,426 & 2.06 .3 & 0.07 & $\mathrm{~d}$ & -1 & - & - & - & - & - & - & - & $\mathrm{t}$ & $\mathrm{CCS}$ \\
\hline 1,427 & 2.06 .3 & 0.06 & $d$ & -2 & - & - & - & - & - & - & - & c & CCS \\
\hline 1,428 & 2.06 .3 & 0.15 & d & -2 & - & - & - & - & - & - & - & c & CCS \\
\hline 1,429 & 2.06 .3 & 0.07 & $\mathrm{f}$ & -2 & - & - & - & 0 & - & - & - & c & CCS \\
\hline 1,430 & 2.06 .3 & 0.09 & $\mathrm{f}$ & -2 & - & - & - & 0 & - & - & - & c & CCS \\
\hline 1,431 & 2.06 .3 & 0.00 & $\mathrm{~d}$ & -1 & - & - & - & - & - & - & - & c & CCS \\
\hline 1,432 & 2.06 .3 & 0.11 & $\mathrm{f}$ & -2 & - & - & - & 0 & - & - & - & c & CCS \\
\hline 1,433 & 2.06 .3 & 0.05 & $\mathrm{f}$ & -2 & - & - & - & 0 & - & - & - & c & CCS \\
\hline 1,434 & 2.06 .3 & 0.00 & $\mathrm{c}$ & -1 & $\mathrm{cx}$ & 0 & 3 & 0 & 2.49 & 6.19 & 0.83 & c & CCS \\
\hline 1,435 & 2.06 .3 & 0.00 & $\mathrm{f}$ & -1 & - & - & - & 0 & - & - & - & c & $\mathrm{CCS}$ \\
\hline 1,436 & 2.06 .3 & 0.00 & $\mathrm{f}$ & -1 & - & - & - & 0 & - & - & - & c & $\mathrm{CCS}$ \\
\hline 1,437 & 2.06 .3 & 0.00 & $\mathrm{f}$ & -2 & - & - & - & 0 & - & - & - & c & CCS \\
\hline 1,438 & 2.06 .3 & 0.00 & $\mathrm{f}$ & -2 & - & - & - & 0 & - & - & - & c & $\mathrm{CCS}$ \\
\hline 1,439 & 2.06 .3 & 0.00 & $\mathrm{f}$ & -1 & - & - & - & 0 & - & - & - & c & $\mathrm{CCS}$ \\
\hline 1,440 & 2.06 .3 & 0.14 & $\mathrm{f}$ & -2 & - & - & - & 0 & - & - & - & c & CCS \\
\hline 1,441 & 2.06 .3 & 0.05 & $\mathrm{f}$ & -2 & - & - & - & 0 & - & - & - & c & CCS \\
\hline 1,442 & 2.06 .3 & 0.09 & $\mathrm{f}$ & -2 & - & - & - & 0 & - & - & - & c & $\mathrm{CCS}$ \\
\hline 1,443 & 2.06 .3 & 4.00 & $\mathrm{~d}$ & -1 & - & - & - & - & - & - & - & c & $\mathrm{CCS}$ \\
\hline 1,444 & 2.06 .3 & 0.00 & $\mathrm{f}$ & -11 & - & - & - & 0 & - & - & - & c & $\mathrm{CCS}$ \\
\hline 1,445 & 2.06 .3 & 0.05 & $\mathrm{~d}$ & -1 & - & - & - & - & - & - & - & c & $\mathrm{CCS}$ \\
\hline 1,446 & 2.06 .3 & 0.00 & $\mathrm{f}$ & -1 & - & - & - & 0 & - & - & - & c & $\mathrm{CCS}$ \\
\hline 1,447 & 2.06 .3 & 0.06 & $\mathrm{f}$ & -1 & - & - & - & 0 & - & - & - & c & $\mathrm{CCS}$ \\
\hline 1,448 & 2.06 .3 & 0.00 & $\mathrm{f}$ & -1 & - & - & - & 0 & - & - & - & c & $\mathrm{CCS}$ \\
\hline 1,449 & 2.06 .3 & 0.04 & $\mathrm{~d}$ & -1 & - & - & - & - & - & - & - & oc & $\mathrm{CCS}$ \\
\hline 1,450 & 2.06 .3 & 0.05 & $\mathrm{f}$ & -2 & - & - & - & 0 & - & - & - & c & $\mathrm{CCS}$ \\
\hline 1,451 & 2.06 .3 & 0.00 & $\mathrm{f}$ & -1 & - & - & - & 0 & - & - & - & c & CCS \\
\hline
\end{tabular}




\begin{tabular}{|c|c|c|c|c|c|c|c|c|c|c|c|c|c|}
\hline 1,452 & 2.06 .3 & 0.00 & $\mathrm{f}$ & \begin{tabular}{|l|l|}
- & 1 \\
\end{tabular} & - & - & - & 0 & - & - & - & $\mathrm{r}$ & CCS \\
\hline 1,453 & 2.06 .3 & 0.05 & d & -1 & - & - & - & - & - & - & - & $\mathrm{t}$ & CCS \\
\hline 1,454 & 2.06 .3 & 0.03 & $\mathrm{~d}$ & -1 & - & - & - & - & - & - & - & c & $\mathrm{CCS}$ \\
\hline 1,455 & 2.06 .3 & 0.00 & $\mathrm{f}$ & -1 & - & - & - & 0 & - & - & - & c & CCS \\
\hline 1,456 & 2.06 .3 & 0.00 & d & -1 & - & - & - & - & - & - & - & c & CCS \\
\hline 1,457 & 2.06 .3 & 0.00 & $\mathrm{f}$ & -1 & - & - & - & 0 & - & - & - & c & CCS \\
\hline 1,458 & 2.06 .3 & 0.00 & f & -1 & - & - & - & 0 & - & - & - & c & CCS \\
\hline 1,459 & 2.06 .3 & 0.00 & $\mathrm{f}$ & -1 & - & - & - & 0 & - & - & - & c & CCS \\
\hline 1,460 & 2.06 .3 & 0.00 & f & -1 & - & - & - & 0 & - & - & - & $t$ & CCS \\
\hline 1,461 & 2.06 .3 & 0.00 & d & -1 & - & - & - & - & - & - & - & c & CCS \\
\hline 1,462 & 2.06 .3 & 0.00 & f & -1 & - & - & - & 0 & - & - & - & c & CCS \\
\hline 1,463 & 2.06 .3 & 0.00 & $\mathrm{f}$ & -1 & - & - & - & 0 & - & - & - & c & CCS \\
\hline 1,464 & 2.06 .3 & 0.09 & f & -1 & - & - & - & 0 & - & - & - & c & CCS \\
\hline 1,465 & 2.06 .3 & 0.00 & $\mathrm{f}$ & -1 & - & - & - & 0 & - & - & - & c & CCS \\
\hline 1,466 & 2.06 .3 & 0.00 & d & -2 & - & - & - & - & - & - & - & c & CCS \\
\hline 1,467 & 2.06 .3 & 0.00 & $\mathrm{f}$ & -1 & - & - & - & 0 & - & - & - & c & CCS \\
\hline 1,468 & 2.06 .3 & 0.00 & d & -1 & - & - & - & - & - & - & - & c & $\mathrm{CCS}$ \\
\hline 1,469 & 2.06 .3 & 0.00 & $\mathrm{f}$ & -1 & - & - & - & 0 & - & - & - & c & CCS \\
\hline 1,470 & 2.06 .3 & 0.00 & $\mathrm{f}$ & -1 & - & - & - & 0 & - & - & - & c & CCS \\
\hline 1,471 & 2.06 .3 & 0.05 & $\mathrm{f}$ & -1 & - & - & - & 0 & - & - & - & c & CCS \\
\hline 1,472 & 2.06 .3 & 0.03 & $\mathrm{f}$ & -1 & - & - & - & 0 & - & - & - & c & CCS \\
\hline 1,473 & 2.06 .3 & 0.00 & $\mathrm{f}$ & -1 & - & - & - & 0 & - & - & - & c & CCS \\
\hline 1,474 & 2.06 .3 & 0.00 & d & -1 & - & - & - & - & - & - & - & c & $\mathrm{CCS}$ \\
\hline 1,475 & 2.06 .3 & 0.00 & $\mathrm{f}$ & -1 & - & - & - & 0 & - & - & - & w & CCS \\
\hline 1,476 & 2.06 .3 & 0.00 & $\mathrm{f}$ & -1 & - & - & - & 0 & - & - & - & c & $\mathrm{CCS}$ \\
\hline 1,477 & 2.06 .3 & 0.07 & $\mathrm{f}$ & -1 & - & - & - & 0 & - & - & - & c & CCS \\
\hline 1,478 & 2.06 .3 & 0.05 & $\mathrm{f}$ & -1 & - & - & - & 0 & - & - & - & $\mathrm{r}$ & CCS \\
\hline 1,479 & 2.06 .3 & 0.00 & $\mathrm{f}$ & -1 & - & - & - & 0 & - & - & - & c & CCS \\
\hline 1,480 & 2.06 .3 & 0.00 & $\mathrm{f}$ & -1 & - & - & - & 0 & - & - & - & c & CCS \\
\hline 1,481 & 2.06 .3 & 0.00 & f & -1 & - & - & - & 0 & - & - & - & w & CCS \\
\hline 1,482 & 2.06 .3 & 0.00 & $\mathrm{f}$ & -1 & - & - & - & 0 & - & - & - & c & CCS \\
\hline 1,483 & 2.06 .3 & 0.00 & $\mathrm{~b}$ & $\begin{array}{ll}\mathrm{s} & 1 \\
\end{array}$ & $\mathrm{f}$ & 0 & 3 & 0 & 2.45 & 5.68 & 1.13 & c & CCS \\
\hline 1,484 & 2.06 .3 & 0.09 & $\mathrm{f}$ & -1 & - & - & - & 0 & - & - & - & c & CCS \\
\hline 1,485 & 2.06 .3 & 0.00 & d & -1 & - & - & - & - & - & - & - & c & CCS \\
\hline 1,486 & 2.06 .3 & 0.00 & $\mathrm{f}$ & -1 & - & - & - & 0 & - & - & - & c & CCS \\
\hline 1,487 & 2.06 .3 & 0.00 & f & -1 & - & - & - & 0 & - & - & - & $\mathrm{c}$ & CCS \\
\hline 1,488 & 2.06 .3 & 0.04 & f & -2 & - & - & - & 0 & - & - & - & c & CCS \\
\hline 1,489 & 2.06 .3 & 0.00 & f & -1 & - & - & - & 0 & - & - & - & c & CCS \\
\hline 1,490 & 2.06 .3 & 0.00 & $\mathrm{f}$ & -1 & - & - & - & 0 & - & - & - & c & CCS \\
\hline 1,491 & 2.06 .3 & 0.06 & d & -1 & - & - & - & - & - & - & - & c & CCS \\
\hline 1,492 & 2.06 .3 & 0.00 & d & -1 & - & - & - & - & - & - & - & c & CCS \\
\hline 1,493 & 2.06 .3 & 0.06 & f & -1 & - & - & - & 0 & - & - & - & c & CCS \\
\hline 1,494 & 2.06 .3 & 0.00 & $\mathrm{f}$ & -1 & - & - & - & 0 & - & - & - & c & CCS \\
\hline
\end{tabular}




\begin{tabular}{|c|c|c|c|c|c|c|c|c|c|c|c|c|c|}
\hline 1,495 & 2.06 .3 & 0.00 & $\mathrm{f}$ & \begin{tabular}{|l|l}
- & 1 \\
\end{tabular} & - & - & - & 0 & - & - & - & $\mathrm{r}$ & CCS \\
\hline 1,496 & 2.06 .3 & 0.00 & $\mathrm{f}$ & -1 & - & - & - & 0 & - & - & - & c & CCS \\
\hline 1,497 & 2.06 .3 & 0.00 & $\mathrm{f}$ & -1 & - & - & - & 0 & - & - & - & c & $\mathrm{CCS}$ \\
\hline 1,498 & 2.06 .3 & 0.00 & $\mathrm{f}$ & -1 & - & - & - & 0 & - & - & - & c & CCS \\
\hline 1,499 & 2.06 .3 & 0.00 & $\mathrm{f}$ & -1 & - & - & - & 0 & - & - & - & c & CCS \\
\hline 1,500 & 2.06 .3 & 0.00 & $\mathrm{f}$ & -1 & - & - & - & 0 & - & - & - & c & CCS \\
\hline 1,501 & 2.06 .3 & 0.00 & $\mathrm{f}$ & -1 & - & - & - & 0 & - & - & - & c & CCS \\
\hline 1,502 & 2.06 .3 & 0.00 & $\mathrm{f}$ & -1 & - & - & - & 0 & - & - & - & c & CCS \\
\hline 1,503 & 2.06 .3 & 0.00 & $\mathrm{f}$ & -1 & - & - & - & 0 & - & - & - & c & CCS \\
\hline 1,504 & 2.06 .3 & 0.00 & $\mathrm{f}$ & -1 & - & - & - & 0 & - & - & - & c & CCS \\
\hline 1,505 & 2.06 .3 & 0.04 & $\mathrm{~d}$ & -11 & - & - & - & - & - & - & - & c & CCS \\
\hline 1,506 & 2.06 .3 & 0.00 & $\mathrm{f}$ & -1 & - & - & - & 0 & - & - & - & c & CCS \\
\hline 1,507 & 2.06 .3 & 0.06 & $\mathrm{f}$ & -11 & - & - & - & 0 & - & - & - & c & CCS \\
\hline 1,508 & 2.06 .3 & 0.00 & $\mathrm{~d}$ & -1 & - & - & - & - & - & - & - & c & CCS \\
\hline 1,509 & 2.06 .3 & 0.00 & $\mathrm{f}$ & -11 & - & - & - & 0 & - & - & - & c & CCS \\
\hline 1,510 & 2.06 .3 & 0.06 & $\mathrm{f}$ & -2 & - & - & - & 0 & - & - & - & c & CCS \\
\hline 1,511 & 2.06 .3 & 0.06 & $\mathrm{f}$ & -2 & - & - & - & 0 & - & - & - & c & CCS \\
\hline 1,512 & 2.06 .3 & 0.04 & $\mathrm{f}$ & -2 & - & - & - & 0 & - & - & - & c & CCS \\
\hline 1,513 & 2.06 .3 & 0.06 & $\mathrm{~d}$ & -1 & - & - & - & - & - & - & - & c & CCS \\
\hline 1,514 & 2.06 .3 & 0.00 & $f$ & -1 & - & - & - & 0 & - & - & - & c & CCS \\
\hline 1,515 & 2.06 .3 & 0.00 & $\mathrm{~d}$ & -1 & - & - & - & - & - & - & - & $t$ & CCS \\
\hline 1,516 & 2.06 .3 & 0.00 & $\mathrm{f}$ & -1 & - & - & - & 0 & - & - & - & c & CCS \\
\hline 1,517 & 2.06 .3 & 0.00 & $\mathrm{f}$ & -2 & - & - & - & 0 & - & - & - & c & CCS \\
\hline 1,518 & 2.06 .3 & 0.00 & $\mathrm{f}$ & -2 & - & - & - & 0 & - & - & - & c & CCS \\
\hline 1,519 & 2.06 .3 & 0.00 & $\mathrm{f}$ & -1 & - & - & - & 0 & - & - & - & c & CCS \\
\hline 1,520 & 2.06 .3 & 0.00 & $\mathrm{~d}$ & -1 & - & - & - & - & - & - & - & w & CCS \\
\hline 1,521 & 2.06 .3 & 0.00 & $\mathrm{~d}$ & -1 & - & - & - & - & - & - & - & c & CCS \\
\hline 1,522 & 2.06 .3 & 0.00 & $\mathrm{f}$ & -1 & - & - & - & 0 & - & - & - & c & CCS \\
\hline 1,523 & 2.06 .3 & 0.00 & $\mathrm{f}$ & -1 & - & - & - & 0 & - & - & - & $\mathrm{g}$ & CCS \\
\hline 1,524 & 2.06 .3 & 0.03 & $\mathrm{f}$ & -2 & - & - & - & 0 & - & - & - & c & CCS \\
\hline 1,525 & 2.06 .3 & 0.00 & $\mathrm{f}$ & -1 & - & - & - & 0 & - & - & - & $\mathrm{b}$ & CCS \\
\hline 1,526 & 2.06 .3 & 0.00 & $\mathrm{f}$ & -11 & - & - & - & 0 & - & - & - & c & CCS \\
\hline 1,527 & 2.06 .3 & 0.00 & $\mathrm{f}$ & -11 & - & - & - & 0 & - & - & - & c & CCS \\
\hline 1,528 & 2.06 .3 & 0.00 & $\mathrm{~b}$ & \begin{tabular}{|l|l|}
$\mathrm{s}$ & 1 \\
\end{tabular} & $\mathrm{f}$ & 0 & 3 & 0 & 1.97 & 6.11 & 0.68 & c & CCS \\
\hline 1,529 & 2.06 .3 & 0.00 & $\mathrm{~d}$ & -1 & - & - & - & - & - & - & - & c & CCS \\
\hline 1,530 & 2.06 .3 & 0.00 & $\mathrm{f}$ & -11 & - & - & - & 0 & - & - & - & c & CCS \\
\hline 1,531 & 2.06 .3 & 0.00 & d & -1 & - & - & - & - & - & - & - & c & $\mathrm{CCS}$ \\
\hline 1,532 & 2.06 .3 & 0.00 & $\mathrm{f}$ & -1 & - & - & - & 0 & - & - & - & c & CCS \\
\hline 1,533 & 2.06 .3 & 0.00 & $\mathrm{~d}$ & -1 & - & - & - & - & - & - & - & c & CCS \\
\hline 1,534 & 2.06 .3 & 0.00 & $\mathrm{f}$ & -1 & - & - & - & 0 & - & - & - & c & CCS \\
\hline 1,535 & 2.06 .3 & 0.00 & $\mathrm{f}$ & -1 & - & - & - & 0 & - & - & - & c & CCS \\
\hline 1,536 & 2.06 .3 & 0.00 & $\mathrm{~d}$ & -1 & - & - & - & - & - & - & - & c & CCS \\
\hline 1,537 & 2.06 .3 & 0.00 & f & -1 & - & - & - & 0 & - & - & - & $\mathrm{c}$ & CCS \\
\hline
\end{tabular}




\begin{tabular}{|c|c|c|c|c|c|c|c|c|c|c|c|c|c|}
\hline 1,538 & 2.06 .3 & 0.00 & $\mathrm{f}$ & \begin{tabular}{|l|l}
- & 1 \\
\end{tabular} & - & - & - & 0 & - & - & - & $\mathrm{c}$ & CCS \\
\hline 1,539 & 2.06 .3 & 0.00 & f & -1 & - & - & - & 0 & - & - & - & c & CCS \\
\hline 1,540 & 2.06 .3 & 0.00 & $\mathrm{f}$ & -1 & - & - & - & 0 & - & - & - & $\mathrm{g}$ & CCS \\
\hline 1,541 & 2.06 .3 & 0.00 & c & \begin{tabular}{l|l} 
o & 1 \\
\end{tabular} & $\mathrm{f}$ & 0 & 0 & 0 & 2.69 & 5.77 & 0.64 & c & CCS \\
\hline 1,542 & 2.06 .3 & 0.00 & $\mathrm{f}$ & -1 & - & - & - & 0 & - & - & - & c & CCS \\
\hline 1,543 & 2.06 .3 & 0.00 & f & -1 & - & - & - & 0 & - & - & - & c & CCS \\
\hline 1,544 & 2.06 .3 & 0.00 & $\mathrm{~d}$ & -1 & - & - & - & - & - & - & - & c & CCS \\
\hline 1,545 & 2.06 .3 & 0.00 & $\mathrm{f}$ & -1 & - & - & - & 0 & - & - & - & c & CCS \\
\hline 1,546 & 2.06 .3 & 0.00 & f & -1 & - & - & - & 0 & - & - & - & $\mathrm{r}$ & CCS \\
\hline 1,547 & 2.06 .3 & 0.00 & $\mathrm{~d}$ & -1 & - & - & - & - & - & - & - & $\mathrm{c}$ & CCS \\
\hline 1,548 & 2.06 .3 & 0.00 & $\mathrm{f}$ & -11 & - & - & - & 0 & - & - & - & c & CCS \\
\hline 1,549 & 2.06 .3 & 0.00 & $\mathrm{f}$ & -1 & - & - & - & 0 & - & - & - & c & CCS \\
\hline 1,550 & 2.06 .3 & 0.00 & $\mathrm{f}$ & -11 & - & - & - & 0 & - & - & - & $\mathrm{c}$ & CCS \\
\hline 1,551 & 2.06 .3 & 0.00 & $\mathrm{f}$ & -11 & - & - & - & 0 & - & - & - & c & CCS \\
\hline 1,552 & 2.06 .3 & 0.00 & $\mathrm{f}$ & -11 & - & - & - & 0 & - & - & - & $\mathrm{c}$ & CCS \\
\hline 1,553 & 2.06 .3 & 0.00 & $\mathrm{~d}$ & -11 & - & - & - & - & - & - & - & c & CCS \\
\hline 1,554 & 2.06 .3 & 0.00 & $\mathrm{c}$ & \begin{tabular}{|l|l|} 
o & 1 \\
\end{tabular} & $\mathrm{cx}$ & 0 & 2 & 0 & 1.91 & 4.06 & 0.47 & c & CCS \\
\hline 1,555 & 2.06 .3 & 0.00 & $\mathrm{f}$ & -11 & - & - & - & 0 & - & - & - & c & CCS \\
\hline 1,556 & 2.06 .3 & 0.00 & $\mathrm{f}$ & -1 & - & - & - & 0 & - & - & - & c & CCS \\
\hline 1,557 & 2.06 .3 & 0.00 & $\mathrm{~d}$ & -1 & - & - & - & - & - & - & - & c & CCS \\
\hline 1,558 & 2.06 .3 & 0.00 & $\mathrm{f}$ & -1 & - & - & - & 0 & - & - & - & c & CCS \\
\hline 1,559 & 2.06 .3 & 0.00 & $\mathrm{f}$ & -1 & - & - & - & 0 & - & - & - & c & CCS \\
\hline 1,560 & 2.06 .3 & 0.00 & $\mathrm{f}$ & -1 & - & - & - & 0 & - & - & - & c & CCS \\
\hline 1,561 & 2.06 .3 & 0.00 & $\mathrm{~b}$ & \begin{tabular}{|l|l}
$\mathrm{S}$ & 1 \\
\end{tabular} & $\mathrm{cx}$ & 0 & 3 & 0 & 1.19 & 3.78 & 0.64 & $\mathrm{c}$ & CCS \\
\hline 1,562 & 2.06 .3 & 0.00 & $\mathrm{f}$ & -1 & - & - & - & 0 & - & - & - & c & CCS \\
\hline 1,563 & 2.06 .3 & 0.00 & $\mathrm{f}$ & -1 & - & - & - & 0 & - & - & - & w & CCS \\
\hline 1,564 & 2.06 .3 & 0.00 & $\mathrm{~d}$ & -1 & - & - & - & - & - & - & - & $\mathrm{c}$ & CCS \\
\hline 1,565 & 3.04 & 3.24 & c & -6 & $\mathrm{cx}$ & 1 & 3 & 0 & 5.87 & 28.47 & 6.27 & c & CCS \\
\hline 1,567 & 3.04 & 2.22 & $\mathrm{~d}$ & -5 & - & - & - & - & - & - & - & c & CCS \\
\hline 1,568 & 3.04 & 1.58 & $\mathrm{f}$ & -5 & - & - & - & 0 & - & - & - & $\mathrm{r}$ & CCS \\
\hline 1,570 & 3.04 & 0.75 & c & -4 & $\mathrm{cx}$ & 0 & 3 & 0 & 5.56 & 20.78 & 2.80 & $\mathrm{t}$ & CCS \\
\hline 1,571 & 3.04 & 1.31 & $\mathrm{f}$ & -3 & - & - & - & 0 & - & - & - & $\mathrm{i}$ & Igneous \\
\hline 1,572 & 3.04 & 0.76 & c & -4 & $\mathrm{cx}$ & 0 & 0 & 0 & 10.92 & 22.62 & 1.80 & c & CCS \\
\hline 1,573 & 3.04 & 1.31 & $\mathrm{f}$ & -3 & - & - & - & 2 & - & - & - & $\mathrm{t}$ & CCS \\
\hline 1,574 & 3.04 & 0.96 & $\mathrm{f}$ & -4 & - & - & - & 0 & - & - & - & $\mathrm{c}$ & CCS \\
\hline 1,575 & 3.04 & 0.68 & $\mathrm{f}$ & -3 & - & - & - & 1 & - & - & - & $\mathrm{c}$ & CCS \\
\hline 1,576 & 3.04 & 0.20 & $\mathrm{~d}$ & -3 & - & - & - & - & - & - & - & $\mathrm{c}$ & CCS \\
\hline 1,577 & 3.04 & 0.42 & $\mathrm{f}$ & -3 & - & - & - & 0 & - & - & - & c & CCS \\
\hline 1,578 & 3.04 & 1.13 & $\mathrm{~d}$ & -3 & - & - & - & - & - & - & - & $\mathrm{W}$ & CCS \\
\hline 1,579 & 3.04 & 0.39 & $\mathrm{f}$ & -2 & - & - & - & 0 & - & - & - & $\mathrm{c}$ & CCS \\
\hline 1,580 & 3.04 & 0.60 & $\mathrm{~b}$ & -4 & $\mathrm{a}$ & 0 & 2 & 1 & 5.36 & 19.38 & 3.27 & $\mathrm{~g}$ & CCS \\
\hline 1,581 & 3.04 & 0.36 & $\mathrm{~d}$ & -3 & - & - & - & - & - & - & - & $\mathrm{b}$ & CCS \\
\hline 1,582 & 3.04 & 0.33 & $\mathrm{f}$ & -3 & - & - & - & 0 & - & - & - & $\mathrm{c}$ & CCS \\
\hline
\end{tabular}




\begin{tabular}{|c|c|c|c|c|c|c|c|c|c|c|c|c|c|}
\hline 1,583 & 3.04 & 0.40 & $\mathrm{f}$ & $-1-3$ & - & - & - & 0 & - & - & - & $\mathrm{g}$ & CCS \\
\hline 1,584 & 3.04 & 0.33 & $\mathrm{f}$ & -3 & - & - & - & 0 & - & - & - & w & CCS \\
\hline 1,585 & 3.04 & 0.34 & $\mathrm{~d}$ & -3 & - & - & - & - & - & - & - & c & CCS \\
\hline 1,586 & 3.04 & 0.27 & $\mathrm{f}$ & -3 & - & - & - & 0 & - & - & - & c & CCS \\
\hline 1,587 & 3.04 & 0.26 & $\mathrm{~b}$ & \begin{tabular}{|l|l|}
$\mathrm{s}$ & 2 \\
\end{tabular} & $\mathrm{cx}$ & 0 & 0 & 0 & 5.61 & 13.61 & 1.79 & w & CCS \\
\hline 1,588 & 3.04 & 0.17 & $\mathrm{f}$ & -2 & - & - & - & 0 & - & - & - & w & CCS \\
\hline 1,589 & 3.04 & 0.11 & $\mathrm{~d}$ & -2 & - & - & - & - & - & - & - & c & CCS \\
\hline 1,590 & 3.04 & 0.15 & $\mathrm{~d}$ & -3 & - & - & - & - & - & - & - & $\mathrm{t}$ & CCS \\
\hline 1,591 & 3.04 & 0.16 & $\mathrm{f}$ & -2 & - & - & - & 0 & - & - & - & c & CCS \\
\hline 1,592 & 3.04 & 0.23 & $\mathrm{f}$ & -2 & - & - & - & 0 & - & - & - & $\mathrm{r}$ & CCS \\
\hline 1,593 & 3.04 & 0.09 & $\mathrm{f}$ & -3 & - & - & - & 0 & - & - & - & c & CCS \\
\hline 1,594 & 3.04 & 0.15 & $\mathrm{f}$ & -2 & - & - & - & 0 & - & - & - & c & CCS \\
\hline 1,595 & 3.04 & 0.41 & $\mathrm{~d}$ & -2 & - & - & - & - & - & - & - & c & CCS \\
\hline 1,596 & 3.04 & 0.04 & $\mathrm{~d}$ & -11 & - & - & - & - & - & - & - & c & CCS \\
\hline 1,597 & 3.04 & 0.05 & $\mathrm{f}$ & -2 & - & - & - & 0 & - & - & - & c & CCS \\
\hline 1,598 & 3.04 & 0.06 & $\mathrm{f}$ & -11 & - & - & - & 0 & - & - & - & c & CCS \\
\hline 1,599 & 3.04 & 0.10 & $\mathrm{~d}$ & -1 & - & - & - & - & - & - & - & $\mathrm{i}$ & Igneous \\
\hline 1,600 & 3.04 & 0.18 & $\mathrm{~d}$ & -2 & - & - & - & - & - & - & - & c & CCS \\
\hline 1,601 & 3.04 & 0.27 & $\mathrm{~d}$ & -2 & - & - & - & - & - & - & - & $\mathrm{b}$ & CCS \\
\hline 1,602 & 3.04 & 0.13 & $\mathrm{~d}$ & -1 & - & - & - & - & - & - & - & c & CCS \\
\hline 1,603 & 3.04 & 0.12 & $\mathrm{~d}$ & -2 & - & - & - & - & - & - & - & w & CCS \\
\hline 1,604 & 3.04 & 0.00 & $\mathrm{f}$ & -1 & - & - & - & 0 & - & - & - & $\mathrm{r}$ & CCS \\
\hline 1,605 & 3.04 & 0.00 & $\mathrm{f}$ & -2 & - & - & - & 0 & - & - & - & c & CCS \\
\hline 1,606 & 3.04 & 0.06 & $\mathrm{~d}$ & -2 & - & - & - & - & - & - & - & c & CCS \\
\hline 1,607 & 3.04 & 0.00 & $\mathrm{f}$ & -1 & - & - & - & 0 & - & - & - & c & CCS \\
\hline 1,608 & 3.04 & 0.05 & $\mathrm{f}$ & -2 & - & - & - & 0 & - & - & - & c & CCS \\
\hline 1,609 & 3.04 & 0.00 & $\mathrm{f}$ & -2 & - & - & - & 0 & - & - & - & c & CCS \\
\hline 1,610 & 3.04 & 0.07 & $\mathrm{f}$ & -2 & - & - & - & 0 & - & - & - & c & CCS \\
\hline 1,611 & 3.04 & 0.08 & $\mathrm{f}$ & -2 & - & - & - & 0 & - & - & - & W & CCS \\
\hline 1,612 & 3.04 & 0.07 & $\mathrm{~d}$ & -2 & - & - & - & - & - & - & - & $\mathrm{r}$ & CCS \\
\hline 1,613 & 3.04 & 0.12 & $\mathrm{f}$ & -2 & - & - & - & 0 & - & - & - & w & CCS \\
\hline 1,614 & 3.04 & 0.00 & $\mathrm{f}$ & -1 & - & - & - & 0 & - & - & - & $\mathrm{b}$ & CCS \\
\hline 1,615 & 3.04 & 0.10 & $\mathrm{~d}$ & \begin{tabular}{|l|l|}
- & 1 \\
\end{tabular} & - & - & - & - & - & - & - & c & CCS \\
\hline 1,616 & 3.04 & 0.00 & $\mathrm{f}$ & \begin{tabular}{|l|l|} 
& 1 \\
\end{tabular} & - & - & - & 0 & - & - & - & $\mathrm{g}$ & CCS \\
\hline 1,617 & 3.04 & 0.26 & $\mathrm{~d}$ & -3 & - & - & - & - & - & - & - & c & CCS \\
\hline 1,618 & 3.04 & 0.14 & $\mathrm{f}$ & -2 & - & - & - & 0 & - & - & - & $\mathrm{g}$ & CCS \\
\hline 1,619 & 3.04 & 0.12 & $f$ & -2 & - & - & - & 0 & - & - & - & c & CCS \\
\hline 1,620 & 3.04 & 0.00 & $\mathrm{~d}$ & -2 & - & - & - & - & - & - & - & w & CCS \\
\hline 1,621 & 3.04 & 0.16 & $\mathrm{f}$ & -2 & - & - & - & 0 & - & - & - & c & CCS \\
\hline 1,622 & 3.04 & 0.04 & $\mathrm{~d}$ & -1 & - & - & - & - & - & - & - & $\mathrm{g}$ & CCS \\
\hline 1,623 & 3.04 & 0.12 & $\mathrm{~b}$ & \begin{tabular}{|l|l}
$\mathrm{s}$ & 2 \\
\end{tabular} & cx & 2 & 2 & 0 & 8.39 & 11.40 & 2.33 & c & CCS \\
\hline 1,624 & 3.04 & 0.14 & $\mathrm{f}$ & -2 & - & - & - & 2 & - & - & - & c & CCS \\
\hline 1,625 & 3.04 & 0.24 & $\mathrm{~d}$ & -3 & - & - & - & - & - & - & - & $\mathrm{g}$ & CCS \\
\hline
\end{tabular}




\begin{tabular}{|c|c|c|c|c|c|c|c|c|c|c|c|c|c|}
\hline 1,626 & 3.04 & 0.14 & $\mathrm{f}$ & -2 & - & - & - & 0 & - & - & - & w & CCS \\
\hline 1,627 & 3.04 & 0.12 & $\mathrm{f}$ & -2 & - & - & - & 0 & - & - & - & c & CCS \\
\hline 1,628 & 3.04 & 0.07 & $\mathrm{f}$ & -2 & - & - & - & 0 & - & - & - & c & CCS \\
\hline 1,629 & 3.04 & 0.06 & d & -2 & - & - & - & - & - & - & - & c & $\mathrm{CCS}$ \\
\hline 1,630 & 3.04 & 0.04 & $\mathrm{f}$ & -2 & - & - & - & 0 & - & - & - & c & CCS \\
\hline 1,631 & 3.04 & 0.10 & $\mathrm{f}$ & -2 & - & - & - & 0 & - & - & - & c & $\mathrm{CCS}$ \\
\hline 1,632 & 3.04 & 0.05 & d & -1 & - & - & - & - & - & - & - & $\mathrm{i}$ & Igneous \\
\hline 1,633 & 3.04 & 0.10 & c & \begin{tabular}{l|l} 
o & 2 \\
\end{tabular} & cx & 0 & 3 & 0 & 1.68 & 11.48 & 1.57 & c & CCS \\
\hline 1,634 & 3.04 & 0.08 & $\mathrm{f}$ & -2 & - & - & - & 0 & - & - & - & w & CCS \\
\hline 1,635 & 3.04 & 0.10 & d & -2 & - & - & - & - & - & - & - & c & $\mathrm{CCS}$ \\
\hline 1,636 & 3.04 & 0.06 & $\mathrm{f}$ & -2 & - & - & - & 0 & - & - & - & w & CCS \\
\hline 1,637 & 3.04 & 0.04 & $\mathrm{f}$ & -1 & - & - & - & 0 & - & - & - & c & $\mathrm{CCS}$ \\
\hline 1,639 & 3.04 & 0.00 & $\mathrm{~d}$ & -1 & - & - & - & - & - & - & - & c & $\mathrm{CCS}$ \\
\hline 1,640 & 3.04 & 0.00 & $\mathrm{f}$ & -1 & - & - & - & 0 & - & - & - & c & $\mathrm{CCS}$ \\
\hline 1,641 & 3.04 & 0.07 & $\mathrm{f}$ & -1 & - & - & - & 0 & - & - & - & $\mathrm{r}$ & $\mathrm{CCS}$ \\
\hline 1,642 & 3.04 & 0.05 & $\mathrm{f}$ & -1 & - & - & - & 0 & - & - & - & c & $\mathrm{CCS}$ \\
\hline 1,643 & 3.04 & 0.06 & $\mathrm{f}$ & -1 & - & - & - & 0 & - & - & - & w & $\mathrm{CCS}$ \\
\hline 1,644 & 3.04 & 0.00 & $\mathrm{f}$ & -1 & - & - & - & 0 & - & - & - & c & $\mathrm{CCS}$ \\
\hline 1,645 & 3.04 & 0.04 & d & -2 & - & - & - & - & - & - & - & w & CCS \\
\hline 1,646 & 3.04 & 0.06 & d & -2 & - & - & - & - & - & - & - & $\mathrm{g}$ & CCS \\
\hline 1,647 & 3.04 & 0.04 & $\mathrm{f}$ & -1 & - & - & - & 0 & - & - & - & c & CCS \\
\hline 1,648 & 3.04 & 0.04 & d & -1 & - & - & - & - & - & - & - & w & $\mathrm{CCS}$ \\
\hline 1,649 & 3.04 & 0.00 & d & -1 & - & - & - & - & - & - & - & $\mathrm{g}$ & CCS \\
\hline 1,650 & 3.04 & 0.00 & $\mathrm{f}$ & -2 & - & - & - & 0 & - & - & - & c & CCS \\
\hline 1,651 & 3.04 & 0.06 & $\mathrm{f}$ & -2 & - & - & - & 0 & - & - & - & c & CCS \\
\hline 1,652 & 3.04 & 0.05 & d & -1 & - & - & - & - & - & - & - & $\mathrm{g}$ & CCS \\
\hline 1,653 & 3.04 & 0.03 & d & -1 & - & - & - & - & - & - & - & $\mathrm{b}$ & CCS \\
\hline 1,654 & 3.04 & 0.00 & $\mathrm{f}$ & -1 & - & - & - & 0 & - & - & - & c & CCS \\
\hline 1,655 & 3.04 & 0.06 & $\mathrm{f}$ & -2 & - & - & - & 0 & - & - & - & w & CCS \\
\hline 1,656 & 3.04 & 0.05 & d & -1 & - & - & - & - & - & - & - & c & CCS \\
\hline 1,657 & 3.04 & 0.00 & $\mathrm{f}$ & -2 & - & - & - & 0 & - & - & - & $\mathrm{g}$ & CCS \\
\hline 1,658 & 3.04 & 0.09 & d & -2 & - & - & - & - & - & - & - & c & CCS \\
\hline 1,659 & 3.04 & 0.12 & d & -2 & - & - & - & - & - & - & - & W & CCS \\
\hline 1,660 & 3.04 & 0.04 & d & -2 & - & - & - & - & - & - & - & w & CCS \\
\hline 1,661 & 3.04 & 0.00 & d & -1 & - & - & - & - & - & - & - & c & CCS \\
\hline 1,662 & 3.04 & 0.00 & d & -1 & - & - & - & - & - & - & - & $\mathrm{i}$ & Igneous \\
\hline 1,663 & 3.04 & 0.00 & d & -2 & - & - & - & - & - & - & - & $\mathrm{g}$ & $\mathrm{CCS}$ \\
\hline 1,664 & 3.04 & 0.05 & $\mathrm{f}$ & -1 & - & - & - & 0 & - & - & - & c & $\mathrm{CCS}$ \\
\hline 1,665 & 3.04 & 0.12 & d & -2 & - & - & - & - & - & - & - & $\mathrm{g}$ & $\mathrm{CCS}$ \\
\hline 1,666 & 3.04 & 0.05 & $\mathrm{f}$ & -2 & - & - & - & 0 & - & - & - & c & CCS \\
\hline 1,667 & 3.04 & 0.15 & $\mathrm{f}$ & -2 & - & - & - & 0 & - & - & - & w & $\mathrm{CCS}$ \\
\hline 1,668 & 3.04 & 0.09 & $\mathrm{f}$ & -2 & - & - & - & 0 & - & - & - & c & $\mathrm{CCS}$ \\
\hline 1,669 & 3.04 & 0.10 & $\mathrm{f}$ & -2 & - & - & - & 0 & - & - & - & c & CCS \\
\hline
\end{tabular}




\begin{tabular}{|c|c|c|c|c|c|c|c|c|c|c|c|c|c|}
\hline 1,670 & 3.04 & 0.00 & $\mathrm{~d}$ & $-1-1$ & - & - & - & - & - & - & - & c & CCS \\
\hline 1,671 & 3.04 & 0.06 & $\mathrm{f}$ & -1 & - & - & - & 0 & - & - & - & c & CCS \\
\hline 1,672 & 3.04 & 0.14 & d & -2 & - & - & - & - & - & - & - & $\mathrm{g}$ & CCS \\
\hline 1,673 & 3.04 & 0.07 & d & -1 & - & - & - & - & - & - & - & c & $\mathrm{CCS}$ \\
\hline 1,674 & 3.04 & 0.00 & f & -1 & - & - & - & 0 & - & - & - & w & CCS \\
\hline 1,675 & 3.04 & 0.00 & d & -1 & - & - & - & - & - & - & - & $\mathrm{t}$ & $\mathrm{CCS}$ \\
\hline 1,676 & 3.04 & 0.06 & f & -1 & - & - & - & 0 & - & - & - & c & CCS \\
\hline 1,677 & 3.04 & 0.00 & f & -1 & - & - & - & 0 & - & - & - & c & CCS \\
\hline 1,678 & 3.04 & 0.04 & $\mathrm{f}$ & -1 & - & - & - & 0 & - & - & - & w & $\mathrm{CCS}$ \\
\hline 1,679 & 3.04 & 0.09 & $\mathrm{f}$ & -2 & - & - & - & 0 & - & - & - & c & $\mathrm{CCS}$ \\
\hline 1,680 & 3.04 & 0.00 & d & -1 & - & - & - & - & - & - & - & i & Igneous \\
\hline 1,681 & 3.04 & 0.00 & d & -1 & - & - & - & - & - & - & - & $\mathrm{g}$ & $\mathrm{CCS}$ \\
\hline 1,682 & 3.04 & 0.00 & d & -1 & - & - & - & - & - & - & - & c & CCS \\
\hline 1,683 & 3.04 & 0.06 & $\mathrm{f}$ & -1 & - & - & - & 0 & - & - & - & $\mathrm{t}$ & $\mathrm{CCS}$ \\
\hline 1,684 & 3.04 & 0.07 & d & -1 & - & - & - & - & - & - & - & $\mathrm{b}$ & $\mathrm{CCS}$ \\
\hline 1,685 & 3.04 & 0.00 & $\mathrm{~d}$ & -1 & - & - & - & - & - & - & - & $\mathrm{t}$ & $\mathrm{CCS}$ \\
\hline 1,686 & 3.04 & 0.00 & d & -1 & - & - & - & - & - & - & - & c & $\mathrm{CCS}$ \\
\hline 1,687 & 3.04 & 0.00 & $\mathrm{~d}$ & -1 & - & - & - & - & - & - & - & c & $\mathrm{CCS}$ \\
\hline 1,688 & 3.04 & 0.00 & $\mathrm{f}$ & -1 & - & - & - & 0 & - & - & - & c & $\mathrm{CCS}$ \\
\hline 1,689 & 3.04 & 0.08 & d & -1 & - & - & - & - & - & - & - & w & $\mathrm{CCS}$ \\
\hline 1,690 & 3.04 & 0.00 & $\mathrm{f}$ & -1 & - & - & - & 0 & - & - & - & c & $\mathrm{CCS}$ \\
\hline 1,692 & 3.04 & 0.00 & $\mathrm{f}$ & -1 & - & - & - & 0 & - & - & - & $\mathrm{g}$ & $\mathrm{CCS}$ \\
\hline 1,693 & 3.04 & 0.04 & $\mathrm{f}$ & -2 & - & - & - & 0 & - & - & - & c & $\mathrm{CCS}$ \\
\hline 1,694 & 3.04 & 0.03 & d & -1 & - & - & - & - & - & - & - & i & Igneous \\
\hline 1,695 & 3.04 & 0.00 & $\mathrm{f}$ & -1 & - & - & - & 0 & - & - & - & $\mathrm{g}$ & $\mathrm{CCS}$ \\
\hline 1,696 & 3.04 & 0.00 & $\mathrm{f}$ & -1 & - & - & - & 0 & - & - & - & w & $\mathrm{CCS}$ \\
\hline 1,697 & 3.04 & 0.00 & d & -1 & - & - & - & - & - & - & - & c & CCS \\
\hline 1,698 & 3.04 & 0.05 & d & -1 & - & - & - & - & - & - & - & $b$ & CCS \\
\hline 1,699 & 3.04 & 0.00 & $\mathrm{f}$ & -1 & - & - & - & 0 & - & - & - & c & $\mathrm{CCS}$ \\
\hline 1,700 & 3.04 & 0.00 & d & -1 & - & - & - & - & - & - & - & $\mathrm{g}$ & CCS \\
\hline 1,701 & 3.04 & 0.00 & $\mathrm{f}$ & -1 & - & - & - & 0 & - & - & - & $\mathrm{g}$ & CCS \\
\hline 1,702 & 3.04 & 0.04 & $\mathrm{f}$ & -1 & - & - & - & 0 & - & - & - & c & CCS \\
\hline 1,703 & 3.04 & 0.00 & d & -1 & - & - & - & - & - & - & - & w & CCS \\
\hline 1,704 & 3.04 & 0.00 & $\mathrm{f}$ & -1 & - & - & - & 0 & - & - & - & c & CCS \\
\hline 1,706 & 3.04 & 0.00 & d & -1 & - & - & - & - & - & - & - & c & CCS \\
\hline 1,707 & 3.04 & 0.00 & f & -1 & - & - & - & 0 & - & - & - & W & CCS \\
\hline 1,708 & 3.04 & 0.05 & $\mathrm{f}$ & -1 & - & - & - & 0 & - & - & - & c & CCS \\
\hline 1,709 & 3.04 & 0.08 & $\mathrm{~d}$ & -2 & - & - & - & - & - & - & - & w & CCS \\
\hline 1,710 & 3.04 & 0.00 & f & -1 & - & - & - & 0 & - & - & - & c & CCS \\
\hline 1,711 & 3.04 & 0.00 & d & -1 & - & - & - & - & - & - & - & w & CCS \\
\hline 1,712 & 3.04 & 0.03 & d & -1 & - & - & - & - & - & - & - & $\mathrm{g}$ & CCS \\
\hline 1,713 & 3.04 & 0.04 & c & $\begin{array}{lll} & 1 \\
\end{array}$ & $\mathrm{cx}$ & 0 & 3 & 0 & 3.14 & 6.55 & 1.21 & $\mathrm{~g}$ & CCS \\
\hline 1,714 & 3.04 & 0.09 & $\mathrm{~d}$ & -1 & - & - & - & - & - & - & - & $\mathrm{c}$ & CCS \\
\hline
\end{tabular}




\begin{tabular}{|c|c|c|c|c|c|c|c|c|c|c|c|c|c|}
\hline 1,715 & 3.04 & 0.00 & d & \begin{tabular}{|l|l|}
- & 1 \\
\end{tabular} & - & - & - & - & - & - & - & c & CCS \\
\hline 1,716 & 3.04 & 0.07 & $\mathrm{f}$ & -1 & - & - & - & 0 & - & - & - & c & CCS \\
\hline 1,717 & 3.04 & 0.00 & d & -1 & - & - & - & - & - & - & - & $\mathrm{g}$ & CCS \\
\hline 1,718 & 3.04 & 0.00 & d & -2 & - & - & - & - & - & - & - & c & CCS \\
\hline 1,719 & 3.04 & 0.00 & $\mathrm{f}$ & -1 & - & - & - & 0 & - & - & - & b & CCS \\
\hline 1,720 & 3.04 & 0.00 & f & -1 & - & - & - & 0 & - & - & - & c & CCS \\
\hline 1,721 & 3.04 & 0.00 & f & -1 & - & - & - & 0 & - & - & - & W & CCS \\
\hline 1,722 & 3.04 & 0.00 & f & -1 & - & - & - & 0 & - & - & - & c & CCS \\
\hline 1,723 & 3.04 & 0.00 & $\mathrm{f}$ & -1 & - & - & - & 0 & - & - & - & c & CCS \\
\hline 1,724 & 3.04 & 0.00 & $\mathrm{f}$ & -1 & - & - & - & 0 & - & - & - & c & CCS \\
\hline 1,725 & 3.04 & 0.00 & d & -1 & - & - & - & - & - & - & - & $\mathrm{g}$ & CCS \\
\hline 1,726 & 3.04 & 0.00 & $\mathrm{f}$ & -1 & - & - & - & 0 & - & - & - & c & CCS \\
\hline 1,727 & 3.04 & 0.00 & $\mathrm{f}$ & -1 & - & - & - & 0 & - & - & - & c & CCS \\
\hline 1,728 & 3.04 & 0.00 & $\mathrm{~d}$ & -1 & - & - & - & - & - & - & - & $\mathrm{t}$ & CCS \\
\hline 1,729 & 3.04 & 0.00 & d & -1 & - & - & - & - & - & - & - & c & CCS \\
\hline 1,730 & 3.04 & 0.00 & $\mathrm{f}$ & -1 & - & - & - & 0 & - & - & - & W & CCS \\
\hline 1,731 & 3.04 & 0.00 & d & -1 & - & - & - & - & - & - & - & c & CCS \\
\hline 1,732 & 3.04 & 0.00 & $\mathrm{f}$ & -1 & - & - & - & 0 & - & - & - & $\mathrm{g}$ & CCS \\
\hline 1,733 & 3.04 & 0.00 & $\mathrm{f}$ & -1 & - & - & - & 0 & - & - & - & W & CCS \\
\hline 1,734 & 3.04 & 0.00 & $\mathrm{f}$ & -1 & - & - & - & 0 & - & - & - & w & CCS \\
\hline 1,735 & 3.04 & 0.03 & d & -1 & - & - & - & - & - & - & - & $t$ & CCS \\
\hline 1,736 & 3.04 & 0.00 & d & -1 & - & - & - & - & - & - & - & w & CCS \\
\hline 1,737 & 3.04 & 0.00 & d & -1 & - & - & - & - & - & - & - & $\mathrm{w}$ & CCS \\
\hline 1,738 & 3.04 & 0.00 & $\mathrm{f}$ & -1 & - & - & - & 0 & - & - & - & $\mathrm{b}$ & CCS \\
\hline 1,739 & 3.04 & 0.04 & $\mathrm{f}$ & -1 & - & - & - & 0 & - & - & - & $\mathrm{r}$ & CCS \\
\hline 1,740 & 3.04 & 0.00 & $\mathrm{f}$ & -1 & - & - & - & 0 & - & - & - & $\mathrm{b}$ & CCS \\
\hline 1,741 & 3.04 & 0.00 & d & -1 & - & - & - & - & - & - & - & c & CCS \\
\hline 1,742 & 3.04 & 0.00 & $\mathrm{f}$ & -1 & - & - & - & 0 & - & - & - & c & CCS \\
\hline 1,743 & 3.04 & 0.00 & $\mathrm{f}$ & -1 & - & - & - & 0 & - & - & - & c & CCS \\
\hline 1,744 & 3.04 & 0.00 & d & -1 & - & - & - & - & - & - & - & $\mathrm{r}$ & $\mathrm{CCS}$ \\
\hline 1,745 & 3.04 & 0.00 & d & -1 & - & - & - & - & - & - & - & $t$ & $\mathrm{CCS}$ \\
\hline 1,746 & 3.04 & 0.00 & $\mathrm{f}$ & -1 & - & - & - & 0 & - & - & - & c & CCS \\
\hline 1,747 & 3.04 & 0.00 & d & -1 & - & - & - & - & - & - & - & c & $\mathrm{CCS}$ \\
\hline 1,748 & 3.04 & 0.00 & $\mathrm{~b}$ & $\begin{array}{ll}\mathrm{s} & 1 \\
\end{array}$ & $\mathrm{f}$ & 0 & 3 & 0 & 2.92 & 7.16 & 0.56 & c & $\mathrm{CCS}$ \\
\hline 1,749 & 3.04 & 0.00 & d & -1 & - & - & - & - & - & - & - & $\mathrm{w}$ & $\mathrm{CCS}$ \\
\hline 1,750 & 3.04 & 0.00 & d & -1 & - & - & - & - & - & - & - & $\mathrm{g}$ & $\mathrm{CCS}$ \\
\hline 1,751 & 3.04 & 0.00 & d & -1 & - & - & - & - & - & - & - & c & $\mathrm{CCS}$ \\
\hline 1,752 & 3.04 & 0.00 & d & -1 & - & - & - & - & - & - & - & $\mathrm{c}$ & CCS \\
\hline 1,753 & 3.04 & 0.00 & $\mathrm{f}$ & -1 & - & - & - & 0 & - & - & - & $\mathrm{t}$ & $\mathrm{CCS}$ \\
\hline 1,754 & 3.04 & 0.00 & $\mathrm{f}$ & -1 & - & - & - & 0 & - & - & - & c & $\mathrm{CCS}$ \\
\hline 1,755 & 3.04 & 0.00 & $\mathrm{~d}$ & -1 & - & - & - & - & - & - & - & $\mathrm{i}$ & Igneous \\
\hline 1,756 & 3.04 & 0.00 & $\mathrm{f}$ & -1 & - & - & - & 0 & - & - & - & $\mathrm{g}$ & CCS \\
\hline 1,757 & 3.04 & 0.00 & d & -1 & - & - & - & - & - & - & - & $\mathrm{c}$ & $\mathrm{CCS}$ \\
\hline
\end{tabular}




\begin{tabular}{|c|c|c|c|c|c|c|c|c|c|c|c|c|c|}
\hline 1,758 & 3.04 & 0.00 & $\mathrm{~d}$ & \begin{tabular}{|l|l|}
- & 1 \\
\end{tabular} & - & - & - & - & - & - & - & $\mathrm{b}$ & CCS \\
\hline 1,759 & 3.04 & 0.00 & $\mathrm{~d}$ & \begin{tabular}{|l|l}
- & 1 \\
\end{tabular} & - & - & - & - & - & - & - & $\mathrm{r}$ & CCS \\
\hline 1,760 & 3.04 & 0.00 & $\mathrm{f}$ & \begin{tabular}{|l|l|}
- & 1 \\
\end{tabular} & - & - & - & 0 & - & - & - & $\mathrm{c}$ & CCS \\
\hline 1,761 & 3.04 & 0.00 & $\mathrm{f}$ & \begin{tabular}{|l|l|}
- & 1 \\
\end{tabular} & - & - & - & 0 & - & - & - & $\mathrm{c}$ & CCS \\
\hline 1,762 & 3.04 & 0.00 & $\mathrm{~d}$ & \begin{tabular}{|l|l}
- & 1 \\
\end{tabular} & - & - & - & - & - & - & - & W & CCS \\
\hline 1,763 & 3.04 & 0.00 & $\mathrm{f}$ & \begin{tabular}{|l|l}
- & 1 \\
\end{tabular} & - & - & - & 0 & - & - & - & $t$ & CCS \\
\hline 1,764 & 3.04 & 0.00 & $\mathrm{~d}$ & \begin{tabular}{|l|l}
- & 1 \\
\end{tabular} & - & - & - & - & - & - & - & c & CCS \\
\hline 1,765 & 3.04 & 0.00 & $\mathrm{f}$ & -1 & - & - & - & 0 & - & - & - & w & CCS \\
\hline 1,766 & 3.04 & 0.00 & $\mathrm{f}$ & \begin{tabular}{|l|l}
- & 1 \\
\end{tabular} & - & - & - & 0 & - & - & - & c & CCS \\
\hline 1,767 & 3.04 & 0.00 & $\mathrm{f}$ & \begin{tabular}{|l|l}
- & 1 \\
\end{tabular} & - & - & - & 0 & - & - & - & $\mathrm{c}$ & CCS \\
\hline 1,768 & 3.04 & 0.00 & $\mathrm{f}$ & -1 & - & - & - & 0 & - & - & - & $\mathrm{g}$ & CCS \\
\hline 1,769 & 3.04 & 0.00 & $\mathrm{f}$ & -2 & - & - & - & 0 & - & - & - & $\mathrm{c}$ & CCS \\
\hline 1,770 & 3.04 & 0.00 & $\mathrm{~b}$ & \begin{tabular}{|l|l}
$\mathrm{s}$ & 1 \\
\end{tabular} & $\mathrm{cx}$ & 0 & 2 & 0 & 2.90 & 5.47 & 0.83 & $\mathrm{c}$ & CCS \\
\hline 1,771 & 3.04 & 0.00 & $\mathrm{~d}$ & -1 & - & - & - & - & - & - & - & $\mathrm{w}$ & CCS \\
\hline 1,772 & 3.04 & 0.00 & $\mathrm{~d}$ & -1 & - & - & - & - & - & - & - & $\mathrm{c}$ & CCS \\
\hline 1,773 & 3.04 & 0.00 & $\mathrm{c}$ & \begin{tabular}{|l|l|} 
o & 1 \\
\end{tabular} & $\mathrm{f}$ & 0 & 2 & 0 & 2.10 & 6.45 & 0.99 & $\mathrm{w}$ & CCS \\
\hline 1,774 & 3.04 & 0.00 & $\mathrm{~d}$ & -1 & - & - & - & - & - & - & - & W & CCS \\
\hline 1,775 & 3.04 & 0.00 & $\mathrm{f}$ & -1 & - & - & - & 0 & - & - & - & $\mathrm{c}$ & CCS \\
\hline 1,776 & 3.04 & 0.00 & $\mathrm{~d}$ & -1 & - & - & - & - & - & - & - & $\mathrm{c}$ & CCS \\
\hline 1,777 & 3.04 & 0.00 & $\mathrm{f}$ & -1 & - & - & - & 0 & - & - & - & $\mathrm{r}$ & CCS \\
\hline 1,778 & 3.04 & 0.00 & $\mathrm{f}$ & -1 & - & - & - & 0 & - & - & - & $\mathrm{c}$ & CCS \\
\hline 1,779 & 3.04 & 0.00 & $\mathrm{~d}$ & -1 & - & - & - & - & - & - & - & $\mathrm{c}$ & CCS \\
\hline 1,780 & 3.04 & 0.00 & $\mathrm{f}$ & -1 & - & - & - & 0 & - & - & - & $\mathrm{c}$ & CCS \\
\hline 1,781 & 3.04 & 0.04 & $\mathrm{f}$ & -1 & - & - & - & 0 & - & - & - & $\mathrm{c}$ & CCS \\
\hline 1,782 & 3.04 & 0.00 & $\mathrm{f}$ & -1 & - & - & - & 0 & - & - & - & $\mathrm{g}$ & CCS \\
\hline 1,783 & 3.04 & 0.00 & $\mathrm{f}$ & -1 & - & - & - & 0 & - & - & - & $\mathrm{b}$ & CCS \\
\hline 1,784 & 3.04 & 0.00 & $\mathrm{~d}$ & -1 & - & - & - & - & - & - & - & $\mathrm{i}$ & Igneous \\
\hline 1,785 & 3.04 & 0.00 & $\mathrm{f}$ & -1 & - & - & - & 0 & - & - & - & c & CCS \\
\hline 1,786 & 3.04 & 0.00 & $\mathrm{~d}$ & -2 & - & - & - & - & - & - & - & $\mathrm{c}$ & CCS \\
\hline 1,787 & 3.04 & 0.00 & $\mathrm{~d}$ & -1 & - & - & - & - & - & - & - & $\mathrm{c}$ & $\mathrm{CCS}$ \\
\hline 1,788 & 3.04 & 0.00 & $\mathrm{~d}$ & -1 & - & - & - & - & - & - & - & $\mathrm{i}$ & Igneous \\
\hline 1,789 & 3.04 & 0.00 & $\mathrm{f}$ & -1 & - & - & - & 0 & - & - & - & $\mathrm{c}$ & CCS \\
\hline 1,790 & 3.04 & 0.00 & $\mathrm{f}$ & -1 & - & - & - & 0 & - & - & - & $\mathrm{c}$ & $\mathrm{CCS}$ \\
\hline 1,791 & 3.04 & 0.00 & $\mathrm{f}$ & -1 & - & - & - & 0 & - & - & - & $\mathrm{c}$ & $\mathrm{CCS}$ \\
\hline 1,792 & 3.04 & 0.00 & $\mathrm{f}$ & -1 & - & - & - & 0 & - & - & - & $\mathrm{g}$ & CCS \\
\hline 1,793 & 3.04 & 0.00 & $\mathrm{f}$ & -1 & - & - & - & 0 & - & - & - & $\mathrm{c}$ & $\mathrm{CCS}$ \\
\hline 1,794 & 3.04 & 0.00 & $\mathrm{~d}$ & -1 & - & - & - & - & - & - & - & c & CCS \\
\hline 1,795 & 3.04 & 0.00 & $\mathrm{f}$ & -1 & - & - & - & 0 & - & - & - & $\mathrm{r}$ & $\mathrm{CCS}$ \\
\hline 1,796 & 3.04 & 0.00 & $\mathrm{~d}$ & -1 & - & - & - & - & - & - & - & $\mathrm{c}$ & $\mathrm{CCS}$ \\
\hline 1,797 & 3.04 & 0.00 & $\mathrm{~d}$ & -1 & - & - & - & - & - & - & - & $\mathrm{c}$ & $\mathrm{CCS}$ \\
\hline 1,798 & 3.04 & 0.00 & $f$ & -1 & - & - & - & 0 & - & - & - & c & CCS \\
\hline 1,799 & 3.04 & 0.00 & $\mathrm{f}$ & -1 & - & - & - & 0 & - & - & - & $\mathrm{c}$ & CCS \\
\hline 1,800 & 3.04 & 0.00 & $\mathrm{f}$ & $-1-1$ & - & - & - & 0 & - & - & - & $\mathrm{c}$ & CCS \\
\hline
\end{tabular}




\begin{tabular}{|c|c|c|c|c|c|c|c|c|c|c|c|c|c|}
\hline 1,801 & 3.04 & 0.00 & $\mathrm{~d}$ & \begin{tabular}{|l|l}
- & 1 \\
\end{tabular} & - & - & - & - & - & - & - & c & CCS \\
\hline 1,802 & 3.04 & 0.00 & $\mathrm{f}$ & -1 & - & - & - & 0 & - & - & - & c & CCS \\
\hline 1,803 & 3.04 & 0.00 & $\mathrm{~d}$ & -1 & - & - & - & - & - & - & - & $\mathrm{W}$ & CCS \\
\hline 1,804 & 3.04 & 0.00 & $\mathrm{f}$ & -1 & - & - & - & 0 & - & - & - & $\mathrm{c}$ & CCS \\
\hline 1,805 & 3.04 & 0.00 & $\mathrm{f}$ & -1 & - & - & - & 0 & - & - & - & w & $\mathrm{CCS}$ \\
\hline 1,806 & 3.04 & 0.00 & $\mathrm{f}$ & -1 & - & - & - & 0 & - & - & - & c & CCS \\
\hline 1,807 & 3.04 & 0.00 & $\mathrm{~d}$ & -1 & - & - & - & - & - & - & - & c & $\mathrm{CCS}$ \\
\hline 1,808 & 3.04 & 0.00 & $\mathrm{f}$ & -1 & - & - & - & 0 & - & - & - & w & CCS \\
\hline 1,809 & 3.04 & 0.00 & $\mathrm{~d}$ & -1 & - & - & - & - & - & - & - & $\mathrm{i}$ & Igneous \\
\hline 1,810 & 3.04 & 0.00 & $\mathrm{f}$ & -1 & - & - & - & 0 & - & - & - & w & CCS \\
\hline 1,811 & 3.04 & 0.00 & $\mathrm{f}$ & -11 & - & - & - & 0 & - & - & - & $\mathrm{c}$ & CCS \\
\hline 1,812 & 3.04 & 0.00 & $\mathrm{f}$ & -1 & - & - & - & 0 & - & - & - & w & CCS \\
\hline 1,813 & 3.04 & 0.00 & $\mathrm{~d}$ & -11 & - & - & - & - & - & - & - & $\mathrm{c}$ & CCS \\
\hline 1,814 & 2.05 & 2.90 & $\mathrm{f}$ & -8 & - & - & - & 0 & - & - & - & c & CCS \\
\hline 1,815 & 2.05 & 1.17 & $\mathrm{f}$ & -6 & - & - & - & 0 & - & - & - & c & CCS \\
\hline 1,816 & 2.05 & 2.68 & $\mathrm{f}$ & -5 & - & - & - & 0 & - & - & - & $\mathrm{g}$ & CCS \\
\hline 1,817 & 2.05 & 0.62 & $\mathrm{~b}$ & \begin{tabular}{|l|l}
$\mathrm{s}$ & 4 \\
\end{tabular} & $\mathrm{cx}$ & 0 & 2 & 0 & 5.31 & 21.45 & 1.94 & $\mathrm{c}$ & CCS \\
\hline 1,818 & 2.05 & 3.14 & $\mathrm{f}$ & -6 & - & - & - & 0 & - & - & - & $\mathrm{t}$ & CCS \\
\hline 1,819 & 2.05 & 0.81 & $\mathrm{~d}$ & -3 & - & - & - & - & - & - & - & i & Igneous \\
\hline 1,820 & 2.05 & 0.67 & $\mathrm{~d}$ & -4 & - & - & - & - & - & - & - & c & CCS \\
\hline 1,821 & 2.05 & 0.84 & $\mathrm{f}$ & -4 & - & - & - & 0 & - & - & - & c & CCS \\
\hline 1,822 & 2.05 & 0.92 & $\mathrm{f}$ & -3 & - & - & - & 0 & - & - & - & c & CCS \\
\hline 1,823 & 2.05 & 0.98 & $\mathrm{f}$ & -4 & - & - & - & 0 & - & - & - & $\mathrm{g}$ & CCS \\
\hline 1,824 & 2.05 & 0.89 & $\mathrm{f}$ & -5 & - & - & - & 0 & - & - & - & c & CCS \\
\hline 1,825 & 2.05 & 0.55 & $\mathrm{f}$ & -3 & - & - & - & 0 & - & - & - & c & CCS \\
\hline 1,826 & 2.05 & 0.19 & c & \begin{tabular}{l|l} 
o & 3 \\
\end{tabular} & $\mathrm{f}$ & 0 & 0 & 0 & 7.11 & 12.08 & 1.61 & c & CCS \\
\hline 1,827 & 2.05 & 0.52 & $\mathrm{f}$ & -3 & - & - & - & 1 & - & - & - & c & CCS \\
\hline 1,828 & 2.05 & 0.76 & $\mathrm{~d}$ & -4 & - & - & - & - & - & - & - & $\mathrm{g}$ & CCS \\
\hline 1,829 & 2.05 & 0.47 & $\mathrm{f}$ & -3 & - & - & - & 0 & - & - & - & c & CCS \\
\hline 1,830 & 2.05 & 1.02 & $\mathrm{~d}$ & -5 & - & - & - & - & - & - & - & c & $\mathrm{CCS}$ \\
\hline 1,831 & 2.05 & 0.67 & $\mathrm{f}$ & -3 & - & - & - & 1 & - & - & - & $\mathrm{c}$ & CCS \\
\hline 1,832 & 2.05 & 0.67 & $\mathrm{~d}$ & -4 & - & - & - & - & - & - & - & $\mathrm{W}$ & CCS \\
\hline 1,833 & 2.05 & 0.39 & $\mathrm{~d}$ & -2 & - & - & - & - & - & - & - & $\mathrm{c}$ & CCS \\
\hline 1,834 & 2.05 & 0.23 & $\mathrm{~d}$ & -2 & - & - & - & - & - & - & - & $\mathrm{c}$ & $\mathrm{CCS}$ \\
\hline 1,835 & 2.05 & 0.32 & $\mathrm{f}$ & -2 & - & - & - & 0 & - & - & - & $\mathrm{g}$ & CCS \\
\hline 1,836 & 2.05 & 0.23 & $\mathrm{~b}$ & \begin{tabular}{|l|l|}
$\mathrm{s}$ & 2 \\
\end{tabular} & $\mathrm{cx}$ & 2 & 3 & 0 & 10.38 & 9.41 & 2.50 & $\mathrm{r}$ & CCS \\
\hline 1,837 & 2.05 & 0.30 & $\mathrm{~d}$ & -2 & - & - & - & - & - & - & - & $\mathrm{w}$ & CCS \\
\hline 1,838 & 2.05 & 0.06 & $\mathrm{f}$ & -2 & - & - & - & 0 & - & - & - & $\mathrm{c}$ & CCS \\
\hline 1,839 & 2.05 & 0.49 & $\mathrm{f}$ & -3 & - & - & - & 2 & - & - & - & $\mathrm{c}$ & CCS \\
\hline 1,840 & 2.05 & 0.23 & $f$ & -2 & - & - & - & 0 & - & - & - & $\mathrm{b}$ & CCS \\
\hline 1,841 & 2.05 & 0.28 & $\mathrm{f}$ & -2 & - & - & - & 0 & - & - & - & c & CCS \\
\hline 1,842 & 2.05 & 0.15 & $\mathrm{~d}$ & -2 & - & - & - & - & - & - & - & $\mathrm{c}$ & CCS \\
\hline 1,843 & 2.05 & 0.10 & $\mathrm{f}$ & -2 & - & - & - & 0 & - & - & - & $\mathrm{g}$ & CCS \\
\hline
\end{tabular}




\begin{tabular}{|c|c|c|c|c|c|c|c|c|c|c|c|c|c|}
\hline 1,844 & 2.05 & 0.15 & $\mathrm{~d}$ & -2 & - & - & - & - & - & - & - & $\mathrm{c}$ & CCS \\
\hline 1,845 & 2.05 & 0.14 & $\mathrm{~d}$ & -2 & - & - & - & - & - & - & - & c & CCS \\
\hline 1,846 & 2.05 & 0.13 & $\mathrm{~d}$ & -3 & - & - & - & - & - & - & - & c & CCS \\
\hline 1,847 & 2.05 & 0.20 & $\mathrm{~d}$ & -3 & - & - & - & - & - & - & - & c & $\mathrm{CCS}$ \\
\hline 1,848 & 2.05 & 0.14 & $\mathrm{f}$ & -3 & - & - & - & 0 & - & - & - & c & CCS \\
\hline 1,849 & 2.05 & 0.21 & d & -3 & - & - & - & - & - & - & - & c & CCS \\
\hline 1,850 & 2.05 & 0.07 & $\mathrm{~b}$ & $\begin{array}{ll}\mathrm{s} & 2 \\
\end{array}$ & $\mathrm{cx}$ & 0 & 3 & 0 & 1.67 & 9.80 & 1.89 & c & CCS \\
\hline 1,851 & 2.05 & 0.30 & $\mathrm{f}$ & -3 & - & - & - & 0 & - & - & - & $\mathrm{g}$ & CCS \\
\hline 1,852 & 2.05 & 0.09 & $\mathrm{f}$ & -2 & - & - & - & 0 & - & - & - & c & CCS \\
\hline 1,853 & 2.05 & 0.23 & $\mathrm{~b}$ & $\begin{array}{ll}\mathrm{s} & 2 \\
\end{array}$ & $\mathrm{cx}$ & 0 & 3 & 0 & 5.30 & 11.49 & 1.94 & c & $\mathrm{CCS}$ \\
\hline 1,854 & 2.05 & 0.06 & f & -2 & - & - & - & 0 & - & - & - & c & CCS \\
\hline 1,855 & 2.05 & 0.04 & $\mathrm{f}$ & -1 & - & - & - & 0 & - & - & - & c & CCS \\
\hline 1,856 & 2.05 & 0.15 & $\mathrm{~d}$ & -2 & - & - & - & - & - & - & - & $\mathrm{t}$ & $\mathrm{CCS}$ \\
\hline 1,857 & 2.05 & 0.11 & f & -1 & - & - & - & 0 & - & - & - & c & CCS \\
\hline 1,858 & 2.05 & 0.00 & f & -1 & - & - & - & 0 & - & - & - & w & CCS \\
\hline 1,859 & 2.05 & 0.00 & $\mathrm{~d}$ & -1 & - & - & - & - & - & - & - & c & $\mathrm{CCS}$ \\
\hline 1,860 & 2.05 & 0.06 & $\mathrm{f}$ & -1 & - & - & - & 0 & - & - & - & $\mathrm{g}$ & CCS \\
\hline 1,861 & 2.05 & 0.09 & $\mathrm{f}$ & -2 & - & - & - & 0 & - & - & - & c & $\mathrm{CCS}$ \\
\hline 1,862 & 2.05 & 0.00 & $\mathrm{f}$ & -1 & - & - & - & 0 & - & - & - & c & CCS \\
\hline 1,863 & 2.05 & 0.05 & $f$ & -1 & - & - & - & 0 & - & - & - & W & CCS \\
\hline 1,864 & 2.05 & 0.00 & f & -1 & - & - & - & 0 & - & - & - & $\mathrm{b}$ & CCS \\
\hline 1,865 & 2.05 & 0.00 & $\mathrm{f}$ & -1 & - & - & - & 0 & - & - & - & c & $\mathrm{CCS}$ \\
\hline 1,866 & 2.05 & 0.04 & f & -2 & - & - & - & 0 & - & - & - & $\mathrm{b}$ & CCS \\
\hline 1,867 & 2.05 & 0.16 & $\mathrm{f}$ & -2 & - & - & - & 0 & - & - & - & c & $\mathrm{CCS}$ \\
\hline 1,868 & 2.05 & 0.00 & $\mathrm{f}$ & -1 & - & - & - & 0 & - & - & - & $\mathrm{g}$ & $\mathrm{CCS}$ \\
\hline 1,869 & 2.05 & 0.00 & $f$ & -1 & - & - & - & 0 & - & - & - & $\mathrm{b}$ & $\mathrm{CCS}$ \\
\hline 1,870 & 2.05 & 0.10 & d & -1 & - & - & - & - & - & - & - & $\mathrm{g}$ & $\mathrm{CCS}$ \\
\hline 1,871 & 2.05 & 0.07 & d & -2 & - & - & - & - & - & - & - & c & $\mathrm{CCS}$ \\
\hline 1,872 & 2.05 & 0.09 & d & -1 & - & - & - & - & - & - & - & $\mathrm{i}$ & Igneous \\
\hline 1,873 & 2.05 & 0.00 & d & -1 & - & - & - & - & - & - & - & c & $\mathrm{CCS}$ \\
\hline 1,874 & 2.05 & 0.00 & $\mathrm{f}$ & -1 & - & - & - & 0 & - & - & - & c & $\mathrm{CCS}$ \\
\hline 1,875 & 2.05 & 0.00 & d & -1 & - & - & - & - & - & - & - & $\mathrm{b}$ & $\mathrm{CCS}$ \\
\hline 1,876 & 2.05 & 0.00 & d & -1 & - & - & - & - & - & - & - & $\mathrm{i}$ & Igneous \\
\hline 1,877 & 2.05 & 0.06 & $\mathrm{f}$ & -2 & - & - & - & 0 & - & - & - & w & $\mathrm{CCS}$ \\
\hline 1,878 & 2.05 & 0.00 & d & -1 & - & - & - & - & - & - & - & c & $\mathrm{CCS}$ \\
\hline 1,879 & 2.05 & 0.12 & $\mathrm{f}$ & -3 & - & - & - & 0 & - & - & - & $\mathrm{r}$ & $\mathrm{CCS}$ \\
\hline 1,880 & 2.05 & 0.15 & d & -2 & - & - & - & - & - & - & - & w & $\mathrm{CCS}$ \\
\hline 1,881 & 2.05 & 0.00 & d & -1 & - & - & - & - & - & - & - & $\mathrm{t}$ & $\mathrm{CCS}$ \\
\hline 1,882 & 2.05 & 0.00 & $\mathrm{f}$ & -1 & - & - & - & 0 & - & - & - & c & $\mathrm{CCS}$ \\
\hline 1,883 & 2.05 & 0.13 & $\mathrm{f}$ & -2 & - & - & - & 0 & - & - & - & c & CCS \\
\hline 1,884 & 2.05 & 0.00 & $\mathrm{f}$ & -1 & - & - & - & 0 & - & - & - & $\mathrm{b}$ & CCS \\
\hline 1,885 & 2.05 & 0.04 & $\mathrm{f}$ & -1 & - & - & - & 0 & - & - & - & c & $\mathrm{CCS}$ \\
\hline 1,886 & 2.05 & 0.00 & $\mathrm{~d}$ & -1 & - & - & - & - & - & - & - & $\mathrm{g}$ & CCS \\
\hline
\end{tabular}




\begin{tabular}{|c|c|c|c|c|c|c|c|c|c|c|c|c|c|}
\hline 1,887 & 2.05 & 0.00 & d & \begin{tabular}{|l|l|}
- & 1 \\
\end{tabular} & - & - & - & - & - & - & - & c & CCS \\
\hline 1,888 & 2.05 & 0.00 & d & \begin{tabular}{|l|l}
- & 1 \\
\end{tabular} & - & - & - & - & - & - & - & $\mathrm{r}$ & CCS \\
\hline 1,889 & 2.05 & 0.00 & $\mathrm{~d}$ & \begin{tabular}{|l|l}
- & 1 \\
\end{tabular} & - & - & - & - & - & - & - & $\mathrm{g}$ & CCS \\
\hline 1,890 & 2.05 & 0.00 & $\mathrm{f}$ & \begin{tabular}{|l|l|}
- & 1 \\
\end{tabular} & - & - & - & 0 & - & - & - & $t$ & CCS \\
\hline 1,891 & 2.05 & 0.00 & d & \begin{tabular}{|l|l}
- & 1 \\
\end{tabular} & - & - & - & - & - & - & - & $\mathrm{i}$ & Igneous \\
\hline 1,892 & 2.05 & 0.00 & $\mathrm{f}$ & \begin{tabular}{|l|l}
- & 1 \\
\end{tabular} & - & - & - & 0 & - & - & - & $\mathrm{g}$ & CCS \\
\hline 1,893 & 2.05 & 0.00 & d & \begin{tabular}{|l|l}
- & 1 \\
\end{tabular} & - & - & - & - & - & - & - & W & CCS \\
\hline 1,894 & 2.05 & 0.00 & d & \begin{tabular}{|l|l}
- & 1 \\
\end{tabular} & - & - & - & - & - & - & - & c & CCS \\
\hline 1,895 & 2.05 & 0.00 & $\mathrm{f}$ & -1 & - & - & - & 0 & - & - & - & $\mathrm{r}$ & CCS \\
\hline 1,896 & 2.05 & 0.00 & d & \begin{tabular}{|l|l}
- & 1 \\
\end{tabular} & - & - & - & - & - & - & - & $\mathrm{g}$ & CCS \\
\hline 1,897 & 2.05 & 0.00 & d & -1 & - & - & - & - & - & - & - & c & CCS \\
\hline 1,898 & 2.05 & 0.00 & $\mathrm{f}$ & -1 & - & - & - & 0 & - & - & - & $\mathrm{g}$ & CCS \\
\hline 1,899 & 2.05 & 0.05 & $\mathrm{f}$ & -1 & - & - & - & 0 & - & - & - & c & CCS \\
\hline 1,900 & 2.05 & 0.07 & $\mathrm{f}$ & -1 & - & - & - & 0 & - & - & - & W & CCS \\
\hline 1,901 & 2.05 & 0.00 & d & -1 & - & - & - & - & - & - & - & c & CCS \\
\hline 1,902 & 2.05 & 0.00 & $\mathrm{f}$ & -1 & - & - & - & 0 & - & - & - & c & CCS \\
\hline 1,903 & 2.05 & 0.00 & $\mathrm{f}$ & -1 & - & - & - & 0 & - & - & - & c & CCS \\
\hline 1,904 & 2.05 & 0.00 & d & -1 & - & - & - & - & - & - & - & $\mathrm{r}$ & CCS \\
\hline 1,905 & 2.05 & 0.04 & $\mathrm{f}$ & -2 & - & - & - & 0 & - & - & - & c & CCS \\
\hline 1,906 & 2.05 & 0.00 & $\mathrm{f}$ & -1 & - & - & - & 0 & - & - & - & c & CCS \\
\hline 1,907 & 2.05 & 0.00 & $\mathrm{f}$ & -1 & - & - & - & 0 & - & - & - & c & CCS \\
\hline 1,908 & 2.05 & 0.00 & $\mathrm{f}$ & -1 & - & - & - & 0 & - & - & - & c & CCS \\
\hline 1,909 & 2.05 & 0.05 & $\mathrm{f}$ & -2 & - & - & - & 0 & - & - & - & c & CCS \\
\hline 1,910 & 2.05 & 0.00 & $\mathrm{f}$ & -1 & - & - & - & 0 & - & - & - & c & CCS \\
\hline 1,911 & 2.05 & 0.00 & $\mathrm{f}$ & -1 & - & - & - & 0 & - & - & - & c & CCS \\
\hline 1,912 & 2.05 & 0.00 & $\mathrm{f}$ & -1 & - & - & - & 0 & - & - & - & c & CCS \\
\hline 1,913 & 2.05 & 0.00 & $\mathrm{f}$ & -1 & - & - & - & 0 & - & - & - & $\mathrm{g}$ & CCS \\
\hline 1,914 & 2.05 & 0.00 & $\mathrm{f}$ & -1 & - & - & - & 0 & - & - & - & c & CCS \\
\hline 1,915 & 2.05 & 0.00 & d & -1 & - & - & - & - & - & - & - & c & CCS \\
\hline 1,916 & 2.05 & 0.00 & $\mathrm{f}$ & -1 & - & - & - & 0 & - & - & - & $\mathrm{r}$ & CCS \\
\hline 1,917 & 2.05 & 0.00 & $\mathrm{f}$ & -1 & - & - & - & 0 & - & - & - & c & CCS \\
\hline 1,918 & 2.05 & 0.00 & d & -1 & - & - & - & - & - & - & - & c & CCS \\
\hline 1,919 & 2.05 & 0.00 & $\mathrm{f}$ & -1 & - & - & - & 0 & - & - & - & $\mathrm{g}$ & CCS \\
\hline 1,920 & 2.05 & 0.00 & $\mathrm{f}$ & -1 & - & - & - & 0 & - & - & - & c & CCS \\
\hline 1,921 & 2.05 & 0.00 & d & -1 & - & - & - & - & - & - & - & c & CCS \\
\hline 1,922 & 2.05 & 0.00 & $\mathrm{f}$ & -1 & - & - & - & 0 & - & - & - & W & CCS \\
\hline 1,923 & 2.05 & 0.00 & $\mathrm{f}$ & -1 & - & - & - & 0 & - & - & - & $\mathrm{g}$ & CCS \\
\hline 1,924 & 2.05 & 0.00 & d & -1 & - & - & - & - & - & - & - & $\mathrm{r}$ & CCS \\
\hline 1,925 & 2.05 & 0.00 & $\mathrm{f}$ & -1 & - & - & - & 0 & - & - & - & c & CCS \\
\hline 1,926 & 2.05 & 0.00 & $\mathrm{f}$ & -1 & - & - & - & 0 & - & - & - & c & CCS \\
\hline 1,927 & 2.05 & 0.00 & $\mathrm{f}$ & -1 & - & - & - & 0 & - & - & - & $\mathrm{r}$ & CCS \\
\hline 1,928 & 2.05 & 0.04 & $\mathrm{f}$ & -1 & - & - & - & 0 & - & - & - & c & CCS \\
\hline 1,929 & 2.05 & 0.00 & $\mathrm{f}$ & -1 & - & - & - & 0 & - & - & - & c & CCS \\
\hline
\end{tabular}




\begin{tabular}{|c|c|c|c|c|c|c|c|c|c|c|c|c|c|}
\hline 1,930 & 2.05 & 0.00 & $\mathrm{f}$ & \begin{tabular}{|l|l}
- & 1 \\
\end{tabular} & - & - & - & 0 & - & - & - & $\mathrm{r}$ & CCS \\
\hline 1,931 & 2.05 & 0.00 & f & -1 & - & - & - & 0 & - & - & - & $\mathrm{b}$ & CCS \\
\hline 1,932 & 2.05 & 0.00 & $\mathrm{f}$ & -1 & - & - & - & 0 & - & - & - & c & $\mathrm{CCS}$ \\
\hline 1,933 & 2.05 & 0.00 & $\mathrm{f}$ & -1 & - & - & - & 0 & - & - & - & w & CCS \\
\hline 1,934 & 2.05 & 0.00 & d & -1 & - & - & - & - & - & - & - & $\mathrm{g}$ & CCS \\
\hline 1,935 & 2.05 & 0.00 & c & \begin{tabular}{l|l} 
o & 1 \\
\end{tabular} & $\mathrm{cx}$ & 0 & 3 & 0 & 2.19 & 4.60 & 1.07 & c & CCS \\
\hline 1,936 & 2.05 & 0.00 & d & -1 & - & - & - & - & - & - & - & $\mathrm{b}$ & CCS \\
\hline 1,937 & 2.05 & 0.00 & d & -1 & - & - & - & - & - & - & - & c & CCS \\
\hline 1,938 & 2.05 & 0.00 & d & -1 & - & - & - & - & - & - & - & w & CCS \\
\hline 1,939 & 2.05 & 0.00 & f & -1 & - & - & - & 0 & - & - & - & $\mathrm{g}$ & CCS \\
\hline 1,940 & 2.05 & 0.00 & f & -1 & - & - & - & 0 & - & - & - & $\mathrm{r}$ & CCS \\
\hline 1,941 & 2.05 & 0.00 & f & -1 & - & - & - & 0 & - & - & - & c & CCS \\
\hline 1,942 & 2.05 & 0.00 & f & -1 & - & - & - & 0 & - & - & - & c & CCS \\
\hline 1,943 & 2.05 & 0.00 & f & -1 & - & - & - & 0 & - & - & - & c & CCS \\
\hline 1,944 & 2.06 .2 & 5.16 & c & $\begin{array}{ll} & 8 \\
\end{array}$ & c & 2 & 3 & 1 & 16.24 & 38.98 & 6.06 & c & CCS \\
\hline 1,945 & 2.06 .2 & 2.07 & f & -7 & - & - & - & 0 & - & - & - & c & CCS \\
\hline 1,946 & 2.06 .2 & 2.61 & f & -5 & - & - & - & 0 & - & - & - & c & $\mathrm{CCS}$ \\
\hline 1,947 & 2.06 .2 & 1.01 & f & -5 & - & - & - & 0 & - & - & - & c & CCS \\
\hline 1,948 & 2.06 .2 & 2.87 & d & -7 & - & - & - & - & - & - & - & $t$ & CCS \\
\hline 1,949 & 2.06 .2 & 0.86 & f & -4 & - & - & - & 2 & - & - & - & $\mathrm{r}$ & CCS \\
\hline 1,950 & 2.06 .2 & 1.12 & f & -5 & - & - & - & 0 & - & - & - & $t$ & CCS \\
\hline 1,951 & 2.06 .2 & 1.90 & c & $\begin{array}{ll}\text { o } & 6 \\
\end{array}$ & c & 2 & 3 & 1 & 13.51 & 27.30 & 4.92 & c & CCS \\
\hline 1,952 & 2.06 .2 & 0.67 & d & -4 & - & - & - & - & - & - & - & c & $\mathrm{CCS}$ \\
\hline 1,953 & 2.06 .2 & 0.68 & f & -3 & - & - & - & 0 & - & - & - & c & CCS \\
\hline 1,954 & 2.06 .2 & 0.63 & d & -4 & - & - & - & - & - & - & - & c & $\mathrm{CCS}$ \\
\hline 1,955 & 2.06 .2 & 0.34 & f & -3 & - & - & - & 0 & - & - & - & c & CCS \\
\hline 1,956 & 2.06 .2 & 0.19 & $\mathrm{f}$ & -4 & - & - & - & 0 & - & - & - & c & CCS \\
\hline 1,957 & 2.06 .2 & 0.48 & f & -2 & - & - & - & 0 & - & - & - & $\mathrm{t}$ & CCS \\
\hline 1,958 & 2.06 .2 & 0.70 & f & -5 & - & - & - & 0 & - & - & - & $\mathrm{g}$ & CCS \\
\hline 1,959 & 2.06 .2 & 0.54 & d & -2 & - & - & - & - & - & - & - & c & CCS \\
\hline 1,960 & 2.06 .2 & 0.12 & d & -3 & - & - & - & - & - & - & - & c & CCS \\
\hline 1,961 & 2.06 .2 & 0.22 & $\mathrm{f}$ & -2 & - & - & - & 0 & - & - & - & c & CCS \\
\hline 1,962 & 2.06 .2 & 0.54 & c & \begin{tabular}{l|l} 
o & 4 \\
\end{tabular} & $\mathrm{a}$ & 0 & 3 & 0 & 6.31 & 22.23 & 2.28 & $\mathrm{r}$ & CCS \\
\hline 1,963 & 2.06 .2 & 0.26 & $\mathrm{f}$ & -2 & - & - & - & 0 & - & - & - & c & CCS \\
\hline 1,964 & 2.06 .2 & 0.21 & d & -2 & - & - & - & - & - & - & - & $\mathrm{r}$ & CCS \\
\hline 1,965 & 2.06 .2 & 0.23 & d & -2 & - & - & - & - & - & - & - & c & CCS \\
\hline 1,966 & 2.06 .2 & 0.07 & f & -2 & - & - & - & 0 & - & - & - & c & CCS \\
\hline 1,967 & 2.06 .2 & 0.16 & $\mathrm{f}$ & -2 & - & - & - & 0 & - & - & - & c & CCS \\
\hline 1,968 & 2.06 .2 & 0.10 & d & -2 & - & - & - & - & - & - & - & $\mathrm{g}$ & CCS \\
\hline 1,969 & 2.06 .2 & 0.08 & $\mathrm{f}$ & -2 & - & - & - & 0 & - & - & - & c & CCS \\
\hline 1,970 & 2.06 .2 & 0.14 & f & -2 & - & - & - & 0 & - & - & - & c & CCS \\
\hline 1,971 & 2.06 .2 & 0.00 & $\mathrm{~d}$ & -1 & - & - & - & - & - & - & - & c & CCS \\
\hline 1,972 & 2.06 .2 & 0.16 & f & -3 & - & - & - & 0 & - & - & - & c & CCS \\
\hline
\end{tabular}




\begin{tabular}{|c|c|c|c|c|c|c|c|c|c|c|c|c|c|}
\hline 1,973 & 2.06 .2 & 0.11 & $\mathrm{f}$ & -1 & - & - & - & 0 & - & - & - & $\mathrm{g}$ & CCS \\
\hline 1,974 & 2.06 .2 & 0.12 & d & -2 & - & - & - & - & - & - & - & w & CCS \\
\hline 1,975 & 2.06 .2 & 0.10 & $\mathrm{~d}$ & -2 & - & - & - & - & - & - & - & c & CCS \\
\hline 1,976 & 2.06 .2 & 0.11 & $\mathrm{~d}$ & -2 & - & - & - & - & - & - & - & c & CCS \\
\hline 1,977 & 2.06 .2 & 0.00 & f & -1 & - & - & - & 0 & - & - & - & c & CCS \\
\hline 1,978 & 2.06 .2 & 0.03 & d & -1 & - & - & - & - & - & - & - & W & CCS \\
\hline 1,979 & 2.06 .2 & 0.05 & d & -2 & - & - & - & - & - & - & - & c & CCS \\
\hline 1,980 & 2.06 .2 & 0.00 & d & -1 & - & - & - & - & - & - & - & c & CCS \\
\hline 1,981 & 2.06 .2 & 0.00 & d & -1 & - & - & - & - & - & - & - & c & CCS \\
\hline 1,982 & 2.06 .2 & 0.00 & $\mathrm{~d}$ & -2 & - & - & - & - & - & - & - & c & CCS \\
\hline 1,983 & 2.06 .2 & 0.00 & d & -1 & - & - & - & - & - & - & - & c & CCS \\
\hline 1,984 & 2.06 .2 & 0.00 & d & -1 & - & - & - & - & - & - & - & c & CCS \\
\hline 1,985 & 2.06 .2 & 0.07 & f & -1 & - & - & - & 0 & - & - & - & c & CCS \\
\hline 1,986 & 2.06 .2 & 0.00 & $\mathrm{f}$ & -1 & - & - & - & 0 & - & - & - & c & CCS \\
\hline 1,987 & 2.06 .2 & 0.00 & d & -1 & - & - & - & - & - & - & - & $\mathrm{i}$ & Igneous \\
\hline 1,988 & 2.06 .2 & 0.00 & f & -1 & - & - & - & 0 & - & - & - & c & CCS \\
\hline 1,989 & 2.06 .2 & 0.12 & d & -1 & - & - & - & - & - & - & - & c & CCS \\
\hline 1,990 & 2.06 .2 & 0.06 & d & -1 & - & - & - & - & - & - & - & c & CCS \\
\hline 1,991 & 2.06 .2 & 0.00 & d & -2 & - & - & - & - & - & - & - & c & CCS \\
\hline 1,992 & 2.06 .2 & 0.00 & d & -1 & - & - & - & - & - & - & - & W & CCS \\
\hline 1,993 & 2.06 .2 & 0.00 & d & -1 & - & - & - & - & - & - & - & c & CCS \\
\hline 1,994 & 2.06 .2 & 0.04 & f & -1 & - & - & - & 0 & - & - & - & $\mathrm{g}$ & CCS \\
\hline 1,995 & 2.06 .2 & 0.19 & f & -2 & - & - & - & 0 & - & - & - & c & CCS \\
\hline 1,996 & 2.06 .2 & 0.08 & f & -2 & - & - & - & 0 & - & - & - & c & CCS \\
\hline 1,997 & 2.06 .2 & 0.00 & f & -1 & - & - & - & 0 & - & - & - & c & $\mathrm{CCS}$ \\
\hline 1,998 & 2.06 .2 & 0.05 & f & -1 & - & - & - & 0 & - & - & - & c & CCS \\
\hline 1,999 & 2.06 .2 & 0.00 & $\mathrm{f}$ & -1 & - & - & - & 0 & - & - & - & c & CCS \\
\hline 2,000 & 2.06 .2 & 0.08 & d & -2 & - & - & - & - & - & - & - & c & CCS \\
\hline 2,001 & 2.06 .2 & 0.03 & d & -1 & - & - & - & - & - & - & - & c & CCS \\
\hline 2,002 & 2.06 .2 & 0.00 & d & -1 & - & - & - & - & - & - & - & W & CCS \\
\hline 2,003 & 2.06 .2 & 0.00 & d & -1 & - & - & - & - & - & - & - & c & CCS \\
\hline 2,004 & 2.06 .2 & 0.00 & $\mathrm{f}$ & -1 & - & - & - & 0 & - & - & - & c & CCS \\
\hline 2,005 & 2.06 .2 & 0.05 & $\mathrm{f}$ & -2 & - & - & - & 0 & - & - & - & c & CCS \\
\hline 2,006 & 2.06 .2 & 0.00 & d & -1 & - & - & - & - & - & - & - & c & CCS \\
\hline 2,007 & 2.06 .2 & 0.00 & $\mathrm{f}$ & -1 & - & - & - & 0 & - & - & - & $\mathrm{r}$ & CCS \\
\hline 2,008 & 2.06 .2 & 0.00 & d & -1 & - & - & - & - & - & - & - & $\mathrm{i}$ & Igneous \\
\hline 2,009 & 2.06 .2 & 0.00 & f & -1 & - & - & - & 0 & - & - & - & c & CCS \\
\hline 2,010 & 2.06 .2 & 0.00 & d & -1 & - & - & - & - & - & - & - & W & CCS \\
\hline 2,011 & 2.06 .2 & 0.00 & $\mathrm{f}$ & -1 & - & - & - & 0 & - & - & - & c & CCS \\
\hline 2,012 & 2.06 .2 & 0.00 & d & -1 & - & - & - & - & - & - & - & c & CCS \\
\hline 2,013 & 2.06 .2 & 0.00 & $\mathrm{f}$ & -1 & - & - & - & 0 & - & - & - & c & CCS \\
\hline 2,014 & 2.06 .2 & 0.00 & $\mathrm{~d}$ & -1 & - & - & - & - & - & - & - & c & CCS \\
\hline 2,015 & 2.06 .2 & 0.00 & $\mathrm{f}$ & -1 & - & - & - & 0 & - & - & - & c & CCS \\
\hline
\end{tabular}




\begin{tabular}{|c|c|c|c|c|c|c|c|c|c|c|c|c|c|}
\hline 2,016 & 2.06 .2 & 0.00 & $\mathrm{~d}$ & -1 & - & - & - & - & - & - & - & $\mathrm{r}$ & CCS \\
\hline 2,017 & 2.06 .2 & 0.00 & d & -1 & - & - & - & - & - & - & - & c & CCS \\
\hline 2,018 & 2.06 .2 & 0.00 & d & -1 & - & - & - & - & - & - & - & w & CCS \\
\hline 2,019 & 2.06 .2 & 0.00 & d & -1 & - & - & - & - & - & - & - & c & $\mathrm{CCS}$ \\
\hline 2,020 & 2.06 .2 & 0.00 & d & -1 & - & - & - & - & - & - & - & c & CCS \\
\hline 2,021 & 2.06 .2 & 0.00 & d & -1 & - & - & - & - & - & - & - & c & $\mathrm{CCS}$ \\
\hline 2,022 & 2.06 .2 & 0.00 & f & -1 & - & - & - & 0 & - & - & - & c & CCS \\
\hline 2,023 & 2.06 .2 & 0.00 & d & -1 & - & - & - & - & - & - & - & c & CCS \\
\hline 2,024 & 2.06 .2 & 0.00 & f & -1 & - & - & - & 0 & - & - & - & c & CCS \\
\hline 2,025 & 2.06 .2 & 0.00 & $\mathrm{f}$ & -1 & - & - & - & 0 & - & - & - & $\mathrm{c}$ & $\mathrm{CCS}$ \\
\hline 2,026 & 2.06 .2 & 0.00 & f & -1 & - & - & - & 0 & - & - & - & c & CCS \\
\hline 2,027 & 2.06 .2 & 0.00 & f & -1 & - & - & - & 0 & - & - & - & $\mathrm{c}$ & $\mathrm{CCS}$ \\
\hline 2,028 & 2.06 .2 & 0.00 & d & -1 & - & - & - & - & - & - & - & c & CCS \\
\hline 2,029 & 2.06 .2 & 0.00 & $\mathrm{~d}$ & -1 & - & - & - & - & - & - & - & $\mathrm{c}$ & $\mathrm{CCS}$ \\
\hline 2,030 & 2.06 .2 & 0.00 & d & -1 & - & - & - & - & - & - & - & c & $\mathrm{CCS}$ \\
\hline 2,031 & 2.06.2 & 0.00 & d & -1 & - & - & - & - & - & - & - & $\mathrm{c}$ & CCS \\
\hline 2,032 & 2.06 .2 & 0.00 & f & -1 & - & - & - & 0 & - & - & - & c & $\mathrm{CCS}$ \\
\hline 2,033 & 2.06 .2 & 0.00 & $\mathrm{f}$ & -1 & - & - & - & 0 & - & - & - & $\mathrm{c}$ & $\mathrm{CCS}$ \\
\hline 2,036 & 3.10 & 0.28 & c & o 3 & $\mathrm{a}$ & 0 & 3 & 0 & 7.09 & 15.56 & 2.21 & $\mathrm{t}$ & $\mathrm{CCS}$ \\
\hline 2,037 & 3.10 & 0.34 & $\mathrm{f}$ & -3 & - & - & - & 0 & - & - & - & $\mathrm{t}$ & CCS \\
\hline 2,038 & 3.10 & 0.42 & f & -4 & - & - & - & 0 & - & - & - & $\mathrm{b}$ & $\mathrm{CCS}$ \\
\hline 2,039 & 3.10 & 0.25 & $\mathrm{f}$ & -3 & - & - & - & 1 & - & - & - & $\mathrm{c}$ & $\mathrm{CCS}$ \\
\hline 2,040 & 3.10 & 0.38 & d & -3 & - & - & - & - & - & - & - & $\mathrm{i}$ & Igneous \\
\hline 2,041 & 3.10 & 0.49 & d & -2 & - & - & - & - & - & - & - & $\mathrm{i}$ & Igneous \\
\hline 2,043 & 3.10 & 0.27 & d & -3 & - & - & - & - & - & - & - & $\mathrm{i}$ & Igneous \\
\hline 2,044 & 3.10 & 0.00 & d & -1 & - & - & - & - & - & - & - & $\mathrm{t}$ & $\mathrm{CCS}$ \\
\hline 2,045 & 3.10 & 0.11 & $\mathrm{f}$ & -2 & - & - & - & 0 & - & - & - & $\mathrm{t}$ & $\mathrm{CCS}$ \\
\hline 2,046 & 3.10 & 0.00 & $\mathrm{f}$ & -1 & - & - & - & 0 & - & - & - & $\mathrm{w}$ & $\mathrm{CCS}$ \\
\hline 2,047 & 3.10 & 0.25 & $\mathrm{f}$ & -2 & - & - & - & 0 & - & - & - & $\mathrm{r}$ & $\mathrm{CCS}$ \\
\hline 2,048 & 3.10 & 0.00 & c & $\begin{array}{lll}\text { o } & 1 \\
\end{array}$ & $\mathrm{f}$ & 0 & 3 & 0 & 2.50 & 8.71 & 1.04 & w & $\mathrm{CCS}$ \\
\hline 2,049 & 3.10 & 0.00 & d & -1 & - & - & - & - & - & - & - & $\mathrm{w}$ & $\mathrm{CCS}$ \\
\hline 2,050 & 3.10 & 0.09 & $\mathrm{f}$ & -2 & - & - & - & 0 & - & - & - & $t$ & $\mathrm{CCS}$ \\
\hline 2,051 & 3.10 & 0.08 & $\mathrm{f}$ & -2 & - & - & - & 0 & - & - & - & $\mathrm{c}$ & CCS \\
\hline 2,052 & 3.10 & 0.06 & d & -2 & - & - & - & - & - & - & - & $\mathrm{r}$ & $\mathrm{CCS}$ \\
\hline 2,053 & 3.10 & 0.15 & $\mathrm{f}$ & -2 & - & - & - & 0 & - & - & - & $t$ & $\mathrm{CCS}$ \\
\hline 2,054 & 3.10 & 0.14 & d & -1 & - & - & - & - & - & - & - & $\mathrm{i}$ & Igneous \\
\hline 2,055 & 3.10 & 0.17 & d & -2 & - & - & - & - & - & - & - & $\mathrm{r}$ & $\mathrm{CCS}$ \\
\hline 2,056 & 3.10 & 0.16 & d & -2 & - & - & - & - & - & - & - & $\mathrm{r}$ & $\mathrm{CCS}$ \\
\hline 2,057 & 3.10 & 0.00 & $\mathrm{f}$ & -1 & - & - & - & 0 & - & - & - & $t$ & CCS \\
\hline 2,058 & 3.10 & 0.00 & d & -1 & - & - & - & - & - & - & - & c & CCS \\
\hline 2,059 & 3.10 & 0.00 & d & -2 & - & - & - & - & - & - & - & $t$ & $\mathrm{CCS}$ \\
\hline 2,060 & 3.10 & 0.09 & d & -2 & - & - & - & - & - & - & - & $\mathrm{i}$ & Igneous \\
\hline 2,061 & 3.10 & 0.00 & c & \begin{tabular}{l|l} 
o & 1 \\
\end{tabular} & $\mathrm{cx}$ & 0 & 3 & 0 & 4.23 & 7.03 & 1.57 & $\mathrm{~b}$ & CCS \\
\hline
\end{tabular}




\begin{tabular}{|c|c|c|c|c|c|c|c|c|c|c|c|c|c|}
\hline 2,062 & 3.10 & 0.00 & $\mathrm{~b}$ & \begin{tabular}{l|l}
$\mathrm{S}$ & 2 \\
\end{tabular} & \begin{tabular}{|l|l|}
2 & $\mathrm{cx}$ \\
\end{tabular} & 0 & 3 & 0 & 2.62 & 9.78 & 0.89 & $\mathrm{t}$ & CCS \\
\hline 2,063 & 3.10 & 0.07 & $\mathrm{f}$ & -2 & $2-$ & - & - & 0 & - & - & - & $\mathrm{t}$ & CCS \\
\hline 2,064 & 3.10 & 0.00 & d & -1 & $1-$ & - & - & - & - & - & - & $\mathrm{t}$ & CCS \\
\hline 2,065 & 3.10 & 0.00 & c & $\begin{array}{ll} & 1 \\
\end{array}$ & cx & 0 & 3 & 0 & 1.27 & 8.83 & 0.98 & $\mathrm{t}$ & CCS \\
\hline 2,066 & 3.10 & 0.11 & f & -2 & $2-$ & - & - & 0 & - & - & - & $t$ & CCS \\
\hline 2,067 & 3.10 & 0.04 & d & -1 & $1-$ & - & - & - & - & - & - & $\mathrm{t}$ & CCS \\
\hline 2,068 & 3.10 & 0.09 & d & -2 & $2-$ & - & - & - & - & - & - & c & CCS \\
\hline 2,069 & 3.10 & 0.00 & d & -1 & $1-$ & - & - & - & - & - & - & $\mathrm{t}$ & CCS \\
\hline 2,070 & 3.10 & 0.00 & f & -1 & $1-$ & - & - & 0 & - & - & - & w & CCS \\
\hline 2,071 & 3.10 & 0.14 & d & -2 & $2-$ & - & - & - & - & - & - & $\mathrm{i}$ & Igneous \\
\hline 2,072 & 3.10 & 0.00 & d & -1 & $1-$ & - & - & - & - & - & - & $\mathrm{t}$ & CCS \\
\hline 2,073 & 3.10 & 0.00 & $\mathrm{f}$ & -1 & $1-$ & - & - & 0 & - & - & - & W & CCS \\
\hline 2,074 & 3.10 & 0.00 & d & -1 & $1-$ & - & - & - & - & - & - & $\mathrm{t}$ & CCS \\
\hline 2,075 & 3.10 & 0.00 & $\mathrm{f}$ & -1 & $1-$ & - & - & 0 & - & - & - & $\mathrm{g}$ & CCS \\
\hline 2,076 & 3.10 & 0.00 & d & -1 & $1-$ & - & - & - & - & - & - & c & $\mathrm{CCS}$ \\
\hline 2,077 & 3.10 & 0.00 & $\mathrm{f}$ & -1 & $1-$ & - & - & 0 & - & - & - & $\mathrm{b}$ & CCS \\
\hline 2,078 & 3.10 & 0.00 & $\mathrm{~b}$ & $\begin{array}{ll}\mathrm{s} & 1 \\
\end{array}$ & $\mathrm{cx}$ & 0 & 3 & 0 & 1.14 & 6.79 & 0.87 & $\mathrm{t}$ & CCS \\
\hline 2,079 & 3.10 & 0.00 & d & -1 & $1-$ & - & - & - & - & - & - & $\mathrm{i}$ & Igneous \\
\hline 2,080 & 3.10 & 0.00 & $\mathrm{~b}$ & $\begin{array}{ll}\text { s } & 1 \\
\end{array}$ & cx & 0 & 3 & 0 & 1.54 & 4.51 & 0.65 & $t$ & CCS \\
\hline 2,081 & 3.10 & 0.00 & $\mathrm{f}$ & -1 & $1-$ & - & - & 0 & - & - & - & b & CCS \\
\hline 2,082 & 3.10 & 0.00 & d & -1 & $1-$ & - & - & - & - & - & - & W & CCS \\
\hline 2,083 & 3.10 & 0.00 & f & -1 & $1-$ & - & - & 0 & - & - & - & w & CCS \\
\hline 2,084 & 3.10 & 0.00 & $\mathrm{f}$ & -1 & $1-$ & - & - & 0 & - & - & - & $\mathrm{b}$ & CCS \\
\hline 2,085 & 3.10 & 0.07 & f & -2 & $2-$ & - & - & 0 & - & - & - & c & CCS \\
\hline 2,086 & 3.10 & 0.09 & d & -1 & $1-$ & - & - & - & - & - & - & $\mathrm{b}$ & CCS \\
\hline 2,087 & 3.10 & 0.04 & d & -1 & $1-$ & - & - & - & - & - & - & $\mathrm{i}$ & Igneous \\
\hline 2,088 & 3.10 & 0.00 & d & -1 & $1-$ & - & - & - & - & - & - & $\mathrm{r}$ & CCS \\
\hline 2,089 & 3.10 & 0.00 & d & -1 & $1-$ & - & - & - & - & - & - & $\mathrm{r}$ & CCS \\
\hline 2,090 & 3.10 & 0.00 & d & -1 & $1-$ & - & - & - & - & - & - & $\mathrm{t}$ & CCS \\
\hline 2,091 & 3.10 & 0.00 & d & -1 & $1-$ & - & - & - & - & - & - & $t$ & $\mathrm{CCS}$ \\
\hline 2,092 & 3.10 & 0.00 & d & -1 & $1-$ & - & - & - & - & - & - & $\mathrm{r}$ & CCS \\
\hline 2,093 & 3.10 & 0.00 & $\mathrm{f}$ & -1 & $1-$ & - & - & 0 & - & - & - & $\mathrm{g}$ & CCS \\
\hline 2,094 & 3.10 & 0.00 & d & -1 & $1-$ & - & - & - & - & - & - & $t$ & $\mathrm{CCS}$ \\
\hline 2,095 & 3.10 & 0.00 & $\mathrm{f}$ & -1 & $1-$ & - & - & 0 & - & - & - & $t$ & CCS \\
\hline 2,096 & 3.10 & 0.00 & d & -1 & $1-$ & - & - & - & - & - & - & $t$ & CCS \\
\hline 2,097 & 3.10 & 0.00 & $\mathrm{~b}$ & $\begin{array}{ll}\mathrm{s} & 1 \\
\end{array}$ & cx & \begin{tabular}{l|l}
$x$ & 0 \\
\end{tabular} & 3 & 0 & 0.71 & 3.99 & 0.63 & $\mathrm{t}$ & $\mathrm{CCS}$ \\
\hline 2,098 & 3.10 & 0.00 & f & -1 & $1-$ & - & - & 0 & - & - & - & c & CCS \\
\hline 2,099 & 3.10 & 0.00 & c & $\begin{array}{lll}\text { o } & 1 \\
\end{array}$ & cx & \begin{tabular}{l|l}
$x$ & 0 \\
\end{tabular} & 2 & 0 & 2.10 & 5.44 & 1.06 & $\mathrm{t}$ & CCS \\
\hline 2,100 & 3.10 & 0.00 & f & -1 & $1-$ & - & - & 0 & - & - & - & $\mathrm{b}$ & CCS \\
\hline 2,101 & 3.10 & 0.00 & $\mathrm{f}$ & -1 & $1-$ & - & - & 0 & - & - & - & w & CCS \\
\hline 2,102 & 3.10 & 0.00 & f & -1 & $1-$ & - & - & 0 & - & - & - & $\mathrm{b}$ & CCS \\
\hline 2,103 & 3.10 & 0.00 & $\mathrm{f}$ & -1 & $1-$ & - & - & 0 & - & - & - & w & CCS \\
\hline 2,104 & 3.10 & 0.00 & f & -1 & $1-$ & - & - & 0 & - & - & - & $\mathrm{i}$ & Igneous \\
\hline
\end{tabular}




\begin{tabular}{|c|c|c|c|c|c|c|c|c|c|c|c|c|c|}
\hline 2,105 & 3.10 & 0.00 & $\mathrm{f}$ & \begin{tabular}{|l|l|}
- & 1 \\
\end{tabular} & - & - & - & 0 & - & - & - & b & CCS \\
\hline 2,106 & 3.10 & 0.00 & d & -1 & - & - & - & - & - & - & - & w & CCS \\
\hline 2,107 & 3.10 & 0.00 & f & -1 & - & - & - & 0 & - & - & - & w & CCS \\
\hline 2,108 & 3.10 & 0.00 & f & -1 & - & - & - & 0 & - & - & - & w & CCS \\
\hline 2,109 & 3.10 & 0.00 & f & -1 & - & - & - & 0 & - & - & - & $\mathrm{b}$ & CCS \\
\hline 2,110 & 3.10 & 0.00 & c & $\begin{array}{ll}0 & 1 \\
\end{array}$ & cx & 0 & 3 & 0 & 1.91 & 5.19 & 1.10 & $\mathrm{~b}$ & CCS \\
\hline 2,111 & 3.10 & 0.00 & f & -1 & - & - & - & 0 & - & - & - & w & CCS \\
\hline 2,112 & 3.10 & 0.00 & d & -1 & - & - & - & - & - & - & - & $t$ & CCS \\
\hline 2,113 & 3.10 & 0.00 & d & -1 & - & - & - & - & - & - & - & $\mathrm{r}$ & CCS \\
\hline 2,114 & 3.10 & 0.00 & c & $\begin{array}{lll} & 1 & 1 \\
\end{array}$ & $\mathrm{cx}$ & 0 & 3 & 0 & 1.45 & 6.39 & 1.12 & $\mathrm{~b}$ & CCS \\
\hline 2,115 & 3.10 & 0.00 & d & -1 & - & - & - & - & - & - & - & w & CCS \\
\hline 2,116 & 3.10 & 0.00 & $\mathrm{~d}$ & -1 & - & - & - & - & - & - & - & c & CCS \\
\hline 2,117 & 3.10 & 0.00 & d & -1 & - & - & - & - & - & - & - & W & CCS \\
\hline 2,118 & 3.10 & 0.00 & d & -1 & - & - & - & - & - & - & - & $\mathrm{t}$ & CCS \\
\hline 2,119 & 3.10 & 0.00 & d & -1 & - & - & - & - & - & - & - & c & CCS \\
\hline 2,120 & 3.10 & 0.00 & $\mathrm{~d}$ & -1 & - & - & - & - & - & - & - & $\mathrm{t}$ & CCS \\
\hline 2,121 & 3.10 & 0.00 & f & -1 & - & - & - & 0 & - & - & - & w & CCS \\
\hline 2,122 & 3.10 & 0.00 & $\mathrm{f}$ & -1 & - & - & - & 0 & - & - & - & $\mathrm{t}$ & CCS \\
\hline 2,123 & 3.10 & 0.00 & d & -1 & - & - & - & - & - & - & - & w & CCS \\
\hline 2,124 & 3.10 & 0.00 & d & -1 & - & - & - & - & - & - & - & c & CCS \\
\hline 2,125 & 3.10 & 0.00 & d & -1 & - & - & - & - & - & - & - & b & CCS \\
\hline 2,126 & 3.10 & 0.00 & d & -1 & - & - & - & - & - & - & - & $\mathrm{r}$ & CCS \\
\hline 2,127 & 3.10 & 0.00 & $\mathrm{f}$ & -1 & - & - & - & 0 & - & - & - & $\mathrm{b}$ & CCS \\
\hline 2,128 & 3.10 & 0.00 & c & $\begin{array}{lll} & 1 & 1 \\
\end{array}$ & $\mathrm{cx}$ & 0 & 0 & 0 & 2.22 & 4.33 & 0.73 & b & CCS \\
\hline 2,132 & 3.01 & 0.79 & d & -2 & - & - & - & - & - & - & - & $\mathrm{a}$ & Igneous \\
\hline 2,133 & 3.01 & 0.30 & d & -1 & - & - & - & - & - & - & - & $\mathrm{i}$ & Igneous \\
\hline 2,134 & 3.01 & 0.10 & d & -1 & - & - & - & - & - & - & - & $\mathrm{a}$ & Igneous \\
\hline 2,135 & 3.01 & 0.00 & d & -1 & - & - & - & - & - & - & - & $\mathrm{a}$ & Igneous \\
\hline 2,136 & 3.01 & 0.00 & d & -1 & - & - & - & - & - & - & - & $\mathrm{a}$ & Igneous \\
\hline 2,137 & 3.01 & 0.77 & $\mathrm{f}$ & -4 & - & - & - & 0 & - & - & - & c & $\mathrm{CCS}$ \\
\hline 2,138 & 3.01 & 0.07 & $\mathrm{f}$ & -2 & - & - & - & 0 & - & - & - & c & $\mathrm{CCS}$ \\
\hline 2,139 & 3.01 & 0.10 & d & -2 & - & - & - & - & - & - & - & c & CCS \\
\hline 2,140 & 3.01 & 0.10 & $\mathrm{f}$ & -2 & - & - & - & 0 & - & - & - & c & $\mathrm{CCS}$ \\
\hline 2,141 & 3.01 & 0.07 & $\mathrm{f}$ & -1 & - & - & - & 0 & - & - & - & c & CCS \\
\hline 2,142 & 3.01 & 0.09 & $\mathrm{f}$ & -2 & - & - & - & 0 & - & - & - & c & CCS \\
\hline 2,143 & 3.01 & 0.07 & d & -2 & - & - & - & - & - & - & - & c & $\mathrm{CCS}$ \\
\hline 2,144 & 3.01 & 0.06 & f & -1 & - & $\begin{array}{ll}- \\
-\end{array}$ & - & 0 & - & - & - & c & CCS \\
\hline 2,145 & 3.01 & 0.04 & $\mathrm{f}$ & -2 & - & - & - & 0 & - & - & - & c & CCS \\
\hline 2,146 & 3.01 & 0.06 & f & -1 & - & - & - & 0 & - & - & - & $\mathrm{g}$ & CCS \\
\hline 2,147 & 3.01 & 0.00 & d & -1 & - & - & - & - & - & - & - & w & CCS \\
\hline 2,148 & 3.01 & 0.00 & d & -1 & - & - & - & - & - & - & - & c & CCS \\
\hline 2,149 & 3.01 & 0.00 & d & -1 & - & - & - & - & - & - & - & c & CCS \\
\hline 2,150 & 3.01 & 0.00 & f & -1 & - & - & - & 0 & - & - & - & $\mathrm{c}$ & CCS \\
\hline
\end{tabular}




\begin{tabular}{|c|c|c|c|c|c|c|c|c|c|c|c|c|c|}
\hline 2,151 & 3.01 & 0.00 & $\mathrm{f}$ & \begin{tabular}{|l|l|}
- & 1 \\
\end{tabular} & - & - & - & 0 & - & - & - & w & CCS \\
\hline 2,152 & 3.01 & 0.00 & f & \begin{tabular}{|l|l}
- & 1 \\
\end{tabular} & - & - & - & 0 & - & - & - & c & CCS \\
\hline 2,153 & 3.01 & 0.00 & d & \begin{tabular}{|l|l}
- & 1 \\
\end{tabular} & - & - & - & - & - & - & - & c & CCS \\
\hline 2,154 & 3.02 & 3.29 & d & -5 & - & - & - & - & - & - & - & c & $\mathrm{CCS}$ \\
\hline 2,155 & 3.02 & 2.35 & d & -6 & - & - & - & - & - & - & - & c & CCS \\
\hline 2,156 & 3.02 & 1.61 & d & -4 & - & - & - & - & - & - & - & $b$ & $\mathrm{CCS}$ \\
\hline 2,157 & 3.02 & 0.45 & f & -4 & - & - & - & 0 & - & - & - & c & CCS \\
\hline 2,158 & 3.02 & 0.49 & f & -3 & - & - & - & 0 & - & - & - & $\mathrm{g}$ & CCS \\
\hline 2,159 & 3.02 & 0.32 & f & -3 & - & - & - & 0 & - & - & - & $t$ & $\mathrm{CCS}$ \\
\hline 2,160 & 3.02 & 0.26 & $\mathrm{~d}$ & -2 & - & - & - & - & - & - & - & $\mathrm{a}$ & Igneous \\
\hline 2,161 & 3.02 & 0.39 & $\mathrm{~d}$ & -3 & - & - & - & - & - & - & - & $\mathrm{c}$ & $\mathrm{CCS}$ \\
\hline 2,162 & 3.02 & 0.35 & f & -2 & - & - & - & 0 & - & - & - & c & $\mathrm{CCS}$ \\
\hline 2,163 & 3.02 & 0.37 & $\mathrm{f}$ & -3 & - & - & - & 1 & - & - & - & c & CCS \\
\hline 2,164 & 3.02 & 0.05 & $\mathrm{f}$ & -2 & - & - & - & 0 & - & - & - & $\mathrm{c}$ & $\mathrm{CCS}$ \\
\hline 2,165 & 3.02 & 0.09 & $\mathrm{f}$ & -2 & - & - & - & 0 & - & - & - & c & $\mathrm{CCS}$ \\
\hline 2,166 & 3.02 & 0.08 & $\mathrm{~d}$ & -2 & - & - & - & - & - & - & - & $\mathrm{i}$ & Igneous \\
\hline 2,167 & 3.02 & 0.11 & f & 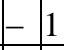 & - & - & - & 1 & - & - & - & c & $\mathrm{CCS}$ \\
\hline 2,168 & 3.02 & 0.09 & $\mathrm{~d}$ & -2 & - & - & - & - & - & - & - & c & $\mathrm{CCS}$ \\
\hline 2,169 & 3.02 & 0.03 & f & - 1 & - & - & - & 0 & - & - & - & c & $\mathrm{CCS}$ \\
\hline 2,170 & 3.02 & 0.04 & d & \begin{tabular}{|l|l}
- & 1 \\
\end{tabular} & - & - & - & - & - & - & - & c & CCS \\
\hline 2,171 & 3.02 & 0.07 & f & 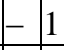 & - & - & - & 0 & - & - & - & $\mathrm{g}$ & $\mathrm{CCS}$ \\
\hline 2,172 & 3.02 & 0.00 & $\mathrm{~d}$ & \begin{tabular}{|l|l|}
- & 1 \\
\end{tabular} & - & - & - & - & - & - & - & $\mathrm{g}$ & CCS \\
\hline 2,173 & 3.02 & 0.00 & f & 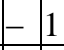 & - & - & - & 0 & - & - & - & $\mathrm{g}$ & $\mathrm{CCS}$ \\
\hline 2,174 & 3.02 & 0.00 & $\mathrm{f}$ & \begin{tabular}{|l|l|}
- & 1 \\
\end{tabular} & - & - & - & 0 & - & - & - & c & $\mathrm{CCS}$ \\
\hline 2,175 & 3.02 & 0.00 & $\mathrm{f}$ & 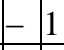 & - & - & - & 0 & - & - & - & c & $\mathrm{CCS}$ \\
\hline 2,176 & 3.02 & 0.11 & d & -2 & - & - & - & - & - & - & - & c & $\mathrm{CCS}$ \\
\hline 2,177 & 3.02 & 0.04 & $\mathrm{f}$ & 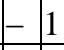 & - & - & - & 0 & - & - & - & c & $\mathrm{CCS}$ \\
\hline 2,178 & 3.02 & 0.00 & $\mathrm{~d}$ & \begin{tabular}{|l|l}
- & 1 \\
\end{tabular} & - & - & - & - & - & - & - & $\mathrm{c}$ & CCS \\
\hline 2,179 & 3.02 & 0.00 & d & \begin{tabular}{|l|l|}
- & 1 \\
\end{tabular} & - & - & - & - & - & - & - & c & $\mathrm{CCS}$ \\
\hline 2,180 & 3.02 & 0.00 & $\mathrm{f}$ & -1 & - & - & - & 0 & - & - & - & $\mathrm{g}$ & $\mathrm{CCS}$ \\
\hline 2,181 & 3.02 & 0.00 & d & \begin{tabular}{|l|l}
- & 1 \\
\end{tabular} & - & - & - & - & - & - & - & c & $\mathrm{CCS}$ \\
\hline 2,182 & 3.02 & 0.00 & $\mathrm{f}$ & \begin{tabular}{|l|l|}
- & 1 \\
\end{tabular} & - & - & - & 0 & - & - & - & $\mathrm{g}$ & $\mathrm{CCS}$ \\
\hline 2,183 & 3.02 & 0.00 & $\mathrm{f}$ & -1 & - & - & - & 0 & - & - & - & $\mathrm{g}$ & CCS \\
\hline 2,184 & 3.02 & 0.00 & d & -1 & - & - & - & - & - & - & - & $\mathrm{g}$ & $\mathrm{CCS}$ \\
\hline 2,185 & 3.02 & 0.00 & $\mathrm{f}$ & - 1 & - & - & - & 0 & - & - & - & c & $\mathrm{CCS}$ \\
\hline 2,186 & 3.02 & 0.00 & d & -1 & - & - & - & - & - & - & - & c & $\mathrm{CCS}$ \\
\hline 2,187 & 3.02 & 0.00 & f & - 1 & - & - & - & 0 & - & - & - & $\mathrm{r}$ & CCS \\
\hline 2,188 & 3.02 & 0.00 & d & -1 & - & - & - & - & - & - & - & c & $\mathrm{CCS}$ \\
\hline 2,189 & 3.02 & 0.00 & d & -1 & - & - & - & - & - & - & - & c & CCS \\
\hline 2,190 & 3.02 & 0.00 & d & - 1 & - & - & - & - & - & - & - & c & CCS \\
\hline 2,192 & $3.09 \mathrm{a}$ & 1.72 & d & -5 & - & - & - & - & - & - & - & $\mathrm{i}$ & Igneous \\
\hline 2,193 & $3.09 a$ & 0.23 & $\mathrm{f}$ & -2 & - & - & - & 0 & - & - & - & c & $\mathrm{CCS}$ \\
\hline 2,194 & $3.09 \mathrm{a}$ & 0.13 & d & -2 & - & - & - & - & - & - & E & $\mathrm{r}$ & CCS \\
\hline
\end{tabular}




\begin{tabular}{|c|c|c|c|c|c|c|c|c|c|c|c|c|c|}
\hline 2,195 & $3.09 \mathrm{a}$ & 0.00 & d & -1 & - & - & - & - & - & - & - & $\mathrm{t}$ & CCS \\
\hline 2,196 & $3.09 \mathrm{a}$ & 0.00 & d & -1 & - & - & - & - & - & - & - & $\mathrm{i}$ & Igneous \\
\hline 2,197 & $3.09 \mathrm{a}$ & 0.00 & $\mathrm{~d}$ & -1 & - & - & - & - & - & - & - & $\mathrm{i}$ & Igneous \\
\hline 2,198 & $3.09 \mathrm{a}$ & 0.03 & d & -1 & - & - & - & - & - & - & - & $\mathrm{i}$ & Igneous \\
\hline 2,199 & $3.09 \mathrm{a}$ & 0.00 & f & -1 & - & - & - & 0 & - & - & - & c & CCS \\
\hline 2,200 & $3.09 \mathrm{a}$ & 0.00 & $\mathrm{f}$ & -1 & - & - & - & 0 & - & - & - & $t$ & CCS \\
\hline 2,201 & $3.09 \mathrm{a}$ & 0.00 & d & -1 & - & - & - & - & - & - & - & $\mathrm{t}$ & CCS \\
\hline 2,202 & $3.09 \mathrm{a}$ & 0.00 & d & -1 & - & - & - & - & - & - & - & $t$ & CCS \\
\hline 2,203 & $3.09 \mathrm{a}$ & 0.00 & d & -1 & - & - & - & - & - & - & - & c & CCS \\
\hline 2,204 & $3.09 \mathrm{a}$ & 0.00 & c & $\begin{array}{lll} & 1 & 1 \\
\end{array}$ & $\mathrm{cx}$ & 0 & 3 & 0 & 2.22 & 5.41 & 0.67 & $t$ & CCS \\
\hline 2,205 & $3.09 \mathrm{a}$ & 0.00 & d & -1 & - & - & - & - & - & - & - & $\mathrm{t}$ & CCS \\
\hline 2,206 & $3.09 \mathrm{a}$ & 0.00 & $\mathrm{~d}$ & -1 & - & - & - & - & - & - & - & $\mathrm{t}$ & CCS \\
\hline 2,207 & $3.09 \mathrm{a}$ & 0.00 & $\mathrm{f}$ & -1 & - & - & - & 0 & - & - & - & $\mathrm{t}$ & CCS \\
\hline 2,208 & $3.09 \mathrm{a}$ & 0.00 & d & -1 & - & - & - & - & - & - & - & $\mathrm{t}$ & CCS \\
\hline 2,209 & $3.09 \mathrm{a}$ & 2.33 & d & -4 & - & - & - & - & - & - & - & $\mathrm{i}$ & Igneous \\
\hline 2,210 & $3.09 \mathrm{a}$ & 0.14 & $\mathrm{~d}$ & -2 & - & - & - & - & - & - & - & $\mathrm{w}$ & CCS \\
\hline 2,211 & $3.09 \mathrm{a}$ & 0.14 & d & -2 & - & - & - & - & - & - & - & $\mathrm{a}$ & Igneous \\
\hline 2,212 & $3.09 \mathrm{a}$ & 0.09 & d & -1 & - & - & - & - & - & - & - & $\mathrm{a}$ & Igneous \\
\hline 2,214 & $3.09 \mathrm{a}$ & 0.00 & d & -1 & - & - & - & - & - & - & - & $\mathrm{a}$ & Igneous \\
\hline 2,215 & $3.09 \mathrm{a}$ & 0.00 & d & -1 & - & - & - & - & - & - & - & $\mathrm{t}$ & CCS \\
\hline 2,216 & $3.09 \mathrm{a}$ & 0.00 & $\mathrm{f}$ & -1 & - & - & - & 0 & - & - & - & $\mathrm{b}$ & CCS \\
\hline 2,217 & $3.09 \mathrm{a}$ & 0.00 & f & -1 & - & - & - & 0 & - & - & - & $t$ & CCS \\
\hline 2,218 & $3.09 \mathrm{a}$ & 0.00 & f & -1 & - & - & - & 0 & - & - & - & $\mathrm{t}$ & CCS \\
\hline 2,219 & $3.09 \mathrm{a}$ & 0.00 & f & -1 & - & - & - & 0 & - & - & - & c & CCS \\
\hline 2,220 & $3.09 \mathrm{a}$ & 0.00 & $\mathrm{f}$ & -1 & - & - & - & 0 & - & - & - & $t$ & $\mathrm{CCS}$ \\
\hline 2,221 & $3.09 \mathrm{~b}$ & 0.35 & $\mathrm{f}$ & -3 & - & - & - & 0 & - & - & - & $t$ & CCS \\
\hline 2,222 & $3.09 \mathrm{~b}$ & 0.63 & d & -3 & - & - & - & - & - & - & - & c & $\mathrm{CCS}$ \\
\hline 2,223 & $3.09 \mathrm{~b}$ & 0.32 & $\mathrm{~b}$ & $\mathrm{~s} \quad 3$ & $\mathrm{cx}$ & 0 & 3 & 0 & 4.95 & 13.84 & 3.05 & $t$ & $\mathrm{CCS}$ \\
\hline 2,224 & $3.09 \mathrm{~b}$ & 0.38 & d & -3 & - & - & - & - & - & - & - & c & CCS \\
\hline 2,225 & $3.09 \mathrm{~b}$ & 0.32 & d & -2 & - & - & - & - & - & - & - & $\mathrm{i}$ & Igneous \\
\hline 2,226 & $3.09 \mathrm{~b}$ & 0.24 & d & -2 & - & - & - & - & - & - & - & $\mathrm{a}$ & Igneous \\
\hline 2,227 & $3.09 \mathrm{~b}$ & 0.11 & d & -1 & - & - & - & - & - & - & - & $\mathrm{a}$ & Igneous \\
\hline 2,228 & $3.09 \mathrm{~b}$ & 0.00 & d & -1 & - & - & - & - & - & - & - & $\mathrm{i}$ & Igneous \\
\hline 2,229 & $3.09 \mathrm{~b}$ & 0.20 & d & -2 & - & - & - & - & - & - & - & $\mathrm{i}$ & Igneous \\
\hline 2,230 & $3.09 \mathrm{~b}$ & 0.00 & d & -1 & - & - & - & - & - & - & - & $\mathrm{i}$ & Igneous \\
\hline 2,231 & $3.09 \mathrm{~b}$ & 0.00 & d & -1 & - & - & - & - & - & - & - & $\mathrm{i}$ & Igneous \\
\hline 2,232 & $3.09 \mathrm{~b}$ & 0.09 & d & -2 & - & $\begin{array}{ll}- \\
-\end{array}$ & - & - & - & - & - & $\mathrm{t}$ & CCS \\
\hline 2,233 & $3.09 \mathrm{~b}$ & 0.00 & $\mathrm{~b}$ & $\begin{array}{ll}\mathrm{s} & 2 \\
\end{array}$ & $\mathrm{cx}$ & 0 & 2 & 0 & 3.34 & 8.82 & 1.26 & $t$ & $\mathrm{CCS}$ \\
\hline 2,234 & $3.09 \mathrm{~b}$ & 0.00 & f & -1 & - & - & - & 0 & - & - & - & $\mathrm{w}$ & CCS \\
\hline 2,235 & $3.09 \mathrm{~b}$ & 0.10 & $\mathrm{f}$ & -1 & - & - & - & 0 & - & - & - & c & $\mathrm{CCS}$ \\
\hline 2,236 & $3.09 \mathrm{~b}$ & 0.00 & d & -1 & - & - & - & - & - & - & - & $t$ & $\mathrm{CCS}$ \\
\hline 2,237 & $3.09 \mathrm{~b}$ & 0.00 & $\mathrm{f}$ & -1 & - & - & - & 0 & - & - & - & $\mathrm{g}$ & CCS \\
\hline 2,238 & $3.09 \mathrm{~b}$ & 0.00 & f & -1 & - & - & - & 0 & - & - & - & $\mathrm{b}$ & CCS \\
\hline
\end{tabular}




\begin{tabular}{|c|c|c|c|c|c|c|c|c|c|c|c|c|c|}
\hline 2,239 & $3.09 \mathrm{~b}$ & 0.00 & $\mathrm{f}$ & -1 & - & - & - & 0 & - & - & - & $\mathrm{t}$ & CCS \\
\hline 2,240 & $3.09 \mathrm{~b}$ & 0.00 & d & -1 & - & - & - & - & - & - & - & $\mathrm{b}$ & $\mathrm{CCS}$ \\
\hline 2,241 & $3.09 \mathrm{~b}$ & 0.00 & f & -1 & - & - & - & 0 & - & - & - & $\mathrm{r}$ & CCS \\
\hline 2,242 & $3.09 \mathrm{~b}$ & 0.00 & d & -1 & - & - & - & - & - & - & - & $\mathrm{r}$ & CCS \\
\hline 2,243 & $3.09 \mathrm{~b}$ & 0.03 & d & -1 & - & - & - & - & - & - & - & $\mathrm{r}$ & CCS \\
\hline 2,244 & $3.09 \mathrm{~b}$ & 0.00 & d & -1 & - & - & - & - & - & - & - & $\mathrm{r}$ & CCS \\
\hline 2,245 & $3.09 \mathrm{~b}$ & 0.00 & d & -1 & - & - & - & - & - & - & - & $\mathrm{r}$ & CCS \\
\hline 2,246 & 3.10 .5 & 0.12 & d & -1 & - & - & - & - & - & - & - & $a$ & Igneous \\
\hline 2,247 & 3.10 .5 & 0.10 & $\mathrm{~b}$ & $\begin{array}{ll}\mathrm{s} & 2 \\
\end{array}$ & cx & 0 & 2 & 0 & 1.88 & 10.94 & 1.20 & $\mathrm{~b}$ & CCS \\
\hline 2,248 & 3.10 .5 & 0.00 & $\mathrm{f}$ & -1 & - & - & - & 0 & - & - & - & $\mathrm{t}$ & CCS \\
\hline 2,249 & 3.10 .5 & 0.00 & d & -1 & - & - & - & - & - & - & - & $\mathrm{t}$ & CCS \\
\hline 2,250 & 3.11 & 1.53 & $\mathrm{~b}$ & $\begin{array}{ll}\mathrm{s} & 4 \\
\end{array}$ & $\mathrm{a}$ & 0 & 2 & 0 & 19.29 & 15.88 & 4.45 & c & CCS \\
\hline 2,251 & 3.11 & 1.34 & f & -4 & - & - & - & 0 & - & - & - & c & $\mathrm{CCS}$ \\
\hline 2,252 & 3.11 & 0.13 & c & $\begin{array}{ll}\mathrm{o} & 2 \\
\end{array}$ & $\mathrm{a}$ & 0 & 3 & 0 & 3.27 & 11.01 & 1.45 & $\mathrm{t}$ & CCS \\
\hline 2,253 & 3.11 & 0.21 & d & -2 & - & - & - & - & - & - & - & $\mathrm{i}$ & Igneous \\
\hline 2,254 & 3.11 & 0.06 & $\mathrm{f}$ & -2 & - & - & - & 0 & - & - & - & $\mathrm{t}$ & CCS \\
\hline 2,255 & 3.11 & 0.06 & f & -2 & - & - & - & 0 & - & - & - & $\mathrm{r}$ & CCS \\
\hline 2,256 & 3.11 & 0.09 & f & -2 & - & - & - & 0 & - & - & - & $\mathrm{r}$ & $\mathrm{CCS}$ \\
\hline 2,257 & 3.11 & 0.05 & $\mathrm{f}$ & -2 & - & - & - & 0 & - & - & - & $t$ & CCS \\
\hline 2,258 & 3.11 & 0.08 & c & $\begin{array}{ll}0 & 2 \\
\end{array}$ & cx & 0 & 3 & 0 & 4.90 & 11.78 & 1.74 & $\mathrm{t}$ & CCS \\
\hline 2,259 & 3.11 & 0.00 & $\mathrm{f}$ & -1 & - & - & - & 0 & - & - & - & W & CCS \\
\hline 2,260 & 3.11 & 0.00 & f & -1 & - & - & - & 0 & - & - & - & $\mathrm{i}$ & Igneous \\
\hline 2,261 & 3.11 & 0.07 & $\mathrm{~d}$ & -1 & - & - & - & - & - & - & - & $\mathrm{t}$ & CCS \\
\hline 2,262 & 3.11 & 0.00 & f & -1 & - & - & - & 0 & - & - & - & $\mathrm{r}$ & CCS \\
\hline 2,263 & 3.11 & 0.00 & $\mathrm{f}$ & -1 & - & - & - & 0 & - & - & - & $\mathrm{b}$ & CCS \\
\hline 2,264 & 3.11 & 0.00 & $\mathrm{f}$ & -1 & - & - & - & 0 & - & - & - & w & CCS \\
\hline 2,265 & 3.11 & 0.00 & $\mathrm{~d}$ & -1 & - & - & - & - & - & - & - & $\mathrm{t}$ & CCS \\
\hline 2,266 & 3.12 & 0.00 & d & -1 & - & - & - & - & - & - & - & $\mathrm{b}$ & CCS \\
\hline 2,267 & 3.12 & 0.00 & $\mathrm{f}$ & -1 & - & - & - & 0 & - & - & - & b & CCS \\
\hline 2,268 & 2.01 & 2.75 & d & -4 & - & - & - & - & - & - & - & c & $\mathrm{CCS}$ \\
\hline 2,269 & 2.01 & 1.03 & $\mathrm{f}$ & -5 & - & - & - & 0 & - & - & - & c & CCS \\
\hline 2,270 & 2.01 & 1.04 & d & -5 & - & - & - & - & - & - & - & $\mathrm{w}$ & CCS \\
\hline 2,271 & 2.01 & 0.85 & d & -4 & - & - & - & - & - & - & - & $\mathrm{g}$ & $\mathrm{CCS}$ \\
\hline 2,272 & 2.01 & 0.39 & $\mathrm{f}$ & -3 & - & - & - & 0 & - & - & - & c & CCS \\
\hline 2,273 & 2.01 & 0.37 & $\mathrm{f}$ & -3 & - & - & - & 0 & - & - & - & $\mathrm{g}$ & CCS \\
\hline 2,274 & 2.01 & 0.30 & $\mathrm{f}$ & -3 & - & - & - & 0 & - & - & - & c & $\mathrm{CCS}$ \\
\hline 2,275 & 2.01 & 0.15 & f & -2 & - & - & - & 0 & - & - & - & $\mathrm{g}$ & CCS \\
\hline 2,276 & 2.01 & 0.11 & $\mathrm{f}$ & -2 & - & - & - & 0 & - & - & - & $t$ & CCS \\
\hline 2,277 & 2.01 & 0.16 & $\mathrm{~d}$ & -2 & - & - & - & - & - & - & - & $\mathrm{t}$ & CCS \\
\hline 2,278 & 2.01 & 0.00 & d & -1 & - & - & - & - & - & - & - & $\mathrm{w}$ & CCS \\
\hline 2,279 & 2.01 & 0.00 & $\mathrm{~d}$ & -1 & - & - & - & - & - & - & - & $\mathrm{t}$ & CCS \\
\hline 2,280 & 2.01 & 0.04 & $\mathrm{f}$ & -2 & - & - & - & 0 & - & - & - & c & CCS \\
\hline 2,281 & 2.01 & 0.00 & f & -1 & - & - & - & 0 & - & - & - & $\mathrm{c}$ & CCS \\
\hline
\end{tabular}




\begin{tabular}{|c|c|c|c|c|c|c|c|c|c|c|c|c|c|}
\hline 2,282 & 2.01 & 0.00 & $\mathrm{f}$ & -1 & - & - & - & 0 & - & - & - & W & CCS \\
\hline 2,283 & 2.01 & 0.00 & $\mathrm{f}$ & -1 & - & - & - & 0 & - & - & - & c & CCS \\
\hline 2,284 & 2.01 & 0.06 & f & -1 & - & - & - & 0 & - & - & - & $\mathrm{g}$ & CCS \\
\hline 2,285 & 2.01 & 0.04 & d & -2 & - & - & - & - & - & - & - & c & CCS \\
\hline 2,286 & 2.01 & 0.00 & $\mathrm{f}$ & -1 & - & - & - & 0 & - & - & - & c & CCS \\
\hline 2,287 & 2.01 & 0.00 & d & -1 & - & - & - & - & - & - & - & c & CCS \\
\hline 2,288 & 2.01 & 0.00 & $\mathrm{f}$ & -1 & - & - & - & 0 & - & - & - & c & CCS \\
\hline 2,289 & 2.01 & 0.07 & d & -1 & - & - & - & - & - & - & - & c & CCS \\
\hline 2,290 & 2.01 & 0.07 & $\mathrm{f}$ & -2 & - & - & - & 0 & - & - & - & c & CCS \\
\hline 2,291 & 2.01 & 0.00 & $\mathrm{f}$ & -1 & - & - & - & 0 & - & - & - & $\mathrm{g}$ & CCS \\
\hline 2,292 & 2.01 & 0.03 & $\mathrm{f}$ & -2 & - & - & - & 0 & - & - & - & c & CCS \\
\hline 2,293 & 2.01 & 0.00 & $\mathrm{f}$ & -1 & - & - & - & 0 & - & - & - & c & CCS \\
\hline 2,294 & 2.01 & 0.00 & d & -1 & - & - & - & - & - & - & - & c & CCS \\
\hline 2,295 & 2.01 & 0.00 & d & -1 & - & - & - & - & - & - & - & c & CCS \\
\hline 2,296 & 2.01 & 0.00 & $\mathrm{f}$ & -1 & - & - & - & 0 & - & - & - & c & CCS \\
\hline 2,297 & 2.02 & 1.72 & $\mathrm{f}$ & -4 & - & - & - & 0 & - & - & - & $\mathrm{t}$ & CCS \\
\hline 2,298 & 2.02 & 1.14 & $\mathrm{f}$ & -7 & - & - & - & 0 & - & - & - & $\mathrm{g}$ & CCS \\
\hline 2,299 & 2.02 & 1.91 & $\mathrm{f}$ & -5 & - & - & - & 0 & - & - & - & c & CCS \\
\hline 2,300 & 2.02 & 1.03 & d & -4 & - & - & - & - & - & - & - & w & CCS \\
\hline 2,301 & 2.02 & 0.54 & $\mathrm{f}$ & -4 & - & - & - & 0 & - & - & - & c & CCS \\
\hline 2,302 & 2.10 & 0.15 & d & -2 & - & - & - & - & - & - & - & c & CCS \\
\hline 2,302 & 2.02 & 0.69 & d & -2 & - & - & - & - & - & - & - & d & Igneous \\
\hline 2,303 & 2.02 & 0.34 & d & -2 & - & - & - & - & - & - & - & $\mathrm{t}$ & CCS \\
\hline 2,304 & 2.02 & 0.22 & $\mathrm{f}$ & -2 & - & - & - & 0 & - & - & - & $\mathrm{g}$ & CCS \\
\hline 2,305 & 2.02 & 0.32 & d & -3 & - & - & - & - & - & - & - & $\mathrm{g}$ & CCS \\
\hline 2,306 & 2.02 & 0.19 & $\mathrm{f}$ & -3 & - & - & - & 0 & - & - & - & c & CCS \\
\hline 2,307 & 2.02 & 0.11 & $\mathrm{f}$ & -2 & - & - & - & 0 & - & - & - & c & CCS \\
\hline 2,308 & 2.02 & 0.17 & $\mathrm{f}$ & -2 & - & - & - & 0 & - & - & - & c & CCS \\
\hline 2,309 & 2.02 & 0.10 & $\mathrm{f}$ & -2 & - & - & - & 0 & - & - & - & $\mathrm{g}$ & CCS \\
\hline 2,310 & 2.02 & 0.17 & d & -2 & - & - & - & - & - & - & - & $\mathrm{b}$ & CCS \\
\hline 2,311 & 2.02 & 0.10 & d & -2 & - & - & - & - & - & - & - & $\mathrm{W}$ & CCS \\
\hline 2,312 & 2.02 & 0.07 & d & -2 & - & - & - & - & - & - & - & c & CCS \\
\hline 2,313 & 2.02 & 0.20 & d & -1 & - & - & - & - & - & - & - & c & CCS \\
\hline 2,314 & 2.02 & 0.07 & d & -1 & - & - & - & - & - & - & - & W & CCS \\
\hline 2,315 & 2.02 & 0.08 & $\mathrm{f}$ & -2 & - & - & - & 0 & - & - & - & c & CCS \\
\hline 2,316 & 2.02 & 0.09 & $\mathrm{f}$ & -2 & - & - & - & 0 & - & - & - & c & CCS \\
\hline 2,317 & 2.02 & 0.00 & $\mathrm{f}$ & -1 & - & - & - & 0 & - & - & - & $\mathrm{r}$ & CCS \\
\hline 2,318 & 2.02 & 0.05 & d & -2 & - & - & - & - & - & - & - & c & CCS \\
\hline 2,320 & 2.02 & 0.07 & d & -1 & - & - & - & - & - & - & - & c & CCS \\
\hline 2,321 & 2.02 & 0.00 & d & -1 & - & - & - & - & - & - & - & c & CCS \\
\hline 2,322 & 2.02 & 0.00 & $\mathrm{f}$ & -1 & - & - & - & 0 & - & - & - & W & CCS \\
\hline 2,323 & 2.02 & 0.00 & f & -1 & - & - & - & 0 & - & - & - & b & CCS \\
\hline 2,324 & 2.02 & 0.04 & d & -1 & - & - & - & - & - & - & - & $\mathrm{i}$ & Igneous \\
\hline
\end{tabular}




\begin{tabular}{|c|c|c|c|c|c|c|c|c|c|c|c|c|c|}
\hline 2,325 & 2.02 & 0.00 & d & \begin{tabular}{|l|l|}
- & 1 \\
\end{tabular} & - & - & - & - & - & - & - & b & CCS \\
\hline 2,326 & 2.02 & 0.00 & f & \begin{tabular}{|l|l}
- & 1 \\
\end{tabular} & - & - & - & 0 & - & - & - & c & CCS \\
\hline 2,327 & 2.02 & 0.00 & $\mathrm{~d}$ & \begin{tabular}{|l|l}
- & 1 \\
\end{tabular} & - & - & - & - & - & - & - & c & CCS \\
\hline 2,328 & 2.02 & 0.00 & $\mathrm{~d}$ & \begin{tabular}{|l|l|}
- & 1 \\
\end{tabular} & - & - & - & - & - & - & - & $\mathrm{g}$ & CCS \\
\hline 2,329 & 2.02 & 0.00 & f & -1 & - & - & - & 0 & - & - & - & c & CCS \\
\hline 2,330 & 2.02 & 0.00 & f & \begin{tabular}{|l|l}
- & 1 \\
\end{tabular} & - & - & - & 0 & - & - & - & c & CCS \\
\hline 2,331 & 2.02 & 0.00 & $\mathrm{~b}$ & $\begin{array}{ll}\text { s } & 1 \\
\end{array}$ & $\mathrm{cx}$ & 0 & 3 & 0 & 2.11 & 5.14 & 0.59 & $t$ & CCS \\
\hline 2,333 & 2.04 & 1.35 & f & -4 & - & - & - & 0 & - & - & - & c & CCS \\
\hline 2,334 & 2.04 & 0.37 & $\mathrm{~d}$ & -3 & - & - & - & - & - & - & - & b & CCS \\
\hline 2,336 & 2.04 & 0.35 & $\mathrm{~d}$ & -3 & - & - & - & - & - & - & - & $\mathrm{i}$ & Igneous \\
\hline 2,337 & 2.04 & 0.11 & f & -3 & - & - & - & 0 & - & - & - & c & CCS \\
\hline 2,338 & 2.04 & 0.21 & f & -3 & - & - & - & 0 & - & - & - & $\mathrm{g}$ & CCS \\
\hline 2,339 & 2.04 & 0.20 & d & -2 & - & - & - & - & - & - & - & w & CCS \\
\hline 2,340 & 2.04 & 0.09 & f & -2 & - & - & - & 0 & - & - & - & w & CCS \\
\hline 2,341 & 2.04 & 0.13 & d & -2 & - & - & - & - & - & - & - & $\mathrm{g}$ & CCS \\
\hline 2,342 & 2.04 & 0.19 & d & -2 & - & - & - & - & - & - & - & $\mathrm{b}$ & CCS \\
\hline 2,343 & 2.04 & 0.08 & f & -2 & - & - & - & 0 & - & - & - & $\mathrm{b}$ & CCS \\
\hline 2,344 & 2.04 & 0.10 & d & -1 & - & - & - & - & - & - & - & c & CCS \\
\hline 2,345 & 2.04 & 0.11 & f & -3 & - & - & - & 0 & - & - & - & c & CCS \\
\hline 2,346 & 2.04 & 0.05 & f & -2 & - & - & - & 0 & - & - & - & c & CCS \\
\hline 2,347 & 2.04 & 0.00 & d & -1 & - & - & - & - & - & - & - & c & CCS \\
\hline 2,348 & 2.04 & 0.00 & d & -1 & - & - & - & - & - & - & - & $\mathrm{r}$ & CCS \\
\hline 2,349 & 2.04 & 0.00 & d & -1 & - & - & - & - & - & - & - & $\mathrm{i}$ & Igneous \\
\hline 2,351 & 2.04 & 0.00 & f & -1 & - & - & - & 0 & - & - & - & w & CCS \\
\hline 2,352 & 2.04 & 0.00 & d & -1 & - & - & - & - & - & - & - & c & CCS \\
\hline 2,353 & 2.04 & 0.04 & f & -1 & - & - & - & 0 & - & - & - & $\mathrm{g}$ & CCS \\
\hline 2,354 & 2.04 & 0.00 & d & -1 & - & - & - & - & - & - & - & c & CCS \\
\hline 2,355 & 2.04 & 0.04 & f & -2 & - & - & - & 0 & - & - & - & c & CCS \\
\hline 2,357 & 2.04 & 0.00 & d & -1 & - & - & - & - & - & - & - & $\mathrm{a}$ & Igneous \\
\hline 2,358 & 2.04 & 0.04 & d & -1 & - & - & - & - & - & - & - & c & CCS \\
\hline 2,359 & 2.04 & 0.00 & f & -1 & - & - & - & 0 & - & - & - & c & CCS \\
\hline 2,360 & 2.04 & 0.00 & $\mathrm{f}$ & -1 & - & - & - & 0 & - & - & - & c & CCS \\
\hline 2,361 & 2.04 & 0.05 & $\mathrm{f}$ & -1 & - & - & - & 0 & - & - & - & $\mathrm{a}$ & Igneous \\
\hline 2,362 & 2.04 & 0.05 & $\mathrm{f}$ & -1 & - & - & - & 0 & - & - & - & c & CCS \\
\hline 2,363 & 2.04 & 0.05 & d & -1 & - & - & - & - & - & - & - & $\mathrm{b}$ & CCS \\
\hline 2,364 & 2.04 & 0.00 & f & -2 & - & - & - & 0 & - & - & - & c & CCS \\
\hline 2,365 & 2.04 & 0.00 & f & -1 & - & - & - & 0 & - & - & - & $\mathrm{g}$ & CCS \\
\hline 2,366 & 2.04 & 0.00 & d & -2 & - & - & - & - & - & - & - & c & CCS \\
\hline 2,367 & 2.04 & 0.00 & d & -1 & - & - & - & - & - & - & - & $\mathrm{a}$ & Igneous \\
\hline 2,368 & 2.04 & 0.00 & d & -1 & - & - & - & - & - & - & - & $\mathrm{a}$ & Igneous \\
\hline 2,369 & 2.04 & 0.05 & d & -2 & - & - & - & - & - & - & - & c & CCS \\
\hline 2,370 & 2.04 & 0.00 & f & -1 & - & - & - & 0 & - & - & - & c & CCS \\
\hline 2,371 & 2.08 & 0.73 & $\mathrm{f}$ & -3 & - & - & - & 0 & - & - & - & $\mathrm{g}$ & CCS \\
\hline
\end{tabular}




\begin{tabular}{|c|c|c|c|c|c|c|c|c|c|c|c|c|c|}
\hline 2,372 & 2.08 & 0.10 & $\mathrm{f}$ & \begin{tabular}{|l|l}
- & 2 \\
\end{tabular} & - & - & - & 0 & - & - & - & $\mathrm{c}$ & CCS \\
\hline 2,373 & 2.08 & 0.07 & d & -2 & - & - & - & - & - & - & - & c & CCS \\
\hline 2,374 & 2.08 & 0.08 & d & \begin{tabular}{|l|l}
- & 1 \\
\end{tabular} & - & - & - & - & - & - & - & $\mathrm{r}$ & CCS \\
\hline 2,376 & 2.09 & 1.25 & d & $\begin{array}{ll}- & 6 \\
\end{array}$ & - & - & - & - & - & - & - & c & CCS \\
\hline 2,377 & 2.09 & 0.48 & $\mathrm{f}$ & \begin{tabular}{|l|l}
- & 4 \\
\end{tabular} & - & - & - & 0 & - & - & - & $t$ & CCS \\
\hline 2,378 & 2.09 & 0.38 & $\mathrm{~d}$ & -3 & - & - & - & - & - & - & - & c & CCS \\
\hline 2,379 & 2.09 & 0.37 & d & -3 & - & - & - & - & - & - & - & $\mathrm{r}$ & CCS \\
\hline 2,380 & 2.09 & 0.29 & $\mathrm{f}$ & -3 & - & - & - & 1 & - & - & - & $t$ & CCS \\
\hline 2,381 & 2.09 & 0.11 & $\mathrm{f}$ & -2 & - & - & - & 0 & - & - & - & $t$ & CCS \\
\hline 2,382 & 2.09 & 0.11 & d & -2 & - & - & - & - & - & - & - & $\mathrm{r}$ & $\mathrm{CCS}$ \\
\hline 2,383 & 2.09 & 0.08 & $\mathrm{f}$ & -2 & - & - & - & 0 & - & - & - & b & CCS \\
\hline 2,384 & 2.09 & 0.00 & $\mathrm{f}$ & \begin{tabular}{|l|l}
- & 1 \\
\end{tabular} & - & - & - & 0 & - & - & - & $t$ & $\mathrm{CCS}$ \\
\hline 2,385 & 2.09 & 0.00 & d & \begin{tabular}{|l|l}
- & 1 \\
\end{tabular} & - & - & - & - & - & - & - & $\mathrm{g}$ & CCS \\
\hline 2,386 & 2.09 & 0.00 & $\mathrm{f}$ & \begin{tabular}{|l|l}
- & 1 \\
\end{tabular} & - & - & - & 0 & - & - & - & $\mathrm{b}$ & CCS \\
\hline 2,387 & 2.09 & 0.00 & $\mathrm{f}$ & \begin{tabular}{|l|l|}
- & 1 \\
\end{tabular} & - & - & - & 0 & - & - & - & $t$ & CCS \\
\hline 2,388 & 2.09 & 0.00 & $\mathrm{f}$ & \begin{tabular}{|l|l}
- & 1 \\
\end{tabular} & - & - & - & 0 & - & - & - & $t$ & CCS \\
\hline 2,389 & 2.10 & 1.15 & $\mathrm{~d}$ & \begin{tabular}{|l|l}
-5 \\
\end{tabular} & - & - & - & - & - & - & - & $\mathrm{r}$ & CCS \\
\hline 2,390 & 2.10 & 0.45 & $\mathrm{~d}$ & \begin{tabular}{|l|}
-2 \\
\end{tabular} & - & - & - & - & - & - & - & $\mathrm{i}$ & Igneous \\
\hline 2,391 & 2.10 & 0.12 & $\mathrm{f}$ & -2 & - & - & - & 0 & - & - & - & $\mathrm{b}$ & CCS \\
\hline 2,392 & 2.10 & 0.05 & $\mathrm{f}$ & -2 & - & - & - & 0 & - & - & - & $t$ & CCS \\
\hline 2,393 & 2.10 & 0.00 & $\mathrm{~d}$ & \begin{tabular}{|l|l}
- & 1 \\
\end{tabular} & - & - & - & - & - & - & - & $\mathrm{t}$ & CCS \\
\hline 2,394 & 2.10 & 0.05 & d & \begin{tabular}{|l|l|}
- & 1 \\
\end{tabular} & - & - & - & - & - & - & - & $b$ & CCS \\
\hline 2,395 & 2.10 & 0.00 & $\mathrm{f}$ & \begin{tabular}{|l|l}
- & 1 \\
\end{tabular} & - & - & - & 0 & - & - & - & $b$ & CCS \\
\hline 2,396 & 2.10 & 0.00 & c & \begin{tabular}{|l|l|} 
o & 1 \\
\end{tabular} & $\mathrm{cx}$ & 0 & 2 & 0 & 2.86 & 3.17 & 0.59 & $\mathrm{~b}$ & CCS \\
\hline 2,397 & 2.10 & 0.26 & d & -2 & - & - & - & - & - & - & - & $\mathrm{r}$ & CCS \\
\hline 2,398 & 2.10 & 0.13 & $\mathrm{f}$ & -3 & - & - & - & 0 & - & - & - & $\mathrm{r}$ & CCS \\
\hline 2,400 & 2.10 & 1.20 & d & -4 & - & - & - & - & - & - & - & $\mathrm{r}$ & CCS \\
\hline 2,401 & 2.10 & 0.32 & d & -3 & - & - & - & - & - & - & - & $\mathrm{r}$ & CCS \\
\hline 2,403 & 2.10 & 0.07 & c & $\begin{array}{lll}\text { o } 2 \\
\end{array}$ & cx & 0 & 2 & 0 & 4.45 & 8.21 & 1.21 & $\mathrm{~b}$ & CCS \\
\hline 2,404 & 2.10 & 0.00 & $\mathrm{f}$ & \begin{tabular}{|l|l}
- & 1 \\
\end{tabular} & - & - & - & 0 & - & - & - & $t$ & CCS \\
\hline 2,405 & 2.10 & 0.00 & d & \begin{tabular}{|l|l}
- & 1 \\
\end{tabular} & - & - & - & - & - & - & - & c & CCS \\
\hline 2,406 & 2.10 & 0.00 & $\mathrm{f}$ & \begin{tabular}{|l|l}
- & 1 \\
\end{tabular} & - & - & - & 0 & - & - & - & $\mathrm{b}$ & CCS \\
\hline 2,407 & 2.06 & 0.03 & $\mathrm{f}$ & $\begin{array}{ll}-1 & 2\end{array}$ & - & - & - & 0 & - & - & - & c & CCS \\
\hline
\end{tabular}

